INTER NATIONAL MONETARY FUND
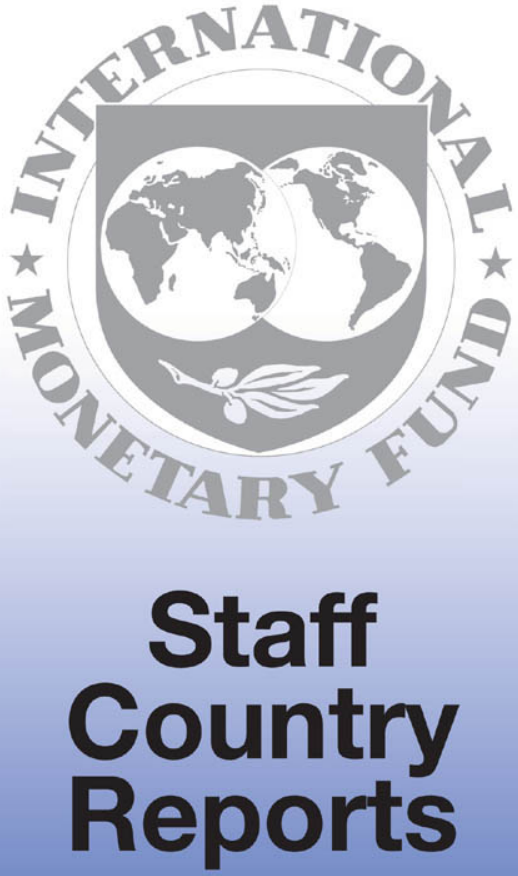


\section{Cape Verde: Poverty Reduction Strategy Paper}

Poverty Reduction Strategy Papers (PRSPs) are prepared by member countries in broad consultation with stakeholders and development partners, including the staffs of the World Bank and the IMF. Updated every three years with annual progress reports, they describe the country's macroeconomic, structural, and social policies in support of growth and poverty reduction, as well as associated external financing needs and major sources of financing. This country document for Cape Verde, dated September 2004, is being made available on the IMF website by agreement with the member country as a service to users of the IMF website.

To assist the IMF in evaluating the publication policy, reader comments are invited and may be sent by e-mail to publicationpolicy@imf.org.

Copies of this report are available to the public from

International Monetary Fund • Publication Services

$70019^{\text {th }}$ Street, N.W. • Washington, D.C. 20431

Telephone: (202) 623-7430 • Telefax: (202) 623-7201

E-mail: publications@imf.org •Internet: http://www.imf.org

Price: $\$ 15.00$ a copy

\section{International Monetary Fund \\ Washington, D.C.}


This page intentionally left blank

CInternational Monetary Fund. Not for Redistribution 


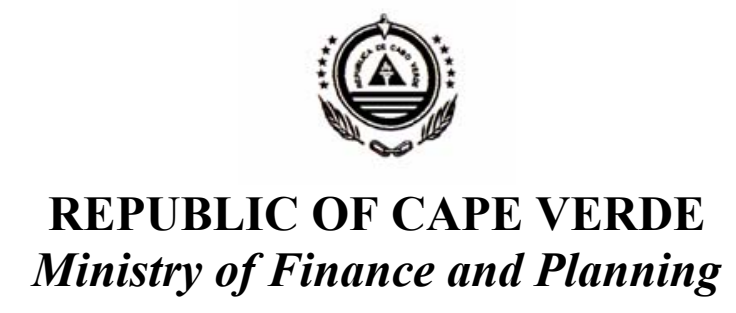

\section{GROWTH AND POVERTY REDUCTION STRATEGY PAPER (GPRSP)}

Revised, September 2004 


\section{TABLE OF CONTENTS}

EXECUTIVE SUMMARY $\underline{6}$

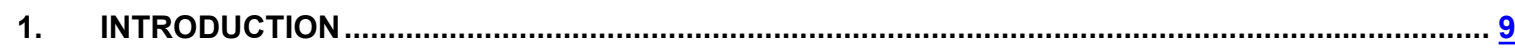

2. GROWTH, EMPLOYMENT, AND POVERTY REDUCTION POLICIES …....................................14

2.1 Problems, policy responses and structural reforms................................... 14

2.2 Sectoral policies: problems, policy measures and outcomes............................ $\underline{23}$

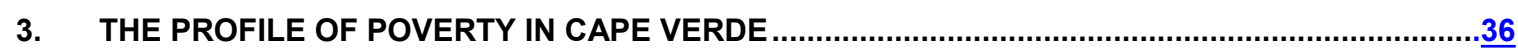

3.1 The dynamics and characterization of poverty in Cape Verde .................... $\underline{36}$

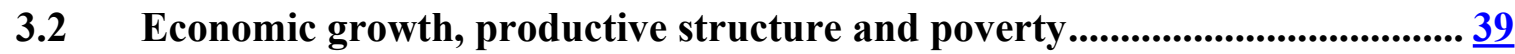

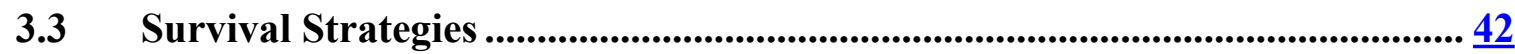

4. STRATEGIC FRAMEWORK FOR GROWTH AND POVERTY REDUCTION ...................................44

4.1 Development vision for Cape Verde........................................................ 44

4.2 General and sectoral objectives ............................................................ 49

4.3 Macroeconomic framework for the GPRS ...................................................... $\underline{76}$

5. TOTAL COST AND FINANCING PLAN FOR THE GPRS …................................................

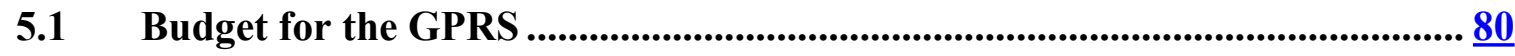

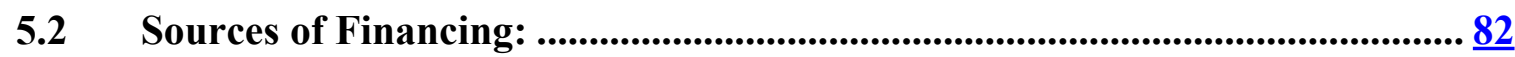

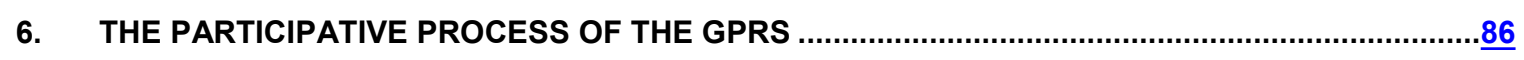

7. IMPLEMENTATION, MONITORING AND EVALUATION OF THE GPRS .......................................

Implementation mechanisms ..................................................................... 89

7.2 Monitoring and evaluation mechanisms for the GPRS.............................. 91

7.3 Performance indicators for the GPRS ............................................................... $9 \underline{6}$ 
7.4 Risks for monitoring and evaluating the GPRS.

\section{FIGURES}

Figure 1-1: Cape Verde's planning system ..................................................... $\frac{11}{12}$

Figure 1-2: Strategic plans and respective timeframes .......................................... $\frac{12}{51}$

Figure 4-1: Architecture of the Growth and Poverty Reduction Strategy..................... $\frac{51}{94}$

Figure 7-1: Institutional framework for monitoring and evaluating the GPRS............ 94

\section{BOXES}

Box 2-1: Cape Verde in brief.......................................................................... 15

Box 2-2: Cape Verde's vulnerability profile................................................................ $\frac{16}{25}$

Box 2-3: A few indicators of tax incidence in Cape Verde ........................................ $\frac{25}{46}$

Box 4-1: Pillars of the Grand Options of the Plan (2002-2005) ................................... 46

Box 4-2: Millennium Development Goals: overview of Cape Verde's performance ....... $\underline{48}$

Box 4-3: The focal policies of the growth and poverty reduction strategy.................... $\underline{53}$ 


\section{ABBREVIATIONS AND ACRONYMS}

\begin{tabular}{|c|c|}
\hline ADB & African Development Bank \\
\hline AFD & Agence Française de Developpement (French Development Agency) \\
\hline ANMCV & Associação Nacional dos Municípios de Cabo Verde (National Association of Municipalities) \\
\hline ANSA & Agência Nacional de Segurança Alimentar (National Food Security Agency) \\
\hline ARE & Agência de Regulação Económica (Economic Regulatory Agency) \\
\hline ARFA & $\begin{array}{l}\text { Agência de Regulação do Controlo da Qualidade dos Produtos Farmacêuticos e Alimentares (Food } \\
\text { and Drug Regulatory Agency) }\end{array}$ \\
\hline CFAA & Country Financial Accountability Assessment \\
\hline $\mathrm{CNDH}$ & Comité Nacional para os Direitos Humanos (National Human Rights Committee) \\
\hline CPAR & Country Procurement Assessment Review \\
\hline CRP & Regional Partners Committee \\
\hline CVAPHRC & Cape Verdean Action Plan for Human Rights and Citizenship \\
\hline DGCl & Direcção Geral da Cooperação Internacional (General Directorate for International Cooperation) \\
\hline DGO & Direcção Geral do Orçamento (General Directorate for Budget) \\
\hline DGP & Direcção Geral do Planeamento (General Directorate for Planning) \\
\hline DGPE & Direcção Geral do Património do Estado (Directorate General for State Assets) \\
\hline DGT & Direcção Geral do Tesouro (General Directorate for Treasury) \\
\hline EEZ & Economic Exclusivity Zone \\
\hline EMPA & Empresa Pública de Abastecimento (Public Enterprise for Food Import and Distribution) \\
\hline EU & European Union \\
\hline FAIMO & Frentes de Alta Intensidade de Mão-de-Obra (Labor Intensive Work Fronts) \\
\hline FR & Fundo Rodoviário (Road Fund) \\
\hline GDP & Gross Domestic Product \\
\hline GEP & Gabinete de Estudos e Planeamento (Office for Planning and Studies) \\
\hline GNSS & Global Navigation Satellite System \\
\hline GOP & Grandes Opções do Plano (Grand Options of the Plan) \\
\hline GPRS & Growth and Poverty Reduction Strategy \\
\hline GPRSP & Growth and Poverty Reduction Strategy Paper \\
\hline
\end{tabular}




\begin{tabular}{|c|c|}
\hline IDA & International Development Association \\
\hline IEFP & Instituto do Emprego e Formação Profissional (Employment and Professional Training Institute) \\
\hline IFAD & International Fund for Agricultural Development \\
\hline IGF & Inspecção Geral das Finanças (Inspectorate General for Finances) \\
\hline IMF & International Monetary Fund \\
\hline INE & Instituto Nacional de Estatística (National Institute for Statistics) \\
\hline IPRSP & Interim Poverty Reduction Strategy Paper \\
\hline IRDF & Inquérito às Receitas e Despesas Familiares (Household Income and Expenditure Survey) \\
\hline IUR & Imposto Único sobre o Rendimento (National Income Tax) \\
\hline LLDC & Least Developed Countries \\
\hline MDG & Millennium Development Goals \\
\hline MFP & Ministry of Finance and Planning \\
\hline MPAP & Municipal Poverty Alleviation Program \\
\hline MTEF & Medium Term expenditure Framework \\
\hline MTSEF & Medium Term Sectoral Expenditure Framework \\
\hline NDP & National Development Plan \\
\hline NOSI & Núcleo Operacional para a Sociedade da Informação (ICT Task Force) \\
\hline PANA II & Programa de Acção Nacional para o Ambiente II (Second National Environmental Action Plan \\
\hline PER & Public Expenditure Review \\
\hline PNLP & Programa Nacional de Luta Contra a Pobreza (National Poverty Alleviation Program) \\
\hline PRGF & Poverty Reduction and Growth Facility \\
\hline SEM & Sistema Estatístico Nacional (National Statistical System) \\
\hline STAD & Secretariado Técnico de Apoio ao Desenvolvimento (Technical Secretariat for Development Support) \\
\hline TA & Technical Assistance \\
\hline UNDP & United Nations Development Program \\
\hline VAT & Value Added Tax \\
\hline WTO & World Trade Organization \\
\hline
\end{tabular}




\section{Executive Summary}

Scope of the growth and poverty reduction strategy. This document describes the growth and poverty reduction strategy (GPRS) the Government of Cape Verde intends to implement during the period 2004-2007.

The approach used to design the strategy considers that the GPRS should be at the center of public policies designed to fight poverty by promoting economic growth, with strong involvement of the private sector. Three levels are thus emphasized: (i) global level (governance, macroeconomic policy); (ii) sectoral level, by means of specific programs targeting the social sectors with greatest impact on poverty; and (iii) regional and local level, by taking advantage of participation and of the greater effectiveness of decentralizing policies in fighting poverty.

The GPRS is part of a broader strategic planning exercise that has been under way in Cape Verde and has as main pillars the Grand Options of the Plan 2002-2005 (GOP) and the National Development Plan (NDP). The link between the NDP and the GPRS ensures global coherence of the planning instruments, thus facilitating management and monitoring of the various programs, and avoids duplication of efforts and procedures. On the other hand, both the NDP and the GPRS include the same sectoral programs, thus guaranteeing coherence between the global growth and poverty reduction goals on one hand, and the sectoral policies, on the other.

Further, through the GPRS, growth and poverty reduction policies become more visible on the national budget, thus lending more transparency to the allocation of public resources on a sectoral and regional basis, according to established policy objectives. A budget model is currently being developed, following a program approach. The model embodies a multi-year perspective by means of a Medium Term Expenditure Framework (MTEF) at the global and sectoral levels. The MTEF will be the appropriate tool for allocating public financial resources according to priorities set forth in the GPRS.

Growth, employment, and poverty. Over the past 15 years, the Government has implemented a strategy based on strong and sustained economic growth, anchored on the private sector and integration of Cape Verde in the world economy. Private investment especially external private investment - played a key role in the process by replacing public investment, which dominated until then.

The tertiary sector became dominant in the productive structure, supported by strong growth in tourism, as well as transports, banking and trade. The primary sector moved slowly. With the growing rural population, and considering that agricultural incomes play a key role in the survival of one quarter of the labor force, the weak performance of the primary sector had a crucial negative impact on the income and poverty risks facing rural workers.

The economic acceleration of the past decade led to the creation of jobs and their more balanced distribution in terms of gender. The result was a reduction in male unemployment, even though female employment also grew, especially in the informal sector. However, despite the positive impact on employment, the economic growth failed to reduce relative poverty.

Poverty profile. Relative poverty increased significantly in Cape Verde during the past decade. The poverty profile shows that: (i) extreme poverty is mostly found in rural areas, although it has also increased in urban areas; (ii) poverty is more likely to occur when the head of the household is a woman; (iii) poverty increases with family size; (iv) education significantly affects poverty; (v) the predominantly agricultural islands of Santo Antão and Fogo have the most poverty; (vi) unemployment affects the poor more than the non-poor; (vii) agriculture and fisheries workers are more likely to be poor than those in other sectors.

Income inequality increased significantly during the past decade. The economic acceleration was accompanied by deep structural change in the economy, with services coming out on top. This situation had an important impact in terms of resource allocation among the sectors and on 
factor output, and, thus, on income and wealth distribution, on a national level, as well as within each island. On the other hand, the strong expansion in income in sectors such as tourism and other services worsened the imbalances in income distribution. Increasing demographic pressure, combined with erosion of agricultural soils, led to a negative impact on rural per capita incomes, thus also contributing to increase inequalities in income distribution.

Introduction of the Value Added Tax (VAT) contributed to increase the progressive impact of indirect taxation. As for direct taxation, increased poverty means a heavier tax incidence as proportion of income. This trend is more evident when considering taxes on property and capital income as compared to taxes on income and pensions, due to the larger weight of the former types of income in the income structure of the more well off.

Overall, personal income taxes are progressive, despite some regressive occurrences, such as specific deductions in personal income taxes resulting from significant differences in specific deductions enjoyed by wage earners and pensioners.

Causes of poverty relate essentially to living conditions in rural areas and to the low employability of the poor. The combination of the nature of Cape Verdean agriculture, the high population growth rate, and the random nature of the climate, explain the rural stagnation and low incomes. In fact, this process may aggravate soil erosion, which reduces their productivity and availability.

To overcome the lack of resources in Cape Verde, the poor turn to migration and to the informal sector. At first, migration led Cape Verdeans abroad, but later, facing increasing difficulties in the host countries, they also started moving to the urban areas within the country. A clear evidence of this is the increase in population recorded in the city of Praia, with resulting pressure on sanitation, housing, education, and health facilities.

The FAIMO have become the main safety net in rural areas. Subsistence animal husbandry also plays a key role in rural areas, as it represents a security factor against the crises that follow periods of drought. In urban areas, informal activities are the main way out for many families, as indicated by the surge in the informal economy. Women play a key role in this area, leading to a reduction in female poverty during the 1990s.

Policy guidelines and the growth and poverty reduction strategy. The Government of Cape Verde envisages an all-around poverty reduction policy, covering macroeconomic policies (budget, monetary and exchange rate), public management and governance policies, as well as sectoral and microeconomic policies targeting the poor. The GPRS is built around a set of basic policies from which are derived five strategic pillars. The basic policies are: (i) growth and macroeconomic stability policy; (ii) decentralization policy; (iii) employment policy, including integration of the FAIMO; (iv) agriculture development policy; (v) policy of maximizing the impact of productive sectors with a multiplier effect on employment; (vi) income distribution and social protection policy, and (vii) environmental policy.

The strategic pillars set forth the various forms of public intervention at the central and local level, using a combination of programs and policy measures. The five pillars are: (1) Promote good governance, reinforcing effectiveness and guaranteeing equity; (2) Promote competitiveness to foster economic growth and employment creation; (3) Develop and upgrade human capital; (4) Improve and develop basic infrastructure, promote land use management, and protect the environment; (5) Improve the effectiveness and sustainability of the social protection system.

The GPRS will be implemented in a context of macroeconomic stability. The reference scenario used to design macroeconomic policies for the coming three years assumes a $6.5 \%$ average growth rate per year. Projected growth will be driven essentially by private and public investment, and exports. Supply side sectors expected to be more dynamic are hotels, industry, energy, fisheries and construction. 
Fiscal performance will be guided by prudence, in line with the overall policy of macroeconomic stability, sustainable growth and poverty reduction. As a result, the primary current balance will record a surplus for every year of the period, and average $3.8 \%$ of GDP for the period as a whole.

Monetary targets are in line with the goals of price stability and credibility of the exchange rate regime reflected in the upward trend in reserves relatively to imports of goods and services. It is also consistent with the principle of making internal resources available to finance the development effort. In this regard, credit to the economy as percentage of total credit is projected to expand.

The current account balance, including official transfers, is expected to evolve favourably in relative terms, leading to a significant reduction in the deficit, as a result of a relative stabilization of imports and an increase in exports during the period. The current account balance is expected to consolidate below double digits, reaching an average of $-7.1 \%$ of GDP during the period. Gross international reserves are projected to reach 2.5 months of imports of goods and services.

Financing implementation of the strategy. Having become recently a middle-income country, Cape Verde will soon be faced with a change in external financing patterns: less concessional credit, less food aid and a higher proportion of aid in the form of credit. This will happen eventually, even if a transition period is allowed. Under these conditions, Cape Verde will have to rely more on internal sources of finance. The importance of these sources of finance is conditioned by the effectiveness of the tax system. Foreign aid has actually been dropping during the last few years, as the proportion of multilateral aid increases.

At the same time, a switch from project aid to budget aid is taking place, at both the global and sectoral levels. The new approach calls for sweeping changes in budget management, thus raising its effectiveness. While retaining their own mechanisms and procedures, relevant services will be subject to new responsibilities with regards to budget management, but at the sectoral level as well. Achievement of these goals will be monitored using performance indicators. Regular and transparent reporting will be another key feature of the new system.

The implementation system. The GPRS will be implemented within the public planning and budget systems, which are currently undergoing reforms. Implementation will be guided by strong participation of community-based organizations, decentralized entities, and private sector representatives. To support the process, the Government has decide to establish, starting with the 2005 national budget, a Medium Term Expenditure Framework (MTEF) and a number of Medium Term Sectoral Expenditure Frameworks (MTSEF) within key line Ministries. It is expected that such a set-up will improve: i) prioritising programs and projects that directly contribute towards the GPRS objectives and the sectoral objectives; ii) budgeting of programs and projects according to resources that can be mobilized; iii) medium term (three years) budget allocation according to priorities in order to reach the established development targets.

To implement these guidelines, the Government has begun a number of reforms to make the public management system more efficient, more reliable and more transparent. In this regard, a number of measures are being designed to implement the recommendations from the PER, CFAA, and CPAR exercises.

The institutional framework for implementing the GPRS will consist of the existing administrative apparatus, after the necessary functional changes in structure are introduced. The National Poverty Reduction Board is an advisory body that includes the main stakeholders, drawn from public administration, the private sector, and civil society. At the central level, the General Directorate of Planning, supported by a Technical Secretariat, will be responsible for coordination and technical support. At the sectoral level, the GEPs within each line Ministry will prepare, monitor and evaluate priority programs and projects included in the strategy. At the local level, there will be Regional Poverty Reduction Boards, advisory bodies that will secure the input from local stakeholders. 


\section{INTRODUCTION}

1. This Growth and Poverty Reduction Strategy Paper (GPRSP) was prepared in fulfillment of the Government policy objective of an integrated and horizontal approach to poverty reduction, cutting across the various areas of governance and in close coordination with policies to foster economic growth. It also reflects a commitment to the social dimension of development as an inevitable component of the process of economic development, stemming from the belief that these two dimensions are inseparable, particularly with regards to their impact on human development.

2. This new approach breaks away from previous poverty reduction policies based essentially on activities at the grassroots level, which targeted the most vulnerable population groups by means of multi-sector programs. This perspective, which has guided the National Poverty Alleviation Plan (NPAP), shows that poverty reduction in Cape Verde has a tradition, which is older than the practice, now common in developing countries, of preparing growth and poverty reduction strategies ${ }^{1}$.

3. However, the new approach places new emphasis on the poverty reduction strategy by placing it at the center of public policies at the global (governance, macroeconomic policies) as well as sector, regional and local levels, thus taking full advantage of decentralizing policies in fighting poverty.

\section{From the IPRSP to the Growth and Poverty Reduction Strategy document}

4. In December 2001, the Government of Cape Verde approved an interim version of its Growth and Poverty Reduction Strategy ${ }^{2}$. This strategy was jointly evaluated by the staffs of the World Bank and of the International Monetary Fund, who made some recommendations to be considered in drafting the final version.

5. Overall, the iPRSP included a preliminary poverty profile, due to the fact that results from the Household Income and Expenditure Survey (IRDF 2001-2002) were not yet available at the time. The recent publication of said survey results made it possible to prepare a more adequate poverty profile, thus establishing a basis for preparing the global and sector poverty reduction strategies.

6. In the meantime, significant developments have occurred with regards to some strategic sector plans, leading to new guidelines, which were not always envisaged in the National Development Plan (NDP).

\section{Relationship between the GPRSP and other planning tools}

7. The Growth and Poverty Reduction Strategy (GPRS) comes into being in the context of the strategic planning process under way for some time now in Cape Verde. The fundamental tools of this process are the Grand Options of the Plan (GOP) and the National Development Plan (NDP). A look back over the past few decades of public policy in Cape Verde clearly shows that poverty reduction has played a key role in the definition and implementation of development and growth strategies. What is new in the current context is the clear commitment to poverty reduction policy as an integral part of public policy at the global level, something to be considered in any strategic options made at this level.

\footnotetext{
${ }^{1}$ Commonly referred to as PRSP-Poverty Reduction Strategy Paper.

${ }^{2}$ Referred to as iPRSP
} 
8. Also new is the fact that growth and poverty reduction policies are now more visible in the national budget, thus adding transparency to the way financial resources are allocated on a sector and regional basis, according to policy objectives.

9. In fact, as described in the following paragraphs, poverty reduction strategy is now conceived on several levels: at the macro level, and at the sector level (by means of a program approach), as well as the micro level, through the implementation of specific measures targeting the poor. At the micro level, the NPAP has played a key role and accumulated significant experience in the area of project implementation at the grassroots level. This experience could be useful in implementing the current strategy, despite its much broader scope.

10. This paper presents the growth and poverty reduction strategy for the 2004-2007 period. Its structure - policy lines, strategic pillars, objective trees and indicators - follows the structure of the $\mathrm{NDP}^{3}$, thus ensuring global coherence of existing planning tools, facilitating the management and monitoring processes, and avoiding duplication of processes and procedures. In short, the GPRSP stems from the NDP by focusing on the measures with greater impact on growth and poverty reduction.

11. The GPRSP has an integrating nature, a mission to bring together policies, measures and interventions in the areas of economic growth and poverty reduction. To this end, it articulates with the complete set of planning tools at the macro and sector level that make up the planning universe in Cape Verde. As shown in Fig 1-1, Cape Verde's planning system tends to link and integrate the planning-programming-budgeting cycle, thus connecting the phases of strategic planning (GOP), programming (NDP) and budgeting. This is true of the medium term, through a medium term expenditure outlook, as well as on an annual basis, thru the national budget.

12. It should be pointed out that this system is undergoing development, particularly with regards to the link between programming by objectives and the budget system, as well as with regards to integration of medium term expenditure outlook in the programming and budgeting structure. This explains some of the difficulties felt in the preparation of the GPRSP, particularly with regards to budgeting.

\footnotetext{
${ }^{3}$ This explains why the structure of this GPRSP differs from that of the iPRSP: it is now assumed that the pillars of the GPRS stem from those of the NDP and, therefore, the measures and activities of the GPRS are a subset of the measures and activities of the NDP selected on the basis of their contribution to poverty reduction. For practical purposes, and starting from the list of measures and projects included in the NDP, those which are a priority for the next three years were selected to makeup the GPRS.
} 
Figure 1-1: Cape Verde's planning system

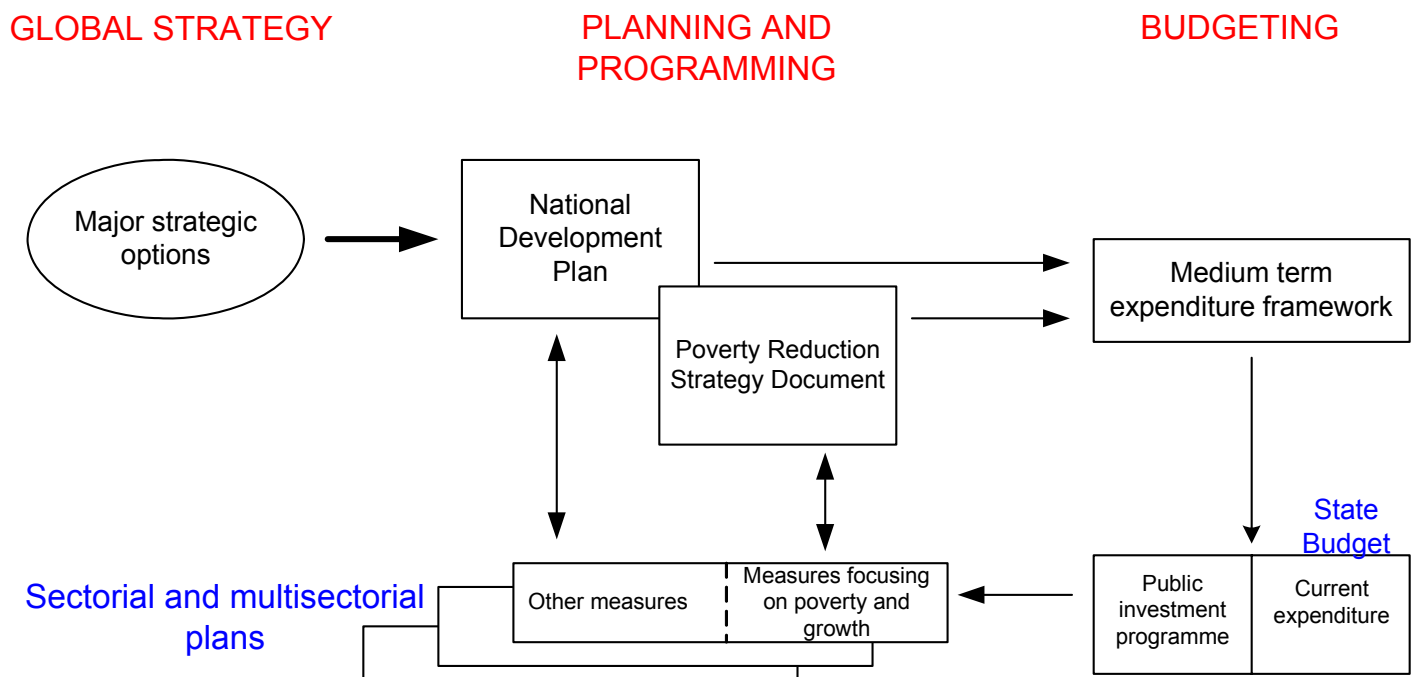

13. Two areas of the above system will need adjustment and development in the future. The first one is related to coherence between the timeframe of the different plans and programs. In this regard, the GPRS covers the 2005-2007 period, thus including three full years plus a transition year, 2004. Considering that the current legislature behind the NDP ends in 2005, the GPRS timeframe goes beyond the current legislature as well as the period covered by the NDP itself.

14. The second area has to do with the need to strengthen the consistency among the various planning tools. The GPRSP provides a link between the NDP and the sector and multi-sector programs, thus promoting global coherence between the strategic objectives and program activities with greater impact on poverty. Fig 1-2 lists the various plans currently under way, thus offering a clear perspective of the need for seeking coherence among them.

15. From the onset, coherence between the NDP and the GPRSP is guaranteed, due to the fact that the strategic pillars and priority measures included in the GPRSP come straight from the NDP. It can actually be said that the policy measures and program activities that makeup the GPRSP are a subset of those included in the NDP, with the latter being a general framework for development policies, as it covers areas beyond those considered as priorities under the GPRSP.

16. However, the relationship between the GPRSP and the sector programs need to be strengthened. To this end, a program preparation methodology that ensures global system coherence needs to be adopted. In this regard, the budget model is already being designed, based on a program approach. This model also allows for a multi-year perspective by means of a Medium Term Expenditure Framework, addressing global as well as sector concerns and providing an adequate framework for allocating public resources in accordance with GPRS priorities. 
Figure 1-2: Strategic plans and respective timeframes

\begin{tabular}{|l|l|}
\hline Plans and programs & Timeframe \\
\hline Global Plans & $2002-2005$ \\
Grand Options of the Plan (GOP) & $2002-2005$ \\
National Development Plan (NDP) & $2004-2007$ \\
Growth and Poverty Reduction Strategy (GPRS) & $2001-2005$ \\
\hline Government Program (6 ${ }^{\text {th }}$ Legislature) & \\
\hline Sector Plans & $2002-2012$ \\
Education Strategic Plan & $2004-2014$ \\
$2^{\text {nd }}$ National Action Plan for the Environment & $2003-2012$ \\
National Energy Plan & $2004-2015$ \\
Agriculture Strategic Plan & $2004-2015$ \\
Tourism Strategic Development Plan & $2003-2015$ \\
National Plan for Food Security & $1996-2008$ \\
National Poverty Reduction Plan & $2002-2005$ \\
Justice Strategic Plan & (draft stage) \\
Strategy for Development of Social Security & (final draft stage) \\
National Plan for Gender Equality and Equity & \\
\hline Foreign aid programs & $2002-2004$ \\
Poverty Reduction Growth Facility (PRGF) & $2004-2007$ \\
Poverty Reduction Support Credit (PRSC) (*) & $2001-2007$ \\
\hline Strategy for EU - Cape Verde Cooperation &
\end{tabular}

(*) Approval should occur following conclusion of the GPRSP.

\section{Preparation of the GPRSP}

17. This paper was prepared under guidance of a Coordinating Committee made up of representatives from public and private entities as well as civil society organizations traditionally involved in the issue of poverty reduction. Executive responsibility was left with the STAD. The paper drew on some technical studies carried out by external consultants who worked on some specialized areas ${ }^{4}$.

18. The sectoral Offices for Planning and Studies (GEPs) within each line Ministry contributed by specifying their respective policy objectives and policies envisaged to overcome the problems identified in the context of the poverty profile. Based on the agreed strategy, each sector then proceeded to draft a list of measures and activities it considers relevant, all of which must be coherent with those measures and activities included in the NDP ${ }^{5}$. This list of measures was then used to derive the performance indicators and the budgets.

\footnotetext{
${ }^{4}$ The following studies were carried out:

- $\quad$ MFP/UNDP (2004 a), Growth, Employment and Poverty Reduction Policies;

- $\quad$ MFP (2004 b), Standardized information on Poverty Reduction Measures;

- $\quad$ MFP (2004 c), Growth, Employment, Income, and Poverty in Cape Verde;

- MFP (2004), Tax Incidence in Cape Verde-Analysis Based on the 2000 IRDF

- MFP (2004 d), Economic Activities and Access to Land by Rural Populations;

- $\quad$ INE (2004), Poverty Profile in Cape Verde
}

${ }^{5}$ For more information on the priority measures, refer to Annex 2. 


\section{Document structure}

19. This paper is organized into seven chapters. After the Introduction (Chapter 1), Chapter 2 presents an analysis of the growth process in Cape Verde during the 1990s, with emphasis on the issues of poverty, employment and income distribution. Chapter 3 presents the poverty profile prepared using information from the IRDF 2001-2002. Chapter 4 presents the strategic framework for achieving growth and poverty reduction, out of which the guidelines the Government intends to follow over the coming three years are derived. These guidelines are grouped into 5 strategic pillars, which are then discussed in some detail. Chapter 5 covers financing, starting with recent trends in external financing for Cape Verde and rounding up with an analysis of current possibilities for financing the poverty reduction strategy. The implementation, monitoring and evaluation are covered under Chapter 6.

20. The paper includes a number of annexes with information on the following: statistical data in the areas of population, employment and poverty profile (Annex 1), measures included in the poverty reduction strategy (Annex 2), millennium development goals and the growth and poverty reduction strategy (Annex 3), and list of Cape Verde's development partners by area of cooperation (Annex 4). 


\section{GROWTH, EMPLOYMENT, AND POVERTY REDUCTION POLICIES}

\subsection{Problems, policy responses and structural reforms}

21. This chapter discusses some of the structural problems facing Cape Verde and the policy responses used to address these problems. This approach assumes that the strategy presented in Chapter 4 in fact addresses a number of previously identified problems, but seeks to place them in a new framework in terms of policy coordination and of focus on the growth-poverty relationship. For this reason, one must first look into the policies that have been used and the problems that still persist.

22. Policy reforms implemented in Cape Verde in the last fifteen years can be grouped into three broad categories: (i) structural reforms; (ii) reforms aimed at integrating Cape Verde in the world economy, and (iii) macroeconomic policy reforms.

23. Structural measures act at the microeconomic level to improve the allocation of production factors and enable development of the private sector. These measures have included the following: support to the private sector, promotion of establishment and development of small- and medium scale enterprises, privatization of most state-owned companies, strengthening of property rights in agriculture, elimination of price controls, foreign trade liberalization, modernization of commercial laws, as well as liberalization, albeit limited, of labor legislation.

24. The privatization program ${ }^{6}$ has been guided by the objectives set forth under relevant laws $^{7}$. An important source of opportunities for private sector development, the program ${ }^{8}$ has proceeded with the liquidation of EMPA, which held a monopoly on imports of essential food items. The privatization of Arca Verde (inter-island maritime transportation) was also completed with the company's liquidation in 1999, the only remaining activities being the sale or lease of four ships.

25. The establishment of a regulatory system has met with various difficulties, in part owing to the fact that it is a completely new area to Cape Verde. At present economic regulation is guided by a framework law ${ }^{9}$ that defines the legal environment for regulation of economic and financial activities. Three agencies have been created and installed thus far: (i) a National Agency for Food Security (ANSA), to regulate the market for essential food products; (ii) an Economic Regulatory Agency (ARE), in charge of the areas of telecommunications, water, energy, passenger maritime transportation, and urban public transportation; (iii) a Civil Aviation Institute (IAC), responsible for civil aviation activities. Work is currently under way for the installation of a Food and Drug Regulatory Agency (ARFA).

26. The combination of these measures have contributed to a transformation of the socialist-inspired economic system installed in Cape Verde following independence into a system open to competition and to market incentives guiding production and income distribution decisions. Some of these measures have only been partially implemented

\footnotetext{
${ }^{6}$ Source: "Privatization and Regulatory Capacity Building Project (PRCBP), World Bank / IDA Credit 3121-CV," June 2004.

${ }^{7}$ Law 47/IV/92, dated 6, July, as amended by Law 41/V/97, dated November 17.

${ }^{8}$ The privatization program is supported by the World Bank thru the PRCBP, with a US\$ 10 million credit.

${ }^{9}$ Established under Law 20/VI/2003, dated April 21, which defines the legal framework for regulatory agencies.
} 
owing to persistent legal and administrative constraints that still hinder competition in the markets for goods, services and factors of production.

\section{Box 2-1: Cape Verde in brief}

Cape Verde became independent in 1975 . The country is made up of 10 islands and thirteen islets, located some $450 \mathrm{~km}$ west of Senegal. It has a 4,033 square kilometers land area and a 700,000 square kilometers Economic Exclusivity Zone. Natural resources are rare. The land is mostly bare and organically poor. Only an estimated $10 \%$ of the land area is suitable for agriculture.

According to the 2000 Census, Cape Verde had a 434,625 resident population, of which $55 \%$ lived in urban areas. Santiago is the most populated island, with $54 \%$ of the resident population, followed by S. Vicente and S. Antão, with $15 \%$ and $11 \%$, respectively. Praia, the country's capital, is home to $23 \%$ of the resident population ${ }^{10}$. During the last decade population growth rate averaged $2.4 \%$ per year, whereas fertility rate was 4 children per woman. The population is young, with $68.7 \%$ of Cape Verdeans being under the age of 30.

The labor force was made up of 166 thousand people, of which $46 \%$ are female. $22 \%$ of the labor force was unemployed. More men ( 72 thousand) than women (58 thousand) were employed. More women (19 thousand) than men (17 thousand) were unemployed.

Real per capita GDP is estimated at US\$1,420 (2002), which shows a significant improvement since independence (1975), at which time it was US\$190, or even as compared to 1990 , when it was US\$902. The strong increase in real per capita GDP was accompanied by a significant and continuous improvement of the human development index (HDI), which depicts the situation with regards to life expectancy, income and education. This index went from 0,587 in 1990 to 0,670 in 2002. At present, life expectancy is 72 for women and 66 for men.

Human poverty rate (HPR), which reflects shortage in terms of life expectancy, income, education, literacy and other areas decreased from $28.8 \%$ in 1990 to $17.7 \%$ in 2002 . Despite these improvements the country still struggles with structural vulnerabilities (See Box 2.2.). This notwithstanding, Official Development Aid (ODA) has been steadily decreasing, having dropped from $24.1 \%$ of GDP in 1998 to $13.5 \%$ in 2001.

Sources: 2000 Census, IRDF 2002 and UNDP (2004)

27. The second group of reforms aim at better integrating Cape Verde in the world economy. They included two types of measures: (i) opening the economy to international competition and (ii) export promotion and diversification. Various measures to liberalize foreign trade have been implemented among which the elimination of import quotas, simplification and reduction of custom duties, and the elimination of EMPA's monopoly with regards to food imports.

28. However, trade liberalization has met some difficulties. Custom duties on certain imported products are still high, coupled with non-tariff barriers in some sectors. Another measure that could help promote exports and their diversification was the establishment of free zones (i.e., the awarding of free zone status) to the cities of Praia and Mindelo, in order to attract external investment. There is a natural expectation that these measures will help the integration of the Cape Verdean economy in the world economy by encouraging the development of a light manufacturing industrial sector for export.

29. Cape Verde's option to strengthen its integration in the world economy was confirmed by its 1999 request for admission into the World Trade Organization (WTO), a process that is currently under way. Departing from the tradition followed by its West African neighbours, Cape Verde gave priority to liberalization of multilateral trade, a decision

\footnotetext{
${ }^{10}$ Demographic data from the IRDF 2001-2002 differ from those of the 2000 Census for methodological reasons. As the objective of the former was other than the collection of demographic data, these are only used in the context of analysis of poverty, income and household consumption.
} 
dictated by the structure of the country's ties with the outside world, which are strongly concentrated on the industrialized European countries.

30. The Exchange Rate Agreement signed with Portugal in 1998 allowed for a fixed exchange rate with a basket of currencies, first with the Portuguese escudo, in 1998, but later with the Euro, in 2000. This reduced the country's foreign exchange risk, thus contributing to a stronger economic and financial integration of Cape Verde in the world economy.

31. The third group of reforms involve the new orientations in monetary and fiscal policy. The dominant role of market forces with regards to resource allocation and income distribution has clarified the role of the State in the economy. The new role assignments were followed by various measures. Monetary and budget policy were coordinated thru the establishment of a two-tier banking system: a central bank in charge of conducting monetary policy and supervision of the second tier, made up of commercial banks and other financial institutions.

32. The fiscal system experienced sweeping reforms during the 1990's, leading to simplification of the fiscal structure, unification of taxes on income and taxes on profits, and broadening the tax base. A Value Added Tax (VAT) was introduced in January 2004. In the area of public expenditure management the reform included the introduction of a new public accounting and payment system, currently undergoing implementation. Reform in this area will continue under the umbrella of the CFAA Action Plan.

33. However, in all of these areas the reforms met with some limitations. The Government resorted frequently to the banking sector to finance the deficit, exposing the limits to separation between budget and monetary policy, as well as the limits to independence of the central bank. On the other hand, policies followed during the 1990s led to a steep increase in internal public debt, which in turn resulted in strong pressure on the budget due to the resulting higher debt service. To overcome this problem, the Government mobilized donor support to establish a Trust Fund financed by privatisation revenues, grants, and concessional loans. The Fund's returns would be channelled to service the internal debt. However, the Fund did not fully accomplish its objectives mainly because the envisaged capital base was never completely materialized.

\section{Box 2-2: Cape Verde's vulnerability profile}

Vulnerability regarding agricultural output. Only $10 \%$ of the country's land area, representing some 40,000 hectars is suitable for agriculture. Climate conditions are a permanent threat to agriculture in Cape Verde. Scarce and irregular rainfall result in increasingly longer droughts, which in turn lead to permanent water scarcity and increased desertification. Under these extremely difficult conditions, food production permanently lags behind demand. Cape Verde imports more than $80 \%$ of the food consumed in the country and there is no food self-sufficiency in sight for Cape Verde.

In addition to being insufficient, rainfall is unstable in terms of volume as well as spatial and time distribution of rains. Corn yields vary significantly from year to year, with a 30-year high 36,500 tons recorded in 1999. This output, however only covered about $40 \%$ of demand for cereals. Agricultural output varies considerably and randomly, thus presenting a great risk to rural populations. The high population growth rate $(2.4 \%$ per year during the $1990 \mathrm{~s})$ represents an extreme pressure on the country's food situation, thus leading to a permanent conflict between alternative goals of agricultural production under prevailing conditions in terms of factor availability (soil and water).

Vulnerability regarding imports. Due to its small size and island nature, Cape Verde is more exposed to external shocks, be they economic or natural, than many other economies. These factors represent structural characteristics that limit the possibilities for economic development. The small productive base makes the country depend on the exterior not only with regards to exports, but with regards to the impact of the price of imported products on internal consumption as well. With Cape Verde importing almost everything that is consumed, imports represent as much as $40 \%$ of GDP. This dependency is particularly strong with regards to strategic goods such as food and energy products. Fuel accounts for $6 \%$ of the country's imports, following right after cereal imports.

Vulnerability with regards to the environment. The difficult relationship between population and environment is a key feature of Cape Verdean society. At its worst, this relationship had some tragic consequences, namely devastating 
famines. This harsh relationship has also led to the emigration of thousands of Cape Verdeans. Even today, the country struggles to overcome the fragility of its environment, which represents a series of hurdles to Cape Verde's economic and social development. Shortage of arable land creates great pressure on the environment, forcing farmers to grow crops on the slopes that make up over $60 \%$ of the country's arable land. This practice aggravates soil erosion and accelerates the desertification process.

Vulnerability of insularity. Geographic isolation often leads to non-competitive costs. Unit costs of maritime or air transportation are particularly high not just because of the distance to the markets or to the sources of raw materials, but also because the quantities are generally small and therefore do not allow for economies of scale. Storage costs make exports as well as imports more expensive and, thus increase overall costs, which is a competitive disadvantage. Worse than the country's insularity, it is the dispersion of the islands that represents the most serious economic constraint. This dispersion forces the multiplication of infrastructure (inter-island transport, production and distribution of water and energy, etc) and facilities for rendering social, administrative and security services.

Vulnerability with regards to external aid. Cape Verde's complete dependence on emigrant remittances and foreign aid represents its more serious vulnerabilities. Together they represent some 34\% of GDP and a significant portion of development efforts are based on transfers.

Sources: UNDP, Vulnerability Study, Action Plan for 2001-2010, March 2001.

\section{Per capita GDP growth}

34. Cape Verde has experienced high growth rates since independence, particularly during the first ten years (1975 thru 1985), when growth averaged $10 \%$ per year. There are two main reasons behind this performance. The first one is the import substitution policy, which, like in most countries that followed this strategy, resulted at first in high growth, but later slowed down due to an incentive structure that discouraged exports and to the economy's inability to adjust to changes in relative prices. A second reason is related to development assistance and emigrant remittances, which represented some $50 \%$ and $60 \%$ of GDP, respectively.

35. The second half of the 1990 s is another period marked by high growth rates $-8.4 \%$ per year in average. Despite this acceleration, over one third of the population lived in poverty. Further, the economy showed additional weaknesses such as a random pattern of internal demand as well as negative net external demand. In this regard, the slow growth of exports confirmed the country's low competitiveness, as reflected by the traditionally low percentage of tradable goods in the country's productive structure.

36. Such a growth pattern was the main outcome of the policies implemented in Cape Verde over the past fifteen years, which resulted in strong and sustainable growth based on the private sector and on the integration of Cape Verde in the world economy. The goal of this strategy was to significantly increase real incomes and to combat the structural vulnerability of Cape Verde's economy.

37. Cape Verde's economy has an outstanding track record as compared to other African countries. In fact, over the last decade, the average growth rate in Cape Verde was double that of the African countries as a whole ${ }^{11}$. The high growth rate allowed for a significant improvement in the average standard of living, as shown by the high per capita GDP. Despite a $2.4 \%$ population growth rate per year, per capita GDP increased $3.9 \%$ per year on the average between 1992 and 2000.

38. Notwithstanding the high economic growth rates experienced during the second half of the 1990s, the structural vulnerability of the country's economy - as shown by a high poverty level and by the strong dependency on foreign aid to finance the development effort - remained a major constraint. Such a record of vulnerability calls for a central role for poverty reduction in the context of public policymaking.

\footnotetext{
${ }^{11}$ Source : African Development Bank (2003).
} 


\section{GDP growth factors}

39. Increased output per worker can be caused by one of two factors: (i) an increase in the level of capital available to each worker or (ii) increased productivity of the factors of production. The growth occurred during the 1990s was first and foremost the result of capital accumulation (64\% of per capita GDP growth) and, to a lesser extent, an impact of productivity gains (36\%). However, productivity gains seem to have played an important role in the latter part of the 1990s, which means that the growth became more sustainable. Capital accumulation -- an important factor behind the growth experienced in the 1990s was the result of public and private investment, whereas an analysis of the contribution of these two types of investment makes it easier to understand the role played by productivity gains in the latter part of the $1990 \mathrm{~s}^{12}$.

\section{Impact of investment on GDP}

40. Public investment was dominant during the first half of the 1990s, whereas private investment exceeded half of total investment from 1996 onwards ${ }^{13}$. The increase in private investment and its concentration in the most productive and profitable sectors explain the changes in the sources of output growth per worker that occurred during the 1990s.

41. External investment played a key role in the growth of private investment. Between 1997 and 2000, external investment accounted for over $50 \%$ of private investment ${ }^{14}$, whereas during the early 1990 s it represented only about $1 / 5$.

42. Labor migration from the primary sector - and, to a lesser extent, the secondary sector - into the tertiary sector, played a key role in the productivity gains occurred during the past decade ${ }^{15}$. In the year 2000 , the primary sector employed $24 \%$ of the labor force (as opposed to $57 \%$ for the tertiary sector) and contributed $9.7 \%$ of GDP (as opposed to $74.1 \%$ for the tertiary sector). It is easy to understand that, with productivity of the tertiary sector being three times higher that of the primary sector, labor migration from the latter to the former would lead to a global increase in productivity.

\section{Changes in the productive structure}

43. The tertiary sector generated most of the economic growth experienced since 1990. The share of the secondary sector remained more or less constant for a while but then seemed to decrease in the late 1990s and early 2000s. The share of the primary sector diminished to no more than $10 \%$. The dominance of the tertiary sector is due essentially to the strong performance of tourism, as well as transports, banking and insurance. Hotel services, finance, transports and telecommunications grew between $200 \%$ and $300 \%$ during the 1990s. In the year 2000 these three sectors represented more than $1 / 3$ of the tertiary sector, as compared to $23 \%$ in 1990 . Over the same period, public services grew at the same rate as GDP.

\footnotetext{
12 Emigrant remittances increased significantly in absolute terms after the $1980 \mathrm{~s}$, having increased from $13 \%$ to $19 \%$ of GDP between 1988 and 1996 , and later dropped to $15 \%$. It is necessary to distinguish between remittances used to finance consumption and those that are invested by taking advantage of the incentives to deposits by non-residents. The latter is then turned by the banking system into investment, particularly in the construction sector.

${ }^{13}$ Bourdet, Y. (2002),

${ }^{14}$ According to PROMEX, about half of external investment occurred in tourism, whereas industry decreased from $28 \%$ to $14 \%$ between $1994-96$ and 1997-2000.

${ }^{15}$ With productivity in the primary sector being lower than that of the other sectors, labor reallocation away from the primary sector automatically leads to increased overall productivity.
} 
44. The secondary sector is dominated by construction, which accounted for more than $60 \%$ and about $10 \%$ of GDP in the year 2000 . Ten years earlier construction accounted for $70 \%$ of the secondary sector and $14 \%$ of GDP. Light manufacturing grew considerably during the last decade and accounted for $8 \%$ of the sector and just over $1 \%$ of GDP in the year 2000, as compared to $4 \%$ and $0.8 \%$, respectively, in 1990 .

45. The primary sector ${ }^{16}$ registered little growth in real terms and, as a result, lost weight in the GDP. Fisheries, a potentially important sector in Cape Verde, grew at about half the rate of GDP and in the year 2000 it represented only $1 \%$ of $\mathrm{GDP}^{17}$. Agriculture grew even less in the 1990 s - less than $1 \%$ per year on the average. As a result, in the narrow sense, agriculture's contribution to GDP fell from $12 \%$ to $8 \%$ during this period. Because of the importance (and growth) of rural population and the key role agricultural incomes play on the welfare of some $25 \%$ of the labor force, the sector's poor performance had an important negative impact on the incomes and poverty risk facing rural workers.

\section{Recent macroeconomic developments}

46. Starting in 2001, in the aftermath of the major macroeconomic imbalances occurred specially during the year 2000, the Government embraced macroeconomic policies aimed at promoting stability as a necessary condition for economic development on a sustained and socially-conscious basis, and able to contribute to long lasting poverty reduction.

47. To face the serious challenges, the Government turned to its external partners. Following a Staff Monitored Program signed with the IMF in 2001, which yielded favorable results, the Government signed a second agreement, in the context of the IMF's Poverty Reduction and Growth Facility and valid for the years 2002 thru 2004.

48. The unfavorable international context at the time, coupled with the emphasis on restoring macroeconomic equilibria, resulted in a deceleration of economic activity as compared with the previous period. However, judging from the latest available estimates the economy still recorded an upward trend, with rates of $4.7 \%, 4.9 \%$ and $5.3 \%$ respectively in 2001, 2002 and 2003, and an average growth rate of 5\% for the period.

49. However, the external sector remains one of the economy's weakest areas. In fact, the current account failed to record a significant improvement in the last few years, and the current deficit as percentage of GDP remained at double digits. This poor performance of the current account with regards to the objective of sustainable economic growth was due to, among other factors, the country's low competitiveness, as confirmed by the traditionally low weight of tradable goods in the country's productive structure. In fact, between 2001 and 2003, current account deficit excluding grants reached an average of $15.5 \%$ of GDP, as compared to $10.6 \%$ including grants.

50. Inflation moved within reasonable boundaries during the period: from $3.8 \%$ in 2001 it dropped to $1.2 \%$ in 2003 , which is comfortably below the reference threshold of $2.5 \%$ $3 \%$ that is necessary to maintain price stability and competitiveness of the economy vis-avis the country's main partners in the euro zone.

51. A new organic law for the central bank was approved in 2002. Among various other practical consequences, it underscored the need for coordination between budget and monetary policies. As a result, during the period budget policy contributed decisively for consolidation of macro-economic stability, in a context of deeper reforms, particularly with

\footnotetext{
${ }^{16}$ The primary sector includes agriculture, fisheries and mining.

${ }^{17}$ The poor performance of the fisheries sector was partly due to the embargo by the European Union, which barred Cape Verde's fishing products in the late 1990s because of weak health controls by Cape Verde exporters and authorities. The embargo was lifted in 2002.
} 
regards to the social areas such as education and health - important pillars in the context of the poverty reduction strategy.

\section{Growth and employment}

52. Economic growth was accompanied by a surge in the size of the labor force ${ }^{18}$, which more than doubled over the past twenty years. Female employment recorded the most significant increase - from $12 \%$ in 1980 to $30 \%$ in 2000 . The growth occurred in the 1990 s was far more efficient in creating employment than that occurred in the 1980s. In fact, a $1 \%$ increase in GDP was accompanied by a $0.6 \%$ increase in employment in the $1990 \mathrm{~s}$, as compared to $0.28 \%$ in the 1980 s. This explains why the $6 \%$ employment increase recorded in the 1990 s resulted in a $3.7 \%$ increase in the labor force, even surpassing the population growth rate of $2.6 \%$. It should be pointed out that in the 90 s this increase in employment impacted equally men and women, as opposed to the one occurred in the 80s, which impacted women in a much stronger way - twice as much.

53. This trend was accompanied by a relocation of labor among the main sectors of the economy, with the tertiary sector surpassing the primary and secondary sectors to become the main employer. It should however be said that the steep decline in the primary sector's share in the labor force was not the result of a drop in absolute employment in the sector. Instead, it was due to slower growth in this sector as compared to the tertiary sector. In fact, during the 1990s the number of people employed in agriculture and fisheries increased from 37,000 to 43,700 . This $16 \%$ increase over a 10 -year period is clearly less than the population growth rate, which means that a considerable portion of rural people migrated, probably to urban and semi-urban areas.

\section{Unequal distribution of the labor force}

54. The various islands differ significantly with regards to distribution of labor and employment rate. This is an obvious result of the unequal occurrence of growth in the various sectors, as well as of the specialization of each island. Over half the labor force is concentrated in the island of Santiago. The four most significant islands make up $80 \%$ of the total, even though the islands that are less important in terms of employment have higher employment rates.

55. In the islands of Sal and S. Vicente, the weight of the secondary and tertiary sectors is clearly larger than the national average, as a result of more dynamic tourism, industry and construction activities. In contrast, the primary sector is nearly non-existent in those islands, whereas in the islands of Fogo, S. Nicolau, Santo Antão and Maio it is particularly important.

56. The public sector plays an important role in Cape Verde. For historical reasons, the strategy used in the early years of independence reserved for the State a key role in the industry and service sectors. However, over the past fifteen years, the situation has changed considerably. In fact, the privatizations program, private sector promotion initiatives and the breakup of public monopolies in the import sector, have led to a strong expansion of the private sector in terms of both output and employment. The pace of this change has been different from one island to another. The islands of Boa Vista and Sal have the highest rate of private employment thanks to their dynamic private sectors. The

\footnotetext{
${ }^{18}$ The elasticity of the labor force (employed population plus unemployed population) was used to derive the impact of growth on employment. These elasticities showed the percentage growth in the number of workers relatively to a $1 \%$ growth in GDP. Specifically, during the 1990 s, a $1 \%$ increase in GDP led to a $0.4 \%$ increase in the labor force.
} 
island of Fogo has an important private sector in relative terms along with an undersized public sector, leading to a low employment rate. At the other extreme are the islands of Santo Antão and Brava, with an oversized public sector relatively to the national average and employment rates and employment growth rates significantly below the national average.

\section{Atypical and informal employment}

57. Changes in the sectoral composition of employment have been accompanied by changes in incidence of the various forms of employment. This is no surprise, considering that the forms of employment vary from one sector to another. Therefore, changes in the sectoral composition of employment will inevitably lead to changes in the incidence of the various forms of employment. Another possibility is that the incidence of the various forms of employment within the sectors may result from changes in attitude of employers and employees, or from changes in the labor law. Therefore, it is possible that some of the changes occurred in Cape Verde may be the consequence of reforms in the labor law, which made it easier for workers to move from one sector to another as a result of simplification of contracting and licensing procedures.

58. The weight of independent employment as a percentage of the total is significant (25\%). This is higher than what it was in the mid 80 s (14 to $19 \%$ of urban employment). In fact, independent employment reflects the surge of micro- and small enterprises in the sectors of commerce, hotels and restaurants, that is, the sectors that experienced the highest growth in the 90s. These are also the sectors in which independent workers represent more than $50 \%$ of total employees, often in the context of a family operation ${ }^{19}$.

59. Informal employment also plays an important role in Cape Verde. A key feature of this type of employment is the absence of a formal work contract. In urban areas, informal employment is found in small family-owned businesses that employ unskilled workers. It is estimated that informal employment accounts for about $40 \%$ of total employment ${ }^{20}$. This estimate varies considerably from one sector to another: $50 \%$ in commerce, restaurants and hotels, $34 \%$ in light manufacturing, $25 \%$ in construction, $17 \%$ in personal services and $9 \%$ in transports. The higher percentage in commerce, hotels and restaurants reflects the fast development of these activities in the 1990s and even suggests that transfer from formal to informal employment may have occurred in these sectors.

60. Such trait characteristic is common to most developing countries. An important exception in the case of Cape Verde is the relatively high number of formal civil servants now in the informal sector, which confirms the existence of considerable mobility between formal and informal employment. This peculiarity should be interpreted in light of the important role the State played in the country's economy during the years following independence, as well as of the private sector promotion measures implemented starting in the early 90 s.

61. In summary, the strong economic growth experienced in Cape Verde during the 1990s led to a significant increase in the country's labor force as well as to a considerable reduction in unemployment, especially among men. However, the improved labor market conditions did not contribute to poverty reduction.

62. Other structural factors explain rural poverty and complicate the road out of poverty. The lack of a clear link between economic growth and poverty reduction is mainly due to

\footnotetext{
${ }^{19}$ The 1997 business census clearly shows the strong increase in the number of micro- and small enterprises, as well as their characteristics and geographic distribution. For more details, refer to Instituto Nacional de Estatística (1999)

${ }^{20} 1996$ Employment Survey. Other estimates related to the 1990s confirm this figure. Refer to World Bank (1996).
} 
those factors as well as to the low employability of the very poor. The very poor suffer from a number of constraints in terms of human capital, such as low levels of schooling, lack of skills and lack of professional experience, which make it difficult for them to enter the labor market, considering that their number far exceeds the economy's demand for unskilled labor. About half of the very poor -- some 40,000 people -- are faced with this problem, whereas the other half is below working age. Therefore, most of the very poor get by on activities, often in agriculture, that provide low incomes which are complemented by emigrant remittances, Government transfers (albeit very limited), as well as occasional work in the FAIMO - Frentes de Alta Intensidade de Mão-de-Obra (Labor Intensive Work Fronts).

\section{Growth and unequal distribution}

63. The absence of a positive link between economic growth and poverty reduction during the past decade in Cape Verde may be explained by the increase in inequality in income distribution. On the other hand, unequal distribution of income may, in the long run, offset the positive impact of redistribution policies on poverty.

64. In fact, recent economic research suggests various hypotheses to explain a possible negative impact of a high degree of income inequality on economic growth. The first hypothesis is related to imperfections in the credit market. A large proportion of poor people in the rural areas has no access to credit and, therefore, is unable to finance small investment projects to raise their income. A second hypothesis raises the possibility of social and political unrest, thus jeopardizing the investment and economic growth already attained. It should be pointed out that because of the option to elect tourism as one of the engines of economic growth, Cape Verde has made itself particularly vulnerable to the negative effects on public security, which may result from high unemployment and unequal income distribution.

\section{Unemployment slowly falling but more unequal}

65 . Unemployment fell considerably in the $1990 \mathrm{~s}$, with the global rate having decreased from $25 \%$ in 1990 to $17 \%$ in 2000 . This is a significant improvement that is due to the economic growth and the increase in aggregate demand occurred during this period. Another explanation is found on the labor supply side, characterized by an increase in employability as a result of the reduction in illiteracy, which occurred in the same period. The reduction in unemployment was felt particularly among the male population, whose unemployment rate was cut by more than half in ten years.

66. The female population's risk of unemployment remained high. One in four active females was unemployed in 2000 , that is, the same percentage as in 1990 . This means that the economic acceleration occurred in the 90s merely absorbed females entering the workforce but without changing the female rate of unemployment.

67. Another key feature is unemployment among young people, which is clearly higher than among adults. This higher unemployment is a common rule reflecting the way young people approach the job market and repeatedly search for a job. This phase accounts for the highest rates of people entering the rank of the unemployed. It also reflects the higher probability of young people becoming unemployed, as compared to adults, but also for shorter periods of time. In any case, there was a significant reduction in unemployment in the 15- to 24-age group, which indicates a decrease in difficulty to move from the school to the workplace. 
68. Disparities among the islands are also found here, which clearly shows little integration of the labor market in Cape Verde. The best results are found in the islands of Boa Vista and Sal, the ones with the lowest rates of unemployment overall as well as for women and young people. This may be explained by the higher employability of the local labor force, as indicated by lower illiteracy rates, as well as by the demand for work in services and activities traditionally reserved for females. The worst results are found in the islands of S. Vicente, Fogo and Brava. The case of S. Vicente is worth highlighting as it has higher unemployment rates in all categories, despite one of the highest literacy rates.

\subsection{Sectoral policies: problems, policy measures and outcomes}

69. This section presents a brief description of the ongoing sectoral policies, focusing whenever possible on recent developments in these policies in light of the main problems they seek to overcome. The sectors are grouped according to the pillars of the GPRSP presented in Chapter 4 in order to facilitate comparison between current policy guidelines and their future continuation, in the context of the poverty reduction strategy.

\section{Governance and Public Administration}

70. Cape Verde's performance in terms of governance and existence of a legal framework that promotes and protects private initiative is improving as a result of the policies that have been implemented. In fact, Cape Verde's governance has been improving, and as a result the country is well placed relatively to other countries with the same level of development. The principles of good governance are evident in Cape Verde with regards to rule of law, the political stability and the deep-rooted understanding among the political class of the obligation to be accountable to voters and to citizens in general.

71. In the strategic plan drafted and approved by the Ministry of Justice, the first program, "Promotion of Human Rights, Citizenship and Justice" is dedicated to a global reform of the area of justice whose main objective is to "Guarantee the protection and effective exercise of citizenship rights and reinforce the basis of the Democratic State".

72. Since 1998, Cape Verde has been gradually undertaking a public finances reform in order to facilitate the mobilization of resources to reach envisaged goals and improve the Effectiveness of Government. The following are the most important results achieved thus far:

- preparation of public finance regulations and management instruments undertaken by the RAFE - Reforma da Administração Financeira do Estado (Public Finance Administration Reform task force), which resulted in the Public Accounting Law becoming effective in January 2004;

- separation of the payment authorization and payment function, by moving the Directorate of Public Accounting from Treasury to the General Directorate of Budget;

- preparation of a new accounting system and new budget codes.

73. With regards to public administration, a number of measures are being implemented to improve its Effectiveness and efficiency, its adaptation to a market 
environment, the development of information systems ${ }^{21}$, an organizational culture and careers in public service. Main achievements include the adoption of a Disciplinary Statute (Leg. Decree 8/97); a Career Plan (Decree 86/92) establishing the principles, rules and organizational criteria applicable to public servants with respect to careers, professional development, department structures, and career structure; Law 102/IV/93, modifying the legal framework for constitution, modification and extinction of employment with the public service; new regulation for vacation, absences and leaves; Manager statute; Single Window, published in 1999 but yet to be regulated, namely in regards to electronic documents; the study for setting up the Single Counter for Attending the Citizen.

74. Between 1994 and 2000 the World Bank-supported Public Sector Reform and Capacity Building Project was implemented. From 1994 onwards, the Government made the commitment that public administration and the justice system should be reformed to reduce the public sector's role in the economy and create an environment conducive to private sector development. The objectives of this reform became the cornerstones of the $3^{\text {rd }}$ National Development Plan and had as objectives to: (i) facilitate external investment and liberalization of the economy; (ii) make the private sector the engine of growth; reduce poverty and protect the environment.

75. New dynamics have now been brought into the process of reforming the State and public administration. While still following along the lines of earlier reforms, now the focus is on the citizen, his defense and protection, aiming at poverty reduction with basis on the principles of good governance. More than improving the State's administrative apparatus, the Government made a commitment that reform of the State should be guided by the principle of better service to the citizens. The goal of the new reform is to strengthen citizenship by promoting more efficiency of the State's administrative machine.

76. In the area of macroeconomic policy, Cape Verde currently has an agreement with the International Monetary Fund (IMF) for the period 2002-2004 under the Poverty Reduction and Growth Facility (PRGF) ${ }^{22}$. The objectives of macroeconomic policy for said period were thus established under the agreement, and Cape Verde's performance in these areas has been monitored by periodic IMF missions. The program bears a certain conditionality, meaning that in addition to maintaining macroeconomic stability, the government is committed to a number of structural measures related to fiscal stabilization, strengthening of monetary policy, improvement of the efficiency of the fiscal administration and reduction of budget subsidies to state-owned enterprises.

77. With regards to fiscal reform, the introduction of a Value Added Tax (VAT) in January 2004 reduced said tax's regressive effect. In fact, imposing the VAT on households with basis on their level of income, the average tax incidence remained unchanged, even though the incidence on lower income households was reduced whereas that of higher income households was increased.

78. The regressive effect on income usually associated with this type of tax was reduced. This net effect was the combination of a higher tax incidence of consumption tax with a lower incidence of custom taxes. However, the reduced regressive effect occurred with regards to the consumption tax as well as with regards to the custom taxes. As a result of the reform of indirect taxation the average tax incidence was estimated to be $8.1 \%$.

\footnotetext{
${ }^{21}$ A noteworthy example is the establishment of an information and communication network within the public administration system. The initiative was started by RAFE and is being continued by NOSI.

${ }^{22}$ In connection with this agreement, in April 2002 the IMF approved an SDR 8.64 million credit in the context of the PRGF.
} 


\section{Box 2-3: A few indicators of tax incidence in Cape Verde ${ }^{23}$}

Tax incidence analysis is particularly important in a country like Cape Verde, where due to significant economic and social inequalities, usually as a result of fiscal systems in which the predominant nature of internal indirect taxation and taxes on imported goods and inputs may lead to a regressive impact of taxation. In this context, improvements to the design and implementation of the fiscal system may be used as policy tools to help correct said inequalities, even if, by themselves, they may not be a decisive factor in correcting these inequalities.

The most important taxes are the import duties and the custom taxes, which accounted for $2 / 3$ of fiscal revenue in 2003 , followed by income and profit taxes with $35 \%$ of the total and taxes on imported goods with $12 \%$. This unbalanced fiscal structure is typical of countries with lower relative development.

Overall fiscal incidence in Cape Verde is around $19 \%$ of GDP, excluding social contributions. This is significant if compared to countries of the same level of development. However, in the last few years, fiscal revenues as percentage of GDP have stagnated or even diminished. This is somewhat a paradox considering the rates of economic growth and increase in per capita income experienced, as well as the need for the country to sustainably increase internal resources to finance implementation of the growth and poverty reduction strategy.

79. To a certain extent, the introduction of the VAT in January 2004 and the resulting adjustment of custom taxes and the extinction of other consumption taxes were intended to overcome some disruptions resulting from a distorted fiscal structure. As a result, it is expected that during the current budget year the contribution of the various tax sources will be more balanced. Therefore, according to budget forecasts, the VAT should prevail over all other taxes, bringing in a little over $1 / 4$ of fiscal revenues, followed by personal income taxes and import duties, both with $20 \%$ of the total. Revenues from corporate taxes are expected to remain around $16 \%$ of the total.

80. The average income tax incidence is around $6 \%$ and is expected to increase, albeit irregularly, as the income level increases. Judging income distribution according to the source of income, pensions seem to weigh more on people with higher income and are subject to a lower average tax incidence, irrespective of the tax bracket. Overall, the personal income system is progressive, despite some regressive occurrences such as the case of specific deductions applicable to the personal income tax as a result of significant disparities between specific deductions applicable to labor income and those applicable to pension recipients.

81. The previous considerations clearly show an evolving process of State and public administration reform. In general, the reform process has been implemented in a systematic fashion, the objective being to downsize the administrative apparatus, reduce bureaucratic circuits and contain and refocus public expenditure towards established priorities.

\section{Productive standards and employment}

82. Employment analysis should be performed in the context of the standard of production of goods and services. The structure of Cape Verde's economy changed significantly over the past fifteen years, leading to a clear dominance of the service sector and stagnation of the primary sector ${ }^{24}$. Significant changes occurred even within the secondary and tertiary sectors. However, the changes in distribution of the labor force among sectors (and within sectors) were not as significant as the changes in the structure of the GDP, for several reasons. One is the fact that human capital (education, training and professional experience) did not develop to match the structural changes. Another reason

\footnotetext{
${ }^{23}$ MFP (2004), Tax Incidence in Cape Verde-Analysis Based on the 2001-2002 IRDF.

${ }^{24}$ MFP/PNUD (2004 a)
} 
is the fact that the geographic distribution of labor does not match the geographic distribution of economic growth.

83. FAIMO activities have played an important role in the fight against poverty and have been one of venue to guarantee a certain level of employment, particularly in times of crisis. This approach was adopted in the early years of independence in response to chronic cases of food insecurity plaguing the rural world. An important number of people have been employed by the FAIMO, depending on the quality of the crop season. In mid 1990 s, no less than 10 to $15 \%$ were covered by this system.

84. FAIMO programs offer low pay temporary employment in infrastructure projects, such as road construction, soil and water conservation structures, and reforestation programs. Salary is calculated so as to cover food needs. The work normally lasts between 3 to 8 months, depending on the situation in agriculture. Until the late $90 \mathrm{~s}$, financing for the FAIMO came from local counterpart funds of food aid sold on the local market at world market prices to avoid a negative impact on local agricultural production. The sharp drop in food aid led to the FAIMO being financed by internal budget resources.

85. FAIMO workers consist mainly of the "very poor", as defined under the Household Income and Expenditure Survey ${ }^{25}$. For the most part, they are landless rural workers or farmers who work the land indirectly under a partnership or lease agreement. Women make up over one third of the total, but as many as two thirds in the central and northern regions of the island of Santiago. Half of these women are single mothers with children under care. Further, most FAIMO workers not only have a low level of schooling but also lack any type of professional training. Finally, they are mostly young, with $90 \%$ between the ages of 15 and 44.

86. The correlation between FAIMO workers and the poorer and the unemployed make these activities an inevitable venue in the fight against poverty in Cape Verde. However, the FAIMO have been criticized in many ways. The first complaint regards the lack of efficiency control in certain works or the uncertain Effectiveness of most of these works. The second criticism is that municipal authorities use the FAIMO to avoid deterioration in the labor market, which means that the ones most in need are not always included. The third complaint is that the FAIMO do not motivate (or motivate very little) its workers to look for a job in the regular labor market.

87. To overcome these problems, the Government launched a reform program of the FAIMO in the late 1990s. The first goal of this reform was to strengthen the role of civil society, specially farmer associations and non-governmental organizations, in the process of identification, selection and execution of projects. The idea is that more involvement of agents at the grassroots level is expected to improve the quality of the infrastructure projects, as well as their impact on the target populations. The second goal was the integration of FAIMO workers in the regular labor market or in some form of independent work. A third goal envisaged under the reform targeted the institutional framework responsible for the design, management and monitoring of activities of the FAIMO. This framework includes the National Committee for Poverty Alleviation, the Ministries of Finance and Agriculture, the municipalities, farmer associations and non-governmental organizations. The last component of the reform provided for more active involvement of the private sector in project design and, more importantly, project implementation.

88. It is still too early for a final evaluation as to the impact of the reform. However, some questions can be raised regarding the outcome of the reform considering the persistence and nature of poverty. Reservations about the FAIMO can be grouped into four categories. The first regards the lack of professional training, which means that FAIMO activities have

\footnotetext{
${ }^{25}$ Refer to Chapter 3 for a poverty profile.
} 
little or no effect on the future employability of those who go thru their ranks. The second category refer to the discouraging effects of the scheme: the poorer, who normally are strongly risk averse, tend to accommodate to a minimum subsistence income and stop searching actively for an alternative in the labor market or embark on a self-employment venture. The third criticism is related to the fact that, because of the high degree of decentralization of these activities, there is significant risk of them being captured by local elites, and this discourages people from joining the FAIMO. This risk may be higher than the information gains from a decentralized, participative approach. Finally, the Effectiveness of selected development projects may be questioned. Adding to all these criticisms is the fact that the FAIMO focus on social therapy of extreme poverty - meaning it seeks to guarantee a minimum income -- and only exceptionally it becomes a launching pad for the labor market.

89. There also seem to exist some difficulty in coordinating employment policy with professional training policy. On the institutional level the IEFP is under the Ministry of Labor. However, on the operational level professional training is under the Ministry of Education. In practice this means that the Ministry of Labor is in charge of employment policy whereas the Ministry of Education has the responsibility for drafting and implementing a professional training policy. Having professional training policy under the Ministry of Education has the advantage of facilitating coordination between education policy and employment policy but raises the possibility of conflicts between these two policies.

90. Agriculture is facing a number of constraints that the policies developed in the last few years have not been able to overcome ${ }^{26}$. In fact, agriculture covers a small portion of the country's land area, with unequal distribution from one island to another. Cultivated areas range from $20 \%$ in Santiago to $15 \%$ in Fogo and $8 \%$ in Santo Antão 27 . A crucial feature of agriculture in Cape Verde is the ecosystem's extreme fragility -- characterized by steep slopes, irregular and torrential rainfall, permanent winds, and water scarcity - and the downward trend in resource availability resulting therefrom. This situation is also the result of crop options made by Cape Verdean farmers, such as growing corn in slopes and other practices that accelerate soil erosion.

91. Agriculture in Cape Verde is family-based and characterized by micro-farms averaging 1 to 1.5 hectares in area. Some of these farms are further split into smaller areas, a reflection of Cape Verde's inheritance system. The reduced area available to each farmer is not enough to guarantee the subsistence of rural families. Dry land crops cover $93 \%$ of cultivated areas, thus leaving only $7 \%$ for the higher-yield irrigated crops. The exception is Santo Antão, where irrigated crops represent $17 \%$ of the total.

92. Another key feature is the land tenure system, which include indirect management, leasing, partnerships, and a significant number of landless farmers. This system -- along with the limited market access faced by agricultural products, limited access to credit and the fact that 70 to $85 \%$ of the farms do not produce enough to meet consumption needs -explain to a great extent the problem of rural poverty.

93. The more relevant constraints include the lack of investment in livestock and related activities, lack of appropriate infrastructure for water collection and storage, inadequate production techniques, poor crop selection, and the lack of a credit system suitable for the sectors of agriculture and fisheries despite various experiences in this area. Implementation of a sustainable credit system is still hindered by various constraints, the most relevant being the lack of access to the credit system by farmers and fishermen due to excessive

\footnotetext{
${ }^{26}$ The strategic document for this sector is currently being prepared.

${ }^{27}$ Langworthy et Finan (1997).
} 
bureaucracy, the difficulty in providing collateral, and reimbursement difficulties, particularly in the case of medium and long term credit.

94. Food insecurity is a chronic and recurring problem in Cape Verde that affects specially the poor population. In fact, Cape Verde is faced with a structural food deficit resulting from insufficient arable land and insufficient rainfall ${ }^{28}$. As a result, cereal production covers no more than 10 to $15 \%$ of demand. The situation is considerably better with regards to fishing products. Therefore, and considering the difficulty in paying for imported food due to foreign exchange shortage, Cape Verde must rely on food aid to overcome this situation, while at the same time providing the poorer families with a minimum income by financing small activities with the proceeds of sale of the food aid in the local market.

95. Therefore, and considering that the country already has a National Strategy for Food Security, the next step is to define the mechanisms for achieving the envisaged objectives in terms of guaranteeing social protection and access to food security by the poor.

96. Tourism is becoming one of the engines of growth for Cape Verde's economy, reflecting the country's comparative advantages in this area. Cape Verde's tourist boom began in the year 2000, with the number of beds increasing $28 \%$ between 2000 and 2003 and the number of overnight stays increasing $22 \%$. There has been some effort in the area of professional training but it still falls short of the sector's needs.

97. The quality of tourist services -- dominated by sun and sea - if not improved could jeopardize the sector's long-term sustainability. In particular, there is urgent need for sanitation systems and recycling of sewage water, as well as for improving systems for collecting solid waste.

98. The ongoing preparation of a strategic plan for the sector, as well as integrated development plans for the islands of Sal, Boa Vista and Maio, should result in a socially, economically and environmentally sustainable strategy for the sector.

\section{Education and Health}

99. Cape Verde has had remarkable progress in the area of human capital, particularly as compared to countries of the same level of development. This progress is clearly seen in the sectors of Education and Health.

100. Education sector policies are clear proof of the priority afforded to Cape Verde's education system. An analysis of the recent past, from 2001 onwards $^{29}$, shows that education policy has focused on the following priority pillars:

- Promotion of quality and equity, aiming to improve education quality and learning outcomes, as well as reduction of local and social asymmetries in access to quality education.

- Adequacy, increase and diversification of supply, through optimization of existing resources and implementation of efficient coordination mechanisms between general secondary education and the more specialized areas on one hand, and the labor market and other social partners on the other.

\footnotetext{
${ }^{28}$ In the last 265 years there have been 97 years of drought, which comes to an average of 1 drought every 3 years. 14 of the recorded droughts lasted 3 years or more. (Sustainable National Food Security Strategy, 2002-2015).

${ }^{29}$ Despite the fact that the 1998-2003 period covered different legislatures, there was continuity in education policy, which guaranteed the system's stability.
} 
- Sustainability of the education system, through more cost control, more control of financial resources, and family participation in the costs.

- Strengthening cultural, civic and economic values, by promoting the school as a place for socialization, construction, recovery and transmission of role models, principles, and values that allow for the creation/strengthening the (subjective, cultural and social) basis for personal and socio-economic development.

101. These guidelines have led to remarkable outcomes, including the following: i) the education system has developed rapidly, with basic education covering all of the country and secondary education available in all urban areas; ii) the percentage of children attending pre-school has increased from $49 \%$ in 1997 to $56 \%$ in 2003; iii) universal six years of compulsory education, with the net coverage rate being $96 \%$ for the 2002/2003 school year; iv) equality in access to school by boys and girls in both basic and secondary education; v) generalization of use of manuals in basic education, increasing such use to above $90 \%$; vi) strengthening literacy and adult education programs, as shown by the decrease in illiteracy rate to $25 \%$; vii) significant increase in secondary school enrolment, from 31,602 in $1997 / 98$ to 49,522 in 2002/03; viii) increased opportunities for teacher training and capacity building, through initial, on the job and continuous training; ix) diversification and expansion of training opportunities locally and abroad.

102. However, significant problems persist and need to be addressed. The education system is characterized by stable participation at the basic level and increasing demand for secondary and higher education. Demand structure has been changing rapidly, thus showing weakness in supply in terms of quantity as well as quality. The institutional system's inability to handle the increasing pressure from education demand is equally visible. On the other hand, the system's rapid growth is continuously stressing the national budget.

103. Professional training has experienced some progress. However, various constraints persist, namely the non-existence of a financing mechanism. Efforts are under way to regulate the system of professional training, namely with regards to financing (public, private, and trainees), and addressing regional asymmetries by setting up new infrastructures and taking advantage of local synergies. These efforts are hampered by financial constraints.

104. Some seven thousand students precociously leave through the various exit cycles of the formal system every year. These are students with a relatively high level of schooling, representing precious resources for the country, which need to be used in the best way possible, in a perspective of developing the country and fighting poverty. Therefore, it is urgent that professional training be organized so as to facilitate their entry in the job market. Training programs should aim at bridging qualification gaps that have been identified in sectors such as construction, tourism, agriculture, commerce and others.

105. The Health sector has generally experienced a trend towards improvement of some indicators such as one- and five-year infant mortality, as well as mother mortality. However, some indicators show a negative trend, despite significant progress in terms of quality and relevancy of ongoing interventions, namely those in the areas of Family Planning, Fight Against Polio and Measles, and the Nationwide Vaccination Program.

106. Sexually transmitted diseases are one of the main causes of death. The number of AIDS cases has been increasing, and it is probably under-estimated due to lack of resources for efficient control. Recorded occurrence is in the order of 43.5 per one hundred thousand inhabitants, which is below other countries in the region.

107. Various health facilities have been built or remodelled, namely a reference hospital for the Sotavento region. There have been technical studies and negotiations for a 
policlinic in the island of Sal, as well as for construction and furnishing new Health Service Delivery Points in the municipalities of Maio, Mosteiros, Tarrafal and Boa Vista.

108. The policy to evacuate sick people was continued, as a way to overcome the deficit felt in the country or in some municipalities in terms of diagnostic and treatment.

109. The National Pharmaceutical Policy was reviewed, in order to allow for coordination and orientation of interventions in this sector, following the overall goal of making essential medication available, efficient and safe. Another initiative has been to guarantee the supply of medication in all public health facilities.

110. Training of general medicine doctors and nurses has continued in the country and abroad, as part of human development efforts. Capacity building and refresher courses in public health were offered. Programs to fight AIDS, Tuberculosis and malaria proceeded, as well as the strategy of integrated lookout programs on diseases with epidemic potential. A national laboratory was created and set up as a way to reinforce the fight against transmissible diseases.

\section{Basic Infrastructure, Land Use Planning and environment}

111. This section discusses the sectors of Land Use Planning, transports (infrastructure and services), water, sanitation, energy and environment.

112. The latest diagnostics about land use planning revealed major shortcomings. The first is the priority given to the preparation of Municipal Urban Plans as opposed to Land Use Plans, as provided for under the framework law. On the other hand, most of the Municipal Urban Plans have long exceeded their legal life of 12 years and thus need to be urgently.

113. Two essential tools for land use planning are missing: basic cartography and cadastre. The existing cartography - a key tool for land use planning, urban planning, infrastructure development, private sector entities, professionals, and civil society in general - is particularly outdated, particularly with regards to urban expansion zones and establishment of new productive infrastructure. As for the existing cadastre, a crucial tool for identification of national and municipal territories, updating of land tax base, and enforcing property rights - it suffers from a total lack of legal and regulatory instruments.

114. The latest diagnostics in the context of transport infrastructure ${ }^{\mathbf{3 0}}$ reveals that, despite the significant progress as far as network coverage is concerned, management of the road system is still faced with major shortcomings. Maintenance is not systematic, as it is frequently passed over to make way for more urgent uses for the available resources. Therefore, owing to the lack of a credible maintenance program, gains from the investments already made are in risk of being jeopardized.

115. The sector's institutional constraints have been identified. Road maintenance and management are considered to be fundamental issues. To manage these issues, a Road Institute is currently being established, along with an initiative to reform the Road Fund. The Road Institute represents the government as owner and manager of the main road network. As such, it will draft a long term National Road Plan, define service levels and technical specifications for each road, as well as coordinate execution of the National Road Plan. Reform of the Road Fund will include establishment of an independent entity, with strong user representation and financed by user fees.

\footnotetext{
${ }^{30}$ Discussion Papers for the Consultation with Cape Verde's Development Partners, Praia, April 29 and 30, 2003.
} 
116. In response to calls for urgent connection of some isolated locations, a priority program for road construction and rehabilitation for each island was designed.

117. With regards to road transport services, inter-urban transportation has been totally liberalized. Urban transport has also been totally liberalized even though the market in the city of Praia is dominated by a single private operator, as result of liberalization, weak competition, lack of Effectiveness of the remaining operators and, overall, nonexistence of a legal framework for the sector.

118. In general, transport services are not well defined and this leads to unsatisfied demand since operators tend to select the more profitable routes and leave behind those where there is not enough demand to cover operating costs. This naturally hurts people living in the peripheral rural zones

119. As for maritime transportation, the port network has improved thanks to recent investments, namely in the Port of S. Vicente, which now offers conditions for long haul as well as inter-island services. Work is in progress to complete master plans for three "main" ports, namely the ports of Sal (ongoing) and Praia (ongoing) and Santo Antão, as well as for the other five "secondary" ports. There is a need for a national port master plan, to provide strategic guidelines for the sector.

120. The open policy for the maritime transportation policy derives from the liquidation of the state-owned maritime company "Arca Verde". Work is under way to award a concession for public services in the sector. As for inter-island transportation, the supply chain - including freight forwarders, and other logistic services - either perform badly or do not work at all, thus hurting the profitability of maritime transportation activities. Overall, the sector's performance is in need of clarification of the roles of the various agents. For example, there is no clear separation between the functions of regulation, port management and port operation. As a result, there is a conflict between the port administration company (ENAPOR) and the maritime authority (DGMP) with regards to some regulatory functions. Clarification of these roles and the respective institutional framework will make it possible for each agent to concentrate on its role.

121. National air transportation services are provided by TACV - Cabo Verde Airlines, a company with a major structural imbalance between its workforce and demand for its services. International routes are profitable but inter-island routes generally run at a loss.

122. Airport infrastructures have been modernized, such as the cases of the airports of Sal and S. Vicente. Completion of the Praia international airport is well under way. However, in general the remaining airport facilities are saturated. On the other hand, domestic operation, namely in the smaller airfields is still hampered by the classical navigation means available. This scenario will be improved under the Global Navigation Satellite System (GNSS) project.

123. From an institutional standpoint, Cape Verde's legal, technical and commercial framework meets international norms. This framework (which includes the Air Code, the regulations pertaining to the Chicago Convention, among others) defines the principles, rules and procedures for participants in international civil aviation and has led to the signing of some international cooperation agreements.

124. Interventions and investments in the areas of energy, water and sanitation are made in the context of a US \$ 48 million program supported by several donors and international financial institutions. Through this program, the Government intends to 
improve supply of energy, water and sanitation, raise efficiency in the sectors of energy and water, and promote sound management of water resources ${ }^{31}$.

125. Power generation and distribution were privatised but the Government still owns $34 \%$ of the company and the municipalities $15 \%$. Despite having significantly increased the productive capacity, the privatised company has had serious performance problems, coupled with slow progress in expanding the supply of renewable energy as planned.

126. Due to a large primary energy deficit, Cape Verde must import fuel to produce energy, thus using up considerable financial resources. This leads to permanent pressure on the country's financial resources, be it at the macroeconomic level (by way of the trade balance), or at the microeconomic level, that is in terms of impact on the companies' production costs.

127. Rural electrification has been selected as a strategic tool for the development of rural areas. Considerable investment has been made in this area in the last few years, raising national coverage to 62 or $63 \%$. However, coverage in some islands remains relatively low.

128. A rural electrification project using solar and wind energy was developed to satisfy the demand for electricity in scattered rural areas. The project will reach 12,000 households that are isolated and technically excluded from conventional grids.

129. Another problem is the low percentage of connections in low-income areas despite the fact that the conventional grid reaches these areas. A first step to solve this problem was a project to provide promotional connections. The project will finance the acquisition and installation equipment to connect some 4,000 low-income houses in the outskirts of the main urban areas ${ }^{32}$.

130. Drinking Water is a scarce resource in Cape Verde. Production and distribution costs are high as they involve desalination of brackish or seawater. Main sources of water for domestic use are wells, springs, and desalinated seawater. Despite considerable progress in water supply, coverage rates and service levels fall short of what is needed, as a significant percentage of the population still has no access to regular water supply. According to the last IRDF, only $1 / 3$ of the population has access to piped water. Things are even worse for the poor, of which only $10 \%$ has access. The poor suffer the most, as they depend on the public fountains $(51 \%)^{33}$, which means long waiting lines, higher prices than piped water and having to walk long distances to fetch water. The situation is much worse in rural areas due to dispersion of communities and difficult access.

131. The sector is faced with many problems, one of which is the insufficient coordination in water resources management. From a financial standpoint, water distribution generally operates at a loss, due to a variety of factors: inadequate tariff policy, subsidies for irrigation water, lack of a business mentality on the part of public supply services, the high overhead in central services, and inefficient management.

132. Basic sanitation is characterized by collection and treatment of residual water in the cities of Praia and Mindelo, even though the former's ejection system has been partially damaged since 1999. Serious difficulties in drainage systems, coupled with the low coverage rates and inadequate hygiene practices used by the population, constitute

\footnotetext{
${ }^{31}$ The donors are the World Bank (US\$17.5 million), European Union (US\$7.5 million), Global Environment Facility (US\$7,1 million), OPEC Fund (US\$4.5 million), Austria (US\$ 0.76 million). The Government brings in US\$ 3.5 million, while the local private sector contributes US \$ 7.6 million.

${ }^{32}$ A estratégia inicial de estruturação do projecto revelou-se ineficaz, pelo que foi proposta ao Banco Mundial a reformulação da metodologia de implementação.

${ }^{33}$ Ver Anexo Estatístico
} 
potential public health and environmental hazards as a result of proliferation of pollution sources and a resulting significant impact in the quality of life and poverty perpetuation.

133. The Government is counting on support from the EU to undertake the large investments required by water and environment infrastructures. Agreement was made to concentrate resources in the sectors of water and sanitation, particularly in supply and distribution of drinking water, collection and treatment of residual water and solid waste.

134. The environment is also faced with serious problems, as highlighted by a diagnostics undertaken under the $2^{\text {nd }}$ National Environmental Action Plan. Among the many problems found are soil degradation in rural areas, soil pollution in urban areas, coastline pollution, water and air pollution, and landscape degradation, loss of biodiversity, waste accumulation and dispersion.

135. The diagnostics refer inadequate agricultural practices and overgrazing as being responsible for the environmental degradation in rural areas. Low infiltration and water retention lead to lowering of the water table. On the other hand, the low outputs in agriculture and animal husbandry encourage over-exploration of natural resources as a means to secure alternative incomes. One such example is extraction of sand and gravel along coastal areas, leading to seawater infiltration. Over-exploration causes loss of diversity and decreased water quality for different uses, loss of tourist appeal and, therefore, a reduction in rural sources of income.

136. As a result of lack of an urban development plan, installation of immigrants around urban areas leads to disorganized construction and accumulation of solid waste and residual water, with negative impact on public health. On the other hand, waste accumulation in rural and urban areas lowers tourist attraction, thus reducing incomegenerating opportunities.

137. Finally, inter-island migration causes an increase in construction and, therefore, increased demand for construction materials, particularly sand, thus resulting in strong pressure on natural resources.

\section{Social Protection and fight against poverty}

138. Social protection plays a key role in the context of the poverty reduction strategy. As part of the non-contributive regime of social protection in Cape Verde, various public and private entities are involved in different areas such as families, children, the elderly, handicaps and drug dependents. The goal of these interventions is to contribute to the protection and improvement of living conditions of the poor and the excluded. Various programs and activities have been under way, ranging from school programs to help poor students to full-fledged social programs to provide social facilities and services.

139. Another important development is the existence of a broad solidarity movement. Even though it acts through informal social protection mechanisms, this movement makes up a network of community organizations and associations that have been catering to the needs of the more vulnerable social groups, thus significantly improving their survival and living conditions. However, due to poor coordination among the various actors, it is still not possible to make a global assessment of the real impact of these responses on the lives of those targeted by the different programs around the country.

140. There are also some constraints resulting from scarcity of resources and inefficient coordination in implementing public social policies and in developing sectoral programs. Hence, there is a need for an integrated strategy to conceive a multi-sectoral and concerted intervention, bringing together all actors that intervene in the area of social protection. Therefore, the GPRS seeks to improve the coordination between these actors 
with regards to implementation of social policies. Considering their impact on poverty reduction, priority will be given to policies, strategies and sectoral programs in the areas of health, education, professional training and food security.

141. The National Poverty Alleviation Program (NPAP) has played an instrumental role in the implementation of various projects and activities aimed at the poor population. To such effect, it is worth emphasizing the relationship between the social protection programs that have been developed and the NPAP. The NPAP has the following sub-programs: i) Integration of the poor into the economy; ii) Improve the access of the poor to social services; iii) Social mobilization; and iv) Strengthening institutional capacity.

142. The NPAP defined as its goals to reduce the rate of poverty, to eradicate absolute poverty, to increase the average income of the people living below the poverty line, to improve the productive capacity of the poorest, to improve economic and social infrastructures for the poor communities and to reconvert the FAIMO workers. The target groups of the Program are women, mainly those head of household, FAIMO workers, unemployed and particularly youth unemployed, vulnerable groups such as elderly, handicaps, abandoned children and the invalids.

143. The total cost of the Program was estimated at US\$75 millions ${ }^{34}$. This amount was clearly difficult to be financed only with domestic resources ${ }^{35}$ and thus, the Government resorted to the mobilization of external funding. The Government negotiated with donors and financial institutions (UNDP, IDA, IFAD and ADB) the financial support for the Program. The UNDP financed the elaboration of the Framework Document and consulting cost for the elaboration of the Municipal Poverty Alleviation Programs (PCLPs), whereby 230 poverty pockets were identified in the 17 municipalities. The other institutions financed specific activities under the Program in the total amount of USD 28.1 millions.

144. The NPAP aggregates three Projects: i) The Social Sector Development Project (PDSS); ii) The Rural Poverty Alleviation Program (PLPR); iii) The Project for Social and Economic Promotion of the least favoured groups (PSGD);

145. The Social Sector Development Project focus its intervention on the construction of social infrastructures (community centers, kindergartens, primary schools, health centers, sanitary complexes, etc.) and infrastructures supporting the development of economic activities such as roads, markets, slaughter houses, and others aimed at creating employment and conversion of the FAIMO. The PLPR and PSGD have supported social mobilization activities, adult education, construction of water supply and sanitation infrastructures at the poor rural communities, housing, promotion of income generating activities and self-employment in the sectors of fishing, drip irrigation agriculture, handicrafts, small scale livestock raising and commerce of agriculture products.

146. Since its inception, the National Poverty Alleviation Program has faced many issues and questions about its actual mandate. On one hand, there is the view that the fight against poverty is an exclusive role of the NPAP. On the other hand, due to its decentralized nature in terms of competencies and funding, the NPAP is seen by some municipalities as interfering in some of their functions namely concerning the allocation of funds to Community Associations for the execution of some micro-projects and activities related to poverty alleviation.

147. Finally, it is worth mentioning that the fact that different institutions finance the Program is positive in financial terms. However, given the differences in procedures of each

\footnotetext{
${ }^{34}$ The initial budget was USD 75 million for a 5-year period but as of now only USD 44.5 million has been mobilized $(59 \%)$

${ }^{35}$ MFP / UNDP (2004b).
} 
financing institution, harmonization and overlapping problems have been common during implementation of the Program. 


\section{THE PROFILE OF POVERTY IN CAPE VERDE}

\subsection{The dynamics and characterization of poverty in Cape Verde}

\section{The most relevant data on poverty}

148. According to the Household Income and Expenditure / Household Living Conditions Survey conducted in 2001-2002 by the National Institute of Statistics, $37 \%$ of the population is considered poor, with most of them living in rural areas (62\%). From the total poor population, about $54 \%$ are considered very poor, which corresponds to $20 \%$ of the country's population. About $51 \%$ of the poor are women.

149. Up to then, poverty had been measured in relative terms. To analyze absolute poverty trends, the incidence of poverty in 1989 was re-estimated. The conclusion was a strong fall in the incidence of absolute poverty, from $49 \%$ in $1988-1989$ to $37 \%$ in 2001 2002 , that is a $12 \%$ drop over a period of 13 years, or $0.92 \%$ per year. Had it not been for the increase in inequality, absolute poverty would have fallen by $14 \%$. In terms of number of individuals, instead of the number of poor people increasing by 8,000 since 1989 , it would have increased by only 1,000 .

150. A simple comparison of the two relative measures leads to the conclusion that poverty incidence increased from $30 \%$ in 1989 to $37 \%$ in 2002, whereas the proportion of very poor increased from $14 \%$ to $29 \%$ during the same period, essentially as a result of the increase in inequality. Poverty is mainly a rural issue, as $68 \%$ of the very poor live in rural areas. In relative terms, poverty incidence in the urban areas is higher today (12\%) than in $1989(7 \%)$. This same trend is seen in the rural areas, where $30 \%$ of the population is very poor today, as compared to $23 \%$ in 1989 . The rural exodus of the 90 s is partly responsible for the transfer of poverty from rural to urban areas.

151. The depth of poverty in Cape Verde is $10 \%$. This means that the poor should have an additional $10 \%$ of poverty line equivalent income to be classified as non-poor. There are no significant inequalities among the poor. Consumption variance among the poor is $5 \%$.

\section{A brief snapshot of poverty in Cape Verde}

152. Poverty is a multidimensional phenomenon. Thus, it is important to look at it from different perspectives. In this case poverty is analyzed vis-à-vis gender, age, education and economic activity dimensions.

153. In terms of gender, the incidence of poverty is minor when the head of the household is a man. However, when the depth of poverty is analyzed no major differences in terms of gender are found. In fact, $52 \%$ of the resident population is women, which represents $51.6 \%$ of the poor population thus, leading to the conclusion that the prevalence of poverty is not gender related. It is however worth noticing that $53 \%$ of households led by women is poor. It is also important to point out that the proportion of very poor families headed by women decreased from $20 \%$ in $1988-89$ to $16 \%$ in 2001 2002. The feminization of emigration in the last fifteen years could partly explain such 
change. ${ }^{36}$ However, notwithstanding the fact that the prevalence of poverty is similar for men and women, women constitute one of the most vulnerable groups, with an unemployment rate twice that of men.

154. The poor population is considered to be very young, as $49 \%$ of the poor population is less than 15 years old. This same conclusion is reached among the very poor, where $51 \%$ of them is less than 15 . The distribution of the very poor by age shows that the proportion of youths is greater in this group than in the total poor population. An explanation for this fact is that the very poor families are in a demographic transition phase and normally have more children than the average, thus lowering the per capita income of the family members.

155. Indeed, poverty increases with the size of the household. About half of the households with more than 6 children are poor and need an additional $17 \%$ of poverty line equivalent income to leave poverty.

156. Education has an influence in the determination of poverty. The head of the household's level of education not only influences the probability of the household being poor but also explains the inequality among households. In general, households led by an uneducated person have the greatest incidence and depth of poverty. The poor without education need an additional $15 \%$ of poverty line equivalent income to leave poverty. Although the country has registered positive developments in education during the last decade, the actual rate of illiterate people constitutes a great constraint for the poor to emerge from poverty. Presently, about $1 / 4$ of the population aged 15 and over is illiterate. Of these, $3 / 4$ are women.

157. Poverty is also distributed differently by region and by island. The island of Santo Antão, besides having the greatest incidence of poverty it also presents the deepest rate of poverty (on average the poor need about an additional $16 \%$ of the poverty line equivalent income to leave poverty), and has the greatest number of poor households with extremely low levels of expenses. The islands of Fogo and Santiago follow the island of Santo Antão.

158. The geographical distribution by island partly explains the regional distribution of the number of poor. Thus, the island of Santiago houses $55 \%$ of the total poor population followed by the island of Santo Antão with 16\%, São Vicente and Fogo with $10 \%$ each. In absolute terms, these four islands concentrate $92 \%$ of total poverty in the country.

159. Poverty is more profound in the rural areas than in the urban areas. In fact, about half of the rural population is poor, which contrasts with about a $1 / 4$ of the urban population. The amount that the head of a rural household needs to leave poverty is three times that of the urban households.

160. About $1 / 3$ of the labor force is poor. $48 \%$ of the female population is inactive, as compared to $30 \%$ for the male population. As expected, unemployment greatly affects those that are poor. Indeed, $20 \%$ of the total poor population has been unemployed for more than 12 months while only $10 \%$ of the non-poor population has been unemployed for the same period of time. Thus, the unemployment rate of the poor population ${ }^{37}(33 \%)$ is double that of non-poor, which is about $16 \%$. For the total population the rate is about $22 \%$.

\footnotetext{
${ }^{36}$ The feminization of emigration (the increasing proportion of women in the emigrant's population) is the result of an increase in demand for feminine labor for the service of families in countries such as Portugal, Italy and Spain (Carling, 2001) and also the result of emigration restriction policies, which particularly affects male emigrants.

${ }^{37}$ As defined by: the relationship between the unemployed on the poor population and the labor force of the poor population.
} 
161. The unemployment rate among the poor population is $29 \%$ for male and $46 \%$ for female. This is considered long-term unemployment (more than 12 months). The female population is more affected by long-term unemployment than male ( $58 \%$ of the total).

162. Economic activity strongly determines the propensity for someone to be poor. In fact, it is among workers of the agriculture and fishing sectors that the greater propensity of people to be poor $^{38}$ is found. These sectors are the ones that normally contribute to the unemployed population. About a $1 / 3$ of the poor works in these sectors, followed by the commerce and construction sectors. Of those that are self-employed about $24 \%$ works in the commerce sector where incomes are irregular and precarious.

163. When the professional status is analyzed, the propensity for being poor is greater for those working in a family business without a salary. In contrast, the lowest propensity for being poor occurs among the executives, the technicians and specialists. The greatest the qualification in the occupation, the greater is the income level earned and the least propensity to be poor.

164. The workers in family businesses without a salary are mainly in the agriculture and fishing sectors, which explain the high propensity for being poor. Equally relevant is the fact that while the employers have the least propensity for being poor, $84 \%$ of the poor employers are in the agriculture and fishing sectors. Therefore, working in these sectors strongly determines the probability of being poor.

\section{Income and consumption patterns of the very poor}

165. The level of income varies significantly according to the status of poverty. On average, income represents about $64 \%$ of total revenues. In the case of the very poor families this percentage is slightly higher. It is also worth highlighting that the social contribution has a significant weight in the revenue structure of the families with greater incomes $(5,6 \%)$ than in the very poor families $(3,5 \%)$.

166. When analyzing the consumption pattern of the 95,000 Cape Verdean families we find that the majority of expenses are made towards satisfying essential survival needs such as food and housing, which corresponds to the typical consumption pattern of a developing country. On the other hand, expenses with education, health and entertainment represent only about $6 \%$ of total expenditure. This shows the State's intervention in these sectors assuming the overall cost of services provided. In fact, $36 \%$ of total expenses are made towards food and non-alcoholic beverages and $25 \%$ in housing, water, electricity, cooking gas and other fuel totaling $61 \%$ of total expenditure. For example, in the 1988-89 Household Expenditure Survey food expenses represented about half $(53 \%)$ of the family's total expenditure.

\section{Comfort indicators of the poor}

167. The analysis of the level of comfort allows the drawing of significant conclusions of the access of the poor to public services. Thus, for the type of house that people live in, we find that $86 \%$ of the total population lives in individual housing. For poor families this percentage is even higher, about $91 \%$. In the city of Praia, $85 \%$ of the poor live in individual housing (85\%) and $14 \%$ live in part of a house. Shack-type housing has

\footnotetext{
38 The weight of the employed population by occupation was based on the logical relationship of the following formula: $\left[\left(p^{*}(100-q)\right) /\left(q^{*}(100-p)\right)\right]$, where $p$ is the weight of the poor population and $q$ is the weight of the total population in each occupation.
} 
no significant expression (1\%). On the other hand, the island of S.Vicente is where the poor have the worse housing conditions, with $13 \%$ of the families living in shack-type houses.

168. In most islands, access to electricity is a privilege of the non-poor. The great majority $(85 \%)$ of families use electricity as their main source of lighting while $27 \%$ use petroleum for lighting. Thus, the energy consumption pattern is different for the poor families: about $51 \%$ use petroleum as their main source of energy for lighting and only $32 \%$ use electricity as their source of lighting. On the other hand, $62 \%$ of the poor families use wood for cooking which constitutes a permanent pressure on the limited existing vegetation. In contrast, about $74 \%$ of non-poor families use butane gas for cooking purposes and as source of energy.

169. In reference to the supply of water, $3 / 4$ of the families has access to drinking water. However, only $1 / 3$ of the families are connected to the public water distribution network, while $8 \%$ receives water transported by water-tank trucks and $5 \%$ uses their own reservoir. Thus, about half the families do not need to leave their houses to obtain water for domestic usage. On the poor families only $11 \%$ is connected to the public network of water distribution while for the non-poor families this percentage is $41 \%$. One should underline that for the poor families public fountains are their main source of water supply (51\%).

170. In the area of sanitation the situation of the poor is very precarious due to the fact that $88 \%$ of the poor do not have a bathroom while the nation's average is $55 \%$. This situation exposes the poor to various kinds of diseases. On the other hand, the lack of public sanitation is a common problem, as $3 / 4$ of the families are not connected to the public sanitation system network. The sanitation system network is only present at some areas of the city of Praia and some locations of São Vicente. The lack of sanitation should not be analyzed only as lack of infrastructure but also in the educational and behavioral perspectives. In fact, besides the physical investments in sanitation infrastructures an educational and sensitization policy needs to be developed to promote better and healthier attitude of the population towards sanitation.

171. The access to the State co-financed health system negatively discriminates the very poor. In fact, $73 \%$ of the very poor and $69 \%$ of the poor do not benefit from such access, in contrast to the national average of $67 \%$.

\subsection{Economic growth, productive structure and poverty}

\section{The pattern of economic growth and income distribution}

172. The high economic growth registered in Cape Verde during the last decade profoundly changed its economic structure, thus leading to dominance of the service sector. This situation had an important impact on resource allocation among sectors, on relative prices, on income and productive factors and consequently on the distribution of income (and of wealth) at the national level and among the islands. For example, the high increase of revenues in activities such as tourism and other services induced the increased disparity on the distribution of income. At the other end, the high demographic pressure allied to the degradation of agricultural land had a negative impact on rural per capita income, thus creating an inequality in terms of distribution of income.

173. Cape Verde's economic growth of the last decade resulted in an increase in the inequality of income distribution as shown by the Gini coefficient, which in 1988-89 was 
0.43 and in 2001-2002 it increased to 0.57 . The excessive concentration of wealth is illustrated by the fact that $10 \%$ of the very poor population has only $1 \%$ of total income. The first seven deciles ( $70 \%$ of the families) represent only $28 \%$ of per capita expenditure, while the last deciles (the wealthiest $10 \%$ ) account for $47 \%$ of total expenditures.

174. The island of São Vicente has the highest concentration of wealth, with a 0.60 Gini coefficient, whereas the national average is 0.57 . Next on the list are the islands of Santo Antão, São Nicolau, and Santiago, with 0.56 .

175. Although the worsening pattern of income distribution occurred in various countries during the last decade ${ }^{39}$, for Cape Verde, inequality increased even more when compared to countries with the same income level. For example, Cape Verde is placed at the most unequal deciles among countries with medium level human development according to the UNDP ${ }^{40}$ classification.

\section{Tax incidence on the poor}

176. It is expected that the newly introduced value added tax (VAT) will have differentiated impact on families according to their poverty status. In fact, although the neutrality principle is overall observed, (indirect tax incidence should have decreased from $8,18 \%$ to $8,14 \%$ in $2004^{41}$ ) an analysis of income levels show an increasing trend relatively to the increase in income and even negative figures for the first three levels. Thus, while in 2002 the tax incidence varied from $4,7 \%$ in the first level to $11,8 \%$ in the last level, the differential between these levels increased by 3,5 percent, to 14,3 in 2004.

177. The tax incidence from international trade decreased as a result of lower import duties in the first four brackets and an increase in the last bracket. The abolishment of general customs fees contributed to a lower tax incidence for the poor due to the weight that such fees had on basic consumption goods that now are exempt from any custom duties.

178. An analysis of tax incidence on goods and services using families' expenses as an indicator of well being, shows a slight decrease after the introduction of the fiscal reform, from $11,98 \%$ in 2002 to 11,89 in 2004 . Such neutral result is a combined effect of the decrease in custom duties (and the respective improvement of its distributive pattern) and the increased tax burden from consumption taxes (VAT and others).

179. When the different levels of expenditures are analyzed, we again conclude that the tax incidence differential is increasing and it is negative in the first three expenditure brackets. In 2002, tax incidence on expenses was 10,5\% for the first bracket and continually increased, reaching $13,8 \%$ for the last bracket. In 2004, fiscal incidence went from $7,8 \%$ for the first bracket to $16,7 \%$ for the last bracket. Such differential can be considered a positive development in terms of the relationship between the value added tax on consumption goods and services and the total family expenditure as this tends to have an upward increase in absolute terms with the increase of the level of well being.

180. In terms of inequality before and after tax, the indicators used (Gini, Atkinson) show that in terms of family income, taxes on expenditure contributed to increasing inequality. When using total expenditure as a well-being indicator, we find that such effect

\footnotetext{
${ }^{39}$ See for example Cornia (2001) et Cornia et Addison (2003).

${ }^{40}$ UNDP (2003), pp. 282-285. The UNDP shows 55 Gini coefficient from the 86 countries belonging to the countries with medium human development level. Only 6 of these countries have a higher or equal Gini coefficient as Cape Verde. The average Gini coefficient for the 55 countries is 0.43 , which shows the high inequality prevailing in Cape Verde where such index went from 0.43 in 1989 to 0.59 in 2001-2002

${ }^{41}$ Measured as a function of monetary family income.
} 
was minimized with the introduction of tax reform in 2004. Thus, considering the revenue side, we find that both in 2002 and in 2004 after tax inequality for expenditures increased. However, the 2002 increase was higher and, thus, the regressiveness should had decreased with the introduction of the value added tax. When considering total expenditure as a well being indicator the results show that in 2002 as well as in 2004 the inequality decreased with the consumption tax (internal consumption and international commerce). This effect is more relevant in 2004, thus showing a slight improvement in the distributive effects after the introduction of the fiscal reform.

181. In reference to the Income Tax (IUR) incidence, fiscal incidence on gross revenue, monetary income and expenditure is 7,9\%, 5,9\% and $8,6 \%$, respectively. In reference to gross revenue, $81 \%$ of taxable income comes from labor and pensions and $19 \%$ comes from capital and property income. This implies that the average ratio of property and capital incomes is higher than the average taxable global incomes, being that the former represents only 7,3\% of gross income.

182. According to the status family's poverty status, as the level of poverty increases fiscal incidence also increases proportionally with the monetary income with the exception, of the last level of poverty. This upward evolution is more significant when capital and property taxation are considered, given the weight that capital and property taxes have on the overall structure of taxes for the non-poor. On the contrary, when family expenditure is taken as a well being indicator, a downward tendency is found in the distributive incidence of the income tax by level of expenditure except in the first level. This decreasing tendency is a result of the overall taxation on income and pensions rather than on the fiscal incidence on property and capital revenue, given that on these categories the incidence is increases moderately upward.

183. When calculating the income tax due many fiscal components are taken into consideration such as exemptions, progressive taxes, deductions of various types that have an important impact on the overall distributive outcome. The analysis of such impact led to the conclusion that the legal arrangement on "exempted revenues" contributed to considerably increase inequalities between tax payers and families, while the progressive taxation and deductions (individually, per number of dependents, and other expenses) contributed to decrease inequalities, thus explaining the overall positive effect of the income tax ${ }^{42}$.

184. In any case, the apparent contradictory effects reached when the incidence is measured on revenues and on expenditures need to be carefully studied in order to determine a more equitable fiscal distributive policy.

\section{The conditions of the rural sector and the causes of poverty}

185. When searching for explanations of the causes of poverty in Cape Verde, it is important to look at the agricultural characteristics of the country. Rural poverty is striking and poses a series of questions about the agricultural world, such as its capacity to generate sufficient revenues for rural workers to escape poverty.

186. The low incomes earned by the rural population are explained by the interaction between the characteristics of agriculture in Cape Verde, the high demographic growth and the uncertainty of the climate. When transfer of revenues from other sectors is low, the impact of such stagnation is even greater on poverty. Although significant productivity improvement has taken place in the production of vegetables, such improvement is yet

\footnotetext{
${ }^{42}$ Such effect was confirmed by the progressive index found as a function of the gross income and of the taxable income. Although the actual average tax taken into account was low when compared to marginal taxes above $40 \%$, it seems to bring into evidence high deduction levels and/or understating overall taxable incomes (tax evasion)
} 
concentrated and the natural rural population growth leads to a per capita decrease of income in the rural areas. The decrease of emigration has the tendency to aggravate the poverty generation process in the rural areas by increasing the pressure on agricultural land. Such process can be cumulative to the soil erosion process that greatly decreases productivity and limits the availability of agricultural land. Thus, the conclusion that rural poverty in Cape Verde is mainly the result of these tendencies, and makes its eradication ${ }^{43}$ very difficult.

\subsection{Survival Strategies}

187. The structural characteristics of the causes of poverty have led to behaviors and survival strategies that in general, have not contributed to the solution of such problem. Thus, emigration has been for a long time, one of the main survival strategies adopted by the population to overcome the lack of domestic resources. Migration that normally sought foreign countries, due to the constraints imposed by the destination countries has forced the population to also move to the urban areas. An evidence of such movement is the increase of the population of the city of Praia in the $90 \mathrm{~s}$. The migratory flow to the capital during the 90 's reached 3,500 persons/year and for the city of Mindelo 1,700 persons/year, while the population of the island of Sal doubled. Such migration brings to the city additional sanitation, housing, health and education problems thus changing the profile of poverty.

188. In terms of revenue the amount of emigrant's remittances to their families makes up an important share of total family income (about $11 \%$ of total income for rural areas $^{44}$ ). These transfers have certainly contributed to the alleviation of poverty for a significant number of families.

189. Livestock raising has also assumed a significant role in the rural economy and traditionally has been a security factor during the drought-related crisis. In urban areas the development of informal commerce has been the main alternative for many families as shown by the rapid increase of the informal economy. In this area, women have played a relevant role, which explains the fact that female poverty showed an improvement throughout the 1990s.

190. The formal social protection system has a reduced coverage and includes a marginal number of poor. A minimum pension is distributed to about six thousand poor people, most of who are elderly. The Social Solidarity Pension covers about 8,000 persons and the majority are ex-FAIMO workers; the evacuation of sick poor annually benefit about 2,000 people; the social school program that covers a high number of students $(111,000)$ and also gives some support to families, mainly women head of households, elderly and handicaps, through subsidies and promotion of income generating activities. All such activities do not include the programs and projects developed by organizations and associations of the civil society that greatly contribute to improving living conditions and social protection.

191. However, the main issue pertaining to survival strategies is how to create mechanisms that can assure the transition from these precarious and poorly remunerated situations to a social and economic integration that can constitute the basis for emerging

43 A good discussion of this agricultural sector issue is found in Langworthy et Finan (1997).

44 Emigrant remittances vary from island to island. According to official data for the 1997-2002 period, per resident remittances are three times the national average for the islands of São Nicolau and Boa Vista and about twice the national average for the islands of Maio, Sal, Brava, São Vicente and Fogo. The islands of Santiago and Santo Antão are below the national average. 
out of poverty. The most notorious example can be that of the FAIMO system that has been the main safety network for the poor in the rural areas. Over time, the FAIMO has become a survival strategy by compensating many families' lack of income while guaranteeing the minimum income to survive. This system has allowed an important number of rural workers (landless farmers and, to a lesser extent, some land owners) to live above the subsistence line and to minimize poverty for others through an increase in their income.

192. However, the FAIMO system, just like emigrant remittances, have a negative impact on social mobility and the probability of escaping poverty given that they can be an incentive to the risk averse farmers to continue their agriculture ${ }^{45}$. The fact that FAIMO workers have the right to a pension also reinforces such effect. In the long run, one can state that the effect of the FAIMO system and the remittances of emigrants can contribute to the persistence of poverty thus, decreasing the supply of non-rural labor. Thus, alternative strategies have been suggested for integrating the FAIMO into the labor market.

193. In fact, to increase the access or return of workers that belonged to the FAIMO system it would be necessary to emphasize the development of qualification and skills that facilitate such integration ${ }^{46}$. On the other hand, the integration of ex-FAIMO workers into the labor market would facilitate insertion mechanisms based on human capital (professional training) and eventually on regional mobility incentives in order to facilitate a better match between job demand and supply. The local employment agencies are better placed to apply such measures given that they know the local labor market and the corresponding training needs. Such reform would also contribute to reach one of the main FAIMO objectives of facilitating the return of workers to the labor market.

\footnotetext{
45 The farmers' level of risk aversion depends on the level of income. The poor the farmer the greater his level of risk aversion will be and the greater is the search for a safety system to guarantee the minimum subsistence, as is the case of FAIMO,

${ }^{46}$ MFP/PNUD (2004 a)
} 


\section{STRATEGIC FRAMEWORK FOR GROWTH AND POVERTY REDUCTION}

\subsection{Development vision for Cape Verde}

\section{Development context}

194. Since independence, in 1975, Cape Verde embraced a national development program, at first with Government control of the economy and single-party ruling, but later through a series of reforms to install a market economy and a multi-party democratic system. Starting in the 1980s, the various governments proceeded with economic and political reforms, with satisfactory outcomes. Today, Cape Verde is a democratic country with a track record of more ten years of multi-party democracy, several elections carried out, peaceful political transitions and effective participation of civil society in the governance process.

195. The economic reforms focused on the development of a strong private sector and led to the establishment of one of the most stable and best performing economies in Sub-Saharan Africa. Cape Verde's per capita income is one of the highest in West Africa. Distinguishing features of the country's economy are macroeconomic stability, low inflation and reduced fiscal deficits. Social indicators have also improved significantly, particularly with regards to life expectancy, as well as primary and secondary school enrolment, which cover all respective age groups.

196. Despite the political and economic gains, Cape Verde, just like any other island nation, is highly vulnerable due essentially to its location and geographic condition. Scarce natural resources and non-renewable energy sources, and the Saharian climate, limit the country's opportunities for economic expansion. Unfavorable ecological conditions have been the major cause behind emigration, as well as leading cause of poverty.

197. Cape Verde's success since independence is due mainly to generous foreign aid and emigrant remittances, coupled with good governance and the results of economic reforms. The question is: is this success sustainable in the long run? This is a critical issue considering the overall environment and the persistency of extreme poverty -- despite the high rates of economic growth - and the fact that foreign aid and emigrant remittances are outside the Government's control.

\section{The strategic context}

198. The combined effects of scientific and technological innovations since the second half of the past century, coupled with political changes all over the world, have led to sweeping changes in the world economy. These changes have resulted in a global world economy, without borders and changing at high speed. In this new evolving economy, knowledge has become perhaps the most determining factor of competitiveness of nations, even more so than availability of traditional factors of production such as land, labor and raw materials. These developments represent opportunities as well as threats, for nations and companies alike.

199. With globalization ever more entrenched and the emergence of an ultracompetitive economy, only nations where knowledge is acquired quickly will be able to survive. In such a context, Cape Verde is faced with an enormous challenge due to its 
dependence on two exogenous key factors: foreign aid an emigrant remittances. These factors have contributed to the country's development in the past but may not continue do so in the future. In any case, in the long run these factors may not be the best way for the transformation of Cape Verde.

200. The adoption of new technologies may also limit the importance of the geographic location Cape Verde enjoyed for centuries. An example is transports, a sector where Cape Verde stands to loose due to technological progress, as the number of planes and ships that refuel in Cape Verde keeps decreasing. As a result of all this, Cape Verde is faced with ever more difficult challenges.

201. Adding to the above factors the fact that Cape Verde has little financial resources, it then becomes clear the reason behind the Government's decision to develop a growth and poverty reduction strategy. The main purpose of the efforts to transform Cape Verde is economic growth, poverty eradication and promotion of a self-sustainable, high growth and broad based economy.

\section{Transformation strategy}

202. In 2001, the Government began a series of consultations with private sector and civil society representatives. These consultations included the preparation of the Grand Options of the Plan (GOP), a workgroup to draft a growth strategy and identify future growth mechanisms for the economy, and a forum for creation of consensus about the needs and the means for transforming Cape Verde. Other initiatives were also implemented, such as the preparation of the National Development Plan and an intermediate poverty reduction strategy.

203. The GOP call for promoting good governance, on entrepreneurship, competitiveness and growth, on developing human capital, on developing basic and economic infrastructure and on a global policy for social development. The study group stressed the need for facilitating access to high levels of knowledge and on formulating a strategy for growth and transformation. The key feature of the transformation strategy emphasizes the construction of competitive advantages out of the natural conditions enjoyed by Cape Verde, namely its location, its marine resources and its airspace.

204. The long-term growth and transformation strategy should stand on the advantages offered by the country's geographic location. The main idea is to take advantage of the sea and the airspace. Such a transformation strategy requires adequate air and maritime infrastructures in order to succeed. To this end, the country's ports and airports need to be upgraded. Further, the strategy calls for development of various sealinked industries, including fish processing and commercialisation, as well as for taking advantage of the competitive advantages related to transport of goods and passengers by air. Other recommended areas are the advantages offered by a free trade zone and air traffic control. In this regards, Cape Verde's recent Category 1 classification by ICAO and by the US Federal Aviation Authority (FAA) is an important step towards transforming Cape Verde into an air transportation "hub".

205. The strategy of transforming Cape Verde also calls for the development of an off-shore services industry to support the abovementioned programs and to supply services in the areas of financing, investment and insurance in lusophone African countries. Further, the strategy highlights the need to address short and medium term challenges such as unemployment by means of creation of added value in the sectors of tourism and light manufacturing (instruments and garments) to take advantage of opportunities offered by the European and American markets. 
206. A key aspect of the transformation strategy is the exploration of the country's competitive advantages in key sectors such as tourism, garments, fish processing, shipping and air transportation. A crucial element of this strategy is the need for Cape Verde to build for itself an image of an attractive country for people who want to visit or live in, work and invest in the country. The Government shall, therefore, develop a communication agenda for marketing the strategy for transforming Cape Verde. This marketing effort should make it possible to persuade the outside world that Cape Verde is a safe place, a charming place to visit, live in, and invest. Another crucial aspect of this effort is the need for building an information strategy with the main objective of making information a tool for national transformation. To this end, the Government recently created NOSI, a preliminary version of an information society.

207. The Grand Options of the Plan (GOP) $2002-2005^{47}$ call for the Government to "raise Cape Verdeans to a level of income and quality of life that values their human dignity by means of economic policies to guarantee sustained development, in a way that is compatible from a social, regional and inter-generational standpoint, environmentally sustainable, and based on a growth standard built on increasing productivity gains; overall, a development which minimizes poverty and social exclusion and that may bring about equity and social justice".

208. Com base naqueles princípios foram estabelecidos os seguintes eixos de enquadramento das políticas públicas.

Box 4-1: Pillars of the Grand Options of the Plan (2002-2005)

\begin{tabular}{|l|l|}
\hline 1 & Promote good governance, reform the State, intensify democracy and strengthen citizenship. \\
\hline 2 & Promote entrepreneurship, competitiveness and growth; expand the productive base. \\
\hline 3 & Develop human capital, refocus the education system towards priority development areas. \\
\hline 4 & Promote a global social development policy by fighting poverty and strengthening social cohesion and solidarity. \\
\hline 5 & Develop basic and economic infrastructure, and promote land use planning for a balanced development. \\
\hline
\end{tabular}

209. What's envisaged is a sustained economic and social development, standing on the pillars of macroeconomic stability, freedom of initiative and social inclusion. Based upon these principles, the strategy followed by the Government will focus on the establishment of a framework that is conducive to economic development and private investment, promotion of good governance, implementation of infrastructure that is essential to production of goods and services, and provision of basic social services, thus leading to strong and sustainable growth.

210. By linking the development process with the fight against poverty, the MPOs set the stage for defining the poverty reduction strategy. In fact, the paramount objective is a poverty-free development, based on structural policies to promote accelerated and sustained growth, but at the same time complemented with distributive policies.

211. Economic development will be based on productivity growth and will have the private sector as its engine. Together with a stable macroeconomic framework, the increasing productivity will be the basic ingredients of sustainability, thus leading to an equitable development.

\footnotetext{
${ }^{47}$ Republic of Cape Verde - Council of Ministers (2001), Main Planning Options 2002-2005.
} 
212. The National Development Plan (NDP) 2002-2005, which followed from the Main Options, has identified the following main challenges for Cape Verde for the medium term: i) maintenance of fundamental macroeconomic balances; ii) strengthening and consolidation of the structural reforms; iii) expansion and strengthening the productive base, namely by developing competitive advantages for the economy; iv) economic growth and employment promotion.

213. The GPRSP, in connection with the NDP, emphasizes poverty reduction as an integral part of the growth process, and clarifies the roles of the State and the private sector. The leading role reserved for the private sector as the engine of growth assumes the Government has managed to create an environment that is conducive to development, as well as rational, efficient and transparent use of public goods, while at the same time promoting private investment. Raising the economy's competitiveness requires an adequate social and economic environment, namely with regards to macroeconomic stability, efficient public administration, external investment incentives, as well as quality, externalitygenerating infrastructure.

214. The Government Program calls for a "new social balance stemming from recovering the principle of solidarity". The Program also demands a reduction in social inequalities, increased social cohesion, poverty reduction, elderly protection, development of inter-generational solidarity and strengthening family cohesion as an effective means to achieve balanced social development and to protect children and young people.

215. The issue of regional development is addressed by means of stronger policies and active integration measures at the national and regional levels. These actions are considered as being essential for a balanced economic and social development

\section{The GPRS and the Millennium Development Goals}

216. Cape Verde is strongly committed to achievement of the Millennium Development Goals (MDG) set forth by the United Nations in September 2000. Some of these goals have already been reached, whereas others will follow naturally from implementing the poverty reduction strategy. For instance, the goal of universal primary education has been achieved and now attention has shifted to improving the quality of the education system and to encouraging students to complete secondary or professional education. Reduction of child mortality is progressing satisfactorily and it is expected that the goal of reducing it by two thirds will be reached. Improving maternal health is being accomplished, even though it would be desirable to discover the causes of the deaths that still occur. Measures to combat HIV/AIDS are proceeding, with good results, even though it has not been possible to contain the spreading of the disease. Significant outcomes are expected as a result of the measures intended to ensure environmental sustainability. As for access to safe drinking water, $82 \%$ of the population is already being served.

217. Cape Verde's greatest challenge will be poverty reduction. According to the National Institute of Statistics, current trends in reduction of absolute poverty indicate that should GDP grow at the rates recorded during the last decade, absolute poverty will be reduced to half the level of $1988 / 89$, as set forth under the MDG.

218. However, the situation is different with regards to relative poverty. In fact, current trends seem to pull Cape Verde away from the goal of cutting relative poverty in half by the year $2015^{48}$. Reducing poverty to half its current level by 2010 would require

\footnotetext{
${ }^{48}$ Government of Cape Verde (2004), On the Millennium Development Goals, Cape Verde, status report.
} 
lowering the poverty rate by an average of $9 \%$ per year. The Government's status report on the issue acknowledges that "the challenge is great and the likelihood of success is limited, considering current conditions and unless integrated policies are developed to quickly correct the situation" ${ }^{\prime \prime 9}$. The same report is more pessimistic with regards to extreme poverty: it forecasts a $30 \%$ rate in the year 2015 , considering current trends. In fact, with extreme poverty currently at $20 \%$, reducing it to $8 \%$ in the year 2010 and $7 \%$ in the year 2015 would require an $11 \%$ reduction per year.

\section{- In conclusion, the goal of reducing poverty and extreme poverty to $15 \%$ and $7 \%$, respectively, by the year 2015 is in risk unless recent trends are corrected.}

219. Box 4-2 shows a summary of the status of outcomes reached by Cape Verde. Annex 4 presents a summary table where MDG are compared with those of the GPRS.

Box 4-2: Millennium Development Goals: overview of Cape Verde's performance

Considering the progress made by the country with regards to the Millennium Development Goals, the poverty reduction strategy is likely to contribute with measures that will speed up the achievement of these goals. The pace at which each of the MDG will be reached depends on the gap to be closed and on lessons learned from the various indicators of the progress made thus far. Intermediate references will also be considered in assessing the effectiveness of the measures included in the GPRSP for achieving the MDG in Cape Verde.

\section{Eradicate absolute poverty and hunger}

During the 1990s relative poverty grew worse, despite the strong economic growth. This calls for a determined policy to correct the situation and allow the country to reduce in half the number of poor and very poor people by the year 2015 or within a reasonable span of time. Hunger is not a major concern in Cape Verde, even though the country struggles with food insecurity.

\section{Achieve universal primary education}

Cape Verde has reached the goal of universal primary education. However, it is necessary to improve the quality of the education system and to encourage students to complete secondary or professional education in order to improve their chances of successfully entering the labor market. Literacy rates improved significantly during the past ten years. The track record is impressive but much remains to be done, particularly with regards to gender disparities between rural and urban areas.

\section{Promote gender equality and empower women}

Gender equality is a fact with regards to primary education. Women are becoming increasingly more empowered, even though they continue to be more vulnerable than men when it comes to illiteracy and unemployment. Overall, significant progress has been made with regards to gender equality and empowerment of women. Female rights are formally established and the presence of women in State institutions (Parliament, Government) is constantly increasing.

\section{Reduce child mortality}

Current trends are encouraging with regards to mortality of children less than 5 years old as well as infant mortality. However, the country's vulnerability calls for constant attention namely by means of routine vaccination and improvement of birth conditions in maternities. The goal of reducing child mortality by two thirds by the year 2015 may be achieved if past policies that led to the current results are strengthened.

\section{Improve maternal health}

Mother mortality in Cape Verde is low as compared with the rest of the Sub-saharan region. Improving maternal health is

\footnotetext{
${ }^{49}$ Government of Cape Verde (2004), On the Millennium Development Goals, Cape Verde, status report.
} 
one of those goals where progress is slow, which means that sustaining this goal will require close monitoring of maternal health during all phases, including medical visits in the context of planned parenthood, HIV/AIDS tests, as well as improved knowledge about causes of maternal deaths.

\section{Combat HIV / AIDS, malaria and other diseases}

Because the fight against HIV/AIDS has still not led to containment of the disease in Cape Verde, increased attention and behavior changes are crucial, considering the currently low prevalence. Occurrence of tuberculosis decreased considerably between 1989 and 2002, the same being true of the mortality rate from this disease during the same period. Further, good results have also been achieved in treating this disease. Malaria is under control, with exception of years with strong rains.

\section{Ensure environmental sustainability}

Considerable progress has been made in the area of environmental protection. $82 \%$ of the population had access to drinking water in 2002 , which makes it possible to raise this ratio to $100 \%$ by the year 2015 , on the condition that regional disparities are corrected.

\subsection{General and sectoral objectives}

\section{Main policies and the pillars of the poverty reduction strategy}

220. The growth and poverty reduction strategy (GPRS) is comprehensive and covers all the macroeconomic policies (budgetary, monetary and exchange), and those of public management and good governance, such as the sectoral and macroeconomic policies, aimed at the poor population target groups. Thus, the GPRS aggregates, in an integrated form, both the sectoral programs and the macroeconomic program upon which it is based.

221. It should be noted that the poverty reduction policies have as priority objective the reduction of absolute poverty, which is to say, to assure the reduction of essential needs for the poor. In this context, the poverty reduction strategy assumed by Cape Verde also integrates the notion of equity, to the extent that, by improving the lives of the poor, it promotes the creation of a more egalitarian distribution of resources. Such a strategy has a positive effect on economic growth and at the same time, on the incidence and the nature of poverty.

222. The GPRS architecture centers on a set of focal policies and strategic pillars, represented in Figure 4-1, which highlights the priority policies in promoting economic growth and in the fight to reduce poverty. These policies incorporate the five pillars of strategic and programmed intervention that constitute, in turn, the concrete modes of public intervention that are expressed in the sectoral policies focused on the fight against poverty. The definition of the policy objectives associated with each of the pillars of the poverty reduction strategy results from the poverty profile elaborated by the INE, particularly the factors that explain its evolution along the last decade. It took into account a complete socio-economic diagnostic specifically executed to support the GPRS design and presented synthetically in Chap. 2.

223. GPRS objectives are systematized around 5 strategic pillars:

- Pillar 1: Promote good governance, reinforcing effectiveness and guaranteeing equity

- Pillar 2: Promote competitiveness to foster economic growth and employment creation

- Pillar 3: Develop and upgrade human capital 
- Pillar 4: Develop the infrastructures, promote land use planning and protect the environment.

- Pillar 5: Improve the effectiveness and sustainability of the social security system.

224. These strategic pillars coincide in general with those of the NDP and were designed to be more focused on the growth and poverty reduction policies. In other words, they do not replace the NDP, which remains as the general reference framework for the public policies, but rather, they are evidence of a re-focusing of the policy vectors with greater impact on poverty. The GPRS is based on a multi-sectoral vision of the public interventions and of the initiatives in partnership with the civil society and the private sector. The current planning structure in Cape Verde is, however, a sectorized ${ }^{50}$ structure, $^{2}$ in spite of the existence of some multisectoral programs. In practice, this means that it will be up to each line Ministry to ensure the implementation of the GPRS in the respective sector, prioritizing the activities and the projects that have a greater foreseeable impact on growth and poverty.

\footnotetext{
${ }^{50}$ The concept of "sector" used in this document coincides in practice, with that of the Ministry.
} 
Figure 4-1: Architecture of the Growth and Poverty Reduction Strategy

\section{FOCAL POLICIES FOR \\ GROWTH AND POVERTY REDUCTION}
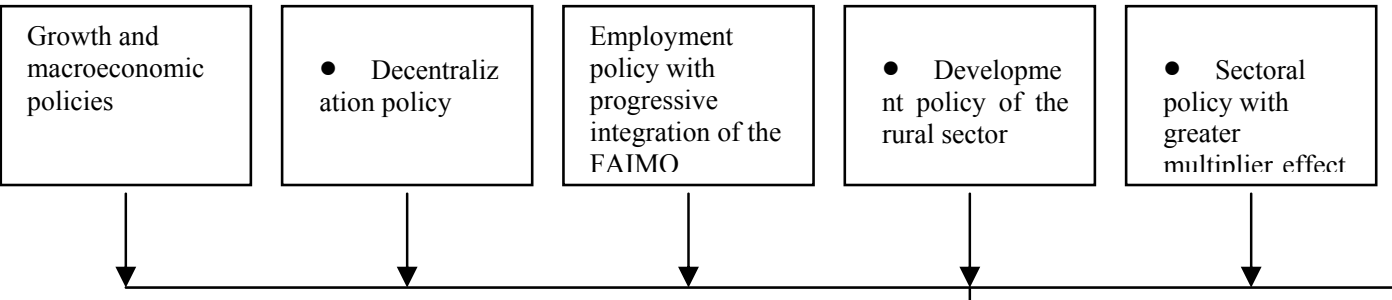

- Redistributi on and social

protection

- Environme

ntal policy

multinlier effect

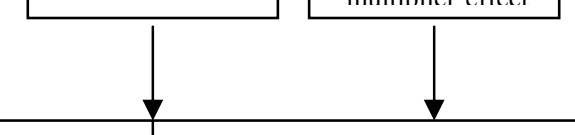

nolicv

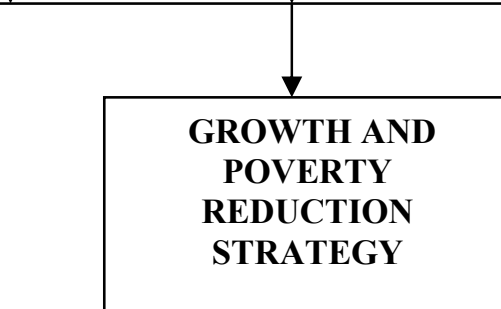

\section{STRATEGIC AND}

PTOGRAMMING PILLARS

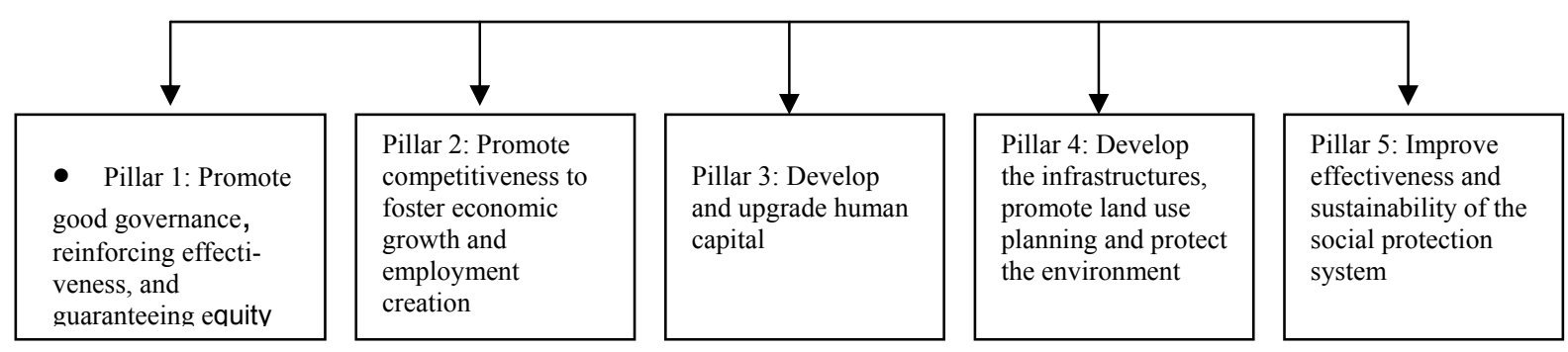


225. In order to minimize the effects of the policies ensuing from the strategy, a special focus should be given to a set of policies, that we shall designate as "focal policies" in relation to growth and to poverty, in as much as they are considered to have a direct impact on poverty reduction, but also have, above all, a high multiplier effect, through the growth - poverty reduction - growth relationship.

226. The objective of the poverty reduction strategy needs to be properly dosed between global economic policy and specific measures centered on the most poor, on the one hand, and between growth policies and redistribution policies, on the other hand ${ }^{51}$. This optimum dosage responds, in the first place, to the characteristics of poverty. Considering that in Cape Verde, approximately $1 / 3$ of the heads of family are unemployed and $37 \%$ do not have a sufficient level of income that would allow them to overcome the poverty threshold, it is clear that that dosage must contain a number of measures aimed at supporting economic growth and increase the number of jobs, but also improve the employability of many poor, in order to improve the quality of their activities, increasing their income, thus permitting them to escape poverty. The ingredients of such dosage may be regrouped into seven categories of focal policies, or strongly interdependent nuclei

- Policy of growth and macroeconomic stability

- Policy of decentralization

- Policy of employment, with progressive integration of the FAIMO

- Policy of development of the agricultural sector

- Policy of support to the productive sectors with greater multiplier effect on employment and with the greatest competitive advantages

- Policy of redistribution and social protection

- Environmental policy

227. In summary, the focal policies set forth the policy guidelines for the interventions with greater impact on growth and poverty, while the strategic pillars provide a pragmatic perspective in connection with the NDP, grouping the set of measures included in the strategy by areas of intervention. Following is a presentation of the general lines of the focal policies (Box 2), and after that, a more detailed presentation of the strategic pillars.

\footnotetext{
${ }^{51}$ MFP/PNUD (2004 a)
} 


\section{Box 4-3: The focal policies of the growth and poverty reduction strategy}

\section{Policy of growth and macroeconomic stability}

Strong and sustainable growth is necessary to create jobs and reduce poverty, under conditions of better employability for the poor. Strong growth is, above all, the result of a policy of incentives to private initiative and of an intervention by the State centered on the sovereignty and security functions and also in the social sectors that have greater impact on poverty and growth. For that reason, the public investment policy shall give priority to the projects and actions that are in line with those principles. Consequently, the public expenditure shall be prioritarily aimed at responding to GPRS needs.

The macroeconomic stability is absolutely necessary for success of the growth policy. For that reason, sustainable economic growth should be pursued, taking in consideration the available resources, and keeping in mind the importance of macroeconomic stability.

In the framework of global coherence in conducting its policies, the Government of Cape Verde shall implement a macroeconomic policy that is coherent with the commitments assumed in the context of the PRGF.

\section{Policy of decentralization}

The reforms that are envisaged in the area of decentralization aim at the consolidation of local power. These reforms also contribute to allow the public administration to get closer to the populations. It is a policy measure of great impact as it allows for direct participation of the populations and the communities in the development process. This impact is achieved through the influence of the decisions by local political entities and because of the participation in the execution of projects and actions by local/regional interest.

In the first line of priority, the instruments of the legal framework necessary to execute the decentralization policy shall be prepared, discussed and approved. This shall be done in decentralized fashion whenever that proves to be more efficient and effective, on a subsidiary basis. This guideline requires the reinforcement of local entities with the greatest capacity and vocation for implementing measures to combat poverty.

\section{Policy of employment, with progressive integration of the FAIMO}

However, for the effect of economic growth on employment to materialize, it is absolutely necessary to improve the employability of the poor, that is, to help them acquire the qualifications and capacities that will allow them to take advantage of the employment creation dynamics generated by the growth. This approach gives the employment policy a clear role in the poverty reduction strategy.

Therefore, the central objectives of the employment policy consist in increasing employability, particularly among the poorest strata and create conditions for the adapting supply and demand in the job market. Under these terms, policy measures that prioritize professional training, as well as professional and territorial mobility, shall particularly be considered.

The structural measures should not exclude emergency measures to face crises situations or economic recession. This type of measure includes public works in the framework of the FAIMO (soil conservation, forestation, road construction), whose objective is to assure a minimum income to the beneficiaries until the end of the emergency period. The FAIMO shall in turn be progressively integrated in the employment structures.

\section{Policy of agricultural sector development}

According to the Plan of Action for Agriculture, the strategic guideline to follow is that of a sustainable agriculture based on the upgrading the specific natural resources of the agricultural zones (water, soil, biotics) and on local socio-economic capital for the optimization of their productive capacities (agricultural and non-agricultural), with a view to improving the living conditions of the rural and urban populations.

The priorities must center on improving family-based farming through agro-forestry-animal raising systems adapted to the specific conditions of the exclusive agricultural areas, resistant to shocks (irrigation agriculture), intensive, diversified and focused on high value added products. The large investments can only be profitable if they translate into high value added products. For this reason, the new agriculture must focus on competitive areas, thus leading to improved living conditions for the farmers. 


\section{Policy of support to the productive sectors with greater multiplier effect on employment and with greater competitive advantages}

The country's small dimension and its scarce endowment in natural resources suggest that it must specialize in the sectors in which it has competitive advantages to insert itself and compete in the world economy. Specifically, the sectors that are more labor intensive and/or take advantage of the country's geographic location and natural conditions. The sectors of tourism, services and international transportation have favorable conditions to impose themselves as productive specialization sectors.

The tourism development policy is, by nature, multisectoral, in as much as its viability and sustainability depend vitally on the effectiveness of the policies for the sectors associated to it. In this context, support to tourism should be coherent with the guidelines to be formulated in the context of the sector's strategic development plan. A more active policy of reinforcement of the infrastructures and promotion of the economic activities associated to the tourism sector should be followed.

Additionally, an approach of reinforcing (maximizing) the multiplying effects should be applied in the export processing zones and industrial parks involved in exports. Included here is a policy of accumulation of human capital (initial and professional training) targeting exactly those zones.

\section{Policy of redistribution of social protection}

The social protection policy shall be pursued in strict articulation with the other public social policies and with the country's strategic economic policies. This policy shall be oriented toward the consolidation of the social protection system under way and its development, so as to guarantee the access to social protection by all the social and professional groups.

Such a system, considered an income distribution instrument, must be structured on the basis of the principles of solidarity, participation and partnership, and assume multi-sectoral characteristics, in which the individual responsibility is combined with the collective responsibility. In particular, the non-Contributive Regime or Base Protection Regime should be incorporated in the social protection strategy currently being prepared, and according to the social risk management approach. Likewise, it must be organized so as to guarantee to the more vulnerable groups the support to satisfy their basic needs, and the prevention and or reparation of the damages caused by the risks that affect them. However, and for the system to be durable and effictive, it becomes necessary to assure its technical and financial sustainability.

Likewise, the social protection policy must be oriented towards contributing to the country's socio-economic development and sustainable reduction in poverty. Under these terms, and income redistribution being one of the key factors to guarantee social equity, justice, and cohesion, it is fundamental to implement redistribution policies that reduce inequalities in income imbalance and in access conditions, particularly for the lower income individuals, to social services and to the satisfaction of their basic needs.

Also, and with a view to the true inclusion of the persons under risk of becoming marginalized, active social policies should be developed that will provide solutions to employability, and the integration of these persons in their participation in the social and economic life of their communities and of the country in general.

\section{Environmental policy}

The environmental protection and conservation policy measures are essential due to the fragility of the Cape Verdean ecosystem, where the imbalance between the exploration of natural resources and demographic pressure is evident. Thus, the focus on environmental training, the active participation of the population in these issues, the promotion of adequate cultural practices, the sustainable management of natural resources (water, soil and biodiversity), a territorial organization that safeguards the environment, and basic infrastructure that takes environmental impact into account, are measures that promote environmental protection and contribute to combat the structural causes of poverty. The sustainability must be based upon a socio-economic development, based on the sustainable equilibrium between the environment, the economy and demographics.

For growth to be durable it is absolutely necessary to respect the weak Cape Verdean ecosystem, above all with regard to agricultural production practices, with the State's actions concentrating on measures with impact on soil degradation and that favor a better management of the rare resources (water for example) and safeguard the environment. PANA II (2004-2014) was elaborated based exactly on those assumptions, and as the planning instrument for execution of the environmental policy in the medium and long terms. 


\section{The GPRS strategic pillars}

228. Following is a presentation of the five pillars of the growth and poverty reduction strategy. Within each of the boxes that follow are described the central objectives of each pillar, as well as the principal strategic guidelines, followed by a brief presentation of the policy measures that will permit the materialization of these objectives. In Annex 3 are listed the specific priority measures that should be implemented in the three-year horizon of the strategy.

\section{Pillar 1: Promote good governance, reinforcing effectiveness and guaranteeing equity}

Good governance facilitates ownership of the poverty reduction policy and increases the possibilities of its success. In effect, good governance reinforces the possibilities that the population, including the poor, will make itself heard, and incites the political class and the public decision-makers to take their aspirations into consideration (better access to education and to the health system, policies which favor job creation, etc.). Therefore, good governance facilitates the way out of poverty, reinforcing the State based on the rule of law and creating a transparent and predictable regulatory framework that encourages the spirit of initiative and the development of a dynamic private sector. In other words, good governance make it possible to improve the effectiveness of economic policies, including their effect on public expenditure as a function of the policy objectives, thus increasing the possibilities of success of measures to fight poverty.

The four vectors that aim at good governance include: i) reform of public administration, ii) strengthening of the judicial system, iii) reform of the State's financial management system and iv) decentralization.

In the area administration reform, the intention is to adopt the principle of management by objectives in a context of strategic planning at the same time as modernization of the management of human resources in Public Administration and investments are made in training and capacity building for public servants, in particular in the areas of information and communication technologies.

The strategic plan for Justice shall have continuity in the period 2005-2007, through the regionalization of the reform program, creating partnerships to transfer the initiative and responsibility to local authorities, NGOs and different regional entities. It is sought in this way to attain the objective of increased intervention capacity of the populations, through better knowledge of their rights, as well as the observance of their duties. As an instrument to attain that objective, regional funds for legal assistance and centers for alternative resolution of conflicts will be created.

The reform of the State's financial system shall proceed with the implementation of the CFAA and CPAR Plans of Action. In this context, there shall be continuity of the budget system reform, on the basis of a program approach, thus assuring a better link between the budget policy and the objectives of the GPRS.

Decentralization and the process of regional development are closely connected and assume the consolidation and strengthening of local authority, in the framework of a decentralization policy that enables and stimulates the participation of the populations, through elected local/regional entities, the private sector and the civil society. The local and regional action, in its various forms, is seen as complementary to that of the State and shall be promoted with due respect for the roles and responsibilities of the various stakeholders in the development process and in a context of global strategic coordination, with a view to the modernization of the municipal administration, the reinforcement of its financial autonomy, the enabling of the local entrepreneurial sector and the improvement of the level and of the quality of civil society organizations participation and of local/regional development.

229. The main pillars of the reform of Justice, that are included in the Strategic Plan of the Ministry of Justice are: i) the promotion of a culture of knowledge and defense of the rights and the duties of the citizen, through an expanded communication program; ii) the reinforcement of the protection of the citizen's right, both through the actions of the National Human Rights Committee and through legislative reforms at the administrative litigious level, of civil rights, penal and civil and penal process, and through the installation of the Constitutional Tribunal and the Justice Promoter; iii) the guarantee of access to 
justice by the citizens by creating a judiciary assistance fund and creating alternative mechanisms for the resolution of conflicts so as to reduce the pressure on the courts and making greater celerity possible; iv) the reinforcement of the independence and effectiveness of justice; v) the institutional development for the execution of the reform that includes action in the areas of training/enabling, operational procedures, improvement in infrastructures, management for change with a view to a culture of quality, reevaluation of justice officials statutes, reform of the judiciary organization, restructuring of the Office of Attorney-General, reform of the legislative package that governs the operation of the Cape Verdean Bar Association.

230. In July 2003 the Council of Ministers approved the National Action Plan for Human Rights and Citizenship (PNADHC), ${ }^{52}$ that seeks to identify the principal violations or constraints to human rights and to the materialization of an active citizenship aware, of its rights, duties and obligations. It seeks, likewise, to elect priorities and present concrete administrative, legislative and institutional proposals to promote, protect and increase the degree of respect for human rights in Cape Verde, and favor citizenship education.

231. The initiatives ensuing from this plan should be put into practice by the public authorities, in partnership with the civil society and the public sector through integrated or sectoral programs and projects that guarantee their follow-up and evaluate their results periodically. The National Committee on Human Rights was instituted as the entity responsible for promoting, protecting and diffusing Human Rights and International Humanitarian Rights, with additional functions of coordination and follow-up of the actions to implement the PNADHC.

232. The objectives of the plan include the creation of a national system of human rights protection and promotion, integrated by State entities and organizations of the civil society, coordinated by the National Human Rights Committee (CNDH), capable of effectively, strive to protect and the promote human rights in Cape Verde. It is equally sought to strengthen a culture of human rights and citizenship in all the islands and municipalities in the country, and at the same time that it seeks to protect and promote the human rights and citizenship of the more vulnerable social groups.

233. The effort to reform public finances is currently underway following up on the recommendations of the diagnostic made in the framework of the CFAA, CPAR and PER exercises.

234. The CFAA ${ }^{53}$ Action Plan defines the following eight intervention modules: i) Budget Programming and Preparation, ii) Management and Control of State Revenues, iii) Management of the State's Treasury and the Public Debt, iv) Conditions of Budget Execution, v) Management of Municipal Finances, vi) Capacities of the General Inspectorate for Finances, vii) Management of State Assets, viii) Food Aid Management and Financial Reporting.

235. Upon approval and nomination of its management body, the CPAR Plan of Action shall have as its priority the approval of the Public Procurement Code, which will bring more financial rigor and rationality to the acquisition of goods and services for the State.

236. Fiscal activity should play a role in the income redistribution framework policies. Thus, with a view to a more effective contribution by expense and income taxation for redistribution purposes, an additional effort should be made at the level of taxation on income, making the IUR a more unitary tax and with more global

\footnotetext{
${ }^{52}$ Government of Cape Verde (2003), National Action Plan for Human Rights and Citizenship in Cape Verde.

${ }^{53}$ Country Financial Accountability Assessment, a study carried out in 2003. See Ministry of Finance, Planning and Regional Development (2003), Evaluation of Public Finance Management and Accounting Practices of the Private Sector.
} 
characteristics, given the reduced weight that the professional, entrepreneurial and commercial income have in their effective tax base ${ }^{54}$.

237. This reform, which is considered necessary, shall contribute to an improvement in the sole tax with direct redistribution effect, its outlook being toward expanding the tax base, as well as rethinking of the actual specific deductions (namely with regard to the pensions) and a reduction of the higher tax margin, maintaining, or even increasing the revenue through an increase in the effective average taxes.

238. The effectiveness of fiscal policy must likewise result from an increase in the effectiveness of the fiscal rules system, the incentive for voluntary fiscal compliance and for a greater and better performance at the level of tax administration, identifying and combating the evasion phenomena, namely in sectors of greater income risk and the small/medium commercial and entrepreneurial activities.

239. With regard to taxation on expenses, it will be sought to improve its effectiveness on the informal sectors of the economy, reinforce the selectivity over certain goods and services in the context of the special taxes on consumption, which shall contribute to minimize the regressive effects that are usually associated to direct taxation.

240. Special priority should be given to the reform of municipal taxes on real estate properties and respective transmission, currently almost insignificant from the financial point of view. The real estate patrimonial tax is desirable principally because it is a source of revenue for the municipalities, reducing the dependence on transfers from the central government and increasing the visibility of the fiscal system to the citizens.

241. The new role of the State in the society and in the economy calls for a Public Administration capable of promoting and supporting entrepreneurship, competitiveness and growth as a condition to expand the country's productive base. Further, a relevant role is expected from the administration in the creation of conditions for the development of human capital as one of the means to fight poverty, and also to create conditions for reinforcing social cohesion and solidarity. These guidelines imply deep reforms in public administration.

242. The strategy of the reform is being defined and it shall be clarified in the process of creating the Institutional Framework for Reform of the State and the elaboration of the National Plan for Reform of the State. Following are the guiding principles of the Public Administration reform, set forth in the GOP, and in the NDP, and now confirmed in the context of the GPRSP:

- Reform of the State and the administration, focusing on the citizen, where the objective is to bring the administration closer to the citizen through programs that simplify and rationalize the public administration and calls for proliferation of the new information technologies in administrative services.

- Reinforcing transparency in public management, by reinforcing the participation of the citizen in the control and oversight of administrative activity, creating the institutional and cultural conditions so that the public services may function according to new public management techniques based on accountability and subject to a better evaluation of the use of public resources.

- Promoting the new information and communication technologies as instrumental engines to change the public management culture and as a means of increasing the access and the simplification of the public services provided.

\footnotetext{
${ }^{54}$ In indirect taxation, the average rate on expenses is $8,1 \%$, whereas in direct taxation the average rate on income is 6\%. See MFP (2004), Fiscal Rate in Cape Verde - Analyses based on the IRDF 2001-2002
} 
- Reinforcing the State's regulatory capacity, by pursuing the privatization policy with the objective of increasing the efficiency, productivity and competitiveness of the economy and the enterprises. The measures to be implemented imply the reduction of the weight of the State in the economy and the development of the private sector, entrepreneurial development and reinforcement of the national entrepreneurial capacity but without setting aside the essential aspects such as promoting competition and regulation of the market operation. For that reason the government is betting on the consolidation of existing regulatory agencies, thus creating the legal, technical and economic conditions for them to begin to exercise their role of overseers of the services rendered, regulate the tariffs of these services and prevent future public monopolies from transforming themselves into private monopolies. In this context, the strengthening of existing consumer protection associations and creation of the conditions for these associations to be extended to the entire national territory is, likewise, envisioned.

243. Specifically, and in light of those objectives, the public administration reform plan should respond to the following needs: i) to implement a public administration simplification program that eliminates useless procedures, prioritizing the services and departments more intensely demanded by the citizens; ii) to reinforce the control of administrative, financial and State asset management; iii) to adopt a restructuring program of the governmental department responsible for conceiving, executing, following-up, coordination and control of the management of the public administration and human resources, so as to adapt them to the competences and technical qualifications, adequate to the exercise of their attributions; iv) to modernize the management of Public Administration human resources through investment in the training and enhancement of the public employees, that attends to the realization of the objectives and serves as support to a career development system (promotion and progression) based on professional merit and fair compensation.

244. As an immediate objective, the census of the public administration personnel, presently under evaluation, should be concluded, along with setting up of the respective database. The latter shall be a fundamental instrument for the management of human resources in public administration, providing yet a solid base for good budgetary management ${ }^{55}$.

245. The National Institute of Administration and Management (INAG) should be instrumental in promoting the public administration reform objectives, transforming itself into an institute for training, research and innovation in the area of public administration. In turn, the ICT Task Force (NOSI) should implement a policy of computerization of the Public Administration capable of promoting the development of computerized solutions and tools for the analysis and support to the decision making process, creation of a public administration structures database and the personnel and information availability through a computer network.

246. The decentralization policy, whose mechanisms and forms must yet be perfected, should proceed. To that end, effective strategic coordination mechanisms should be developed in matters of decentralization of the State's peripheral administration and of the territorial coordination of the public policies for the materialization of the communities' interests.

247. Thus, aside from the policy measures envisaged in the NDP, a partnership strategy should be elaborated, between the public entities (Government, Municipalities) and the civil society organizations (OSC), seeking to reinforce (through appropriation) the participation of the civil society in the decentralization process. This action shall be materialized through the following juridical-financial instruments: i) Law that defines the

\footnotetext{
${ }^{55}$ This activity is supported by the World Bank, through the Growth and Competitiveness Project.
} 
statute of development NGOs, ii) National Fund for Support to development NGOs and OSC, iii) development NGOs Registration Regulation, and iv) Accounting and Registration of assets of development NGOs and OSC.

248. On the legislative side a new law should be approved defining the attributions and competences of the municipalities in the areas of health, education, environment, land use planning, among others. Its objective is the decentralization of new competences and resources to the municipalities on the basis of the subsidiary principle. Complementarily, the law of decentralized cooperation shall be approved seeking the creation of a system of information and management follow-up and evaluation of projects from decentralized cooperation. Finally, the local finances law shall be reviewed. Here, it is proposed to create new criteria for the distribution of the Financial Equilibrium Fund (FEF), regulate the contract-programs and the conditions of access to bank credit by the municipalities.

249. With regards to specific actions, the establishment creation of a line of credit in the national banks is envisaged, to finance municipal projects. It is proposed, with this measure, to diversify the financing sources for local development projects. On the other hand, a department for permanent municipal training shall be created within INAG, for the enabling and enhancement of local human resources. Finally, it is proposed to reinforce the intervention capacity of the stakeholders identified within the Regional Partners Commission (CRP), through training projects for local stakeholders.

250. In the area of privatization, and in line with the international commitments in the context of the PRGF, continuity should be given to the State's exit from the entrepreneurial activity in the areas of imports and distribution of pharmaceuticals, port management, air transport, services to industrial fisheries and dry dock repair.

251. The privatization of ENAPOR is particularly relevant because it fits in the context of the reform of the port system, for the purpose of introducing greater efficiency to the port operations, thereby reducing the operational costs and improving the services provided to economic agents. From this perspective, the privatization strategy for the enterprise was reviewed, which now consists essentially in keeping the infrastructures in the public domain and in granting concessions for the port operations. In the main ports, Praia and Mindelo, there shall be two operators in order to guarantee competition. As for the secondary ports, they should either be associated to the concession of the main ports or they would be offered to domestic operators. In any case, more studies will be carried out to better support the final options.

252. Regarding the TACV, the privatization strategy that had been approved by the government was profoundly altered with the civil aviation recession that was aggravated with the September 11 terrorist attacks. The profound alterations in the market had, as consequence, the fact that the enterprises that traditionally invest in the privatization of small carriers such as the TACV went bankrupt or left the market. After several revisions, the Government and the World Bank recently agreed on the TORs for a management contract to restructure the company. Consequently, a request for expression of interest was published and, at the end of the deadline for submissions, 19 expressions of interest were received, including some of the largest specialized international consulting firms. The restructuring should be concluded in August or September 2005, and the privatization should take place immediately after that.

253. The privatization of EMPROFAC, a state-owned company that still holds the monopoly in the import and distribution of medications, is conditioned to the definition of the regulatory framework for pharmaceutical products. Thus, plans are under way for the installation of the Food and Drug Regulatory Agency (ARFA). The privatization of the enterprise is scheduled for mid 2005. 
254. CABNAVE's privatization was the object of a change in strategy, with the decision to privatize the enterprise separately from ENAPOR. The greatest challenge shall be that of finding a strategic partner interested in its privatization due to the problems that the sector faces on the world level.

255. The privatization of INTERBASE is in its final stage. The strategic partner has been chosen and for the privatization process to be successful, its financial restructuring, the downsizing of its personnel structure are a must, so as to reestablish the financial equilibrium and endow it with an adequate capital structure, making it a more attractive enterprise.

256. Following the privatization process the government is determined to improve the conditions for private sector competitiveness ${ }^{56}$. The reduction to the barriers to investment, the improvement of the legal system and the conclusion of the installation of the regulatory system for the private activities in the post privatization phase are the priorities. Further measures include the establishment of public-private partnerships, the reduction of administrative barriers, as well as promoting training in areas that contribute to business competitiveness.

257. Financial system reform is also under way in several aspects, among them, the reinforcement of the Central Bank's autonomy and capacity, in particular in the areas of regulation and supervision, improvement in the national payment system, and its integration in the VISA system, the establishment of anti-fraud controls, and studies to introduce new financial instruments such as leasing and venture capital.

\section{Pillar 2: Promote competitiveness to favor economic growth and employment creation}

This priority pillar incorporates the set of global, sectoral and transversal policies, with impact on competitiveness and growth of the economy. Public policies should assure growth, whether as a result of the accumulation of capital, human and physical, or of productivity gains. Strong and durable growth requires an economic policy that has macroeconomic stability and competitiveness of the economy as priority objectives, in coordination with a set of structural measures. Among the latter measures, can be cited, as a complement to the fiscal and budget reform (included in Pillar 1): promoting competition, construction of economic infrastructures (included in Pillar 4) as complement to private investments and improvement in the qualifications of the Cape Verdean workers (Pillar 3). All these measures seek, at the same time, to attract national and foreign investors and encourage the production and sale of goods and services throughout the country.

Taking into account the country's small dimensions and the constraints that this implies in terms of endowment in resources for production and export, the government's efforts should concentrate on a small number of sectors in which the country has comparative advantages. For the same reason, measures should be implemented to promote competition in the sectors of the economy, with the objective of improving its competitiveness. The small Cape Verdean economy makes the absence of competition, or of minute competition, in several sectors, an obstacle to economic growth. The competition policy, in the ample sense, makes the entrance of new actors (enterprises) easier in all the sectors in which the country is noncompetitive, which must pertain as much to the sectors that produce goods as to the sector of services, financial and others, and also pertains to the installation of enterprises, both domestic and foreign.

The new role the State has been assuming in the latter years, on the privatizations process, increases its responsibilities in the matter of economic regulation and legislation, in order to guarantee competition, the quality of services provided at fair prices, and the health and safety of the citizens.

\footnotetext{
${ }^{56}$ These initiatives are supported by the World Bank under the Growth and Competitiveness Project, approved in June 2003 , in the amount of US\$11.5 millions (complemented with US\$2 millions from the government of Cape Verde and local stakeholders). Also included in the Project, are activities related to pension reform.
} 
258. In this strategic pillar are included the sectors of economic activity susceptible of having a greater impact on growth and in the combat to poverty, namely agriculture and tourism (policies of a sectoral nature), as well as the areas of horizontal State intervention. Also included are the factors that contribute to the increase in the country's competitiveness in the international market. Generally, these factors were identified in the Competitiveness Forum, and include the reduction in factor costs, reducing the costs of communication, as well as strengthening the capacity for information processing, management and dissemination.

259. In the context of this strategy the business sector has a central role to play, especially through its capacity to develop and operate small and micro enterprises, as well as in the promotion of partnerships with foreign investors. The State takes on the role of facilitator and regulator, but for that it needs to create an institutional framework to ensure that the administrative and political structures are adequate, to promote reform of the labor legislation, and to promote professional training in line with job market needs.

260. In the framework of the transversal policies, the employment policy emerges with a central role. In fact, the low elasticity of poverty relatively to employment in the last fifteen years ${ }^{57}$, places the employment policy at the center of the poverty reduction strategy. Thus, the principal objective of the employment policy is the improvement in the operation of the labor market and the creation of conditions for adapting job offers to job demand. On these terms, the measures that favor professional and geographic mobility are assumed as essential measures to make the professional and geographic characteristics of the offers adequate to the demand for jobs.

261. Focusing on the poor as the target population, these policy measures should contribute to the improvement of employability, which should reflect greater elasticity of poverty in relation to employment. As a consequence, it is expected that, in time, the better allocation of assets by sector, regions and professions, as well as the accumulation of human capital, will have a positive effect on growth.

262. The structural measures referred to above should not exclude the more immediate measures that are derived from crisis situations, or from an economic recession. In this type of measures are included the materialization of public works (soil conservation, forestation, road construction), whose objective is to ensure a minimum income to the beneficiaries, maintaining their qualifications and motivation, until the end of the difficult period. It is considered, however, that this type of measure has a limited effect on the total volume of employment, not to mention the adverse effects it may provoke, specifically, a pressure on the public expenditures and an eviction effect on other employment in the economy. For this reason, these measures should be temporary and limited to regions and populations in situations of great need. The progressive integration of the FAIMO in the framework of and under the responsibility of the employment policy is also necessary to integrate all the poor, essentially of rural origin, in the dynamics of economic growth.

263. The analysis of poverty in Cape Verde shows that women and young people are particularly exposed to the risk of poverty, with unemployment being one of the most important explaining factors. In the case of young people, the solutions to the problem must include making the school system and professional training adequate, eventually incorporating them in the employment policy. In the case of women, whose period of unemployment lasts longer than that of men and whose illiteracy rate is clearly higher than

\footnotetext{
${ }^{57}$ MFP/PNUD (2004 a)
} 
men's, that alone justifies that some employment and professional training policy mechanisms be directed specifically to women ${ }^{58}$.

264. In summary, following are the general objectives of the policy:

- Develop a statistical information system about the employment market and improve the communication system with the users of that information that allows for obtaining information about the job market, employment and the needs of the economy and the society. The information system should be adequate, permanent and reliable.

- Promote self-employment by developing entrepreneurship and the spirit of initiative in microentrepreneurs.

- Contribute to the professional integration of more disfavored groups in the employment market.

265. In spite of the conversion efforts attempted in the last 13 years, the FAIMO continue to be a useful instrument in the fight against poverty, independently of the contracting institution, in the execution of the projects of the FAIMO type. Through a community animation process, projects with high multiplier effects should be prioritized for the reduction of poverty in the beneficiary groups/communities. Included in this group is the mobilization work for irrigation water, the creation of micro and small enterprises in the areas of agriculture, livestock, agro-forestry-livestock tending, transformation of agriculture-livestock products, actions to promote rural tourism, crafts, informal trade, etc.

266. From a sustained poverty reduction perspective, the temporary jobs generating activities to face up to emergency temporary situations, such as the occurrence of droughts, should be incorporated within economically viable and socially useful objectives, prioritizing the communities considered as pockets of poverty and benefiting the poor and very poor persons of these communities, above all the women heads of family and the youth. For the interventions to be sustainable, the members of the communities involved shall be implicated in the identification, execution, follow-up, (self) evaluation and maintenance of the micro-projects and actions to fight poverty, contributing, likewise, with labor, land, and/or money for its execution, in as much as the impact shall be greater in terms of optimization of the means and of the appropriation and valuation of the public investments made.

267. The conversion of the FAIMO must have as objectives improving the contracting and execution of the rural engineering works, and should enable the Regional Partners Commission -- integrated by Community Development Associations, NGO, Municipalities and Decentralized State Services -- in its execution, follow up, management and maintenance. As a general principle, it should implicate the entire community in the identification, execution, follow-up, evaluation and self-evaluation of the works executed, and in particular it should reinforce the recruiting of women for the execution of the works.

268. The development of adequate financing mechanisms designed for the small local economies is an essential instrument for promoting economic activity and creating employment. Micro-credit plays an important role in this context. The GPRS elects access to productive capital and to financial capital, and particularly to credit, as one of the principal ways to guarantee employment (self-employment) to the poorest population, the exercise of an income generating activity and, as a consequence, the possibility of reducing its level of poverty.

269. This position results from the recent experience in Cape Verde in the area of micro financing, in which special attention has been placed on the needs of the poorest. Internal and external resources have been mobilized and managed in the form of micro

\footnotetext{
${ }^{58}$ MFP/PNUD (2004 a)
} 
credits, channeled to the financing of micro-initiatives, benefiting the poor in particular. They have benefited particularly the women heads of family and the street merchants (informal trade), the farmers in the introduction of drip irrigation systems and in livestock, the small entrepreneurs in the various areas such as carpentry, food transformation, and artisanal fishermen in the construction of small boats.

270. Because the impact of the micro credit is recognized in reducing the levels of poverty, in guaranteeing employment (self-employment) and in increasing income for the poor, the GPRS envisages the development of micro-finances, with focus, above all, in financial intermediation. To this end, the following measures are envisaged:

- The reinforcement and expansion of financial intermediation so as to guarantee greater coverage of the poorest zones and the neediest families;

- The development of a more vigorous action in the dissemination and demonstration of the micro credit potential, based on the knowledge of the sector and on the successful experiences (case studies);

- The reinforcement of the training actions, both of the intermediaries and of the credit beneficiaries, in basic management tools, with a view to better allocating the resources made available and to a more efficient exercise of income generating activities.

- A better use of the potentials introduced by other sectors of economic activity, with greater multiplier effects, as is the case with tourism.

271. The sustainable growth of Agriculture should be based on an approach of integrated and participative development of the different agricultural sectors (vegetable, animal and forestry production) and non-agricultural production (rural tourism, etc), capable of optimizing sustainable economic returns, based on the potentials of the different agro-ecologic zones. The principal pillars of this policy include: i) durable and integrated enhancement of the water and agrarian resources, ii) the enhancement of the agricultural products, iii) the reinforcement of the technical, human and social capacities, iv) the reinforcement of the physical, economic and financial capacities, and the v) reinforcement of the political and institutional capacities.

272. The priority policy measures that justify the public support to the sector include the following: organization of the hydrographic basins, promoting rural financial services oriented toward profitable investments, promoting the efficient and rational management of the water resources, namely in the generalization of micro-irrigation, the use of residual waters, applied research and the introduction and dissemination of new technological packages such as variety selection, hydroponic agriculture and the introduction of improved species, and others. These factors shall contribute to minimize the natural constraints, increase productivity and production and, in general, improve the quality of life of the rural population.

273. In the area of food security, the following objectives are considered:

- To promote the sustained development of the national agro-food system (increase of production/productivity and diversification), to ensure an adequate and permanent supply of food products to the population, by promoting the distribution and the commercialization of the agricultural products. The development of the system requires the modernization of production technologies, application of ICTs in agriculture, and sophisticated irrigation systems.

- To guarantee food availability and stability in the supply of the central and periphery markets, assuring the normal operation of the food markets and a management that involves the private commercial management in supplying the market. 
- To improve the access to food and to basic social services by vulnerable groups and zones in the rural and urban areas.

- To Improve the means of prevention and management of crises in the framework of the food security system, implementing a system of information on food security that allows for anticipating crises and minimize their effect on the more vulnerable populations. The functionality of this apparatus must support the inter-institutional coordination, which facilitates the decision-making by the different intergovernmental institutions, organizations of the civil society and international agencies operating in the country.

- To reinforce the actors' institutional capacity and promote a good management of the food security. The sustained management of food security requires the involvement of the internal and external partners, of the private sector, from the local, municipal and regional collectivities, and of the entire civil society, in defining the guidelines and the objectives to be attained in the matter of food security, and for the technical and institutional capacity building for the various actors.

- To promote sanitary security and the quality of food and water, with a view to protect the public and the consumer, by promoting food and nutritional information and education of the population. Measures should be implemented aiming at the hygiene, the improvement of the food diet and the nutritional well being of the population, especially the most vulnerable.

274. The development of Fisheries may give an important contribution to the reduction of poverty. In truth, artesanal fishing represents most of fishing's gross value added. Considered as a strategic sector for the country's development, the measures that contribute to the reorganization and development of the sector, namely the growth of the productive base, the construction of new infrastructures, the sustained exploration of the resources, the oversight of the EEZ, research and evaluation of the principal resources, contribute to minimize the poverty situation of men and women that have fishing as their principal activity or as a complementary activity. The priority policy lines include:

- Promotion of the rational and sustainable exploration of fishing resources;

- Promotion of the rational and sustainable exploration of the fishing resources in order to preserve the durable equilibrium of the ecosystem;

- Modernization of the productive infrastructures by the introduction of new technologies;

- Diversification of the production, reinforcement of the commercialization and upgrading circuits for sea products, with a view to the internal and external markets, especially through promoting transformation industries, for an added contribution of the sector to employment and exports;

- Reinforcement of the technical and professional capacity of the different actors in the sector for a participative follow-up and control, including sanitary and quality control of the fishing products. Creation of a label for the international identification of Cape Verde's products.

- Making the financing modalities, for the development of the fishing sector, adequate to the specific needs and characteristics of the sector (bank credit, Government subsidies, etc.);

- Development of aquaculture, contributing to the growth and productivity of the sector;

- Reinforcement of the regional, sub-regional and international cooperation, aiming at: i) a rational exploration and the preservation of the fishing resources; ii) the expansion of the fishing activities beyond the country's EEZ.

275. In the sector of Tourism, the guidelines assumed by the government are derived from the Strategic Plan for the Development of Tourism, now being elaborated. However, the following guidelines have already been agreed: 
- Tourism shall be structured on the basis of a strategy of growth obtained by consensus with municipalities and the private sector, preserving the environmental, historic and cultural assets. It is in this framework that organizational conditions are being created with a view to the financing of the basic infrastructures necessary to the expansion of tourism in the islands of Sal, Boa Vista and Maio, as well as in the islands of S. Vicente and Santiago;

- The strategy for the development of tourism is seen from a multisectoral perspective. In this context the sectors that precede tourism, such as agriculture and transportation, specifically in inter islands connections, shall be the object of support measures;

- Tourism shall be promoted more aggressively and in its own organizational framework;

- Support to the tourism promoting enterprises, granting financial incentives adjusted to their needs;

- The environmental impact of tourism is one of the principal venues for promoting the sector, assuring the preservation of the natural resources and an adequate urban planning;

- Promotion of the participation of the emigrated and resident Cape Verdean communities in investment projects in tourism;

- The development of a hotel school so as to guarantee the quality of the labor necessary for the growth of the sector;

- The evaluation of the economic, social, cultural and ecologic costs and benefits of major tourism projects, favoring those that best harmonize with the social, environmental and cultural interests of the country.

276. Linking the Tourism sector with the environmental policy is vital to secure the development of the sector and its sustainability on the basis of quality patterns. For this reason, measures should be promoted and implemented. In fact, such measures have already been defined within PANA II, thus assuring the diversification of the national tourism product and the development of greater promotional effort for eco-tourism in its various types. As a complement, it will be sought to assure the integration of the environmental concerns in the professional training on tourism and the absolute need to reduce the negative impact of the tourism activities shall be taken into account, through adequate management of solid waste and residual water.

277. The tourism strategic development plan shall take in due account the link with the sectors that are vital to its sustainability, such as transportation infrastructures, energy, water and sanitation, education and health and land use planning. 


\section{Pillar 3: Develop and upgrade human capital}

Upgrading human resources implies improving the education system and reinforcing professional training. Improving the education system means to expand attendance of kindergarten, instill quality at all levels of teaching, paying attention to the regional, social and gender asymmetries, but in this context it shall mean, fundamentally, to promote the access to Secondary Education so as to elevate the general level of the population's education, and provide young people with the necessary tools through school and vocational/professional education. It means creating alternatives for professional training and specialization, and enabling adequate insertion in the job market. It also means organizing Higher Education, creating a framework for the currently existing institutions and, above all, creating the conditions for the development of an endogenous capacity for knowledge through research in the different areas of science and technology, thus catering to the real needs of the populations.

Strengthening professional education is absolutely an essential policy measure for the reduction of poverty. It seeks to increase the qualification of labor, independently of its basic academic education (basic, secondary and post-secondary), creating a professionalizing alternative for the youths that abandon the school system. Professional training guarantees specialization in diversified areas, in the perspective of creating self-sustaining lifetime projects, susceptible of responding to the needs of the market.

In spite of the positive evolution of some Health indicators, the reform of the sector is indispensable to the fight against poverty, namely with regard to improving access of the poor to health services. The main priorities of the health policy are centered on promoting sexual and reproductive health, in maternal-infant health, in the integrated vigilance against diseases with an epidemic potential, in the fight against nontransmissible diseases. These guidelines should be supported by the structuring of the health system and by the development of human resources. The promotion of equity in the access to Health care constitutes, likewise, a fundamental pillar in the Government's political options, as one of the principal instruments in the fight against poverty.

The reorientation of the budget expenses for the sectors of education and health favor the accumulation of human capital, which should accelerate economic growth. For this growth to take place on the basis of equity, the allocation of financial resources in those sectors should have the more vulnerable strata of population, in particular the youth and women, as preferential target groups.

278. The Education sector assumes a central role in the context of the growth and poverty reduction strategy. This position ensues from noticing that the poverty indicators show a strong correlation between the education level and poverty. In truth, the probability of being poor increases in an inverse relation with the level of education. To face existing challenges, the strategy to be followed starts with human resources development model that takes into account the various levels of education, from the pre-school to higher education.

279. With regard to the education and the professional training sector, the Government of Cape Verde defined two grand options: i) the development of the human capital and the orientation of the education/training system towards priority development areas and ii) the promotion of a global policy of social development, combating poverty and reinforcing cohesion and solidarity ${ }^{59}$. The definition of those strategic objectives is incorporated, in turn, in the agenda of Education for All, approved in Dakar in 2000 and in the Millennium Declaration, which focus on the strategies to improve the access and the quality of the school learning, taking into consideration the principles of equity and gender ${ }^{60}$.

280. The education policy is currently governed by the political guidelines included in the Government Program for the VI legislature, (2001-2005), by the Grand Options of the

\footnotetext{
${ }^{59}$ Cabo Verde, 2002. Chefia do Governo. As Grandes Opções do Plano: Uma Agenda Estratégica, pp.48-51

${ }^{60}$ UNESCO (2001), Rapport de Suivi sur l'éducation pour tous. p.7
} 
Plan, and by the National Development Plan (2002-2005), from which are derived the following strategic objectives: i) promote equity and improve the quality of pre-school education so as to create conditions for its progressive generalization; ii) improve the quality of Basic Education; iii) make the Secondary School resources adequate to the development demands; iv) promote the development of Higher Education; v) combat illiteracy and promote adult education/training for life; vi) develop professional training, so as to upgrade the human resources, making them adequate to the demands of the of citizenship, growth and the country's competitiveness; vii) consolidate School Social Action; viii) promote a national youth and sports policy that allows better integration of the youth in the social life.

281. From the poverty reduction perspective, the actions to be developed shall be oriented toward:

- The training and recycling of infancy educators as well as the progressive expansion of school lunch programs to the pre-school (about $50 \%$ of pre-schools);

- The reduction of the percentage of teachers without training; threefold increase of number of trainees in teachers training schools; implementation of alternative training models for teachers; prioritizing the municipalities, zones and social groups with priority educational needs, for the materialization of the education for all objective; improvement in the quality of teaching for Mathematics and the Portuguese language through the use of radio (IRI-CV project); combat to the regional and social asymmetries in the access to quality education; improvement of the schools physical conditions and expansion of the network (school construction and repair, construction of WC and office for the managers);

- Programming of the extension of the physical network with a view to the generalization of the first cycle, $7^{\text {th }}$ and $8^{\text {th }}$ grades, BADEA and OPEC Fund package (Achada Falcão, Órgãos, Chão Bom, Achada Leitão, Cidade Velha, Ponta Verde, Cova Figueira, Mosteiros, Maio, Ribeira das Patas, Tarrafal SN, S. Domingos, Boa Vista);

- The reinforcement of the literacy activities in the zones/municipalities with more unfavorable indicators; beginning operations of the Educational Radio studios and reinforcement of the educational and training actions for various levels of the system (Basic Education, professional training, etc.); new human resources mobilization strategies (civic volunteers) to resume some specific programs;

- The reform of the policy and practices for awarding scholarships; reinforcement of the higher education institutions (HEIs); evaluation of the national HEIs; opening new courses of study in the national higher education institutions and its upgrading through scholarship programs;

- The increase of the training offers in the technical schools (Cesaltina Ramos Secondary School pilot experience in partnership with the Government of the Canary Islands); reinforcement of the professional training component in the adult education activities; launching training programs for trainers; definition of a national professional training network that integrates technical schools, professional training centers and employment structures;

- Resuming total coverage of the lunch program in Basic Education and progressive extension to the pre-schools; create a new tuition support program for needy students in the secondary; training and development of actions in the context of pre-school health.

282. The focus on the measures that seek at the same time to improve workers employability and qualifications, particularly those targeting the population in risk of poverty, is the best means to reinforce the link between economic growth and the reduction of poverty. This is one of the perspectives aiming at the accumulation of human capital, for the development of the initial training system but also for the development of a professional training system that makes it possible to improve the employability of the work force in Cape Verde. 
283. The Grand Options of the Plan establishes as one of the priorities for the development of Cape Verde to "Develop the human Capital and turn the educational and training system to the priority development areas". In this context, professional training deserves a special attention in the framework of the Government Program, associating it to competitiveness and to the economic development of Cape Verde. Thus, professional training should be directed to the sectors that show greater comparative advantages, on the basis of continuous training and in partnership with the enterprises.

284. The following priority objectives stand out:

- Increase the physical support and training facilities, with the implementation of professional training actions in the technical schools and expansion of the network of employment centers with the capacity to promote professional training;

- Improvement of the articulation between the Educational sector and the Professional Training sector, with significant impact in the utilization of human, financial and material resources;

- Beginning of regulation of professional training, upon publication of the Professional Training Legal Regime that establishes five levels of professional training.

285. Finally, the promotion of training must be programmed and supported by an efficient and effective job market and training information system. Hence the need to elaborate a Professional Training Strategic Plan that should be preceded by the elaboration of a White Book and resuming employment surveys, structures and modalities of training, and diagnostic of the need for professional training.

286. In the Health sector the following priority objectives have been identified. Together, these should have a significant impact on poverty, to the extent that they will contribute to increase the coverage of the needs, improve the quality of the services provided and promote equity. It is, thus, proposed:

- To reinforce the Health Centers, with priority to the rural zones;

- Rehabilitate the reference hospitals on a national scale;

- Reinforce the capacity of the human resources, including specialized training, so as to increase its capacity to utilize the planning and management instruments;

- Improve the capacity for planning, organization, management and evaluation of the system through the reinforcement of the Health Information System;

- Improve the services, in the areas of early detection of diseases of fecal oral transmission, taking into account the fragility of the environment and the strong exposure of the neediest populations;

- Reinforce the priority programs and strategies (Integrated Attention to Child Diseases-AIDI, Expanded Vaccination Program - PAV, HIV/AIDS, Tuberculosis, Reproductive Health-SR, and Integrated Vigilance of Diseases and Response - VIDR) endowed with personnel, equipment and consumables;

- Define a strategy for the prevention and combat of non-transmissible diseases based on the knowledge thereof;

- Reinforce the population's participation in the promotion of health defense, through reinforcement of the cooperation between sectors and the civil society health organisms.

287. It should be highlighted that the intervention in the area of HIV/AIDS has been supported by a World Bank project in the amount of US\$ 9 million, which has as specific 
objective to mitigate the socio-economic impact of the disease, on the individual, family and community levels, thus sustaining an economically productive population, as well as the establishment of a sustained national capacity to respond to the epidemics. 


\section{Pillar 4: Develop the infrastructure ${ }^{61}$, promote land use planning and protect the} environment

The strategy to be followed in the area of land use planning seeks to contribute to an efficient and effective management of the land and of the natural resources, for the good of the sustainable economic and social development, of the defense and protection of the environment and of the enhancement of the quality of life.

The strategic guidelines for the transports sector (infrastructure and services) seek to contribute to the reduction of poverty, to economic development and to the unification of the national space, through effective and sustainable ${ }^{(*)}$ transport systems. The sectoral strategy conceived by the Government constitutes a basis for the mobilization of internal and external financing.

The enhancement of infrastructures seeks, in the first place, to open up certain islands and facilitate the integration of the goods and services markets. It is a necessary condition for promote a specialization process that will enable certain islands a greater specialization in the activities in which they hold potential comparative advantages and enhance the coat-tail effect of growth in certain sectors, such as tourism, over other sectors of the economy.

By the same token, the enhancement of the social infrastructure should allow for integration of the local job markets into the national job market, which in the long run is the best way to improve the allocation of production resources (namely labor) and to sustain strong growth.

${ }^{(*)}$ Consultation meeting with Cape Verde's Development Partners, Praia, 29-30 April 2003.

288. The strategic guidelines in the area of land use planning are:

- To conceive and implement a national approach to land use planning that (i) encompasses the entire national territory, particularly the special planning zones, (ii) has as its focus of intervention, the activities with strong impact on the territory and (iii) relies on the prevalence of a "culture" of linkage, coordination and complementarity, on the part of the sectors involved;

- To proceed with thorough land use planning of the urban and rural spaces, of the watersheds, of the special tourist zones, of the sea border and industrial parks, as a means of turning the territory into a factor of well being for the citizens and competitiveness of the economy;

- To keep in mind the concern for the fight against poverty, as much for reasons of social sustainability and of equity and social justice, as for the fact that poverty can engender a strong pressure on the territory and the natural resources, thus contributing for environmental degradation.

289. In the sector of transports the following were defined as strategic pillars ${ }^{62}$ :

- Introduce management systems based on commercial principles, with an appropriate regulatory framework;

- Place emphasis on the level of service to respond to user needs, making a minimum service available to the entire population;

\footnotetext{
${ }^{61}$ In this pillar are included the horizontal infrastructures. The specific infrastructures, of each sector, are taken into account in their respective sector (i.e. Health, Education, etc).

${ }^{62}$ The project has been supported by a World Bank loan in the amount of US\$ 17.5 million. An additional project estimated at US\$25 million is currently being prepared.
} 
- Introduce policies, institutional frameworks and financing mechanisms that permit continuous maintenance of the infrastructure, so as to guarantee its durability;

- Re-focus the roles of the public and the private sectors. The Government shall play more and more the role of planner and regulator while the private sector will play the role of executor and manager.

290. In the road transportation sub-sector, the central objective is to facilitate trade and the access to services, through a functional road network maintained in sustained fashion; likewise, it is sought to offer the citizens a road transport service network that is safe and accessible.

291. Keeping in mind the definition of the investment priorities criteria, both in the construction and in the rehabilitation areas, and considering Cape Verde's specific characteristics, the "policy should be centered on a network management logic that assures an effective connectivity of the locations and is not based not only on classic economic profitability criteria" ${ }^{\prime 63}$.

292. The government is determined to enhance the transports sector institutionally, centering its attention on the following pillars: i) institutional support to the General Directorate of Road Transportation; ii) assistance in the management of the roads sector, namely in supporting studies to support the creation of the Roads Institute and Reform of the Roads Fund; iii) technical assistance in the preparation and implementation of the National Road Plan.

293. One of the key issues for road transportation is the creation of an appropriate legal and regulatory framework, taking into account the regulation of the transportation services, including the clarification of the roles of the public and private sectors, and within the public sector itself, specifically between the central and the local administrations. Such regulation must clarify the attributions and competences of the public institutions with responsibility to intervene in the urban passenger transportation sector, surpassing the existing shortcomings, namely in terms of coordination between the Municipalities and the General Directorate of Road Transportation.

294. To that effect, the following policy measures are defined:

- Rationalize road management and encourage the "commercialization" of the roads, making the users pay a price for their utilization;

- Gradually improve the road network on the basis of a National Road Plan;

- Promote quality in urban and inter-urban transportation, in collaboration with the municipalities, supporting the development of the private operators;

- Establish an evaluate the legislative and regulatory framework;

- Improve road security and limit the negative impacts on the physical and social environment.

295. In the maritime sector, a distinction should be made between inter-island and international transport. With regard to the former, the transport policy shall be oriented so as to facilitate the economic integration of the islands that constitute the archipelago, minimizing the natural barrier that fragments the internal market, and turning local distribution and distribution for export more fluid and efficient. In this way, it shall be possible to disseminate through the islands the multiplier effects brought forth by the more dynamic sectors, specifically tourism, thus better distributing the benefic effects of the growth throughout the whole country.

\footnotetext{
${ }^{63}$ Consultation meeting with Cape Verde's Development Partners, Praia, 29-30 April 2003.
} 
296. The sector's objectives are: the integration of the internal market and the improvement of the international and inter-islands maritime services. To attain those objectives, the following policy measures are established: i) modernize the management of the maritime sector; ii) improve the maritime transport service chains.

297. Such objectives seek to respond to the demands of a fundamental sector to assure the competitiveness of the economy of Cape Verde. The main challenge is the modernization of the sector's management to create favorable conditions to investment and guarantee adequate services. Included is a reformulation of the legal framework, clarifying the functions of the three sectoral action groups: i) the regulatory institution, ii) the ports manager and iii) the private operators. In this context, it is envisaged the reinforcement of the Maritime Administration to ensure that the country maintains its obligations in the framework of the international conventions and that the technical and security norms are respected, in coordination with other interested services (police, customs, coastal security, etc.).

298. The modernization of port security shall be done through the progressive application of a landlord port approach in which the port services, currently provided by ENAPOR, shall be concessioned on the basis of performance contracts. The investments for port infrastructures and equipment shall be defined as a function of the master plans for all the ports.

299. In the air sub sector, it is envisaged to facilitate the economic and social development through a transport system that is competitive and adequate for the development needs, in particular of tourism. The corresponding policy measures are centered on i) the modernization of the airport navigation systems, ii) the promotion of regional integration in the market of the African sub-region.

300. In particular, it is proposed to create a platform for the reinforcement of the air connections in the corridors "Europe-Americas-Africa". For that reason, it shall be necessary to envisage the expansion of the airports and of the local air terminals as a function of the master plans under way and of the modernization of the technical and navigational instruments. With regard to inter-island transport services, the greatest challenge is that of finding viable solutions as incentives to be offered by the services in chronically deficit lines.

301. The energy sector has registered the conclusion, in November 2003, of the National Energy Plan, covering the period 2003-2012. The plan defines as global objective of the Energy Policy in Cape Verde: "To guarantee the satisfaction of the energy needs of the population, the economy and the country, making energy available in sufficient quantities and at a cost that contributes to improve the well being and the quality of life of the population and for the competitiveness of the national economy, without creating macroeconomic or environmental imbalances or else aggravate the dependence on the outside." From here, the following specific objectives are derived:

- Consolidation of the Energy Sector in Cape Verde. The accelerated growth of many indicators leads to the belief that it is possible to attain ambitious goals of penetration of commercial forms of energy in the entire country and in all the socio-economic strata. Action to that end shall be at three levels: i) structural, which implies enhancing the infrastructures for production, storage, transformation, transport and distribution of energy, so as to cover a greater area of the national territory; ii) of access, increasing the population's access to the commercial forms of energy; iii) institutional, creating legal conditions for the adequate operation of the sector, defining competences, endowing existing entities with means for policymaking and the adaptation of technologies, and establishing the regulatory entities; 
- Guarantee of the Security of Supply in Cape Verde through i) diversification of the energy sources, by resorting, above all, to the utilization of endogenous resources, in as much as natural gas does not seem to be an option for reasons of scale; and ii) of the creation and maintenance of strategic reserves, reorganizing the infrastructures for storage of petroleum derivatives in order to maintain a minimum capacity in managing supply;

- Guarantee of Competitiveness of the National Economy. Through the instruments at its disposal, the State may act to guarantee that the utilization of energy may become a factor in increasing the country's competitiveness: i) regulation, prices and tariffs policy; ii) incentive to competition, decentralized production and self-production; iii) incentive to limit waste and losses in the consumption of energy; iv) incentive to better efficiency in the energy supply systems;

- Minimize the environmental impact of the production, transformation and utilization of energy. It is an objective that shall be plainly attained if the first three are complied with. The limitation of the consumption, a greater efficiency in the supply and the use to renewable energies shall have a visible impact in minimizing the environmental impact of energy use.

302. Finally, reference is made to the fact that incineration of solid urban waste presents itself as a way to reduce local urban pollution, a great concern in Cape Verde. It is still possible to limit the emissions of atmospheric pollutants through greater rigor in the establishment of fuel specifications, whether for consumption in the industrial sector or in the transports.

303. The potable water distribution sector's policy at the level of the principal urban centers has been that of extending the public water distribution grid. Priority is given to the needier communities so as to permit generalized access to the majority of the population in a medium to long-term perspective. This policy allows for the gradual closing of a large part of the existing fountains in the main urban centers and the connection of some of these facilities to the public distribution grid, a fact that will contribute to a significant alteration in the actual situation, with increase in the number of homes connected to the public grid in detriment of the using the fountains and cistern trucks.

304. In the area of basic sanitation, partnerships will be sought with the municipalities and other entities involved namely the health and the education services, the private sector, the NGOs and the civil society organizations, taking into account the objective of developing the collection and treatment of residual waters and solid waste in the country's primary and secondary centers.

305. The environment in Cape Verde now has a strategic plan. The Second National Action Plan for the Environment II (PANA II) ${ }^{64}$, in effect from 2004-2014, was recently approved and it proposes to project the future development of the country in order to secure maximum satisfaction of the present generation's needs without compromising that of future generations. In general terms, PANA has the following objectives:

- To define the main environmental policy guidelines in the framework of the national and regional development policies;

- To define the national resources policies and strategy, identifying the development opportunities and priorities, and establishing actions seeking to utilize the resources with the greatest possible efficiency and effectiveness;

- To define the institutional framework and the inter-sectoral coordination mechanisms that assure the complementarity of the proposed actions, seeking to take advantage of the synergies between the various sectors;

\footnotetext{
${ }^{64}$ General Directorate of Environment (2002), National Action Plan for the Environment, 2004-2014
} 
- To define the adequate instruments for the execution of the environmental policy and ensure their complementarity;

- To promote the integration of the environmental concerns in the planning of the economic and social development, at the national, regional and sectoral levels;

- To promote upgrading of the population's living conditions with regards to quality and availability of resources and basic technology for purposes of comfort, hygiene, and food security.

306. PANA is a notable example of a decentralized planning process, both in the preparation phase and in the implementation phase. Based on this guideline, Municipal Environmental Plans (PAMs) have been elaborated. In the six PAM already elaborated, the areas of waste management, sustainable management of water and natural resources (soils and biodiversity) appear as first priorities. The land use planning, the technical and institutional capacity building and the education, professional training, information and environmental awareness constitute an essential basis for executing programs with technical contents.

307. One other characteristic of PANA II is its multisectoral character. For that reason, nine Inter-sectoral Environmental Plans (PAIS) covering the areas of sustainable management of water resources, public Health, Biodiversity, Land Use Planning, Education, Training, Information and Awareness, Tourism, Agriculture, Forestry and Livestock, Fishing, Industry, Energy and Trade. It is considered that the harmonization of the sectoral plans shall avoid duplications and the omission of strategic options.

308. The multisectoral nature of the environmental policy shall be taken into account in the elaboration of the respective budget, with a view to respond to the financing needs of the measures of an environmental nature carried out by the different line ministries. Likewise, the division of responsibilities and competences between the central and local governments shall be taken into account in the implementation of the environmental policy. 


\section{Pillar 5: Improve effectiveness and sustainability of the social protection system}

The complexity and interdependence of factors that are at the base of the social problems originating the increase of the poverty phenomena, of inequality and social exclusion, augmented by the insufficiency of human, technical and financial resources to respond to the needs of the neediest populations, point to the pertinence and the importance of defining a strategy for the area of social protection in Cape Verde, integrated in the remaining social public policies and in the country's development process.

The Reform of the Social Protection System constitutes one of the priorities of the political agenda and incorporated the different regimes existing in the country: social security regime for those working for someone else; of the central and municipal civil servants; minimum social protection (non-contributing regime) and the regime of protection against work accidents and professional illness. Social security for independent workers is in the implementation phase.

This pillar is centered on the development of the non-contributing regime, as part of the ongoing reform. The aim is to protect the more vulnerable strata of the population and the reduction of poverty in close coordination with the development objectives of the millennium. It is proposed to reformulate the concepts, the practices, the modalities and the management mechanisms of this social protection regime, adopting new intervention strategies, with a multi-sectoral and integrated vision, based on the management of social risk. In this perspective, the coordination between the social protection policies and the other social policies that contribute to the reduction of poverty -- specifically health, education, professional training, food security, sanitation and housing - should be reinforced.

309. According to the main lines of political orientation contained in the Government Program (2001-2005), in the Grand Options of the Plan and in the National Development Plan (2002-2005), the following strategic objectives were established for the area of social protection (non-contributing regime):

- Formulate a strategy of social protection with a new approach based on the management of social risk, with an integrated multi-sector character, that permits supporting the poor and more vulnerable strata of the population in the improvement of their living conditions, in the prevention and management of social risks;

- Improve the intervention capacity in the area of social protection, which must be less palliative and of an assistance nature, and should evolve toward a more participative and promotional intervention;

- Create a normative development framework in this area, that contributes to an improvement in the linkage between the different stakeholders;

- Contribute to the strengthening of the intervention capacity, particularly of the nongovernmental and community organizations, in the development of programs directed to specific groups of the population at risk or socially excluded;

- Promote and support the local and community development initiatives in the fight against poverty and social exclusion;

- Strengthen the link between the different social policies, particularly the policies on health, education and professional training, food security, home and sanitation, that contribute to the reduction of poverty and guarantee the access of the more vulnerable groups to the basic social services.

310. The materialization of these objectives must permit the development of a social protection system, based on the principle of social solidarity and partnership, in which the 
community participates in the construction of protection and support mechanisms to the individuals, families and groups in situation of need, risk and/or social exclusion.

311. In this context, it becomes necessary to implement a financially sustainable pension and social security system. More specifically, a gradual unification of the existing systems, the redefinition of the FAIMO workers' benefits system and the reinforcement of the capacity of the National Social Security Institute ${ }^{65}$.

\subsection{Macroeconomic framework for the $\operatorname{GPRS}^{66}$}

\section{Economic growth}

312. Starting in 2005, the economy will accelerate, with the annual growth rate reaching an average of $6.5 \%$ from 2005 to $2007^{67}$. This acceleration ${ }^{68}$ will be a result of a combination of factors. The first is gross internal investment, with gross fixed capital formation reaching $23.1 \%$ of GDP, as compared to $20.2 \%$ between 2001 and 2004 . The share of private investment in GDP will also increase, to an average of $16 \%$, that is $1.3 \%$ above the previous period. The rate of growth of private investment will also accelerate, from $10.6 \%$ in $2001-2004$ to $15.3 \%$ in $2005-2007$. The upward trend also occurs with regards to public investment, which will increase from 5.5\% of GDP to $7.1 \%$ when the two periods are compared. This will reflect investment efforts by the Government to reach the targets set forth in the growth and poverty reduction strategy. On the average, nominal public investment is expected to increase by $17.7 \%$ per year in $2005-2007$, as compared to $6.8 \%$ in $2001-2007$.

313. The private sector will contribute decisively to this growth. However, the public sector will also contribute, mainly in two ways: (i) a growing public investment effort and (ii) channelling this investment preferably towards the areas with greatest impact on poverty reduction, such as education, health and infrastructure.

314. On the demand side, exports will be one of the main factors of growth, as a result of structural reforms to raise the economy's competitiveness. Nominal exports of goods and services are expected to grow an average of $13.2 \%$ per year during the period, reaching $38.2 \%$ of GDP in 2007 . This is a significant contribution considering the context of internal and external price stability that is anticipated. It also reflects favourable developments with regards to the weight of tradable goods in the economy.

315. In the last few years, Foreign Direct Investment (FDI) has not lived up to its potential in terms of contribution to economic growth. Starting in 2005 FDI will experience considerable improvement, reaching an average of US\$ 64.2 million per year in nominal terms, as compared to US\$15.8 million per year recorded on the balance of payments from 2001 to 2004. As with exports of goods and services, this improvement will be the result of improved competitiveness of the economy, the institutional framework and external promotion efforts, namely as a result of implementation of the new agency for investment and tourism promotion, as well as of an international environment that is more conducive to economic recovery. In sectoral terms, the most dynamic sectors are expected to be tourism, transports and communication. With regards to tourism, a major development will be the implementation of the Tourist Development Corporation for the islands of Boavista and Maio.

\footnotetext{
${ }^{65}$ These actions are supported by the World Bank through the Growth and Competitiveness Project.

${ }^{66} 1 \mathrm{US} \$=88.837$ CVE (exchange rate published by the Central Bank, 20 July, 2004)

${ }^{67}$ See tables 2.7 and 2.8 of the Statistical Annex.

${ }^{68}$ From 2001 to 2003, the average growth rate of GDP was 5\%, with a slight increase in 2004, when it reached 5.5\%.
} 
316. On the supply side, the main sectors are expected to reach the following growth rates: agriculture, forestry and animal husbandry $4.5 \%$; fisheries $8.8 \%$; industry and energy $10.4 \%$; construction $7.1 \%$; hotels $10.1 \%$; transports and communication $7.4 \%$. These sectors are expected to experience higher average growth rates as compared to the previous period. The trade sector should stabilize around $5 \%$, that is a small drop in the average growth rate as compared to the previous period.

\section{Fiscal performance}

317. Fiscal performance will be guided by prudence, in line with the overall policy of macroeconomic stability, sustainable growth and poverty reduction. It should reflect concerns over the structure of public expenditure, namely with regards to the primary balance, in a context of increasing public investment to promote areas that are crucial to poverty reduction.

318. Total revenue is expected to reach $27.6 \%$ of GDP during the period, reaching the amount of US\$ 345.6 million in 2007. On the average, fiscal revenue should make up $19 \%$ of GDP during the period, whereas grants are expected to reach $5.7 \%$ of GDP.

319. Total expenditure is expected to represent $34.6 \%$ of GDP, following a declining trend in relative terms. Recurrent expenditure will also decline as percentage of GDP, in such a way that on the average it should represent less than $20 \%$ of GDP.

320. The weight of public investment in GDP will increase to an average of $14.2 \%$, that is $3.3 \%$ higher than the previous period. Further, this growth will be marked by a steady increase during the period, as opposed to the fluctuations recorded during the previous period. Average annual growth rates will be $17.7 \%$ in nominal terms, as compared to the 6.8 recorded in the previous period.

321. The overall fiscal balance including grants is expected to reach $7 \%$ of GDP, following a declining trend and assuming a financing gap. However, supposing the necessary supplemental resources to finance the gap will be mobilized in the form of grants, the overall deficit would reach $4.8 \%$ of GDP. Considering that the overall deficit reflects essentially the increased public investment effort and the fact that this investment is crucial for achieving the targets set forth in the context of the growth and poverty reduction strategy, it follows that the amount of resources to be mobilized in the form of grants will be a critical variable as far as success of the strategy is concerned.

322. The primary current balance ${ }^{69}$ will record a surplus for every year of the period, and average $3.8 \%$ of GDP for the period as a whole.

323. Both internal and external debt will follow a path that is compatible with sustainability of macroeconomic policy, particularly with regards to budget policy. The ratio of public debt to GDP will decline, namely as result of the acceleration of GDP growth expected during the period.

324. Even though restraining recurrent expenditure will free up resources for public investment, external resources will be crucial for materialization of the public investment program. Therefore, under the envisaged framework, effective mobilization of external resources are a sine qua non condition for achieving the poverty reduction targets set forth in the GPRSP.

\footnotetext{
${ }^{69}$ The primary current deficit is defined as the difference between domestic revenue and recurrent expenditure, net of interest paid on public debt.
} 


\section{Monetary developments}

325. Monetary targets included in the 2005-2007 macroeconomic framework are in line with the goals of price stability and credibility of the exchange rate regime reflected in the upward trend in reserves relatively to imports of goods and services. It is also consistent with the principle of making internal resources available to finance the development effort. In this regard, credit to the economy as percentage of total credit is projected to expand.

326. Broad money growth will remain below double digit through 2007, in line with nominal GDP and assuming constant money velocity. Therefore, during the period broad money will grow an average of $8.6 \%$ per year, and increase to $9.2 \%$ by 2007 .

327. Total internal net credit is projected to expand an average of $5.3 \%$ per year, reaching US\$758.7 million, and an average of US\$718.2 million per year. Credit to the economy is projected to reach an average of US\$ 432.2 million, as result of an average growth annual rate of $8.6 \%$, that is $3.3 \%$ above the growth rate in total net credit, thus reflecting the upward trend in credit to the economy mentioned above. In fact, credit to the economy will represent an average of $58.8 \%$ of total credit, that is $5.4 \%$ above the average for the previous period, as result of an increasingly higher portion of system's resources being channelled to the private sector. As part of this trend, credit to the government will decrease as percentage of total credit, reaching an average of $23.9 \%$ for the period, that is $3.3 \%$ lower than the previous period and reaching US\$ 174.5 million in 2007.

328. The combined effect of monetary and budget policies on the real sector is expected to lead to developments in line with the goal of price stability. Inflation for the period is expected to be around $2 \%$.

329. Net international reserves are projected to reach an average of US\$188 million during the period, and increase steadily to US\$218.4 million in 2007. This will result in higher international reserves relatively to imports -- an average of 2.5 months of imports for the period and reaching 2.8 months of imports in 2007. This improvement will be associated with the good performance of exports of goods and services, as well as foreign direct investment.

\section{Balance of Payments}

330. The projected trend in exports of goods and services is expected to contribute to an improvement of the country's productive structure. In this regard, with exports of goods and services projected to increase around $13.2 \%$, their contribution to GDP during the period should reach $36.5 \%$ on the average, that is $4.7 \%$ higher than the average for the earlier period. As a result of this trend, which is positively correlated with foreign direct investment, exports of goods and services are projected to reach US\$ 481.8 in 2007, which amounts to around $38.2 \%$ of GDP. Another noteworthy development is the increase in tourist revenue, which is expected to grow an average of $7.2 \%$ higher than exports. Imports of goods and services should account for $66.5 \%$ of GDP on the average, following a downward trend in relative terms.

331. Net current transfers are expected to increase an average of $7.8 \%$ in nominal terms during the period, which is about the same rate as its main component, net private transfers, which are expected to increase $7.5 \%$. The former is projected to represent an average of $24 \%$ of nominal GDP, reaching US\$298.3 million in 2007, whereas net private transfers are expected to reach $18.3 \%$ of GDP, thus continuing to play a key role in financing the economy. 
332. Foreign direct investment is expected to record an upward trend during the period, which is crucial for the expected improvement in the real sector and exports. FDI is expected to reach US\$ 68.7 million in 2007 , and an average of US\$ 57.4 million during the period.

333. The current account balance, including official transfers, is expected to evolve favourably in relative terms, leading to a significant reduction in the deficit, as a result of a relative stabilization of imports and an increase in exports during the period. The current account balance is expected to consolidate below double digits, reaching an average of $7.1 \%$ of GDP during the period, as a result of a significant improvement in the economy's relationship with the outside world.

334. Gross international reserves are projected to reach 2.5 months of imports of goods and services.

335. The main risks that could hinder materialization of this scenario are: (i) failure to mobilize the external resources to finance the necessary public investments; (ii) exports increasing less than expected; (iii) foreign direct investment below the projected level. 


\section{TOTAL COST AND FINANCING PLAN FOR THE GPRS}

\subsection{Budget for the GPRS}

336. The implementation of the Growth and Poverty Reduction Strategy (GPRS) will be the framework for resource allocation during the period of 2005-2007, which will require a major fund mobilization effort both internally and externally. The implementation cost of the strategy is summarized in the table below and totals US\$ 459 million, of which US\$ 359 million in investment costs and US\$ 99 million in recurrent expenditures arising from the specific measures and activities resulting from implementation of the GPRS.

Table 5-1: Investment and recurrent expenditures for the GPRS

\begin{tabular}{|c|c|c|c|c|c|}
\hline \multicolumn{6}{|c|}{ (US\$ million) } \\
\hline & 2004 & 2005 & 2006 & 2007 & Total \\
\hline Total GPRS Expenditures & $\mathbf{0}$ & 196 & 177 & 86 & 459 \\
\hline Investment expenditures & 0 & 160 & 144 & 55 & 359 \\
\hline Recurrent expenditures & 0 & 36 & 33 & 31 & 99 \\
\hline $\begin{array}{l}\text { Reference: } \\
\text { Recurrent Expenditures (National } \\
\text { Budget) }\end{array}$ & 208 & 219 & 232 & 245 & 904 \\
\hline
\end{tabular}

Table 5-1-1: Investment and recurrent expenditures for the GPRS, by strategic pillar

\begin{tabular}{|c|c|c|c|c|c|c|c|c|c|c|c|c|}
\hline \multirow{3}{*}{$\begin{array}{l}\text { STRATEGIC } \\
\text { PILLARS }\end{array}$} & \multicolumn{9}{|c|}{ BUDGET } & \multicolumn{3}{|c|}{$\begin{array}{l}\text { (US\$ million) } \\
\text { TOTAL }\end{array}$} \\
\hline & \multicolumn{2}{|c|}{2005} & \multirow{2}{*}{ TOTAL } & \multicolumn{2}{|c|}{2006} & \multirow{2}{*}{ TOTAL } & \multicolumn{2}{|c|}{2007} & \multirow{2}{*}{ TOTAL } & \multicolumn{2}{|c|}{ 2005-2007 } & \multirow[t]{2}{*}{ TOTAL } \\
\hline & INV & REC & & INV & REC & & INV & REC & & INV & REC & \\
\hline $\begin{array}{l}\text { Pillar 1 - Promote } \\
\text { good governance, } \\
\text { strengthening } \\
\text { efficiency and } \\
\text { guaranteeing equity }\end{array}$ & 2 & 5 & 7 & 2 & 4 & 6 & 0.9 & 4 & 5 & 4 & 13 & 17 \\
\hline $\begin{array}{l}\text { Pillar 2-Promote } \\
\text { competitiveness to } \\
\text { improve economic } \\
\text { growth and } \\
\text { employment } \\
\text { creation }\end{array}$ & 17 & 4 & 21 & 17 & 4 & 21 & 18 & 4 & 22 & 53 & 12 & 64 \\
\hline $\begin{array}{l}\text { Pillar } 3 \text { - Develop } \\
\text { and upgrade } \\
\text { human capital }\end{array}$ & 22 & 14 & 36 & 16 & 13 & 29 & 8 & 13 & 21 & 46 & 39 & 85 \\
\hline $\begin{array}{l}\text { Pillar 4 - Improve } \\
\text { and develop basic } \\
\text { infrastructure, } \\
\text { promote land use } \\
\text { planning, and } \\
\text { protect the } \\
\text { environment }\end{array}$ & 108 & 3 & 111 & 98 & 2 & 100 & 19 & 1 & 20 & 225 & 6 & 232 \\
\hline $\begin{array}{l}\text { Pillar 5 - Improve } \\
\text { the social } \\
\text { protection system, } \\
\text { strengthen its } \\
\text { efficiency and } \\
\text { guarantee } \\
\text { sustainability }\end{array}$ & 11 & 10 & 21 & 11 & 10 & 21 & 10 & 9 & 19 & 31 & 29 & 60 \\
\hline TOTAL & 160 & 36 & 196 & 144 & 33 & 177 & 55 & 31 & 86 & 359 & 99 & 459 \\
\hline
\end{tabular}

${ }^{70} 1 \mathrm{US} \$=88,837 \$ \mathrm{ECV}\left(\mathrm{BCV}\right.$ exchange rate for July $\left.20^{\text {th }}, 2004\right)$ 
Table 5-1-2: Investment and recurrent expenditures for the GPRS, by sector

\begin{tabular}{|c|c|c|c|c|c|c|c|c|c|c|c|c|}
\hline \multirow{4}{*}{ SECTORS } & \multirow{2}{*}{\multicolumn{9}{|c|}{ BUDGET }} & \multirow{3}{*}{\multicolumn{2}{|c|}{$\begin{array}{c}\text { Budget } \\
2005-2007 \\
\end{array}$}} & \\
\hline & & & & & & & & & & & & \multirow{3}{*}{ TOTAL } \\
\hline & \multicolumn{2}{|c|}{2005} & \multirow{2}{*}{ TOTAL } & \multicolumn{2}{|c|}{2006} & \multirow{2}{*}{ TOTAL } & \multicolumn{2}{|c|}{2007} & \multirow{2}{*}{ TOTAL } & & & \\
\hline & INV & REC & & INV & REC & & INV & REC & & INV & REC & \\
\hline $\begin{array}{l}\text { PUBLIC } \\
\text { ADMINISTRA- } \\
\text { TION }\end{array}$ & 0,3 & 2 & 2 & 0.3 & 0.03 & 0.3 & 0.3 & 0.03 & 0.3 & 0.8 & 2 & 3 \\
\hline $\begin{array}{l}\text { AGRICULTURE, } \\
\text { FOOD SECURITY, } \\
\text { AND FISHERIES }\end{array}$ & 26 & 5 & 31 & 26 & 6 & 31 & 26 & 6 & 32 & 78 & 17 & 94 \\
\hline Environment & 14 & 2 & 16 & 14 & 2 & 16 & 15 & 2 & 17 & 44 & 6 & 50 \\
\hline ECONOMY & 6 & 0.7 & 7 & 5 & 0.3 & 6 & 4 & 0.3 & 5 & 16 & 1 & 17 \\
\hline Tourism & 0.4 & 0.01 & 0.5 & 0.4 & 0.08 & 0.5 & 0.4 & 0.04 & 0.4 & 1 & 0.2 & 1 \\
\hline Industry & 2 & 0.6 & 3 & 2 & 0.3 & 3 & 2 & 0,2 & 3 & 7 & 1 & 8 \\
\hline Energy & 4 & 0 & 4 & 3 & 0 & 3 & 1 & 0 & 1 & 8 & 0 & 8 \\
\hline EDUCATION & 9 & 7 & 17 & 8 & 6 & 14 & 6 & 5 & 12 & 23 & 19 & 43 \\
\hline $\begin{array}{l}\text { FINANCE AND } \\
\text { PLANNING }\end{array}$ & 1 & 3 & 5 & 1 & 3 & 5 & 0.7 & 4 & 4 & 4 & 11 & 14 \\
\hline $\begin{array}{l}\text { BASIC } \\
\text { SANITATION }\end{array}$ & 17 & 0 & 17 & 24 & 0 & 24 & 4 & 0 & 4 & 46 & 0 & 46 \\
\hline $\begin{array}{l}\text { BASIC AND } \\
\text { TRANSPORT } \\
\text { INFRASTRUCTU- } \\
\text { RE }\end{array}$ & 80 & 2 & 82 & 64 & 2 & 66 & 6 & 0.5 & 6 & 149 & 5 & 154 \\
\hline JUSTICE & 0 & 0.2 & 0.2 & 0 & 0.5 & 0.5 & 0 & 0.4 & 0.4 & 0 & 1 & 1 \\
\hline $\begin{array}{l}\text { SOCIAL } \\
\text { PROTECTION }\end{array}$ & 7 & 8 & 15 & 7 & 8 & 15 & 6 & 8 & 14 & 20 & 24 & 44 \\
\hline Social Housing & 5 & 0 & 5 & 6 & 0 & 6 & 4 & 0 & 4 & 15 & 0 & 15 \\
\hline HEALTH & 13 & 6 & 19 & 8 & 6 & 14 & 1 & 7 & 8 & 23 & 19 & 42 \\
\hline TOTAL & 160 & 36 & 196 & 144 & 33 & 177 & 55 & 31 & 86 & 359 & 99 & 459 \\
\hline
\end{tabular}

337. Annex 2 presents the cost of the GPRS by pillar, sub-pillar and policy initiative.

338. It should be pointed out that the expenditures related to implementation of the GPRS are mainly due to the on-going reforms aimed at establishing the necessary mechanism to strengthen good governance and to improve the access to better quality services provided by the priority sectors of such strategy (social protection, and education). Considering national budget projections for the 2005-2007 period, the additional effort pertaining to implementation of the GPRS means an additional amount equivalent to $11 \%$ of recurrent expenditures of central public administration.

339. Recurrent expenditures associated to routine activities with impact on growth and poverty reduction, as well as derivative recurrent expenditures, will be estimated in the context of the Medium Term Expenditures Framework, currently in preparation.

340. On an annual basis, financing needs for the GPRS will be the following:

2005: US\$ 196 million

2006: US\$ 177 million

2007: US\$ 86 million. 
341. The amount of resources to be mobilized during the 2005-2007 period to finance implementation of the GPRS is estimated at US\$ 420 million, as US\$39 million have already been secured. In this regard, it should be pointed out that, during the 2004, a total of US\$ 162 million were mobilized for financing investment projects.

342. Budget policy will concentrate efforts on the following sectors and sub-sectors:

- Education

- Health and Social Security

- Good governance, economic and social reforms (including social protection), and Public Administration reform

- Training and upgrading human resources, namely with regards to professional training

- Environment and Basic Sanitation

- Agriculture, Fisheries, and Food Security

- Infrastructure and Transportation

- Social Housing.

\subsection{Sources of Financing:}

343. The poverty reduction strategy can be financed with internal and external resources provided by bilateral and multilateral development aid. The share of each source of financing depends on various factors among which we emphasize the capacity to mobilize the community of countries and donors around the objectives of poverty reduction and also Cape Verde's eligibility conditions to benefit from international aid.

344. The relatively high per capita income of Cape Verde and the high inequality of income distribution put the internal distribution mechanism at a very important level. In fact, Cape Verde's per capita income places it in the group of countries with medium income, which makes external financing an even more uncertain source, particularly for the medium and long run.

345. The likely graduation of Cape Verde's status from the least developed countries $(\mathrm{LDCs})^{71}$, even admitting the possibility of a transition phase allowing for gradual adjustment to the new conditions, could affect its eligibility in obtaining concessional credits. In such conditions, Cape Verde should strengthen its internal sources of financing in order to compensate for the reduction of aid and concessional credits. In practice, such orientations should be based on the improvement of the tax system, its efficiency and capacity to generate revenues.

\section{The role of the internal resources}

346. From the early 1990's, Cape Verde started various reforms of the fiscal system with the primary objective to improve its efficiency without affecting the economic growth. Three important phases can be distinguished: The first phase dates back to 1991 and had

\footnotetext{
${ }^{71}$ The LLDC status is based on a number of objective criteria analysed on a thre-year basis by the UN Economic and Social Council (ECOSOC). The inclusion criteria include per capita GDP, Human Capital Index and Economic Vulnerability Index. The specific eligibility limits are defined for each criterion: the limit for per capita GDP is currently US\$ 900. If a country exceeds the limits on two of the criteria it is then taken out of the LLDC list through a phased process. In the 2003 review it was found that Cape Verde was in such situation and, thus, the graduation of Cape Verde is awaiting a decision from the United Nations.
} 
as priority objectives the simplification of the fiscal system, the modernization of taxes, the widening of the tax basis and improvement of customs collecting system. The 1996 reform allowed the unification of the income and profit taxes with the establishment of a single income tax (IUR). Such tax replaced the tax on salary and incomes of independent workers as well as the tax on income, the surtax on additional incomes and surpluses. Finally, the January 2004 reform introduced the Value-Added Tax (VAT) and a new Tariff Code ${ }^{72}$.

347. Such reforms brought a significant increase in fiscal revenues, which in a decade went from $11 \%$ to near $20 \%$ of GDP. During this same period, non-fiscal revenues went from $4,3 \%$ to $2,4 \%$ of GDP. The tax reform brought about greater tax diversification and a decrease of the dependency on customs' revenues. It is expected that the introduction of the VAT will contribute to change the fiscal revenue structure and also increase the volume of internal resources. The improvement of measures to combat tax evasion and fraud will also contribute to increase the volume of State revenues.

348. Finally, the payment of total or part of debt by some public institutions constitutes an important financial source of resources whose scope is yet to be determined.

\section{The external resources}

349. Historically, Cape Verde benefited from a considerable flow of public aid to development. In the 80 's the external aid ratio to GDP was approximately $35 \%$. After that period, it significantly decreased over time and today it is between 10 and $15 \%$ of GDP. At such pace, external development aid could approach 5-8\% of GDP in the year 2010, which poses a serious constraint on budget and revenue policies.

350. A significant change in the structure of development aid in Cape Verde is the ever-decreasing share of grants and the corresponding increase in credits. There is also the tendency to replace bilateral aid for multilateral aid. Presently, the credit share is about 20 to $25 \%$ while in 1980 it did not go beyond $5 \%$. The credit weight should increase even more if Cape Verde leaves the group of the least developed countries. The ever-growing role of multilateral aid to Cape Verde will reinforce such tendency as the multilateral agencies apply very strictly the eligibility rules to the financing conditions reserved for a different group of countries.

351. Another change that occurred refers to the distribution of aid by sectors. Aid to social sectors that are easily associated with poverty alleviation policies has significantly increased during the last twenty years and presently corresponds to more than a $1 / 3$ of total public aid. Food aid, whose sale in the internal market allowed the financing of high intensity labor activities, should also be added to this total. Food aid did not account for more than $19 \%$ of total aid in the early 2000 s while by the late 80 's is was $30 \%$.

352. The decrease of public development aid poses some problems for various initiatives aimed directly at the poor population and also have global effects on poverty reduction policies. The most tangible example is the FAIMO activities that, over the years have been financed with counterpart funds of food aid. In percentage terms, food aid had decreased from $6-12 \%$ of GDP during the 80 's to $2-4 \%$ during the 90 's. This last allocation was used to finance high labor-intensive work whose cost is estimated at about 3-4\% of the GDP during that period. Presently, food aid does not represent more than 1 to $2 \%$ of the GDP which makes it difficult to finance labor-intensive works budgeted at about 1.6$1.7 \%$ of the $\mathrm{GDP}^{73}$. This estimate should be considered with some care as it was done

\footnotetext{
72 The most important aspects of the history of tax reform system are present in the IMF reports. Also see. MFP (2004).

${ }^{73}$ World Bank (2004), Public Expenditure Review
} 
based on data from the last four years, which are considered to be normal agriculture years. If a drought period was to be factored in with all the consequences for the rural population, the cost of FAIMO activities would increase thus bringing the respective pressure for its financing.

\section{Recent trends in aid conditions}

353. A clear tendency in external aid is the progressive substitution of bilateral aid for multilateral aid. There are various on-going programs financed by bilateral aid that are part of the poverty reduction policy. The cooperation strategy adopted by various countries and mainly by the multilateral organizations goes in the sense of channeling financial aid to State budget of the beneficiary country, which has profound implications on budget management. In fact, by grouping all financial resources, both internal and external funding under budget creates more favorable conditions for efficient budget management and a better allocation of funds to the policy objectives.

354. However, this new approach can only be viable if based on a credible planning and budgeting system. It requires planning by objectives as basis and that the objectives be verifiable with basis on appropriate performance indicators. Cape Verde has all conditions to be considered eligible for this type of aid considering that its macro-economic situation is stable (first eligibility condition) it will soon have final its PRSP (second condition) and has an on-going budget reform that will assure reliability of the financial system (third condition).

355. It is precisely in this sense that the CFAA Action Plan will implement the recommendations aimed at budget system reform.

356. There are yet some on-going projects with bilateral financing that should significantly influence the evolution and extent of the characteristics of poverty ${ }^{74}$.

\section{Financing for the poverty reduction strategy}

357. Cape Verde's sustainable per capita income growth and the decrease of bilateral aid during the last 15 years calls for a poverty reduction strategy based on gradual increase of internal resources. The good performance of the fiscal reforms and the consequent increase in budget revenues should facilitate this new role distribution between internal and external financing.

358. Such change has a number of advantages. Firstly, an increase of internal resource in the financing of the strategy is a warranty of greater ownership of the poverty reduction policy by the government and by the civil society. It would also be a warranty of greater efficiency of the programs being that the decision makers would have greater incentives to minimize implementation costs and to maximize the effects to reduce poverty now that internal financing has an important role in financing the strategy.

\section{Which partnership strategy?}

359. Cape Verde is presently at a crossroad, coming from high economic growth associated to a limited distribution of income and going to a paradigm shift of greater internal distribution to fight poverty and inequalities and support economic growth.

\footnotetext{
${ }^{74}$ For a detailed presentation see MFP/PNUD (2004 b) e MFP/PNUD (2004 d).
} 
360. The resource mobilization strategy is thus established based on the following vectors:

- Assumption of the GPRSP as the reference document for resource mobilization;

- Continuation of cooperation with multilateral partners based on the PRGF (IMF), the PRSC (World Bank) and the CIP (European Union);

- Global coordination with the development partners through appropriate mechanisms;

- Development of multilateral framework of cooperation with bilateral partners in order to increase the reliability of financial funds;

- Development of incentive mechanisms for foreign investment considering the development of export of goods and services;

- Development of measures to motivate emigrants' remittances as partial financing for the economy. 


\section{The participative process of the GPRS}

361. As a framework document that establishes the Government's priority objectives for economic growth and poverty reduction, the Growth and Poverty Reduction Strategy has a strong link to: the public investment program, the privatisation process, the fiscal policy and the education, health, agriculture, environment and social protection plans. For such reason, the elaboration of this document was based on a widespread consultation and dialog process aimed at congregating efforts in establishing better options for poverty reduction in Cape Verde. Following the same participative approaches that characterized the elaboration of the main national policy instruments, the formulation of the GPRSP was formally started in August 2003 involving various levels of dialogue: i) overall, involving the administration, civil society and the private sector; ii) at thematic level by taking stock of participative processes related to reference documents that support the GPRS; iii) and with the development partners.

\section{General participation, involving the administration, civil society and the private sector}

362. At this level, the National Coordination Commission (CNC) is composed by: i) representatives of line Ministries directly involved in the process; ii) representatives of the civil society and the private sector; iii) representatives of local governments. A total of 20 members make up the coordinating pivot of the process and the orientation and decisionmaking body for all relevant matters of this process. The line Ministries were represented by the Directors of the respective GEPs, the civil society was represented by the President of the platform of NGOs, the private sector by the Superior Council of the Chambers of Commerce and the Municipalities were represented by the National Association of Municipalities.

363. Acting under the authority of the Ministry of Finance and Planning, the CNC worked continually on gathering, treating and disseminating information and, as appropriate, participating in the elaboration of basic documents so that ideas and proposals from sectors and entities integrating the GPRSP process could be taken in consideration. Lastly, as a collegial body, it secured the logic and coherence of the overall set of policy measures that make up the strategy. As a last task of its mandate, the CNC gave its approval to the final version of the GPRSP submitted for approval to the Council of Ministers.

Thematic participation, through appropriation of results from participative processes related to reference and support instruments to the GPRS

364. The GPRS reflects the appropriation of valuable contributions that made possible the elaboration of the GOP (finalized in January 2002). The GOP is seen as a document that embodied long-term major national development projects and a reference framework document for the GPRS. Thus, the participative process that enabled the formulation of the GOP indirectly guaranteed the sharing and discussion with citizens both residents and in the Diaspora, of key elements that make up the central policies of this strategy. Such sharing, besides the involvement of the administration the private sector and civil society, it consolidated in the auscultation of the political parties, labor organizations and employers' representatives. It should be mentioned that the participative process continued with the elaboration of the National Development Plan (NDP) and the sector strategic plans as supporting documents of the GPRS that also reinforces the participative ways that supported the elaboration of this strategy. 
365. In the same line of thought, and having present the strong relationship between the environment and poverty issues, the participative process that supported the formulation of the Second National Action Plan for the Environment (PANA II) is widely reflected in the GPRS. The elaboration of PANA II based on various thematic studies also includes the following components and phases: i) A Master Plan that involves various partners including central and local government, civil society and private sector; ii) Municipal Environmental Plans formulated in close collaboration between the Environmental Group of the ANMCV and municipal environment teams from the assessment, planning and validation phases; iii) Inter-Sector Environmental Plans that reflect the issues and plans of the various line Ministries and agencies directly involved in environmental issues.

366. As an inspiring document of the poverty reduction strategy, the National Poverty alleviation Program (NPAP) greatly contributed to the participative approach used in the GPRSP by making available all its experience of three years of sensitisation, mobilization, information and communication efforts in terms of intervention strategies, human resource management and procedures in dealing with partners at local level.

\section{Participation by development partners}

367. Throughout the elaboration of the GPRSP, representatives of multilateral and bilateral organisations were called to participate. I) First, the forum specifically organized for the GPRSP issue took place on August 1st 2003 under the auspices of the World Bank, contributed to the elaboration of the "good practice" matrix that guided those in charge of the process; ii) a meeting with the representatives of the United Nations system on December, 4th 2003, made possible the exchange of ideas and information about the elaboration process of the GPRSP; iii) coordination with UNDP on pro-poor policies; iv) coordination with the process of elaborating the national report on MDGs; v) various separate meetings that took place to discuss the implementation process; vi) a meeting to present and analyse the first version of the GPRSP took place on May $14^{\text {th }}, 2004$; vii) two video-conference sessions took place on April $20^{\text {th }}$ and May $6^{\text {th }}, 2004$, thus allowing CNC members to discuss ideas on "results approach" with World Bank specialists"; and finally viii) an workshop organized on May 20 and $21^{\text {st }}, 2004$ with the support of the World Bank to jointly review the projected policy matrices of the GPRS.

\section{The participative approach in the implementation of the GPRS}

368. The implementation of the DGPRS will require strong involvement of all parties: public and private institutions, development partners, civil society and the private sector. It will mainly require that organized groups position themselves as active stakeholders as a condition for the GPRS to have a rapid and lasting impact on the life of the poorest. In this sense, the implementation, monitoring and evaluation mechanisms include appropriate representatives to facilitate dialogue and permanent coordination at various levels and also extended to the entire country.

369. As a first step of coordination efforts on the implementation, monitoring and evaluation of the GPRS, until end of October various workshops will take place at central level and in each island. At regional/local level this activity will be organized in close coordination with the municipal entities, representative services of the central government, as well as local and regional commission of partners.

370. The participative process will continue throughout the implementation phase of the GPRS. The efficiency and depth of the participative process will be the subject of periodical evaluations that the implementation phase will be subjected to. The process will be supported by a Communication Plan that has been elaborated and aims specifically at: 
- The sensitisation of public opinion on the principles, objectives and goals that the GPRSP proposes to reach;

- The establishment of a favorable communication environment that enables accountability and transparency;

- The establishment of a dynamic communication strategy that warrants continuity of the GPRSP process based on the premise that the dissemination of information about results achieved in each phase will encourage the development of subsequent efforts;

- The mobilization of different communication actors from the public and private spheres, thus motivating the circulation of information about the GPRSP;

- The management of expectations on the premise that not all planned objectives and expected results with the implementation of the GPRSP will be achieved during the time established timeframe. 


\section{IMPLEMENTATION, MONITORING AND EVALUATION OF THE GPRS}

371. The Government envisages an integrated approach to implementation, monitoring and evaluation of the growth and poverty reduction strategy. In practical terms, the strategy will be carried out through sectoral action plans and priority development programs and projects seeking to achieve the goal of poverty reduction through sustained economic growth.

372. The process will involve various actors, namely the Ministry of Finance, line ministries and their decentralized departments, as well as decentralized services, namely municipalities, civil society organizations, and the private sector. Monitoring and evaluation will be participative and involve various central and local entities.

\subsection{Implementation mechanisms}

373. Implementation of the strategy will follow the management system for public programs, with strong contribution from community-based organization, decentralized entities and private sector entities with regards to supply of goods and services. The scheme stands on three fundamental mechanisms:

- Medium term financial and budget programming using the Medium Term Expenditure Framework (MTEF), currently being designed;

- Public expenditure execution and control system, currently in the implementation phase;

- Procurement system for public goods and services, also in the design phase.

\section{Establishing a Medium Term Expenditure Framework (MTEF)}

374. To support implementation of the GPRS the Government established, starting with the 2005 national budget, a Medium Term Expenditure Framework (MTEF) and Medium Term Sectoral Expenditure Frameworks (MTSEF), based at key line ministries. It is expected that such a set-up will improve: i) prioritising programs and projects that directly contribute towards the GPRS objectives and the sectoral objectives; ii) budgeting of programs and projects according to resources that can be mobilized; iii) medium term (three years) budget allocation according to priorities in order to reach the established development targets.

375. The MTEF and the MTSEF will allow for implementation of the GPRS by means of a schedule for using public resources according to a balanced macroeconomic framework. In addition to making forecasts of resource flows more reliable, this system will facilitate the establishment of a resource allocation system that is transparent and in line with national and sectoral strategic priorities.

376. The MTEF and the MTSEF will be the main tools for Government decision making with regards to financial resource allocation and utilization. They also provide an operating framework for intervention by donors and financing entities, which will be invited to introduce their contribution to the development process. The MTEF will be the reference for budget support aid, thus replacing the traditional mechanism of financing development projects.

377. Additionally, the Government will consolidate the financial information and management system (FIMS), in order to guarantee efficient monitoring of the implementation of public programs and projects, as well as better control of public 
resources. The system allows for budget consolidation at various levels, on the basis of standardized codes, as well as better identification of public resource circuits.

\section{Institutional framework for implementation of the GPRS}

378. An important portion of the priority programs and projects included in the GPRS will continue to be implemented by public administration services. However, the Government wishes to further the decentralization process by engaging local public services, civil society and the private sector in the implementation of poverty reduction programs and projects. To this end, municipalities and community organizations will have access to more resources in the context of existing budget mechanisms to finance priority programs and projects included in the GPRS.

379. The institutional framework for implementing the GPRS will consist of the existing administrative apparatus, after the necessary functional changes in structure are introduced. Establishment of a MTEF and a MTSEF call for a homogeneous approach by all participating line ministries, to allow for consolidation of programs and budgets by the MFP. In particular, the following entities will be used:

\section{Technical entities:}

380. At the central level, the General Directorate of Planning will be responsible for coordination and support to the MTEF process. Its role will be to: (i) support line ministries in preparing the MTSEF; (ii) train staff of line ministries involved in developing the MTEF approach and its implementation; (iii) coordinate the process of MTSEF preparation, according to GPRS guidelines; (iv) consolidate the various MTSEF and the annual programs and budgets, in collaboration with the General Directorate of Budget; ( $v$ ) prepare arbitration proposals for the line ministries and other decision making entities; (vi) support the search for additional resources to fight poverty; (vii) support the preparation of a system to monitor the implementation of sectoral programs and projects; (viii) cooperate with the General Directorate of Budget in preparing monitoring reports about execution of growth and poverty reduction programs.

381. Budget execution and control will be carried out by the traditional departments (General Directorates of Budget and Treasury, Inspectorate General of Finances, Court of Accounts), which will continue playing their traditional roles. However, this will occur in a reformed and strengthened environment, as envisaged under the CFAA/CPAR action plan.

382. At the sectoral level, the GEPs within each line ministry will be in charge of preparing the MTSEF and of monitoring/evaluating the priority programs and projects. Each GEP Director is technically in charge of the MTSEF process and will also be the focal point for the MTEF process for the respective ministry. The GEPs will work in close coordination with the offices of the respective ministers and the various departments within each ministry, including the General Directorate of Planning, to: (i) define the sectoral goals for the priority programs and projects; (ii) prepare annual budgets in the context of the MTEF and (iii) monitor and evaluate programs and projects being implemented.

383. With regards to implementation of programs and projects included in the GPRS, the arrangement resulting from the integration of administration and technical units will be used. In this regard, the Inspectorate General for Finances will increase its interventions in the priority line ministries. 


\section{Advisory bodies:}

384. To encourage involvement in the MTEF process and its ownership by national stakeholders (private sector, NGOs, local communities) the Government plans to submit the MTSEF and the MTEF to the National Poverty Reduction Board for discussion and validation before the arbitration by the Minister of Finance.

\section{Decision making bodies:}

385. Arbitration with regards to objectives, programs/projects and budgets will occur at the following levels: i) Department Heads within each line ministry; ii) offices of the Ministers; iii) the Minister of Finance, after comments by the National Poverty Reduction Board; iv) Council of Ministers. This process will lead to adoption of a budget framework law.

\section{Risks related to implementation of the GPRS}

386. Execution of the GPRS involves the introduction of deep reforms in the planning, budgeting, execution and control of public programs. Even though these reforms have been identified and some are already under way, there are still some risks involving the institutional capacity to implement the programs and projects included in the GPRS. Public administration needs support to develop instruments such as the MTEF, the MTSEF, and the financial information and management system, as well as for preparation and implementation of execution and control procedures. The Government will use a gradual approach for establishing the MTEF and the MTSEF in order to ensure ownership of these instruments by national cadres. Specifically, enough time will be given to line ministries to adapt to the required institutional changes.

387. There are also risks at the institutional level, considering that an important portion of the GPRS will be implemented by decentralized entities, including organizations from civil society. These entities are weak in the area of operational planning, execution of programs and projects, as well as their monitoring. In the context of the decentralization policy, considerable efforts will be made to afford communities and associations the resources needed for better assuming the development process.

\subsection{Monitoring and evaluation mechanisms for the GPRS}

388. The Government will set up a monitoring and evaluation system for the GPRS to guide the actions of the various actors involved in promoting growth and poverty reduction. In addition to governmental departments, the system will include organizations from civil society, as well as the development partners..

\section{Goals and components of the monitoring and evaluation system for the GPRS}

389. The Government intends to ensure the following functions in the context of the monitoring and evaluation system:

- monitoring and analysis of trends in growth, poverty, vulnerability and inequality;

- monitoring the execution of programs and projects that contribute to improved growth and poverty reduction;

- evaluation of the impact of policies and programs related to growth and poverty reduction. 
390. This system will include three core components and two support components.

i. A monitoring and trend analysis component, with the following objectives:

- Monitor a limited number of indicators of the macroeconomic environment and the performance of the main economic sectors, thus providing guidelines for macroeconomic and sectoral policies;

- Monitor a small number of quality of indicators of quality of life, poverty, vulnerability and inequality, broken down by gender, geographic location and socio-economic group (poor / non poor);

- Identify the most poor areas and groups, as a basis for intervention and resource allocation;

- Understand the causes of growth and poverty developments, be them exogenous or endogenous;

- Monitor and understand developments in poverty over time;

- Monitor performance and impact indicators selected in the context of the pillars of the GPRS, and measure deviation from development targets.

ii. An execution component, with the following objectives:

- Monitor allocation of budget resources among priority programs and projects included in the GPRS;

- Monitor activity indicators for programs and projects;

- Monitor the degree of materialization of the outputs targeted by the programs and projects included in the GPRS;

- Analyse the relationship between inputs used and outputs as a result of implementation of the priority programs and projects.

\section{iii. Impact evaluation of policies and programs}

391. By evaluating the impact of the various policies, programs and projects on growth, quality of life and poverty reduction, the Government will be able to assess the effectiveness of these programs and projects, as well as get valuable insights for the preparation of new programs. The Government intends to immediately start strengthening capacities in this area.

\section{iv. Support components for the monitoring and evaluation of the GPRS}

392. Cape Verde's experience shows that it makes no sense to collect, process and analyse information unless the resulting product is made accessible, validated and used by decision makers in drafting policies, development programs and projects, as well as being made available to the general public.

- The first support component involves creation of a physical, technical institutional and human environment that is conducive to better circulation of data, information and outputs between producers and users. The Government intends to improve the public 
information system, namely by strengthening the National Statistical System (NSS) and the information system being developed by NOSI. In time, this system will allow for integration of financial and administrative data in a single database, as well as create, within the NSS, the conditions for centralizing, certifying and accessing official statistical data to meet the challenges of monitoring and evaluating the GPRS as well as the Millennium Development Goals.

- The second support component involves improving information dissemination, aiming at a participated policy dialogue among the various stakeholders and, eventually, better design and execution of public policy. To this end, the Government has promoted the preparation of a participation strategy, in the context of the GPRS. It is expected that such a strategy will encourage dialogue within society and lead to widespread participation of the population in the debate on development and fight against poverty.

\section{Institutional Framework for monitoring and evaluation of the GPRS}

393. The Government has decided to set up the following three-tiered institutional framework for monitoring and evaluation of the GPRS:

- 1. National Poverty Reduction Board

- 2. The Observatory and Analytical System

- 3. Regional Poverty Reduction Boards.

\section{i. National Board for Poverty Reduction}

394. The National Poverty Reduction Board (NPRB) is a broad-based entity responsible for monitoring and supporting political decisions in the areas of growth and poverty reduction. NPRB will be presided by the cabinet member in charge of Planning and will have the following members:

- Ministry of Health

- Ministry of Education

- Ministry of Labor

- Ministry of Social Affairs

- Ministry of Environment, Agriculture, and Fisheries (represented by the environment)

- Ministry of Foreign Affairs (General Directorate of International Cooperation)

- Ministry of Infrastructure and Transports

- Ministry of Public Administration

- Bank of Cape Verde

- National Institute of statistics

- Institute of Women Affairs

- National Association of Municipalities

- Superior Council of the Chambers of Commerce

- NGO Plataform

- MFP Departments in charge of preparing and implementing the budget (Planning, Budget, Treasury, Taxes, and Public Property)

- Representatives of associations (women, youth, farmers, retired people)

- Representatives of confederations of labor unions 
Figure 7-1: Institutional framework for monitoring and evaluating the GPRS

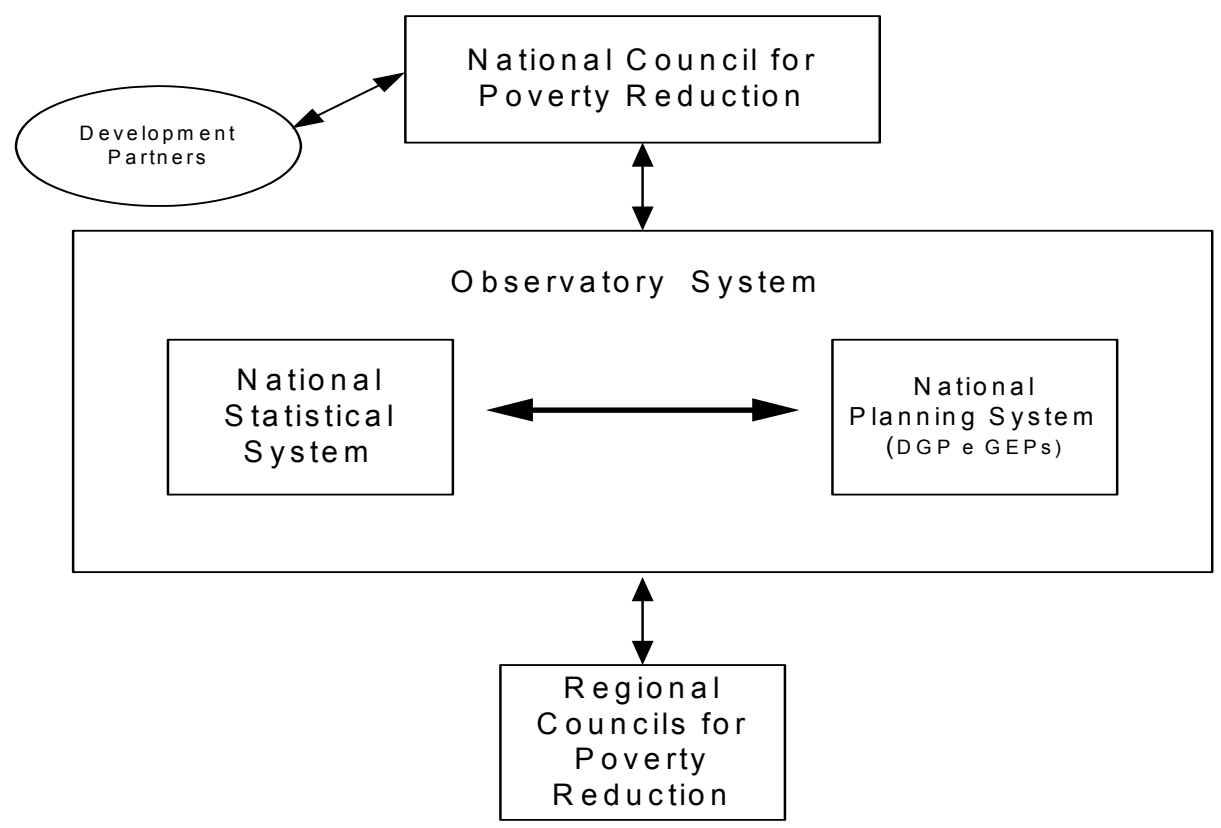

395. The NPRB will play an advisory role consisting of the following:

- Monitor the status of implementation of the GPRS with basis on periodic progress reports prepared by STAD a the national level and, at first, by the GEPs of involved ministries;

- Advise the Government on the relevancy of policies and programs related to growth and poverty reduction;

- Propose the calendar and discussion topics in the context of the annual review of the GPRS;

- Discuss and validate the results of works in the context of the MTEF process (global framework, proposals for allocation of budget resources, etc).

\section{ii. The Observatory and Analytical System}

396. The Observatory and Analytical System is made up of two components: The National Statistical System and the National Planning System. The two systems guarantee the necessary observation and analysis, and supply the National Poverty Reduction Board the inputs (namely studies) for monitoring and drafting growth and poverty reduction policies. The Observatory and Analytical System will include statistic observation and indicator information, namely for monitoring output and impact indicators.

397. INE and the STAD play a key role in the operation of the system: INE in its areas of responsibility as the central component of the National Statistical System, and the STAD in light of the general responsibilities and the role of the Directorate General of Planning, within the broader context of the National Planning System.

\section{National Statistical System (NSS)}

398. NSS is responsible for production of essential statistics, general and specific access to each group of users, specially the STAD, as well as other users along the GPRS monitoring and evaluation chain. 
399. Implementation of the GPRS will be a landmark for definition of NSS priorities, as well as an opportunity for strengthening the NSS with regards to both its capacity and availability of statistical information. To this end, the Government will seek resources for implementing the Statistical Agenda for Development, as well as the establishment of adequate institutional conditions for statistical activity in Cape Verde.

\section{National Planning System (NPS)}

400. NPS is responsible for the planning function with a view to implementation of the GPRS. In this context, NPS will guarantee the monitoring of the implementation of programs and projects by the departments in charge, namely line ministries. In this context, the Technical Secretariat will be responsible specifically for:

- Act as secretariat to the National Poverty Reduction Board, namely by preparing Board meetings;

- Coordinate implementation and monitoring of Board decisions;

- Look after the national institutions and entities involved in the process of monitoring and evaluating the GPRS, and support them in playing their roles;

- Promote the studies and results produced by the various national entities, with a view to supporting the decision making process;

- Take part in output dissemination and work so they may be taken into consideration in the decision making process;

- Produce an annual GPRS progress report on the basis of the sectoral reports drafted by the GEPs and by the municipalities.

401. NOSI shall provide the necessary technological support in terms of ICTs so that the General Directorate of Planning and the Technical Secretariat may be able to monitor the implementation of programs and projects, as well as supply information to INE for the purposes of National Accounts.

402. The Technical Secretariat is managed by the General Director of Planning, who is supported by a Coordinator and teams of specialists from various areas.

\section{iii. Regional Poverty Reduction Boards}

403. The Regional Poverty Reduction Boards (RPRB) are made up of:

- Municipality

- Municipal Office of the Ministry of Health

- Municipal Office of the Ministry of education

- Municipal Office of the Ministry of Environment, Agriculture, and Fisheries

- Municipal Office of the Ministry of Finance and Planning

- Regional Stakeholders Board or Local Stakeholders Board

404. The RPRBs play an advisory role that essentially covers, at first, approving activity proposals for the GPRS and validation of the annual GPRS progress report. 


\subsection{Performance indicators for the GPRS}

405. The Growth and Poverty Reduction Strategy will be implemented through a three level goal-oriented plan: the strategic pillar level, the strategic sub-pillar level and the priority measure level. Each of these three levels is introduced by their own goal and its materialization is verified by a system of indicators. The indicators are of three types: materialization indicators, outcome indicators and impact indicators. Materialization indicators reflect the immediate and tangible effects of the activities (supply side analysis). Outcome indicators describe the effects that the activities have on the beneficiaries (demand analysis). Impact indicators represent the effects on the socio-economic system and are thus more directly related to policymaking.

406. The indicators to be used in monitoring and evaluating the GPRS follow the principles listed below:

- The complete set of indicators should be used as reference by all donors that cooperate with Cape Verde. This way, a multiplicity of donor-specific indicators will be avoided;

- Indicators for monitoring the strategy are located at the pillar and sub-pillar levels, thus being directly related with the policy objectives;

- Each measure or action is defined by its own objective, to which a materialization indicator is attached and, when necessary, an outcome indicator as well;

- The defined indicators are directly or indirectly related to the "millennium indicators";

- Time verification of each indicator is carried out using benchmarks. Benchmarks are the quantitative or qualitative version of the indicator in each year of implementation of the GPRS.

407. The following table show the indicators to be used in monitoring the GPRS. 
- Table 7-1: Indicators for monitoring the Growth and Poverty Reduction Strategy in Cape Verde

\begin{tabular}{|c|c|c|c|c|c|}
\hline \multicolumn{6}{|c|}{ PILLAR 1} \\
\hline \multicolumn{6}{|c|}{ PROMOTE GOOD GOVERNANCE, REINFORCING EFFECTIVENESS AND GUARANTEEING EQUITY } \\
\hline & \multirow[t]{2}{*}{ MACROECONOMIC INDICATORS } & \multicolumn{4}{|c|}{ FORECAST } \\
\hline & & 2004 & 2005 & 2006 & 2007 \\
\hline 1 & Per capita GDP growth rate & $3.6 \%$ & $4.1 \%$ & $4.5 \%$ & $5.0 \%$ \\
\hline 2 & Real GDP growth rate & $5.5 \%$ & $6 \%$ & $6.5 \%$ & $7 \%$ \\
\hline 3 & Inflation rate & $1.0 \%$ & $2 \%$ & $2 \%$ & $2 \%$ \\
\hline 4 & Budget deficit (\% of GDP) & -4.3 & -7.6 & -7.3 & -6.1 \\
\hline \multirow[t]{3}{*}{5} & International reserves (in months of imports) & 2 & 2.3 & 2.5 & 2.8 \\
\hline & & \multicolumn{4}{|c|}{ BENCHMARKS } \\
\hline & Other indicators of good governance & Base & 2005 & 2006 & 2007 \\
\hline 6 & Poor (\%of population) & 36.7 & & & \\
\hline 7 & Very poor ( $\%$ of population) & 19.7 & & & \\
\hline 8 & MTEF drafted and approved by Ministries & 3 & 4 & 5 & \\
\hline 9 & Environmental expenditures (\% of National Budget) & & $3 \%$ & $4 \%$ & $4 \%$ \\
\hline 10 & Education expenditures (\% of National Budget) & $20 \%$ & $22 \%$ & $22.5 \%$ & $23 \%$ \\
\hline 11 & Health expenditures (\% of National Budget) & $6.3 \%$ & $6.5 \%$ & $7 \%$ & $7 \%$ \\
\hline \multicolumn{2}{|c|}{ PILLAR 2} & \multicolumn{4}{|c|}{ BENCHMARKS } \\
\hline \multicolumn{2}{|r|}{$\begin{array}{|llll|}\text { PROMOTE COMPETITIVENESS } & \text { TO } & \text { FOSTER } & \text { ECONOMIC } \\
\text { GROWTH AND JOB CREATION } & & & \\
\end{array}$} & Base & 2005 & 2006 & 2007 \\
\hline 12 & Direct investment (net, US\$ million) & 1,484 & 3,648 & 5,465 & 6,066 \\
\hline 13 & Unemployment rate & 17.3 & & & \\
\hline 14 & Homes connected to power grid (\%) & & $70 \%$ & $75 \%$ & $78 \%$ \\
\hline 15 & Number of overnight stays / tourist & 832,000 & & & \\
\hline \multicolumn{2}{|c|}{ PILLAR 3} & \multicolumn{4}{|c|}{ BENCHMARKS } \\
\hline \multicolumn{2}{|r|}{ DEVELOP AND UPGRADE HUMAN CAPITAL } & Base & 2005 & 2006 & 2007 \\
\hline & Education & & & & \\
\hline 16 & Nr. of people with professional training & 7,453 & & & \\
\hline \multirow[t]{2}{*}{17} & Adult literacy rate (15 to 49 year old) & $86.4 \%$ & $88.5 \%$ & $89.2 \%$ & $90 \%$ \\
\hline & $\mathrm{F}$ & $83.4 \%$ & $85.5 \%$ & $86.2 \%$ & $87 \%$ \\
\hline \multirow[t]{2}{*}{18} & Early childhood coverage rate $(0-5$ years old $)$ & $54 \%$ & $58 \%$ & $62.5 \%$ & $67 \%$ \\
\hline & $\mathrm{F}$ & $52 \%$ & $59 \%$ & $63.5 \%$ & $68 \%$ \\
\hline 19 & Proportion of children completing basic education within 6 years & $44.6 \%$ & $46.6 \%$ & $47.3 \%$ & $48 \%$ \\
\hline 20 & Secondary education gross admission rate & $81.5 \%$ & $82 \%$ & $82.5 \%$ & $83 \%$ \\
\hline \multirow[t]{2}{*}{21} & $\begin{array}{l}\text { Proportion of secondary education students attending the } \\
\text { technical branch }\end{array}$ & $7.4 \%$ & $8.5 \%$ & $10.1 \%$ & $9.2 \%$ \\
\hline & Health & & & & \\
\hline 22 & $\%$ of population with easy access to health facilities & $35 \%$ & $47 \%$ & $76 \%$ & $80 \%$ \\
\hline 23 & Infant mortality rate (per 1,000$)$ & 28.2 & & & \\
\hline
\end{tabular}




\begin{tabular}{|c|c|c|c|c|c|}
\hline 24 & Maternal mortality rate (per 100,000 ) & 7.6 & & & \\
\hline 25 & Immunization rate ( $\%$ of children under 1 year old) & & $80 \%$ & $85 \%$ & $90 \%$ \\
\hline 26 & $\begin{array}{l}\text { Change in occurrence of infectious and parasitical disease } \\
\text { (reduction) }\end{array}$ & & $3 \%$ & $6 \%$ & $10 \%$ \\
\hline 27 & Occurrence of HIVIAIDS on attended pregnant women & & $1.1 \%$ & $1.1 \%$ & $1 \%$ \\
\hline 28 & Children underweight (under 5, per 10,000 & $55,4 \%$ & & & \\
\hline \multicolumn{2}{|c|}{ PILLAR 4} & \multicolumn{4}{|c|}{ BENCHMARKS } \\
\hline \multicolumn{2}{|r|}{\begin{tabular}{|lcccccc} 
IMPROVE & AND & DEVELP & BASIC & \multicolumn{2}{c}{ INFRASTRUCTURE, } \\
PROMOTE & LAND & USE & PLANNING, AND & PROTECT & THE \\
ENVIRONMENT & & & & &
\end{tabular}} & Base & 2005 & 2006 & 2007 \\
\hline 29 & Proportion of families connected to water grid & $25 \%$ & $50 \%$ & $65 \%$ & $80 \%$ \\
\hline 30 & Percentage of families connected to power grid & $58.5 \%$ & & & \\
\hline 31 & Proportion of families with access to sewerage grid & $11.5 \%$ & $30 \%$ & $50 \%$ & $65 \%$ \\
\hline 32 & Population with access to solid waste collection system & & $40 \%$ & $50 \%$ & $55 \%$ \\
\hline 33 & $\begin{array}{l}\text { Area covered by micro-irrigation infrastructure }(\% \text { of total } \\
\text { irrigated area) }\end{array}$ & & $15 \%$ & $20 \%$ & $25 \%$ \\
\hline 34 & Number of watersheds with operational plans & & $5 \%$ & $10 \%$ & $15 \%$ \\
\hline \multicolumn{2}{|c|}{ PILLAR 5} & \multicolumn{4}{|c|}{ BENCHMARKS } \\
\hline \multicolumn{2}{|r|}{$\begin{array}{l}\text { IMPROVE THE EFFECTIVENESS AND SUSTAINABILITY OF } \\
\text { THE SOCIAL PROTECTION SYSTEM }\end{array}$} & Base & 2005 & 2006 & 2007 \\
\hline 35 & $\begin{array}{l}\text { Population covered by a social protection system (\% of total } \\
\text { population) }\end{array}$ & & $10 \%$ & $20 \%$ & $30 \%$ \\
\hline 36 & Number of Minimum Social Security pensioners & 6,514 & 7,600 & 8,600 & 9,500 \\
\hline 37 & Number of Social Solidarity pensioners & 9,373 & 12,500 & 14,200 & 16,000 \\
\hline
\end{tabular}

\subsection{Risks for monitoring and evaluating the GPRS}

408. The Government is well aware that monitoring and evaluating the GPRS is a complex and difficult exercise, thus bearing some risks. It calls not only for following the performance indicators, but also for establishing functional mechanisms to follow the execution by line ministries, peripheral public entities and decentralized partners. This requires an information system that is capable of supplying quality information whenever needed. More specifically, the following risks have been identified:

- Guaranteeing sustainability of the National Statistical System -- in the face of new challenges and greater responsibilities - and effectiveness of Statistical Development Agenda. The Government will strengthen the National Statistical System and will approach donors to secure resources for effective implementation of the Statistical Agenda.

- Inadequate statistic coverage and coordination. The Government will restructure the National Statistical System, confirming INE central role. The new NSS will focus on human resource development, on asserting its authority and on strengthening coordination to improve statistical coverage, raise quality and improve access to official statistics.

- Construction of a system of indicators, as part of a broader monitoring and evaluation system, should be seen as a continuous exercise, based on permanent and gradual increase in the capacity to collect, process, analyse and synthesize data. A multi-faced, flexible approach will make it possible to produce timely progress reports on 
implementation of the GPRS, thus allowing decision makers to carry out policy dialogue in a context of true ownership at the national level.

409. The Government will put up increasing efforts to set up an efficient, transparent and reliable monitoring and evaluation system for the GPRS. Therefore, the Government will seek to achieve donor coordination around this system, by inviting them to actively participate in its development and to organize their interventions around the annual reviews of the GPRS. 


\section{ANNEXES}

CInternational Monetary Fund. Not for Redistribution 


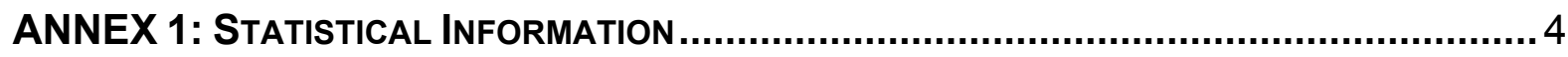

1. DEMOCRAPHY AND EMPLOYMENT ...................................................... 4

2. ECONOMY AND PUBLIC FINANCES …...............................................

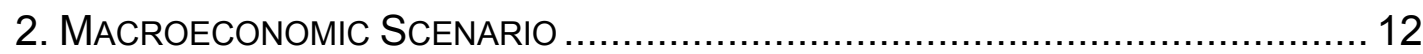

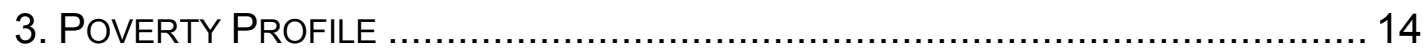

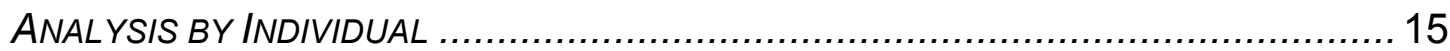

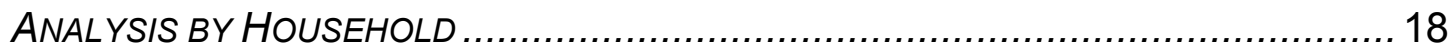

ANNEX 2: Strategies and Activities for Growth AND Poverty Reduction ..................................28

ANNEX 3: SummaRY TABLE OF THE MDG IN NATIONAL PRogramming ............................................... 49

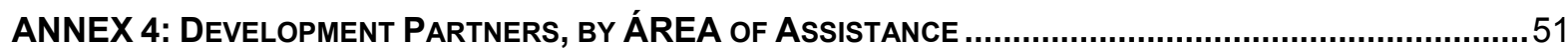

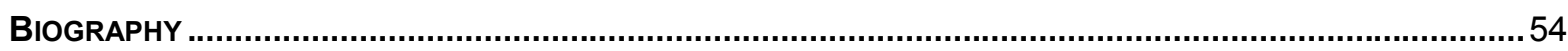




\section{TABLES ÍNDEX}

Table 1: Growth in Cape Verde, 1992-2000, compared to Africa ……...............................................................103

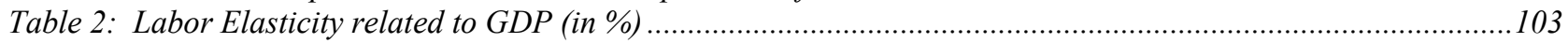

Table 3: Structure of the Active Population, Total and by Island ..................................................................... 103

Table 4: Distribution of Employment in \% of Total Employment, by island (2000) ................................................104

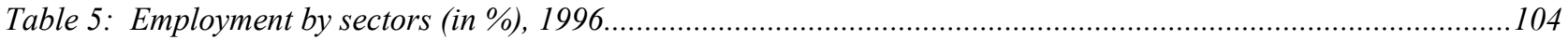

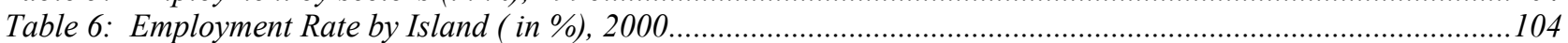

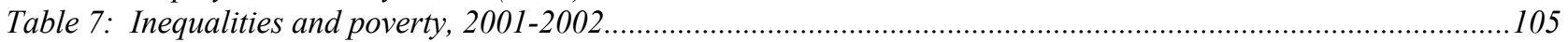

Table 8: Land Structure and size of agricultural production in Santiago and Santo Antão .......................................105

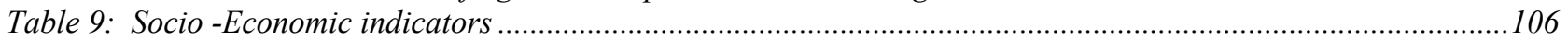

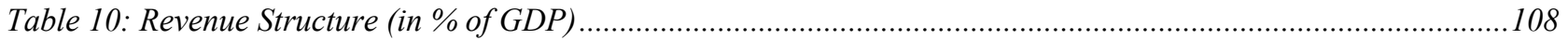

Table 11: Volume and Distribution of Development Aid, 1980-2002 (Annual Average) ..........................................108

Table 12: Portfolio of active Projects of National Poverty Alleviation Program (NPAP) ........................................108

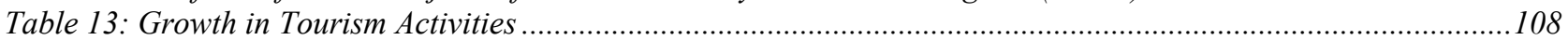

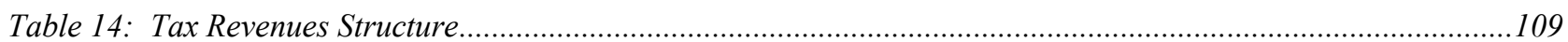

Table 15: Macroeconomic Scenario - Key Economic indicators ...............................................................................110

Table 16: Macroeconomic Scenario - Other Economic indicators .....................................................................110

Table 17: Fiscal Operations of the Central Government ..................................................................................111

Table 18: Poverty and Living Condition Indicators in Cape Verde .................................................................113

Table 19: Population and Households by Poverty Condition ..........................................................................114

Table 20: Cape Verde Population by Poverty Status and Island of Residence ........................................................114

Table 21: Population Spatial Distribution by Sex and Poverty Status .................................................................114

Table 22: Population Distribution by Gender, Age Group and Poverty Status ......................................................115

Table 23: Population 4 years and older by Poverty Status and Educational Level ...............................................115

Table 24: Population over 15 years by Sex, Poverty Status and Employment Condition .........................................116

Table 25: Percentual Distribution of Employed Poor Population by Sector of Activity .........................................116

Table 26: \% of Health System Coverage in Total Health Expenditures, by Poverty Status.......................................116

Table 27: Health Problems and Poverty Status ...................................................................................117

Table 28: Distribution of Individuals from 18 to 60 years of age by Poverty Status and sex, by Body Mass Index ....117

Table 29: Distribution of children under 5 by Poverty Status and Sex, by Age Groups ..........................................117

Table 30: Household Spatial Distribution by Poverty Status .........................................................................118

Table 31: Households by Poverty Status and Education level .........................................................................118

Table 32: Percentage of Head of Household 15 years and over by Poverty Status, Sex, and Employment Condition

Table 33: Distribution of Employed Head of Poor Household by Sector of Activity (in \%) ........................... 119

Table 34: Household Average Monthly Expenditures by Poverty Status and Expenditure Type (in \%)......................119

Table 35: Poor and Not Poor Household Distribution by Housing Type and Island of Residence (in \%) ..................120

Table 36: Poor and Not Poor Household Distribution Proportion by Housing Type and Island of Residence...........121

Table 37: Households Distribution by water quality and domestic usage and by island of residence .......................121

Table 38: Household distribution by main source of water supply for domestic usage and by island of residence ....122

Table 39 : Distribution of poor and non poor household by main source of water for domestic use and by island of

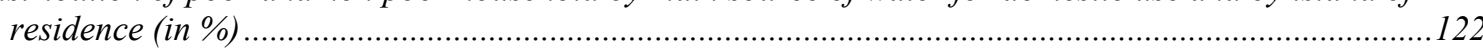

Table 40: Distribution of Households by island of residence and ownership of bathroom with lavatory, by poverty

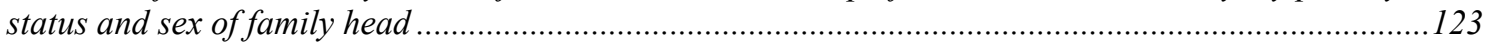

Table 41: Synthesis of Foster-Greer-Thorbecke activities ...........................................................................124

Table 42: Households by island of residence and degree of satisfaction of essential needs....................................125

Table 43: Households by island of residence and degree of satisfaction of essential needs .....................................125

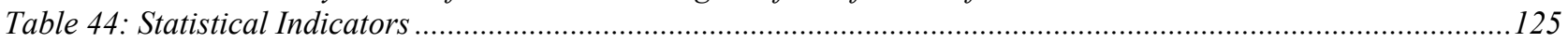

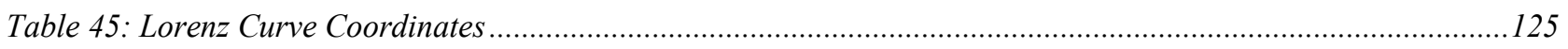

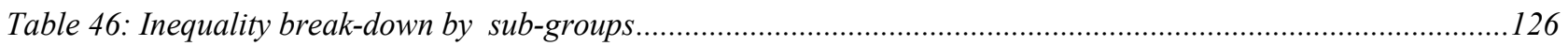

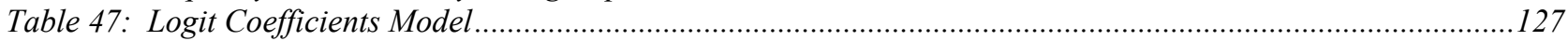




\section{ANNEX 1: Statistical information}

\section{Demography and Employment}

Table 1: Growth in Cape Verde, 1992-2000, compared to Africa

\begin{tabular}{|c|c|c|c|c|c|}
\hline \multirow{2}{*}{ Periods } & \multicolumn{3}{|c|}{$\begin{array}{c}\text { Average Annual Growth Rate } \\
\text { (\%) }\end{array}$} & \multicolumn{2}{c|}{$\begin{array}{c}\text { Growth Contribution to } \\
\text { GDP per worker (\%) }\end{array}$} \\
\cline { 2 - 6 } & GDP & GDP/Inhabitants & $\begin{array}{c}\text { GDP/ } \\
\text { worke } \\
\text { rotal }\end{array}$ & $\begin{array}{c}\text { Ratio } \\
\text { Capital } \\
\text { /Labor }\end{array}$ & $\begin{array}{c}\text { Total Factor } \\
\text { productivity }\end{array}$ \\
\hline $1992-2000$ & 6.3 & 3.9 & 3.2 & 64 & 36 \\
\hline $1992-1996$ & 5.6 & 3.4 & 3.0 & 72 & 28 \\
\hline $1997-2000$ & 7.1 & 4.5 & 3.5 & 56 & 44 \\
\hline \multicolumn{2}{|c|}{ Strong Growth Cases in África : } & & & 38 \\
\hline Failed Take Off a) & 7.0 & 2.7 & 4.3 & 62 & 87 \\
\hline Long Term Growth b) & 6.7 & 2.5 & 4.2 & 13 & \\
\hline
\end{tabular}

a) Cameron, Ivory Cost , Kenya, Malawi, South Africa

b) Botswana, Ghana, Mauritius, Moçambique and Uganda

Sources: Bourdet (2002); Berthélemy e Söderling (2001b)

Table 2: Labor Elasticity related to GDP (in \%)

\begin{tabular}{|c|c|c|c|}
\hline & $\mathbf{1 9 8 0 - 2 0 0 1}$ & $\mathbf{1 9 8 0 - 1 9 9 0}$ & $\mathbf{1 9 9 0 - 2 0 0 1}$ \\
\hline Total Labor & 0.4 & 0.28 & 0.61 \\
\hline Male Labor & 0.35 & 0.21 & 0.61 \\
\hline Female Labor & 0.48 & 0.41 & 0.61 \\
\hline & & & \\
\hline
\end{tabular}

Source: World Bank CD-Rom (World Bank Africa Data Base)

Table 3: Structure of the Active Population, Total and by Island

\begin{tabular}{|c|c|c|c|c|c|c|c|}
\hline & \multicolumn{3}{|c|}{ Employment Rate (\%) } & \multirow[b]{2}{*}{ Male } & \multirow[b]{2}{*}{ Primary \% } & \multirow{2}{*}{$\begin{array}{c}\text { Secondary } \\
\%\end{array}$} & \multirow{2}{*}{$\begin{array}{c}\text { Tertiary } \\
\%\end{array}$} \\
\hline & $\begin{array}{c}\text { Active } \\
\text { Population }\end{array}$ & Total & Female & & & & \\
\hline 1980 & 80645 & 21 & 12 & 33 & 37 & 31 & 33 \\
\hline 1990 & 122064 & 27 & 19 & 36 & 31 & 30 & 40 \\
\hline 2000 & 174644 & 33 & 30 & 38 & 25 & 19 & 57 \\
\hline \multicolumn{8}{|l|}{$\begin{array}{l}\text { (2000) by } \\
\text { Island }\end{array}$} \\
\hline Boavista & 2147 & 48 & 40 & 55 & 23 & 23 & 53 \\
\hline Brava & 2592 & 31 & 21 & 41 & 22 & 19 & 60 \\
\hline Fogo & 15226 & 33 & 29 & 38 & 51 & 14 & 36 \\
\hline Maio & 2901 & 35 & 33 & 39 & 28 & 14 & 58 \\
\hline Sal & 7160 & 44 & 34 & 53 & 6 & 27 & 68 \\
\hline Santiago & 92562 & 33 & 31 & 35 & 26 & 16 & 58 \\
\hline Santo Antão & 18487 & 33 & 24 & 41 & 29 & 18 & 53 \\
\hline São Nicolau & 5938 & 37 & 30 & 44 & 33 & 19 & 48 \\
\hline São Vicente & 27631 & 32 & 27 & 37 & 6 & 30 & 64 \\
\hline
\end{tabular}

Note : The Employment Rate is the ratio of the actives without job by the total active population.

Source: Anuário Estatístico (1995), Population Census 2000, and World Bank (2002) and African Development Indicators 2002. 
Table 4: Distribution of Employment in \% of Total Employment, by island (2000)

\begin{tabular}{|c|c|c|c|c|c|}
\hline & Private sector $\%$ & Public sector $\%$ & Others \% & $\begin{array}{l}\text { Unqualified } \\
\text { Workers \% }\end{array}$ & $\begin{array}{c}\text { Employment } \\
\text { Growth\% }\end{array}$ \\
\hline Cape Verde & 62.7 & 2.4 & 13.9 & 27.8 & 4.7 \\
\hline \multicolumn{6}{|l|}{ By Islands } \\
\hline Boavista & 71.4 & 15.8 & 13 & 24.3 & 7.8 \\
\hline Brava & 57 & 37.2 & 5.7 & 32.5 & 4.6 \\
\hline Fogo & 75 & 14.2 & 10.7 & 18.4 & 6.4 \\
\hline Maio & 52.3 & 25 & 22.7 & 38.9 & 7.8 \\
\hline Sal & 69.3 & 20.1 & 10.6 & 29.5 & 10.6 \\
\hline Santiago & 64 & 23.1 & 12.9 & 27.6 & 4.1 \\
\hline Santo Antão & 50.4 & 36.9 & 12.7 & 34.4 & 2.9 \\
\hline São Nicolau & 63.2 & 26.1 & 10.7 & 29.3 & 3.6 \\
\hline São Vicente & 58.5 & 19.4 & 22.2 & 26.7 & 6.3 \\
\hline
\end{tabular}

a) Others include NGO's, family workers and employees of international organizations

b) Employment Growth refers to period from 1990 to 2000 .

Source : Population Census 2000, INE.

Table 5: Employment by sectors (in \%), 1996

\begin{tabular}{|c|c|c|c|c|c|}
\hline & \multicolumn{4}{|c|}{ Employment } & \multirow{2}{*}{$\begin{array}{c}\text { Independent } \\
\text { workers in \% } \\
\text { of total } \\
\text { employment }\end{array}$} \\
\hline & $\begin{array}{c}\text { Intermediate } \\
\text { Duration }\end{array}$ & Temporaries & Others & Total & \\
\hline Economic sector & & 12 & & & \\
\hline Agriculture and Fishing & 29.9 & 21.7 & 59.4 & 100 & 39.6 \\
\hline Manufacturing & 32.6 & 17.6 & 45.7 & 100 & 34.9 \\
\hline Energy & 50.8 & 26.6 & 31.6 & 100 & 0 \\
\hline Construction & 12.9 & 13.8 & 60.5 & 100 & 19.7 \\
\hline Commerce, restaurants and hotels & 45.9 & 9.7 & 40.3 & 100 & 55.6 \\
\hline Transport and communications & 49 & 17.1 & 41.3 & 100 & 12.8 \\
\hline Banks and insurance & 57.2 & 14.8 & 25.7 & 100 & 6.6 \\
\hline Public, social and personnel services & 50 & 28.6 & 35.2 & 100 & 6.2 \\
\hline Other activities & 33.4 & 15.7 & 38.2 & 100 & 39 \\
\hline Total & 41.8 & & 42.5 & 100 & 25.2 \\
\hline
\end{tabular}

Source: Instituto do Emprego e Formação Profissional (1997).

Table 6: Employment Rate by Island ( in \%), 2000

\begin{tabular}{|c|c|c|c|c|c|c|c|}
\hline & Total & Male & Female & Urban & Rural & $\mathbf{1 5 - 2 4}$ years & Illiteracy rate \\
\hline Cape Verde & & & & & & & \\
\hline 1990 & 25.4 & 25.6 & 25.2 & 25.4 & 25.5 & 40.1 & 35.1 \\
\hline 2000 & 17.4 & 11.1 & 23.8 & 18.7 & 15.7 & 29.7 & 25.2 \\
\hline $\mathbf{2 0 0 0 )}$ by Island & & & & & & & \\
\hline Boavista & 5.6 & 2.9 & 9.6 & 4.6 & 6.6 & 9.2 & 15 \\
\hline Brava & 18.6 & 8.7 & 32.5 & 13.8 & 20.3 & 26.9 & 27.5 \\
\hline Fogo & 18.1 & 9.1 & 27 & 25.9 & 15.7 & 30.5 & 29.2 \\
\hline Maio & 17.7 & 11.2 & 23.6 & 21.8 & 14.9 & 25 & 22.8 \\
\hline Sal & 10.5 & 4.9 & 18.8 & 9.6 & 17.6 & 16.8 & 13.2 \\
\hline Santiago & 16.5 & 9.9 & 22.3 & 17.4 & 15.6 & 28.7 & 25.8 \\
\hline Santo Antão & 16.4 & 10.2 & 26 & 17 & 16.2 & 30.7 & 34 \\
\hline São Nicolau & 15.4 & 8.3 & 23.9 & 20.1 & 12.1 & 24.6 & 25.9 \\
\hline São Vicente & 23.3 & 19.6 & 27.7 & 23.3 & 23.8 & 39 & 19 \\
\hline
\end{tabular}

Source: Anuário Estatístico (1995) and Population Census 2000 
Table 7: Inequalities and poverty, 2001-2002

\begin{tabular}{|c|c|c|c|c|c|c|c|}
\hline & \multirow{2}{*}{$\begin{array}{c}\text { Gini } \\
\text { Coefficient }\end{array}$} & \multirow{2}{*}{ Poor } & \multirow{2}{*}{$\begin{array}{l}\text { Very } \\
\text { poor }\end{array}$} & \multirow{2}{*}{$\begin{array}{c}\text { Rural } \\
\text { Population }\end{array}$} & \multicolumn{3}{|c|}{ Head of Family } \\
\hline & & & & & Total & Female & Male \\
\hline \multicolumn{8}{|l|}{ Cape Verde } \\
\hline $1988-1989$ & 0.43 & 30 & 14 & 56 & - & - & - \\
\hline $2001-2002$ & 0.59 & 37 & 20 & 46 & 27 & 40 & 18 \\
\hline \multicolumn{8}{|c|}{ (2001-2002) by island } \\
\hline Boavista & 0.42 & 13 & 2 & 52 & 12 & 24 & 8 \\
\hline Brava & 0.5 & 41 & 16 & 73 & 22 & 29 & 18 \\
\hline Fogo & 0.57 & 43 & 25 & 78 & 31 & 48 & 22 \\
\hline Maio & 0.52 & 38 & 25 & 60 & 20 & 26 & 15 \\
\hline Sal & 0.56 & 13 & 6 & 10 & 10 & 24 & 5 \\
\hline Santiago & 0.57 & 37 & 20 & 48 & 29 & 42 & 18 \\
\hline Santo Antão & 0.65 & 54 & 34 & 70 & 34 & 51 & 26 \\
\hline São Nicolau & 0.48 & 40 & 24 & 60 & 23 & 34 & 15 \\
\hline São Vicente & 0.62 & 26 & 11 & 6 & 21 & 33 & 13 \\
\hline
\end{tabular}

Source: Family Expenditure survey (2001/2002), Population Census 2000, and Family Expenditure survey (1988-1989).

Table 8: Land Structure and size of agricultural production in Santiago and Santo Antão

\begin{tabular}{|c|c|c|c|c|}
\hline & $\begin{array}{c}\text { Landless (a) in \% of } \\
\text { total cultivated areas }\end{array}$ & $\begin{array}{c}\text { Land } \\
\text { Owners (b) }\end{array}$ & $\begin{array}{c}\text { Average size of agriculture } \\
\text { production (ha) }\end{array}$ & $\begin{array}{c}\text { \% Agriculture } \\
\text { production over 2 Ha }\end{array}$ \\
\hline Dry farming & & & & 27 \\
\hline Santiago & 40 & 22 & 1.3 & 62 \\
\hline Santo Antão & 19 & 52 & 1.7 & \\
\hline Irrigated farming & & & & \\
\hline Santiago & 74 & 18 & 0.1 & 0 \\
\hline Santo Antão & 25 & 53 & 0.8 & 63 \\
\hline
\end{tabular}

Notes : a) Land Farmed in renting system as percentage of total cultivated land

b) land farmed by owners as percentage of total cultivated land

Source : Langworthy et Finan (1997), pp. 70 and 72. 


\section{Economy and Public Finances}

Table 9: Socio -Economic indicators

\begin{tabular}{|c|c|c|c|}
\hline CAPE VERDE & Indicators & Year & Source \\
\hline \multicolumn{4}{|l|}{ POPULATION AND ECONOMY } \\
\hline Total Population & 450,489 & 2002 & INE,Dem.Persp \\
\hline Female & 232,516 & 2002 & INE, Dem persp \\
\hline Male & $217, .973$ & 2002 & INE, Dem Persp \\
\hline Population below15 years & 183,006 & 2002 & INE, Dem Persp \\
\hline Population below 17 years & 217,810 & 2002 & INE, Dem Persp \\
\hline Population between $15-64$ years & $239, .305$ & 2002 & INE, Dem Persp \\
\hline Population up to 65 years & 28,178 & 2002 & INE, Dem Persp \\
\hline Dependency rate $(\%)$ & 88 & 2002 & INE, Dem \\
\hline Urban Population $(\%)$ & 55.20 & 2002 & INE, Dem Persp \\
\hline Rural Population (\%) & 44.80 & 2002 & INE Dem Persp \\
\hline GDP per capita (\$US) & 1,420 & 2002 & INE/FMI \\
\hline Demographic Density (Hab/Km2) & 111.7 & 2002 & INE, Dem Persp \\
\hline Number of Families & $93, .975$ & 2000 & INE; Census 2000 \\
\hline Human Development Index (HDI) & 0.670 & 2002 & INE-RNDH 2003 \\
\hline Poverty Index & 17.7 & 2002 & INE-RNDH 2003 \\
\hline External Effective Debt ( millions of \$US) & 348 & 2002 & $\mathrm{BCV}$ \\
\hline Average Annual Economic Growth Rate 1990-2000(\%) & $6.1 \%$ & $1990-2000$ & INE \\
\hline Average Annual Economic Growth Rate 1997-2000 (\%) & 6.2 & $1997-2000$ & INE \\
\hline Average Annual Economic Growth Rate 1980-1990 (\%) & 4.8 & 1980.1990 & INE \\
\hline $\begin{array}{l}\text { Weight of agriculture, forestry, livestock, fishing on GDP } \\
(\%) \text { (constant prices) }\end{array}$ & 8.5 & 2002 & INE/FMI \\
\hline $\begin{array}{l}\text { Weight of light Industry, electricity and construction on GDP } \\
\qquad \% \text { (constant prices) }\end{array}$ & 16.2 & 2002 & INE/FMI \\
\hline $\begin{array}{c}\text { Weight of services in GDP }(\%) \\
(\text { constant prices })\end{array}$ & $75 ., 3$ & 2002 & INE/FMI \\
\hline Poor (in $\%$ of population ) & 36.7 & 2002 & INE-IDRF 01-02 \\
\hline Very poor (in $\%$ of population ) & 19.7 & 2002 & INE-IDRF 01-02 \\
\hline ICT contribution to GDP (current prices) $(\%)$ & 5.9 & 2002 & INE \\
\hline Unemployment Rate $(\%)$ & 17.3 & 2000 & INE Census 2000 \\
\hline Inflation Rate $(\%)$ & 1.9 & 2002 & INE \\
\hline Nominal Exchange Rate (annual average) (\$US/ECV) & 117.3 & 2002 & $\mathrm{BCV}$ \\
\hline Population Growth Rate (1990-2000) (\%) & 2.4 & 2000 & INE \\
\hline Households with telephone $\%$ & 51.9 & 2002 & INE-IDRF 01-02 \\
\hline Households with Mobile phone $\%$ & 20.0 & 2002 & INE-IDRF 01-02 \\
\hline Households with computer $\%$ & 4.6 & & INE-IDRF 01-02 \\
\hline Households with computer connected to internet $\%$ & 2.3 & 2002 & INE-IDRF 01-02 \\
\hline
\end{tabular}




\begin{tabular}{|c|c|c|c|}
\hline Households with computer without connection to internet $\%$ & 2.3 & 2002 & INE-IDRF 01-02 \\
\hline Households with television $\%$ & 49.1 & 2002 & INE-IDRF 01-02 \\
\hline Households with radio \% & 74.6 & 2002 & INE-IDRF 01-02 \\
\hline Telephone density per 100 inhabitants & 15.5 & 2002 & CVT \\
\hline \multicolumn{4}{|l|}{ Education } \\
\hline $\begin{array}{l}\text { Population Enrollment Rate } \\
\text { (4 years and over) }(\%)\end{array}$ & 38 & 2000 & INE, Census 2000 \\
\hline School Life Expectancy (years) & $11 ., 2$ & & INE, Census 2000 \\
\hline Average duration Basic Education(EBI) (years) & 6.7 & $2001 / 02$ & GEP/MEVRH \\
\hline Men (percentage) & 39 & & \\
\hline Women (percentage) & 37 & & \\
\hline Literacy Rate (\%) & 25.2 & 2000 & INE, Census 2000 \\
\hline Not Enrolled Population 4 years and over (\%) & $17 \%$ & 2000 & INE, Census 2000 \\
\hline - Men $(\%)$ & 35 & & INE, Census 2000 \\
\hline - Women $(\%)$ & 65 & & INE, Census 2000 \\
\hline Gross Enrolment Rate in Basic Education \% & 115.1 & $2002 / 03$ & GEP/ MEVRH \\
\hline Gross Enrolment Rate In Secondary School \% & 67.4 & $2002 / 03$ & GEP/ MEVRH \\
\hline \multicolumn{4}{|l|}{ Net Enrollment Rate (NER) (\%) } \\
\hline - Basic Education (6 years enrollment) & 95.5 & $2002 / 03$ & GEP/ MEVRH \\
\hline - Secondary school (5/6 years of education) & 56.6 & $2002 / 03$ & GEP/ MEVRH \\
\hline \multicolumn{4}{|l|}{ Female Registration rate $(\%)$} \\
\hline Pre-School & 50.0 & $2002 / 03$ & GEP/ MEVRH \\
\hline Basic Education & 48.7 & $2002 / 03$ & GEP/ MEVRH \\
\hline - Secondary Education & 52.0 & $2002 / 03$ & GEP/ MEVRH \\
\hline Investment - Education (CVE) & $1,926,222,280$ & 2003 & GEP-MEVRHOE 2003 \\
\hline Operating Expenditures - Education (CVE) & $4,786,036,914$ & 2003 & GEP-MEVRHOE 2003 \\
\hline \multicolumn{4}{|l|}{ Health } \\
\hline Birth Rate (by 1000) & 29.3 & 2000 & INE; Census 2000 \\
\hline Fertility Index & 4.0 & 2000 & INE; Census 2000 \\
\hline Reproduction Rate & 1.96 & 2000 & INE \\
\hline Infant Mortality Rate (by 1.000) & 32.2 & 2002 & INE-Persp Dem \\
\hline Life Expectancy (Men and Women, by years) & 71.2 & 2002 & INE-Persp Dem \\
\hline Life Expectancy (Women) & 75.3 & 2002 & INE-Persp Dem \\
\hline Life Expectancy (Men) & 67,1 & 2002 & INE-Persp Dem \\
\hline Medical Doctor/inhabitant ratio & $1 / 2682$ & 2002 & GEP/MS \\
\hline Nurses/inhabitant ratio & $1 / 1205$ & 2002 & GEP /MS \\
\hline Inhabitants/bed & 626 & 2000 & GEP/MS \\
\hline \multicolumn{4}{|l|}{ Living Conditions } \\
\hline $\begin{array}{l}\text { Access to Drinking water system (Plumbing, system and } \\
\text { Cistern Truck })(\%)\end{array}$ & 76.1 & 2002 & INE-IDRF 01-02 \\
\hline Coverage rate of Drinking water distribution (\%) & 33 & 2002 & INE-IDRF 01-02 \\
\hline Households that normally treated water for domestic usage (\%) & 47.8 & 2002 & INE-IDRF 01-02 \\
\hline Households without Bathroom and Lavatory (\%) & 55.2 & 2002 & INE-IDRF 01-02 \\
\hline Households without adequate system to dump residual ater(\%) & 74.4 & 2002 & INE-IDRF 01-02 \\
\hline Households with connection to Sanitation System & 11.5 & 2002 & INE-IDRF 01-02 \\
\hline
\end{tabular}




\begin{tabular}{|l|l|l|l|}
\hline Households with access to electricity (\%) & 58.5 & 2002 & INE-IDRF 01-02 \\
\hline Households using mostly wood for cooking (\%) & 32.9 & 2000 & INE, Census 2000 \\
\hline Households using mostly gas for cooking (\%) & 65.6 & 2000 & INE, Census 2000 \\
\hline Children from 0 to 5 years underweight (\%) & 5.8 & 2002 & INE-IDRF 01-02 \\
\hline Population Comfort Level (\%) & & 2000 & INE, Census 2000 \\
\hline . Very low & 30.7 & & INE-IDRF 01-02 \\
\hline . Low & 18.5 & & \\
\hline Medium & 14.8 & & \\
\hline . High & 19.7 & & \\
\hline Very High & 16.3 & & \\
\hline
\end{tabular}

Table 10: Revenue Structure (in \% of GDP)

\begin{tabular}{|c|c|c|c|}
\hline & $\mathbf{1 9 8 8 - 1 9 9 2}$ & $\mathbf{1 9 9 6 - 1 9 9 9}$ & $\mathbf{2 0 0 0 - 2 0 0 2}$ \\
\hline Domestic Revenues & 15.4 & 19.7 & 22.5 \\
\hline Of which: & & & \\
\hline Tax Revenue & 11.1 & 16.6 & 19.8 \\
\hline Wages and Benefits & 3.2 & 5.9 & 7 \\
\hline Consumption & - & - & 3.2 \\
\hline International Trade & 6.9 & 9.4 & 7.9 \\
\hline Others & - & - & 1.5 \\
\hline Nontax revenues & 4.3 & 3.2 & 2.4 \\
\hline
\end{tabular}

Source : IMF (1995), IMF (2001a) and World Bank (2004)

Table 11: Volume and Distribution of Development Aid, 1980-2002 (Annual Average)

\begin{tabular}{|c|c|c|c|}
\hline & $\begin{array}{c}\mathbf{1 9 8 0} \\
\mathbf{8 9}\end{array}$ & $\mathbf{1 9 9 0 - 9 9}$ & $\mathbf{2 0 0 0 - 0 2}$ \\
\hline Commitments in millions of USD & 123.8 & 126.6 & 87.8 \\
\hline Aid Distribution(in \% of & & & \\
\hline Aid Program (Food aid) & $54(32)$ & $29(20)$ & $30(19)$ \\
\hline Infrastructures and social services & 6 & 27 & 36 \\
\hline $\begin{array}{c}\text { Infrastructures services and } \\
\text { sectors }\end{array}$ & 34 & 32 & 27 \\
\hline Debt Amortization & 0 & 3 & 4 \\
\hline Others & 6 & 10 & 3 \\
\hline
\end{tabular}

Note: Aid Includes all grants and loans from governments, official agencies and international organizations Source: OECD, Global Development Statistics

Table 12: Portfolio of active Projects of National Poverty Alleviation Program (NPAP)

\begin{tabular}{c|c|c|c|c|c|c|c|c|c|c|}
\hline \multirow{2}{*}{ No } & \multirow{2}{*}{ Project } & \multirow{2}{*}{ Beginning } & \multirow{2}{*}{ Implementation } & \multirow{2}{*}{$\begin{array}{c}\text { Budget } \\
\text { (millions USD) }\end{array}$} & \multicolumn{3}{|c|}{ Financial Source (\%) } & \multicolumn{2}{c|}{$\begin{array}{c}\text { Geographic } \\
\text { Coverage }\end{array}$} \\
\hline $\mathbf{1}$ & PDSS & $09 / 99$ & $2000-2004$ & 23.1 & 90 & 10 & - & - & - & All Islands \\
\hline $\mathbf{2}$ & PLPR & $14 / 08 / 00$ & $2000-2008$ & 18.3 & - & 36 & 50 & - & 14 & $\begin{array}{c}\text { S.Antão, S.Nicolau, Fogo, Brava, } \\
\text { Santiago (Tarrafal e S.Miguel) }\end{array}$ \\
\hline $\mathbf{3}$ & PSGD & $14 / 06 / 01$ & $2001-2004$ & 6.0 & - & 10 & - & 90 & - & $\begin{array}{c}\text { Pref. S.Antão, S.Vicente e } \\
\text { Santiago }\end{array}$ \\
\hline & TOTAL & & & $\mathbf{4 7 . 4}$ & & & & & & \\
\hline
\end{tabular}

Table 13: Growth in Tourism Activities

\begin{tabular}{|c|c|c|c|c|c|}
\hline & $\mathbf{1 9 9 9}$ & $\mathbf{2 0 0 0}$ & $\mathbf{2 0 0 1}$ & $\mathbf{2 0 0 2}$ & $\mathbf{2 0 0 3}$ \\
\hline Rooms & 1825 & 2391 & 2489 & 2820 & 3146 \\
\hline Beds & 3165 & 4475 & 4628 & 5159 & 5715 \\
\hline Entries & & 145076 & 162095 & 152052 & $\ldots$ \\
\hline Sleepovers & & 684733 & 805924 & 693658 & 832000 \\
\hline
\end{tabular}


Table 14: Tax Revenues Structure

\begin{tabular}{|c|c|c|c|c|c|c|}
\hline & 2004(P) & 2003(E) & 2002 & 2001 & 2000 & 1999 \\
\hline Taxation level & \multicolumn{6}{|c|}{\begin{tabular}{|c|} 
(Taxes in percentage of GDP ) \\
\end{tabular}} \\
\hline Total Tax Revenue & 18.7 & 18.9 & 20.8 & 19.2 & 17.6 & 16.6 \\
\hline Taxes on income and profits & 7.1 & 6.7 & 7.7 & 7.1 & 6.1 & 5.4 \\
\hline Taxes on International Trade & 4.0 & 8.1 & 8.5 & 7.9 & 7.4 & 6.9 \\
\hline Taxes on Goods and Services & 6.7 & 3.2 & 3.4 & 3.1 & 3.0 & 3.2 \\
\hline \multirow[t]{2}{*}{ Other Indirect Taxes } & $1 ., 0$ & 1.0 & 1.3 & 1.1 & 1.1 & 1.1 \\
\hline & 2004(P) & 2003(E) & 2002 & 2001 & 2000 & 1999 \\
\hline \multicolumn{7}{|l|}{ Taxation indicators } \\
\hline Frank Index [(FR/GDP)/GDP per capita] & 103 & 111 & 130 & 125 & 121 & 118 \\
\hline Bird Index [(FR/GDP-FR)/GDP per capita] & 127 & 136 & 164 & 155 & 146 & 142 \\
\hline \multirow[t]{2}{*}{ Elasticity FR, GDP } & 0.85 & -0.20 & 2.35 & 2.41 & 2.09 & 1.13 \\
\hline & 2004(P) & 2003(E) & 2002 & 2001 & 2000 & 1999 \\
\hline Fiscal Structure & \multicolumn{6}{|c|}{ (Taxes in percentage of Total Tax Revenues ) } \\
\hline Total Tax Revenue & 100 & 100 & 100 & 100 & 100 & 100 \\
\hline Direct Taxes & 37.8 & 35.3 & 36.8 & 36.9 & 34.8 & 32.3 \\
\hline Taxes on income and profits & 37.8 & 35.3 & 36.8 & 36.9 & 34.8 & 32.3 \\
\hline $\begin{array}{l}\text { IUR-Tax on salaries and self employment } \\
\text { income }\end{array}$ & 21.4 & 20.1 & 22.6 & 23.6 & 26.3 & 21.4 \\
\hline IUR- tax on business profits & 16.3 & 15.2 & 14.1 & 13.2 & 8.5 & 11.0 \\
\hline Indirect Taxes & 62.2 & 64.7 & 63.2 & 63.1 & 65.2 & 67.7 \\
\hline Taxes on International Trade & 21.2 & 42.6 & 40.6 & 41.1 & 41.9 & 41.8 \\
\hline Import Duties & 21.2 & 28.2 & 26.8 & 28.5 & 29.0 & 28.6 \\
\hline Custom Fees & - & 14.3 & 13.7 & 12.5 & 12.8 & 13.1 \\
\hline Others & - & 0.1 & 0.1 & 0.1 & 0.1 & 0.1 \\
\hline Taxes on Goods and Services & 35.6 & 16.7 & 16.3 & 16.2 & 16.8 & 19.1 \\
\hline IC-Domestic Goods and Services & - & 0.8 & 0.7 & 0.7 & 1.5 & 2.3 \\
\hline IC- Foreign Goods and Services & - & 12.3 & 11.9 & 13.0 & 13.6 & 13.4 \\
\hline VAT & 27.2 & & & & & \\
\hline Tax on Petroleum Products & - & 1.9 & 2.1 & 0.9 & 0.2 & 1.8 \\
\hline Liquor tax & - & 0.9 & 0.8 & 0.8 & 1.0 & 1.1 \\
\hline Tax on Tourism & - & 0.8 & 0.8 & 0.8 & 0.5 & 0.6 \\
\hline ICE- special Consumption Tax & 8.3 & & & & & \\
\hline Other indirect taxes & 5.5 & 5.4 & 6.3 & 5.8 & 6.5 & 6.7 \\
\hline Stamp Tax & 4.6 & 4.1 & 4.8 & 4.5 & 5.2 & 5.4 \\
\hline Others & 0.9 & 1.3 & 1.5 & 1.3 & 1.3 & 1.3 \\
\hline
\end{tabular}

Source: Ministry of Finance and Planning;

2001-2004: Budget Report/ 2004

1999.2000: Budget Report / 2003 


\section{MACROECONOMIC SCENARIO}

Table 15: Macroeconomic Scenario - Key Economic indicators

\begin{tabular}{|c|c|c|c|c|}
\hline & 2004 & 2005 & 2006 & 2007 \\
\hline GDP ( Real Growth Rate ) & 5,5 & 6,0 & 6,5 & 7,0 \\
\hline Inflation & 1,0 & 2,0 & 2,0 & 2,0 \\
\hline Broad Money ( Growth Rate ) & 8,0 & 8,1 & 8,6 & 9,2 \\
\hline Overall balance ( CVE 109 ) & $-3,7$ & $-7,1$ & $-7,5$ & $-6,8$ \\
\hline Overall balance ( in \% GDP ) & $-4,3$ & $-7,6$ & $-7,3$ & $-6,1$ \\
\hline Primary current balance ( CVE $\left.10^{9}\right)$ & 3,2 & 3,4 & 3,8 & 4,6 \\
\hline Primary current balance ( in \% GDP ) & 3,7 & 3,6 & 3,7 & 4,1 \\
\hline Public Investment ( CVE $\left.10^{9}\right)$ & 9,7 & 13,5 & 15 & 15,5 \\
\hline Reserves in month of imports & 2,02 & 2,25 & 2,5 & 2,75 \\
\hline
\end{tabular}

Source: MFP

Table 16: Macroeconomic Scenario - Other Economic indicators

\begin{tabular}{|c|c|c|c|c|}
\hline & 2004 & 2005 & 2006 & 2007 \\
\hline Nominal GDP (CVE 109 ) & 87,4 & 94,4 & 102,6 & 112,1 \\
\hline Total Revenues ( \% GDP ) & 28,1 & 27,6 & 27,7 & 27,4 \\
\hline Tax Revenues ( \% GDP ) & 19,7 & 19 & 19 & 19 \\
\hline Total Expenditures ( \% GDP ) & 32,3 & 35,2 & 35 & 33,5 \\
\hline $\begin{array}{l}\text { Investment Expenditures ( \% GDP ) } \\
\end{array}$ & 11,1 & 14,3 & 14,6 & 13,8 \\
\hline Percentage of Net Credit to the Economy in Net Domestic credit (\%) & 55,2 & 57 & 58,7 & 60,6 \\
\hline Exports of good and services ( \% GDP ) & 33,9 & 35 & 36,3 & 38,2 \\
\hline Net Current transfers ( \% GDP ) & 24,2 & 24,2 & 24,2 & 23,7 \\
\hline Net Private Transfers ( $\%$ GDP ) & 18,6 & 18,4 & 18,3 & 18,1 \\
\hline Imports of goods and services ( \% GDP ) & 66,1 & 67,5 & 66,4 & 65,6 \\
\hline Overall Balance of Payments ( \% GDP ) & $-9,5$ & $-9,6$ & $-7,0$ & $-4,8$ \\
\hline Net External Direct Investment ( \% GDP ) & 1,7 & 3,9 & 5,4 & 5,4 \\
\hline Overall balance of Payments ( in \% GDP ) & $-1,5$ & $-3,9$ & $-0,4$ & 2 \\
\hline
\end{tabular}

Source: MFP 
Table 17: Fiscal Operations of the Central Government

(In millions of CVE)

\begin{tabular}{|c|c|c|c|c|c|}
\hline & 2003 & 2004 & 2005 & 2006 & 2007 \\
\hline Revenue, grants, and net lending & 21.910 & 24.516 & 25.628 & 27.563 & 29.860 \\
\hline Domestic revenue & 17.509 & 19.634 & 21.173 & 23.108 & 25.405 \\
\hline Tax revenue & 15.457 & 17.181 & 18.477 & 20.2 & 22.2 \\
\hline Income and profit taxes & 5.304 & 6.343 & 7.219 & 7.975 & 8.812 \\
\hline Individual income taxes & 2.974 & 3.793 & 4.297 & 4.691 & 5.123 \\
\hline Corporate income taxes & 2.331 & 2.550 & 2.922 & 3.284 & 3.689 \\
\hline Consumption taxes & 2.500 & 5.991 & 6.664 & 7.364 & 8.117 \\
\hline Goods and services taxes & 2.500 & 1.673 & 1.835 & 1.995 & 2.145 \\
\hline VAT & 0.000 & 4.318 & 4.829 & 5.369 & 5.971 \\
\hline International trade taxes & 6.755 & 3.881 & 3.477 & 3.684 & 3.952 \\
\hline Other taxes & 0.898 & 0.966 & 1.117 & 1.220 & 1.332 \\
\hline Non-tax revenue & 1.514 & 2.194 & 2.454 & 2.728 & 3.034 \\
\hline Net lending & 0.538 & 0.260 & 0.243 & 0.137 & 0.158 \\
\hline External grants & 4.400 & 4.882 & 4.455 & 4.455 & 4.455 \\
\hline Capital grants & 3.631 & 4.882 & 4.455 & 4.455 & 4.455 \\
\hline Budget support & 0.769 & 0.000 & 0.000 & 0.000 & 0.000 \\
\hline Total expenditure & 24.585 & 28.252 & 28.723 & 29.865 & 31.020 \\
\hline Recurrent expenditure & 16.281 & 18.520 & 19.485 & 20.577 & 21.728 \\
\hline Primary current expenditure & 14.284 & 16.445 & 17.235 & 18.5 & 19.8 \\
\hline Wages and salaries & 9.361 & 10.765 & 11.200 & 11.653 & 12.124 \\
\hline Goods and services & 1.319 & 1.656 & 1.807 & 2.268 & 2.718 \\
\hline Transfers and subsidies & 2.839 & 3.213 & 3.343 & 3.478 & 3.619 \\
\hline Transfers & 2.205 & 3.129 & 3.256 & 3.387 & 3.524 \\
\hline Subsidies & 0.634 & 0.084 & 0.087 & 0.091 & 0.095 \\
\hline Other expenditures & 0.765 & 0.810 & 0.884 & 1.109 & 1.329 \\
\hline Domestic interest payments & 1.480 & 1.480 & 1.555 & 1.273 & 1.029 \\
\hline External interest payments & 0.516 & 0.595 & 0.695 & 0.796 & 0.910 \\
\hline Extraordinary expenditure & 0.630 & 0.000 & 0.238 & 0.288 & 0.292 \\
\hline Social emergency measures & 0.000 & 0.000 & 0.238 & 0.288 & 0.292 \\
\hline Restructuring costs & 0.630 & 0.000 & 0.000 & 0.000 & 0.000 \\
\hline Capital expenditure & 7.674 & 9.733 & 9.000 & 9.000 & 9.000 \\
\hline Foreign financed & 6.912 & 8.713 & 8.100 & 8.100 & 8.100 \\
\hline Domestically financed & 0.762 & 1.020 & 0.900 & 0.900 & 0.900 \\
\hline Overall balance, including grants & -2.675 & -3.736 & -3.095 & -2.300 & -1.200 \\
\hline Financing & 2.483 & 1.226 & 1.098 & 1.559 & 1.579 \\
\hline Foreign (net) & 1.448 & 1.692 & 1.374 & 1.344 & 1.495 \\
\hline Total drawings & 3.549 & 4.381 & 3.645 & 3.645 & 3.645 \\
\hline Balance of payments, budget & 1.336 & 0.550 & 0.000 & 0.000 & 0.000 \\
\hline Project loans & 2.213 & 3.831 & 3.645 & 3.645 & 3.645 \\
\hline Existing loans & & 3.640 & 2.700 & 1.500 & 0.930 \\
\hline Loans under negotiation & & 0.190 & 0.360 & 0.240 & 0.200 \\
\hline
\end{tabular}




\begin{tabular}{|c|l|l|l|l|l|}
\hline New loans & & & 0.590 & 1.910 & 2.510 \\
\hline Amortization & -2.101 & -2.689 & -2.271 & -2.301 & -2.150 \\
\hline Domestic (net) & 1.035 & -0.466 & -0.276 & 0.215 & 0.084 \\
\hline Banking system & 0.928 & 0.300 & -0.076 & 0.415 & 0.284 \\
\hline Nonbanks & 0.685 & 0.300 & 0.300 & 0.300 & 0.300 \\
\hline Domestic arrears & -0.578 & -1.066 & -0.500 & -0.500 & -0.500 \\
\hline Errors and omissions & 0.192 & & & & \\
\hline Financing gap & & 2.510 & 1.997 & 0.743 & -0.418 \\
\hline Possible financing & & 2.510 & 2.270 & 1.310 & 0.000 \\
\hline Remaining financing gap & & 0.000 & -0.273 & -0.567 & -0.418 \\
\hline Memorandum items: & & & & \\
\hline Overall balance, excluding grants & & & & & \\
\hline Primary current balance & -7.1 & -8.6 & -7.5 & -6.8 & -5.6 \\
\hline Primary balance & 3.2 & 3.2 & 3.9 & 4.6 & 5.6 \\
\hline Domestic balance & -0.7 & -1.7 & -0.8 & -0.2 \\
\hline Domestic expenditure & 0.4 & 0.7 & 1.2 & 2.1 \\
\hline Domestic debt (including arrears) & 17.2 & 18.9 & 19.9 & 21.0 \\
\hline Domestic debt (\% of GDP) & 11.9 & 11.4 & 11.1 & 11.3 \\
\hline
\end{tabular}

Source: Ministry of Finance and Planning 


\section{Poverty Profile}

Table 18: Poverty and Living Condition Indicators in Cape Verde

\begin{tabular}{|c|c|}
\hline Indicator & Value \\
\hline Poor & 172727 \\
\hline Poverty incidence & $37 \%$ \\
\hline Very Poor & $20 \%$ \\
\hline Poor Female Population & 88854 \\
\hline Poor Male Population & 83858 \\
\hline Poor population below 15 years old & 84,240 \\
\hline Poor Population age 65 or over & 9649 \\
\hline Poor Illiteracy rate ( 15 years or over) - in \% & $30 \%$ \\
\hline \multicolumn{2}{|l|}{ Educational Level of the Poor ( 4 years and older) } \\
\hline No schooling - in \% & 23.9 \\
\hline Basic Education - in \% & 60.7 \\
\hline Secondary Education - in \% & 15.1 \\
\hline Post Secondary - in \% & 0.1 \\
\hline \multicolumn{2}{|l|}{ Economic Activities (15 years and older) } \\
\hline Poor, 15 years and older & 88437 \\
\hline Actives & 54568 \\
\hline Employed & 36791 \\
\hline Unemployed & 17777 \\
\hline \multicolumn{2}{|l|}{ Inactive } \\
\hline Unemployment rate 15 years or over $\%$ & 22.0 \\
\hline Poor unemployment rate 15 years or over $\quad$ - in $\%$ & 32.6 \\
\hline Households & 95258 \\
\hline Poor Households & 26693 \\
\hline Poverty incidence $(\mathrm{PO})$ - in \% & 28.0 \\
\hline Poverty Severity (P2) - in \% & 10.0 \\
\hline Poverty Intensity (P3) - in \% & 5.0 \\
\hline \multicolumn{2}{|l|}{ Poverty and Comfort } \\
\hline Households with electricity - in \% & 55836 \\
\hline Poor Households with electricity - in \% & 8550 \\
\hline Households with bathroom and toilette - in \% & 45.0 \\
\hline Households with bathroom and toilette - in \% & 12.0 \\
\hline Households connected to Water System - in \% & 33.0 \\
\hline Poor Households connected to Water System - in \% & 11.0 \\
\hline Households that dumps wasted water around the house (\%) & 75.0 \\
\hline Poor Households that dumps wasted water around the house - in \% & 95.0 \\
\hline Households that utilize mostly gas for cooking - in \% & 63.0 \\
\hline Poor Households that utilize mostly gas for cooking in \% & 36 \\
\hline
\end{tabular}


Table 19: Population and Households by Poverty Condition

\begin{tabular}{|c|c|c|c|c|c|c|c|c|}
\hline & \multicolumn{4}{|c|}{ Population } & \multicolumn{4}{|c|}{ Households } \\
\hline & Poor & $\begin{array}{l}\text { Very } \\
\text { poor }\end{array}$ & Not poor & Total & Poor & $\begin{array}{l}\text { Very } \\
\text { Poor }\end{array}$ & Not poor & Total \\
\hline CAPE VERDE & 92,828 & 79,899 & 297,960 & 470,687 & 13,369 & 13,324 & 68,564 & 95,257 \\
\hline Urban & 29,739 & 35,043 & 194,539 & 259,321 & 4019 & 5481 & 44803 & 54303 \\
\hline Rural & 63,089 & 44,856 & 103,421 & 211,366 & 9350 & 7843 & 23761 & 40954 \\
\hline S. Antão & 17,553 & 9,861 & 23,209 & 50,623 & 2450 & 1850 & 5969 & 10269 \\
\hline S. Vicente & 7,372 & 10,868 & 53,206 & 71,446 & 1006 & 1790 & 12961 & 15757 \\
\hline S. Nicolau & 3,516 & 2,479 & 8,928 & 14,923 & 505 & 407 & 2307 & 3219 \\
\hline Sal & 1,020 & 1,159 & 14,729 & 16,908 & 219 & 163 & 3438 & 3820 \\
\hline B. Vista & 102 & 662 & 4,377 & 5,141 & 34 & 94 & 1005 & 1133 \\
\hline Maio & 1,812 & 1,022 & 4,557 & 7,391 & 220 & 172 & 1191 & 1583 \\
\hline Santiago & 50,329 & 44,697 & 160,948 & 255,974 & 7381 & 7348 & 35559 & 50288 \\
\hline Fogo & 10,262 & 7,101 & 23,872 & 41,235 & 1420 & 1144 & 5033 & 7597 \\
\hline Brava & 862 & 2,050 & 4,134 & 7,046 & 134 & 356 & 1101 & 1591 \\
\hline
\end{tabular}

ANALYSIS BY INDIVIDUAL

Table 20: Cape Verde Population by Poverty Status and Island of Residence

\begin{tabular}{|c|c|c|c|c|c|c|}
\hline & Total & Very Poor & Poor & $\begin{array}{c}\text { Low income not } \\
\text { poor }\end{array}$ & $\begin{array}{c}\text { Medium } \\
\text { income not } \\
\text { poor }\end{array}$ & $\begin{array}{c}\text { High income } \\
\text { not poor }\end{array}$ \\
\hline CAPE VERDE & $\mathbf{4 7 0 . 6 8 7}$ & $\mathbf{9 2 . 8 2 8}$ & $\mathbf{7 9 . 8 9 9}$ & $\mathbf{2 2 7 . 1 9 7}$ & $\mathbf{4 7 . 1 4 1}$ & $\mathbf{2 3 . 6 2 2}$ \\
\hline Urban & 259.321 & 29.739 & 35.043 & 134.542 & 38.509 & 21.488 \\
\hline Rural & 211.366 & 63.089 & 44.856 & 92.655 & 8.632 & 2.134 \\
\hline S. Antão & 50.623 & 17.553 & 9.861 & 19.993 & 2.442 & 774 \\
\hline S. Vicente & 71.446 & 7.372 & 10.868 & 38.909 & 8.482 & 5.815 \\
\hline Fogo & 41.235 & 10.262 & 7.101 & 20.873 & 2.237 & 762 \\
\hline Praia Urbano & 106.595 & 8.246 & 13.391 & 54.866 & 19.375 & 10.717 \\
\hline Santiago Rural & 149.379 & 42.083 & 31.306 & 64.576 & 9.249 & 2.165 \\
\hline SourcidnF $20002001,1 N 5$ & & & & &
\end{tabular}

Source: IDRF 2000/2001, INE.

Table 21: Population Spatial Distribution by Sex and Poverty Status

\begin{tabular}{|c|c|c|c|c|c|c|c|c|c|}
\hline & \multicolumn{3}{|c|}{ TOTAL } & \multicolumn{3}{c|}{ POOR } & \multicolumn{3}{c|}{ Not Poor } \\
\hline & Total & Male & Female & Total & Male & Female & Total & Male & Female \\
\hline Cabo Verde & 470.687 & 227.624 & 243.063 & 172.727 & 83.858 & 88.869 & 297.960 & 143.766 & 154.194 \\
\hline S. Antão & 50.623 & 25.824 & 24.799 & 27.414 & 14.173 & 13.241 & 23.209 & 11.651 & 11.558 \\
\hline S. Vicente & 71.446 & 34.531 & 36.915 & 18.240 & 8.559 & 9.681 & 53.206 & 25.972 & 27.234 \\
\hline Fogo & 41.235 & 20.307 & 20.928 & 17.363 & 8.417 & 8.946 & 23.872 & 11.890 & 11.982 \\
\hline Praia ( Urban) & 106.595 & 50.636 & 55.959 & 21.637 & 10.180 & 11.457 & 84.958 & 40.456 & 44.502 \\
\hline Rural Santiago & 149.379 & 70.458 & 78.921 & 73.389 & 35.170 & 38.219 & 75.990 & 35.288 & 40.702 \\
\hline Other Islands & 51.409 & 25.868 & 25.541 & 14.684 & 7.359 & 7.325 & 36.725 & 18.509 & 18.216 \\
\hline
\end{tabular}

Source: IDRF 2000 
Table 22: Population Distribution by Gender, Age Group and Poverty Status

\begin{tabular}{|c|c|c|c|c|c|c|c|c|c|c|c|c|}
\hline \multirow{3}{*}{$\begin{array}{l}\text { Gender/ Age } \\
\text { Group }\end{array}$} & \multirow{2}{*}{\multicolumn{3}{|c|}{ Total Population }} & \multicolumn{9}{|c|}{ Poverty Status } \\
\hline & & & & \multicolumn{3}{|c|}{ Very Poor } & \multicolumn{3}{|c|}{ Poor } & \multicolumn{2}{|c|}{ Not Poor } & \multirow{2}{*}{ Total } \\
\hline & Male & Female & Total & Male & Female & \begin{tabular}{|l|} 
Total \\
\end{tabular} & male & Female & Total & Male & \begin{tabular}{|l|} 
Female \\
\end{tabular} & \\
\hline Total & \begin{tabular}{|l|}
227.624 \\
\end{tabular} & 243.063 & 470.687 & \begin{tabular}{|l|}
45.198 \\
\end{tabular} & 477.630 & 92.828 & 38.660 & 41.239 & 79.899 & \begin{tabular}{|l|}
143.766 \\
\end{tabular} & \begin{tabular}{|l|}
154.194 \\
\end{tabular} & 297.960 \\
\hline 0 years & \begin{tabular}{|l|}
4.421 \\
\end{tabular} & 4.529 & 8.950 & \begin{tabular}{|l|}
1.031 \\
\end{tabular} & 1.030 & 2.061 & 918 & 965 & 1.883 & 2.472 & 2.534 & 5.006 \\
\hline $1-4$ & 23.084 & 21.349 & 1.433 & 5.656 & 238 & 10.894 & 4.391 & 4.029 & 8.420 & 13.037 & 12.082 & 25.119 \\
\hline $5-9$ & 34.616 & 31.804 & 66.420 & 8.604 & 8.029 & 16.633 & 6.942 & 6.085 & 13.027 & 19.070 & 17.690 & 6.760 \\
\hline $10-14$ & 255 & 37.732 & 5.987 & 8.985 & 838 & 17.823 & 6.805 & 6.694 & 13.499 & 22.465 & 22.200 & 44.665 \\
\hline 15-24 & 117 & .551 & 97.668 & 9.986 & 866 & 17.852 & 8.586 & 211 & 16.797 & 31.545 & 31.474 & 3.019 \\
\hline $25-44$ & 47.377 & 56.220 & 103.597 & 6.587 & 9.728 & 16.315 & 6.574 & 8.094 & 14.668 & 34.216 & 38.398 & 72.614 \\
\hline $45-64$ & 121 & 25.0 & & 2.475 & 880 & 6.555 & 2.441 & 4.210 & 6.651 & 12.205 & 16.752 & 28.957 \\
\hline 65 or over & 12.633 & 18.836 & 31.469 & 1.874 & 2.821 & 4.695 & 2.003 & 2.951 & 4.954 & 8.756 & 13.064 & 21.820 \\
\hline TAL & & 100 & & 110 & & & & & & & & \\
\hline O ANOS & 1, & $1_{t}$ & 1, & 2,3 & & 2,2 & 2,4 & 2,3 & 2,4 & 1,7 & 6 & 1,7 \\
\hline $1-4$ & 10,1 & 8 & 9 & 12,5 & 11,0 & 11,7 & 11,4 & 9,8 & 10,5 & 9,1 & 7,8 & 8,4 \\
\hline $5-9$ & & & & 19,0 & & 17,9 & 18,0 & 14,8 & 16,3 & & 11,5 & 12,3 \\
\hline 10-14 & 16,8 & 15,5 & 16,1 & 19,9 & 18,6 & 19,2 & 17,6 & 16,2 & 16,9 & 15,6 & 14,4 & 15,0 \\
\hline $15-24$ & 22,0 & 19,6 & 20,8 & 22,1 & 16,5 & 19,2 & 22,2 & 19,9 & 21,0 & 21,9 & 20,4 & 21,2 \\
\hline $25-44$ & & & & 14,6 & & 17,6 & 17,0 & 19,6 & 18,4 & 23 & 24,9 & 24,4 \\
\hline $45-64$ & 7,5 & 10,3 & 9,0 & 5,5 & 8,6 & 7,1 & 6,3 & 10,2 & 8,3 & 8,5 & 10,9 & 9,7 \\
\hline 65 Or over & 5,5 & 7,7 & 6,7 & 4,1 & 5,9 & 5,1 & 5,2 & 7,2 & 6,2 & 6,1 & 8,5 & 7,3 \\
\hline
\end{tabular}

Source: IDRF 2000/2001, INE.

Table 23: Population 4 years and older by Poverty Status and Educational Level

\begin{tabular}{|c|c|c|c|c|c|c|}
\hline Education Level & Total & Very Poor & Poor & $\begin{array}{c}\text { Low income } \\
\text { nor poor }\end{array}$ & $\begin{array}{c}\text { Medium } \\
\text { income not } \\
\text { poor }\end{array}$ & $\begin{array}{c}\text { High income } \\
\text { not poor }\end{array}$ \\
\hline No Schooling & 19,5 & 24,8 & 22,7 & 18,8 & 12,8 & 7,9 \\
\hline Basic Education & 54,7 & 61,1 & 60,3 & 54,8 & 45,4 & 29,3 \\
\hline Secondary & 23,2 & 13,8 & 16,7 & 25,2 & 35,4 & 36,5 \\
\hline Post secondary & 2,5 & 0,1 & 0,2 & 1,0 & 6,3 & 26,1 \\
\hline No respondent & 0,2 & 0,2 & 0,1 & 0,2 & 0,1 & 0,1 \\
\hline Total & 100,0 & 100,0 & 100,0 & 100,0 & 100,0 & 100,0 \\
\hline & & & & & & \\
\hline Male & & & & & & 5,3 \\
\hline No Schooling & 15,2 & 21,2 & 17,7 & 14,4 & 9,3 & 5,5 \\
\hline Basic Education & 57,2 & 63,1 & 65,0 & 57,4 & 45,9 & 31,4 \\
\hline Secondary & 24,3 & 15,4 & 17,1 & 26,8 & 37,0 & 32,5 \\
\hline Post Secondary & 3,1 & 0,1 & 0,2 & 1,2 & 7,7 & 30,3 \\
\hline No respondent & 0,2 & 0,3 & 0,1 & 0,2 & 0,1 & 0,3 \\
\hline Total & 100,0 & 100,0 & 100,0 & 100,0 & 100,0 & 100,0 \\
\hline & & & & & & \\
\hline Female & & & & & & \\
\hline No Schooling & 23,4 & 28,2 & 27,4 & 22,8 & 16,2 & 10,5 \\
\hline Basic Education & 52,4 & 59,3 & 55,9 & 52,5 & 44,9 & 27,0 \\
\hline Secondary & 22,2 & 12,3 & 16,3 & 23,8 & 33,8 & 40,8 \\
\hline Post secondary & 2,0 & 0,0 & 0,3 & 0,8 & 5,0 & 21,7 \\
\hline No respondent & 0,1 & 0,1 & 0,1 & 0,1 & 0,1 & 0,0 \\
\hline Total & 100,0 & 100,0 & 100,0 & 100,0 & 100,0 & 100,0 \\
\hline
\end{tabular}

Source: IDRF 2000/2001, INE. 
Table 24: Population over 15 years by Sex , Poverty Status and Employment Condition

\begin{tabular}{|c|c|c|c|c|c|c|c|c|c|}
\hline \multirow{2}{*}{ Employment Condition } & \multicolumn{3}{|c|}{ Poor } & \multicolumn{3}{c|}{ Not Poor } & \multicolumn{3}{c|}{ Total } \\
\cline { 2 - 10 } & Male & Fem & Total & Male & Fem & Total & Male & Fem & Total \\
\hline Active Population & 28.650 & 26.010 & 54.660 & 60.492 & 51.229 & 111.721 & 89.142 & 77.239 & 166.381 \\
\hline \% Employed & 50 & 35 & 42 & 60 & 42 & 50 & 57 & 40 & 47 \\
\hline \% Unemployed & 21 & 20 & 20 & 10 & 9 & 10 & 14 & 13 & 13 \\
\hline \% Inactive & 29 & 46 & 38 & 30 & 49 & 40 & 30 & 48 & 39 \\
\hline Unemployment Rate I (Broad definition) & 29 & 36 & 33 & 15 & 18 & 16 & 19 & 24 & 22 \\
\hline \% Poor/ Not poor ,in active population & 32 & 34 & 33 & 68 & 66 & 67 & 100 & 100 & 100 \\
\hline \% Poor /Tot poor, in employed population & 28 & 28 & 28 & 72 & 72 & 72 & 100 & 100 & 100 \\
\hline \% Poor/ Not poor in unemployed population & 49 & 50 & 49 & 51 & 50 & 51 & 100 & 100 & 100 \\
\hline \% Poor in active population & 31 & 31 & 31 & 69 & 69 & 69 & 100 & 100 & 100 \\
\hline
\end{tabular}

Source: IDRF 2000/2001, INE.

Table 25: Percentual Distribution of Employed Poor Population by Sector of Activity

\begin{tabular}{|c|c|c|c|c|c|c|c|}
\hline & \multirow[b]{2}{*}{$\begin{array}{l}\text { Employed } \\
\text { poors }\end{array}$} & \multicolumn{6}{|c|}{ Employment Situation } \\
\hline & & Employed & $\begin{array}{c}\text { Own } \\
\text { account }\end{array}$ & Employer & $\begin{array}{c}\text { Unpaid Family } \\
\text { workers }\end{array}$ & Other & Total \\
\hline \multirow{6}{*}{ 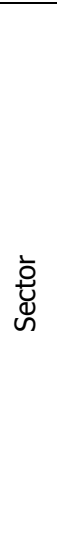 } & $\begin{array}{l}\text { Agriculture, } \\
\text { forestry and } \\
\text { livestock }\end{array}$ & 14 & 41 & 84 & 93 & 0 & 32 \\
\hline & Construction & 16 & 11 & 0 & 1 & 4 & 12 \\
\hline & $\begin{array}{l}\text { commerce } \\
\text { and vehicle } \\
\text { repair and } \\
\text { maintenance }\end{array}$ & 9 & 24 & 0 & 3 & 11 & 13 \\
\hline & $\begin{array}{c}\text { Public } \\
\text { Services }\end{array}$ & 25 & 2 & 0 & 0 & 0 & 14 \\
\hline & Others & 36 & 23 & 16 & 4 & 85 & 29 \\
\hline & Total & 100 & 100 & 100 & 100 & 100 & 100 \\
\hline
\end{tabular}

Source: IDRF 2000/2001, INE.

Table 26: \% of Health System Coverage in Total Health Expenditures, by Poverty Status

\begin{tabular}{|c|c|c|c|c|c|c|}
\hline & \multicolumn{5}{|c|}{$\begin{array}{l}\text { Poverty Status } \\
\end{array}$} & \multirow[b]{2}{*}{ Total } \\
\hline & $\begin{array}{l}\text { Very } \\
\text { poor }\end{array}$ & Poor & $\begin{array}{c}\text { Low Income } \\
\text { Not poor }\end{array}$ & $\begin{array}{l}\text { Medium income } \\
\text { Not Poor }\end{array}$ & $\begin{array}{l}\text { High income } \\
\text { Not poor }\end{array}$ & \\
\hline \multirow{3}{*}{ Yes, Health coverage by State } & 17761 & 17091 & 33638 & 4101 & 1814 & 74465 \\
\hline & $23.9 \%$ & $23.0 \%$ & $45.3 \%$ & $5.5 \%$ & $2.4 \%$ & $100 \%$ \\
\hline & $19.1 \%$ & $21.4 \%$ & $14.8 \%$ & $8.7 \%$ & $7.7 \%$ & $15.8 \%$ \\
\hline \multirow{3}{*}{ Yes, Health Coverage by Hiring Enterprise } & 2807 & 2006 & 12158 & 4103 & 3890 & 24964 \\
\hline & $11.2 \%$ & $8.0 \%$ & $48.7 \%$ & $16.4 \%$ & $15.6 \%$ & $100 \%$ \\
\hline & $3.0 \%$ & $2.5 \%$ & $5.4 \%$ & $8.7 \%$ & $16.5 \%$ & $5.3 \%$ \\
\hline \multirow{3}{*}{ Yes, Health Coverage by INPS } & 4316 & 6000 & 30379 & 10493 & 7075 & 58263 \\
\hline & $7.4 \%$ & $10.3 \%$ & $52.1 \%$ & $18.0 \%$ & $12.1 \%$ & $100 \%$ \\
\hline & $4.6 \%$ & $7.5 \%$ & $13.4 \%$ & $22.3 \%$ & $30.0 \%$ & $12.4 \%$ \\
\hline \multirow{3}{*}{ No } & 67944 & 54802 & 150962 & 28444 & 10843 & 312995 \\
\hline & $21.7 \%$ & $17.5 \%$ & $48.2 \%$ & $9.1 \%$ & $3.5 \%$ & $100 \%$ \\
\hline & $73.2 \%$ & $68.6 \%$ & $66.4 \%$ & $60.3 \%$ & $45.9 \%$ & $66.5 \%$ \\
\hline \multirow{3}{*}{ Total } & 92828 & 79899 & 227197 & 47141 & 23622 & 470687 \\
\hline & $19.7 \%$ & $17.0 \%$ & $48.3 \%$ & $10.0 \%$ & $5.0 \%$ & $100 \%$ \\
\hline & $100 \%$ & $100 \%$ & $100 \%$ & $100 \%$ & $100 \%$ & $100 \%$ \\
\hline
\end{tabular}

Interpretation: $23,9 \%$ refers to the percentage of persons in health participation system that are very poor. The second percentage $(19,1 \%)$ refers to the percentage of very poor in a health participation system throug the State. In other words, $23,9 \%$ of people in a health participation system through the State are poor and $19,1 \%$ of the very poor has health participation system through the State . The same rational applies to the subsequent tables. 
Table 27: Health Problems and Poverty Status

\begin{tabular}{|c|c|c|c|c|c|c|}
\hline \multirow{4}{*}{} & \multicolumn{5}{|c|}{ Poverty Status } & \multirow{2}{*}{ Total } \\
\cline { 2 - 7 } & Very Poor & Poor & $\begin{array}{c}\text { Low income } \\
\text { Not Poor }\end{array}$ & $\begin{array}{c}\text { Medium } \\
\text { Income Not } \\
\text { Poor }\end{array}$ & $\begin{array}{c}\text { High Income } \\
\text { Not poor }\end{array}$ & \\
\hline \multirow{3}{*}{ yes } & 15229 & 14176 & 40821 & 9327 & 4632 & 84185 \\
\cline { 2 - 7 } & $18.1 \%$ & $16.8 \%$ & $48.5 \%$ & $11.1 \%$ & $5.5 \%$ & $100 \%$ \\
\cline { 2 - 7 } No & $16.4 \%$ & $17.7 \%$ & $18.0 \%$ & $19.8 \%$ & $19.6 \%$ & $17.9 \%$ \\
\cline { 2 - 7 } & 77599 & 65723 & 186376 & 37814 & 18990 & 386502 \\
\cline { 2 - 7 } & $20.1 \%$ & $17.0 \%$ & $48.2 \%$ & $9.8 \%$ & $4.9 \%$ & $100 \%$ \\
\hline \multirow{3}{*}{ Total } & $83.6 \%$ & $82.3 \%$ & $82.0 \%$ & $80.2 \%$ & $80.4 \%$ & $82.1 \%$ \\
\cline { 2 - 7 } & 92828 & 79899 & 227197 & 47141 & 23622 & 470687 \\
\cline { 2 - 7 } & $19.7 \%$ & $17.0 \%$ & $48.3 \%$ & $10.0 \%$ & $5.0 \%$ & $100 \%$ \\
\hline
\end{tabular}

Source: IDRF 2000/2001, INE.

Table 28: Distribution of Individuals from 18 to 60 years of age by Poverty Status and sex, by Body Mass Index

\begin{tabular}{|c|c|c|c|c|c|c|c|c|c|}
\hline Classes of Body Mass Index & \multicolumn{3}{|c|}{ Poors } & \multicolumn{3}{c|}{ Not Poors } & \multicolumn{3}{c|}{ Total } \\
\hline & Male & Female & Total & Male & Female. & Total & Male & Female. & Total \\
\hline Chronic Energy deficiency & 1 & 2 & 2 & 1 & 2 & 2 & 1 & 2 & 2 \\
\hline Normal Under Weight & 4 & 6 & 5 & 4 & 5 & 4 & 4 & 5 & 5 \\
\hline Normal Weight & 80 & 66 & 72 & 70 & 59 & 64 & 73 & 61 & 67 \\
\hline Normal overweight & 14 & 21 & 18 & 22 & 25 & 24 & 20 & 24 & 22 \\
\hline Obese & 1 & 5 & 3 & 3 & 9 & 6 & 3 & 8 & 5 \\
\hline Total & 100 & 100 & 100 & 100 & 100 & 100 & 100 & 100 & 100 \\
\hline
\end{tabular}

Source: IDRF 2000/2001, INE

Table 29: Distribution of children under 5 by Poverty Status and Sex, by Age Groups

\begin{tabular}{|c|c|c|c|c|c|c|c|c|c|}
\hline Age Groups & \multicolumn{3}{|c|}{ Poors } & \multicolumn{3}{c|}{ Not Poors } & \multicolumn{3}{c|}{ Total } \\
\hline & Male & Female & Total & Male & Female & Total & Male & Female & Total \\
\hline 0 to 11 months & 1949 & 1995 & 3944 & 2472 & 2534 & 5006 & 4421 & 4529 & 8950 \\
\hline 1 year & 1621 & 1830 & 3451 & 2691 & 2575 & 5166 & 4312 & 4305 & 8617 \\
\hline 2 to 3 years & 5335 & 5004 & 10339 & 6504 & 5924 & 12428 & 11839 & 10928 & 22767 \\
\hline 4 to 5 years & 5580 & 4875 & 10555 & 7241 & 6083 & 13324 & 12821 & 11058 & 23879 \\
\hline Total & 14485 & 13804 & 28289 & 18908 & 17016 & 35924 & 33393 & 30820 & 64213 \\
\hline
\end{tabular}

Source: IDRF 2000/2001, 


\section{Analysis by Household}

Table 30: Household Spatial Distribution by Poverty Status

\begin{tabular}{|c|c|c|c|c|c|c|c|c|c|c|c|c|}
\hline \multirow{3}{*}{ CAPE VERDE } & \multicolumn{2}{|c|}{ Total } & \multicolumn{2}{|c|}{ Very Poor } & \multicolumn{2}{|l|}{ Poor } & \multicolumn{2}{|c|}{ Low Income not poor } & \multicolumn{4}{|c|}{ Medium income not poor High income not poor } \\
\hline & Effectives & $\%$ & Effectives & $\%$ & Effectives & $\%$ & Effectives & $\%$ & Effectives & $\%$ & Effectives & $\%$ \\
\hline & 95,257 & 100.0 & 13,369 & 100.0 & 13,324 & 100.0 & 46,033 & 100.0 & 13,162 & 100.0 & 9,369 & 100.0 \\
\hline Urban & 54,303 & 57.0 & 4,019 & 30.1 & 5,481 & 41.1 & 26,247 & 57.0 & 10,268 & 78.0 & 8,288 & 88.5 \\
\hline Rural & 40,954 & 43.0 & 9,350 & 69.9 & 7,843 & 58.9 & 19,786 & 43.0 & 2,894 & 22.0 & 1,081 & 11.5 \\
\hline S. Antão & 10,269 & 10.8 & 2,450 & 18.3 & 1,850 & 13.9 & 4,552 & 9.9 & 929 & 7.1 & 488 & 5.2 \\
\hline S. Vicente & 15,757 & 16.5 & 1,006 & 7.5 & 1,790 & 13.4 & 8,295 & 18.0 & 2,455 & 18.7 & 2,211 & 23.6 \\
\hline S. Nicolau & 3,219 & 3.4 & 505 & 3.8 & 407 & 3.1 & 1,690 & 3.7 & 359 & 2.7 & 258 & 2.8 \\
\hline Sal & 3,820 & 4.0 & 219 & 1.6 & 163 & 1.2 & 1,781 & 3.9 & 756 & 5.7 & 901 & 9.6 \\
\hline B. Vista & 1,133 & 1.2 & 34 & 0.3 & 94 & 0.7 & 626 & 1.4 & 280 & 2.1 & 99 & 1.1 \\
\hline Maio & 1,583 & 1.7 & 220 & 1.6 & 172 & 1.3 & 849 & 1.8 & 195 & 1.5 & 147 & 1.6 \\
\hline Santiago & 50,288 & 52.8 & 7,381 & 55.2 & 7,348 & 55.1 & 23,398 & 50.8 & 7,422 & 56.4 & 4,739 & 50.6 \\
\hline Fogo & 7,597 & 8.0 & 1,420 & 10.6 & 1,144 & 8.6 & 4,086 & 8.9 & 581 & 4.4 & 366 & 3.9 \\
\hline Brava & 1,591 & 1.7 & 134 & 1.0 & 356 & 2.7 & 756 & 1.6 & 185 & 1.4 & 160 & 1.7 \\
\hline
\end{tabular}

Source: IDRF 2000/2001, INE.

Table 31: Households by Poverty Status and Education level

\begin{tabular}{|c|c|c|c|c|c|c|c|c|c|}
\hline \multirow{3}{*}{$\begin{array}{c}\text { Education } \\
\text { Level }\end{array}$} & \multirow{2}{*}{\multicolumn{3}{|c|}{ Total }} & \multicolumn{6}{|c|}{ Poverty Status } \\
\hline & & & & \multicolumn{3}{|c|}{ Poor } & \multicolumn{3}{|c|}{ Not poor } \\
\hline & Male & Female & Total & Male & Female & Total & Male & Female & Total \\
\hline No Schooling & 9517 & 16982 & 26499 & 4349 & 6742 & 11091 & 5168 & 10240 & 15408 \\
\hline Basic Education & 32642 & 20567 & 53209 & 8994 & 5939 & 14933 & 23648 & 14628 & 38276 \\
\hline \begin{tabular}{|l|} 
Secondary \\
\end{tabular} & 6986 & 3112 & 10098 & 406 & 243 & 649 & 6580 & 2869 & 9449 \\
\hline Post Secondary & 4383 & 1048 & 5431 & 20 & 0 & 20 & 4363 & 1048 & 5411 \\
\hline TOTAL & 53528 & 41729 & 95257 & 13769 & 12924 & 26693 & 39759 & 28805 & 68564 \\
\hline \begin{tabular}{|l|} 
No schooling \\
\end{tabular} & 17,8 & 40,7 & 27,8 & 31,6 & 52,2 & 41,6 & 13,0 & 35,5 & 22,5 \\
\hline Basic Education & 61,0 & 49,3 & 55,9 & 65,3 & 46,0 & 55,9 & 59,5 & 50,8 & 55,8 \\
\hline Secondary & 13,1 & 7,5 & 10,6 & 2,9 & 1,9 & 2,4 & 16,5 & 10,0 & 13,8 \\
\hline Post Secondary & 8,2 & 2,5 & 5,7 & 0,1 & 0,0 & 0,1 & 11,0 & 3,6 & 7,9 \\
\hline \begin{tabular}{|c|} 
TOTAL \\
\end{tabular} & 100,0 & 100,0 & 100,0 & 100,0 & 100,0 & 100,0 & 100,0 & 99,9 & 100,0 \\
\hline No schooling & 35,9 & 64,1 & 100,0 & 39,2 & 60,8 & 100,0 & 33,5 & 66,5 & 100,0 \\
\hline Basic Education & 61,3 & 38,7 & 100,0 & 60,2 & 39,8 & 100,0 & 61,8 & 38,2 & 100,0 \\
\hline Secondary & 69,2 & 30,8 & 100,0 & 62,6 & 37,4 & 100,0 & 69,6 & 30,4 & 100,0 \\
\hline Post Secondary & 80,7 & 19,3 & 100,0 & 100,0 & 0,0 & 100,0 & 80,6 & 19,4 & 100,0 \\
\hline TOTAL & 56,2 & 43,8 & 100,0 & 51,6 & 48,4 & 100,0 & 58,0 & 42,0 & 100,0 \\
\hline
\end{tabular}

Source: IDRF 2000/2001, INE. 
Table 32: Percentage of Head of Household 15 years and over by Poverty Status, Sex, and Employment Condition

\begin{tabular}{|c|c|c|c|c|c|c|c|c|c|}
\hline \multirow{2}{*}{ Employment Condition } & \multicolumn{3}{|c|}{ Poor } & \multicolumn{3}{|c|}{ Not Poor } & \multicolumn{3}{|c|}{ Total } \\
\hline & Male & Female & Total & Male & Female & Total & Male & Female & Total \\
\hline Active Population & 11.067 & 8.759 & 19.826 & 33.517 & 18.277 & 51.794 & 44.584 & 27.036 & 71.620 \\
\hline \% employed & 68 & 54 & 61 & 79 & 56 & 69 & 76 & 56 & 67 \\
\hline$\%$ unemployed & 13 & 13 & 13 & 5 & 7 & 6 & 7 & 9 & 8 \\
\hline$\%$ Inactive & 20 & 32 & 26 & 16 & 37 & 24 & 17 & 35 & 25 \\
\hline Unemployment Rate & 16 & 20 & 18 & 6 & 12 & 8 & 9 & 14 & 11 \\
\hline \% Poors/Not poors in active Population & 25 & 32 & 28 & 75 & 68 & 72 & 100 & 100 & 100 \\
\hline$\%$ de Poors/ Not poors in Employed Population & 23 & 30 & 26 & 77 & 70 & 74 & 100 & 100 & 100 \\
\hline \% Poors / Not poors in Unemployed Population & 45 & 45 & 45 & 55 & 55 & 55 & 100 & 100 & 100 \\
\hline \% Poors in Active population & 30 & 28 & 29 & 70 & 72 & 71 & 100 & 100 & 100 \\
\hline
\end{tabular}
Source: IDRF 2000/2001, INE.

Table 33: Distribution of Employed Head of Poor Household by Sector of Activity (in \%)

Employed Poor

Source: IDRF 2000/2001, INE.

Table 34: Household Average Monthly Expenditures by Poverty Status and Expenditure Type (in \%)

\begin{tabular}{|c|c|c|c|c|c|c|}
\hline Expenditure Type & $\begin{array}{l}\text { Very } \\
\text { Poor }\end{array}$ & Poor & $\begin{array}{l}\text { Low Income } \\
\text { Not Poor }\end{array}$ & $\begin{array}{c}\text { Medium } \\
\text { Income Not } \\
\text { Poor }\end{array}$ & $\begin{array}{c}\text { High } \\
\text { Income } \\
\text { Not Poor }\end{array}$ & Total \\
\hline $\begin{array}{l}\text { Food Products and Non Alcoholic } \\
\text { Beverages }\end{array}$ & 6,5 & 9,2 & 14,6 & 20,3 & 31,8 & 15,2 \\
\hline $\begin{array}{c}\text { Alcoholic Beverages, Tobacco and } \\
\text { Drugs }\end{array}$ & 0,2 & 0,3 & 0,6 & 1,3 & 2,5 & 0,8 \\
\hline Clothes and Shoes & 0,3 & 0,5 & 1,6 & 4,1 & 6,2 & 2,0 \\
\hline $\begin{array}{l}\text { Housing, Water, Electricity, Gas } \\
\text { and Other fuels }\end{array}$ & 3,4 & 5,2 & 9,2 & 16,3 & 24,6 & 10,3 \\
\hline $\begin{array}{c}\text { Furniture, Art and Decor, } \\
\text { Domestic Equipment, painting }\end{array}$ & 0,3 & 0,4 & 1,2 & 4,6 & 8,4 & 2,2 \\
\hline Health & 0,1 & 0,2 & 0,5 & 1,4 & 2,6 & 0,7 \\
\hline Transports & 0,4 & 0,8 & 1,3 & 3,7 & 13,6 & 2,6 \\
\hline Communications & 0,1 & 0,4 & 1,0 & 2,3 & 6,2 & 1,5 \\
\hline $\begin{array}{c}\text { Entertainment, Recreation and } \\
\text { Culture }\end{array}$ & 0,1 & 0,2 & 0,6 & 1,7 & 5,8 & 1,1 \\
\hline $\begin{array}{l}\text { Education } \\
\end{array}$ & 0,03 & 0,05 & 0,2 & 0,7 & 1,6 & 0,4 \\
\hline $\begin{array}{c}\text { Restaurants, Hotels, Cafés and } \\
\text { others }\end{array}$ & 0,1 & 0,2 & 0,5 & 1,2 & 6,1 & 1,1 \\
\hline Good and services Divers & 0,1 & 0,3 & 1,1 & 4,0 & 16,2 & 2,8 \\
\hline Total & 12 & 18 & 32 & 62 & 126 & 41 \\
\hline
\end{tabular}

Source: IDRF 2000/2001, INE. 
Table 35: Poor and Not Poor Household Distribution by Housing Type and Island of Residence (in \%)

\begin{tabular}{|c|c|c|c|c|c|c|c|c|c|}
\hline \multirow{2}{*}{$\begin{array}{l}\text { Housing } \\
\text { Type }\end{array}$} & \multicolumn{3}{|c|}{ Cabo Verde } & \multicolumn{3}{|c|}{ Santo Antão } & \multicolumn{2}{|c|}{ São Vicente } & \multirow{2}{*}{ Total } \\
\hline & Poor & Not Poor & Total & Poor & Not Poor & Total & Poor & Not Poor & \\
\hline Total & 100 & 100 & 100 & 100 & 100 & 100 & 100 & 100 & 100 \\
\hline Individual Home & 90,6 & 84,0 & 85,8 & 89,9 & 88,9 & 89,3 & 77,2 & 78,0 & 77,9 \\
\hline Apartment & 0,1 & 5,8 & 4,2 & 0,0 & 3,4 & 2,0 & 0,0 & 8,0 & 6,5 \\
\hline Town House & 0,1 & 0,9 & 0,7 & 0,0 & 0,0 & 0,0 & 0,0 & 2,7 & 2,2 \\
\hline Tent & 2,8 & 0,7 & 1,3 & 2,4 & 1,6 & 2,0 & 12,7 & 1,5 & 3,5 \\
\hline
\end{tabular}

Source: IDRF 2000/2001, INE. 
Table 36: Poor and Not Poor Household Distribution Proportion by Housing Type and Island of Residence

\begin{tabular}{|c|c|c|c|c|c|c|c|c|c|c|c|c|c|c|c|c|c|c|c|}
\hline \multirow[b]{2}{*}{ Housing Type } & \multicolumn{2}{|c|}{ S. Antão } & \multicolumn{2}{|c|}{ S. Vicente } & \multicolumn{2}{|c|}{ S. Nicolau } & \multicolumn{2}{|r|}{ Sal } & \multicolumn{2}{|c|}{ B. Vista } & \multicolumn{2}{|r|}{ Maio } & \multicolumn{2}{|c|}{ Santiago } & \multicolumn{2}{|r|}{ Fogo } & \multicolumn{2}{|c|}{ Brava } & \multirow[t]{2}{*}{ Total } \\
\hline & Poors & Not Poors & Poors & Not Poors & Poors & Not Poors & Poors & Not Poors & Poors & sot Poors & Poors & Not Poors & Poors & Not Poors & Poors & s Not Poors & Poors & $t$ poors & \\
\hline Individual Home & 89.9 & 88.9 & 77.2 & 78.0 & 86.1 & 90.0 & 34.6 & 67.8 & 75.0 & 83.4 & 77.6 & 90.4 & 95.0 & 84.8 & 92.3 & 92.6 & 98.8 & 92.6 & 85.8 \\
\hline Apartment & & 3.4 & & 8.0 & & & 5.8 & 7.1 & & & & 2.2 & & 6.7 & & 1.5 & & & 4.2 \\
\hline Town House & & & & 2.7 & & & 5.8 & 3.1 & & & & & & 0.4 & & 0.5 & & & 0.7 \\
\hline Tent & 2.4 & 1.6 & 12.7 & 1.5 & & & 41.1 & 3.5 & & 1.3 & & & 0.7 & 0.1 & 0.9 & & & & 1.3 \\
\hline Part of the House & 7.7 & 6.0 & 10.1 & 9.8 & 13.9 & 10.0 & 12.8 & 18.6 & 25.0 & 15.3 & 22.4 & 7.4 & 4.4 & 8.0 & 6.8 & 5.4 & 1.2 & 7.4 & 8.0 \\
\hline Total & 100.0 & 100.0 & 100.0 & 100.0 & 100.0 & 100.0 & 100.0 & 100.0 & 100.0 & 100.0 & 100.0 & 100.0 & 100.0 & 100.0 & 100.0 & 100.0 & 100.0 & 100.0 & 100.0 \\
\hline
\end{tabular}

Source: IDRF 2000/2001, INE.

Table 37: Households Distribution by water quality and domestic usage and by island of residence

\begin{tabular}{|c|c|c|c|c|c|c|c|c|c|c|c|c|c|c|c|c|c|c|c|c|}
\hline \multirow[b]{2}{*}{ Water Source } & \multicolumn{2}{|c|}{ S. Antão } & \multicolumn{2}{|c|}{ S. Vicente } & \multicolumn{2}{|c|}{ S. Nicolau } & \multicolumn{2}{|l|}{ Sal } & \multicolumn{2}{|c|}{ B. Vista } & \multicolumn{2}{|c|}{ Maio } & \multicolumn{2}{|c|}{ Santiago } & \multicolumn{2}{|c|}{ Fogo } & \multicolumn{2}{|c|}{ Brava } & \multicolumn{2}{|c|}{ Total } \\
\hline & Effective & $\%$ & Effective & $\%$ & Effective & $\%$ & Effective & $\%$ & Effective & $\%$ & Effective & $\%$ & Effective & $\%$ & Effective & $\%$ & Effective & $\%$ & Effective & $\%$ \\
\hline Water system & 3,168 & 30.85 & 8,295 & 52.64 & 945 & 29.36 & 2,078 & 54.40 & 479 & 42.28 & 866 & 54.71 & 13,038 & 25.93 & 1,898 & 24.98 & 345 & 21.68 & 31,112 & 32.66 \\
\hline Cistern truck & 297 & 2.89 & 2,122 & 13.47 & 44 & 1.37 & 272 & 7.12 & 116 & 10.24 & 13 & 0.82 & 4,542 & 9.03 & 147 & 1.93 & 6 & 0.38 & 7,559 & 7.94 \\
\hline Home cistern & 56 & 0.55 & & & 42 & 1.30 & & & & & & & 1,222 & 2.43 & 2,788 & 36.70 & 233 & 14.64 & 4,341 & 4.56 \\
\hline Public cistern & 104 & 1.01 & 373 & 2.37 & 21 & 0.65 & 76 & 1.99 & 22 & 1.94 & 13 & 0.82 & 802 & 1.59 & 614 & 8.08 & & & 2,025 & 2.13 \\
\hline Public fountain & 4,982 & 48.51 & 1,824 & 11.58 & 1,795 & 55.76 & 1,369 & 35.84 & 479 & 42.28 & 468 & 29.56 & 20,084 & 39.94 & 1,842 & 24.25 & 969 & 60.91 & 33,812 & 35.50 \\
\hline Well & 17 & 0.17 & 64 & 0.41 & 115 & 3.57 & & & 24 & 2.12 & 105 & 6.63 & 1,394 & 2.77 & & & & & 1,719 & 1.80 \\
\hline Spring & 1,263 & 12.30 & 30 & 0.19 & 193 & 6.00 & & & & & & & 6,111 & 12.15 & 14 & 0.18 & & & 7,611 & 7.99 \\
\hline Water course & 64 & 0.62 & & & & & & & & & 15 & 0.95 & 232 & 0.46 & & & & & 311 & 0.33 \\
\hline Other & 318 & 3.10 & 3,049 & 19.35 & 64 & 1.99 & 25 & 0.65 & 13 & 1.15 & 103 & 6.51 & 2,863 & 5.69 & 294 & 3.87 & 38 & 2.39 & 6,767 & 7.10 \\
\hline Total & 10,269 & 100 & 15,757 & 100 & 3,219 & 100 & 3,820 & 100 & 1,133 & 100 & 1,583 & 100 & 50,288 & 100 & 7,597 & 100 & 1,591 & 100 & 95,257 & 100 \\
\hline
\end{tabular}


Table 38: Household distribution by main source of water supply for domestic usage and by island of residence

\begin{tabular}{|c|c|c|c|c|c|c|c|c|c|c|c|c|c|c|}
\hline \multirow{3}{*}{$\begin{array}{c}\begin{array}{c}\text { Quality of Water } \\
\text { Facility }\end{array} \\
\text { Domestic } \\
\end{array}$} & \multicolumn{14}{|c|}{ Island } \\
\hline & \multicolumn{2}{|c|}{ Cabo Verde } & \multicolumn{2}{|c|}{ Santo Antão } & \multicolumn{2}{|c|}{ São Vicente } & \multicolumn{2}{|c|}{ Fogo } & \multicolumn{2}{|c|}{ Praia (City) } & \multicolumn{2}{|c|}{ Rest of Santiago } & \multicolumn{2}{|c|}{ Other islands } \\
\hline & Effective & Perc. & Effective & Perc. & Effective & Perc. & Effective & Perc. & Effective & Perc. & Effective & Perc. & Effective & Perc. \\
\hline Total & 95257 & 100 & 10269 & 100 & 15757 & 100 & 7597 & 100 & 22370 & 100 & 27918 & 100 & 11346 & 100 \\
\hline Drinking Water & 72483 & 76,1 & 8447 & 82,3 & 12241 & 77,7 & 3887 & 51,2 & 19941 & 89,1 & 17723 & 63,5 & 10244 & 90,3 \\
\hline Non Drinking Water & 22774 & 23,9 & 1822 & 17,7 & 3516 & 22,3 & 3710 & 48,8 & 2429 & 10,9 & 10195 & 36,5 & 1102 & 9,7 \\
\hline
\end{tabular}

Source: IDRF 2000/2001, INE.

Table 39 : Distribution of poor and non poor household by main source of water for domestic use and by island of residence (in \%)

\begin{tabular}{|c|c|c|c|c|c|c|c|c|c|c|c|c|c|c|c|c|c|c|c|}
\hline \multirow[b]{2}{*}{ Sources of Water } & \multicolumn{2}{|c|}{ S. Antão } & \multicolumn{2}{|c|}{ S. Vicente } & \multicolumn{2}{|c|}{ S. Nicolau } & \multicolumn{2}{|c|}{ Sal } & \multicolumn{2}{|c|}{ B. Vista } & \multicolumn{2}{|c|}{ Maio } & \multicolumn{2}{|c|}{ Santiago } & \multicolumn{2}{|c|}{ Fogo } & \multicolumn{2}{|c|}{ Brava } & \multirow[b]{2}{*}{$\begin{array}{c}\text { Tota } \\
\text { I }\end{array}$} \\
\hline & Poor & $\begin{array}{l}\text { Not } \\
\text { Poor }\end{array}$ & Poor & \begin{tabular}{|l|} 
Not \\
Poor \\
\end{tabular} & Poor & $\begin{array}{l}\text { Not } \\
\text { Poor } \\
\end{array}$ & Poor & $\begin{array}{l}\text { Not } \\
\text { Poor }\end{array}$ & Poor & $\begin{array}{l}\text { Not } \\
\text { Poor } \\
\end{array}$ & Poor & \begin{tabular}{|l|} 
Not \\
Poor \\
\end{tabular} & Poor & \begin{tabular}{|l|} 
Not \\
Poor \\
\end{tabular} & Poor & $\begin{array}{l}\text { Not } \\
\text { Poor } \\
\end{array}$ & Poor & \begin{tabular}{|l|} 
Not \\
Poor \\
\end{tabular} & \\
\hline Water system & 19.0 & 39.4 & 21.0 & 59.5 & 7.0 & 38.2 & 5.8 & 59.8 & & 47.7 & 27.6 & 63.6 & 7.5 & 33.6 & 5.4 & 34.9 & 12.2 & 25.9 & 32.7 \\
\hline Cistern Truck & 3.0 & 2.8 & 10.6 & 14.1 & & 1.9 & & 7.9 & & 11.5 & & 1.1 & 3.8 & 11.2 & 1.4 & 2.2 & 1.2 & & 7.9 \\
\hline Home Cistern & & 0.9 & & & & 1.8 & & & & & & & 2.9 & 2.2 & 41.3 & 34.3 & 9.8 & 16.8 & 4.6 \\
\hline Public Cistern & 1.4 & 0.7 & 4.5 & 1.9 & & 0.9 & 6.3 & 1.5 & 9.4 & 1.0 & & 1.1 & 3.0 & 1.0 & 8.7 & 7.7 & & & 2.1 \\
\hline Plumbing & 59.7 & 40.5 & 26.8 & 8.3 & 70.6 & 49.9 & 88.0 & 30.0 & 81.3 & 37.3 & 56.4 & 20.7 & 52.1 & 34.9 & 37.1 & 17.7 & 74.3 & 55.0 & 35.5 \\
\hline Fountain & & 0.3 & 0.8 & 0.3 & 2.5 & 4.0 & & & 9.4 & 1.2 & 16.1 & 3.5 & 6.3 & 1.3 & & & & & 1.8 \\
\hline Water Spring & 13.1 & 11.7 & 0.7 & 0.1 & 16.3 & 1.9 & & & & & & & 20.3 & 8.8 & & 0.3 & & & 8.0 \\
\hline Water Course & 0.4 & 0.8 & & & & & & & & & & 1.3 & 0.5 & 0.5 & & & & & 0.3 \\
\hline Others & 3.6 & 2.7 & 35.6 & 15.8 & 3.5 & 1.4 & & 0.7 & & 1.3 & & 8.6 & 3.6 & 6.6 & 6.0 & 2.8 & 2.4 & 2.4 & 7.1 \\
\hline Total & $\begin{array}{r}100 . \\
0 \\
\end{array}$ & 100.0 & 100.0 & 100.0 & 100.0 & 100.0 & 100.0 & 100.0 & 100.0 & 100.0 & 100.0 & 100.0 & 100.0 & 100.0 & 100.0 & 100.0 & 100.0 & 100.0 & 100.0 \\
\hline
\end{tabular}
Souce: IDRF 2000/2001, INE 
Table 40: Distribution of Households by island of residence and ownership of bathroom with lavatory, by poverty status and sex of family head

\begin{tabular}{|c|c|c|c|c|c|}
\hline \multirow[b]{2}{*}{ Ownership of Bathroom } & \multicolumn{2}{|l|}{ Poor } & \multicolumn{2}{|c|}{ Very Poor } & \multirow[b]{2}{*}{ Total } \\
\hline & Male & Female & Male & Female & \\
\hline S. Antão & 3,096 & 1,204 & 3,936 & 2,033 & 10,269 \\
\hline Bathroom with lavatory & 175 & 205 & 1,649 & 877 & 2,906 \\
\hline Bathroom without lavatory & 250 & & 215 & 121 & 586 \\
\hline Lavatory/Water closet & 160 & & 62 & 53 & 275 \\
\hline Without Bathroom, Lavatory or Water closet & 2,511 & 999 & 2,010 & 982 & 6,502 \\
\hline $\begin{array}{l}\text { S. Vicente } \\
\end{array}$ & 1,253 & 1,543 & 7,971 & 4,990 & 15,757 \\
\hline Bath Bathroom with lavatory & 231 & 429 & 5,570 & 3,462 & 9,692 \\
\hline Bathroom without lavatory & 202 & 141 & 819 & 437 & 1,599 \\
\hline Lavatory/Water closet & 23 & 68 & 40 & 42 & 173 \\
\hline Without Bathroom, Lavatory or Water closet & 797 & 905 & 1,542 & 1,049 & 4,293 \\
\hline S. Nicolau & 383 & 529 & 1,429 & 878 & 3,219 \\
\hline Bathroom with lavatory & 110 & 71 & 880 & 556 & 1,617 \\
\hline Bathroom without lavatory & & & 71 & & 71 \\
\hline lavatory/Water closet & 21 & 72 & & 32 & 125 \\
\hline Without Bathroom, Lavatory or Water closet & 252 & 386 & 478 & 290 & 1,406 \\
\hline Sal & 228 & 154 & 2,432 & 1,006 & 3,820 \\
\hline Ca Bathroom with lavatory & 71 & 56 & 1,856 & 845 & 2,828 \\
\hline Bathroom without lavatory & 48 & 48 & 197 & & 293 \\
\hline lavatory/Water closet & 24 & & & & 24 \\
\hline Without Bathroom, Lavatory or Water closet & 85 & 50 & 379 & 161 & 675 \\
\hline Boa Vista & 95 & 33 & 711 & 294 & 1,133 \\
\hline Bathroom with lavatory & 12 & & 499 & 179 & 690 \\
\hline Bathroom without lavatory & 36 & & 34 & 24 & 94 \\
\hline Without Bathroom, Lavatory or Water closet & 47 & 33 & 178 & 91 & 349 \\
\hline Maio & 237 & 155 & 516 & 675 & 1,583 \\
\hline Bathroom with lavatory & 21 & 15 & 292 & 364 & 692 \\
\hline Bathroom without lavatory & 96 & 21 & 34 & 130 & 281 \\
\hline lavatory/Water closet & 15 & & 28 & 15 & 58 \\
\hline $\begin{array}{c}\text { Se Without Bathroom, Lavatory or Water } \\
\text { closet }\end{array}$ & 105 & 119 & 162 & 166 & 552 \\
\hline Santiago & 6,820 & 7,909 & 19,025 & 16,534 & 50,288 \\
\hline Bathroom with lavatory & 854 & 536 & 11,164 & 7,713 & 20,267 \\
\hline Bathroom without lavatory & 649 & 359 & 973 & 1,027 & 3,008 \\
\hline lavatory/Water closet & 58 & 128 & 244 & 246 & 676 \\
\hline Without Bathroom, Lavatory or Water closet & 5,259 & 6,886 & 6,644 & 7,548 & 26,337 \\
\hline Fogo & 1,441 & 1,123 & 3,026 & 2,007 & 7,597 \\
\hline Bathroom with lavatory & 123 & 187 & 1,799 & 1,150 & 3,259 \\
\hline Bathroom without lavatory & 402 & 108 & 231 & 200 & 941 \\
\hline lavatory/Water closet & 185 & 170 & 213 & 214 & 782 \\
\hline Without Bathroom, Lavatory or Water closet & 731 & 658 & 783 & 443 & 2,615 \\
\hline Brava & 216 & 274 & 713 & 388 & 1,591 \\
\hline Bathroom with lavatory & 92 & 73 & 374 & 180 & 719 \\
\hline Bathroom without lavatory & 82 & 79 & 122 & 83 & 366 \\
\hline lavatory/Water closet & & 6 & 91 & 30 & 127 \\
\hline
\end{tabular}




\begin{tabular}{|r|r|r|r|r|}
42 & 116 & 126 & 95 & 379 \\
\hline 13,769 & 12,924 & 39,759 & 28,805 & 95,257 \\
\hline
\end{tabular}

Table 41: Synthesis of Foster-Greer-Thorbecke activities

\begin{tabular}{|c|c|c|c|}
\hline & P0 & P1 & P2 \\
\hline \multicolumn{4}{|l|}{ Sex } \\
\hline Male & 0.26 & 0.09 & 0.04 \\
\hline female & 0.31 & 0.11 & 0.05 \\
\hline \multicolumn{4}{|l|}{ Education Level } \\
\hline No Schooling & 0.42 & 0.15 & 0.07 \\
\hline Basic Education & 0.28 & 0.10 & 0.05 \\
\hline Secondary & 0.06 & 0.02 & 0.01 \\
\hline Post Secondary & 0.00 & 0.00 & 0.00 \\
\hline \multicolumn{4}{|l|}{ Age Group } \\
\hline $15-24$ & 0.17 & 0.04 & 0.01 \\
\hline $25-44$ & 0.27 & 0.10 & 0.05 \\
\hline $44-64$ & 0.30 & 0.10 & 0.05 \\
\hline 65 or over & 0.29 & 0.10 & 0.04 \\
\hline \multicolumn{4}{|l|}{ Place of Residence } \\
\hline Urban & 0.17 & 0.05 & 0.02 \\
\hline Rural & 0.42 & 0.16 & 0.08 \\
\hline \multicolumn{4}{|l|}{ Island } \\
\hline Santo Antão & 0.42 & 0.16 & 0.08 \\
\hline S. Vicente & 0.18 & 0.05 & 0.02 \\
\hline S. Nicolau & 0.28 & 0.10 & 0.05 \\
\hline Sal & 0.10 & 0.03 & 0.02 \\
\hline Boavista & 0.11 & 0.03 & 0.01 \\
\hline Maio & 0.25 & 0.09 & 0.05 \\
\hline Santiago & 0.29 & 0.10 & 0.05 \\
\hline Fogo & 0.34 & 0.12 & 0.06 \\
\hline Brava & 0.31 & 0.07 & 0.02 \\
\hline \multicolumn{4}{|l|}{ Sector of Activity } \\
\hline Primary Sector & 0.41 & 0.15 & 0.08 \\
\hline Secondary Sector & 0.28 & 0.10 & 0.05 \\
\hline Tertiary Sector excluding Public Administration & 0.19 & 0.06 & 0.03 \\
\hline Public Administration & 0.31 & 0.12 & 0.06 \\
\hline \multicolumn{4}{|l|}{$\begin{array}{ll} & \text { Occupation } \\
\end{array}$} \\
\hline Management, Professional and Related Occupation & 0.04 & 0.01 & 0.00 \\
\hline Armed Forces, Office Workers, Machine Operators & 0.13 & 0.04 & 0.02 \\
\hline Non qualified Workers in Agriculture and Fishing , Non qualified Operators and workers & 0.28 & 0.10 & 0.05 \\
\hline Non Qualified Workers & 0.41 & 0.15 & 0.07 \\
\hline \multicolumn{4}{|l|}{ Family Size } \\
\hline 1 Person & 0.04 & 0.01 & 0.01 \\
\hline 2 Persons & 0.10 & 0.02 & 0.01 \\
\hline 3 Persons & 0.14 & 0.04 & 0.02 \\
\hline 4 Person & 0.22 & 0.07 & 0.03 \\
\hline 5 Persons & 0.27 & 0.09 & 0.04 \\
\hline 6 or over & 0.46 & 0.17 & 0.09 \\
\hline
\end{tabular}


Table 42: Households by island of residence and degree of satisfaction of essential needs

\begin{tabular}{|c|c|c|c|c|}
\hline \multirow{2}{*}{$\begin{array}{c}\text { Island of } \\
\text { Residence }\end{array}$} & \multicolumn{3}{|c|}{ In } & \\
\cline { 2 - 5 } Cape Verde & 10,0 & 34,6 & 55,4 & 100 \\
\hline Santo Antão & 16,7 & 46,0 & 37,3 & 100 \\
\hline S. Vicente & 4,3 & 29,0 & 66,7 & 100 \\
\hline Fogo & 13,1 & 40,3 & 46,5 & 100 \\
\hline Praia Urbano & 3,5 & 23,2 & 73,3 & 100 \\
\hline Santiago Rural & 16,2 & 43,8 & 40,1 & 100 \\
\hline Other Islands & 7,1 & 28,1 & 64,7 & 100 \\
\hline
\end{tabular}

N ALI - Does not satisfy food needs

NSAE - Satisfy food needs but not essential needs

SNE - Satisfy food needs and other essential needs

Source: IDRF 2000/2001, INE

Table 43: Households by island of residence and degree of satisfaction of essential needs

\begin{tabular}{|c|c|c|c|}
\hline \multirow{2}{*}{ Residence } & \multicolumn{2}{|c|}{ Percentage } & \multirow{2}{*}{ Total } \\
\cline { 2 - 3 } & NSAE & SNE & \\
\hline Cape Verde & 100 & 100 & 100 \\
\hline Urban & 42,7 & 70,9 & 57,0 \\
\hline Rural & 57,3 & 29,1 & 43,0 \\
\hline
\end{tabular}

Source: IDRF 2000/2001, INE.

Table 44: Statistical Indicators

\begin{tabular}{|c|c|c|c|c|}
\hline & Skewness & Kurtosis & Jarque-Bera & Probabilities \\
\hline Cape Verde & 19,197 & 577,723 & 63370015,000 & 0,000 \\
\hline Santo Antão & 5,693 & 42,781 & 33031,530 & 0,000 \\
\hline S. Vicente & 15,480 & 312,504 & 2886413,000 & 0,000 \\
\hline S. Nicolau & 2,563 & 9,651 & 343,711 & 0,000 \\
\hline Sal & 5,644 & 47,521 & 15293,820 & 0,000 \\
\hline Boavista & 2,490 & 11,091 & 68,573 & 0,000 \\
\hline Maio & 2,436 & 8,350 & 207,270 & 0,000 \\
\hline Santiago & 20,914 & 674,729 & 46316144,000 & 0,000 \\
\hline Fogo & 4,828 & 36,288 & 17769,900 & 0,000 \\
\hline Brava & 2,065 & 7,206 & 162,146 & 0,000 \\
\hline Praia (city) & 17,183 & 414,897 & 7196645,000 & 0,000 \\
\hline
\end{tabular}

Source: IDRF 2000/2001, INE.

Table 45: Lorenz Curve Coordinates

\begin{tabular}{|c|c|c|}
\hline Deciles & Frequency & Lorenz curve coordinates \\
\hline 1 & 0,0129 & 0,0129 \\
\hline 2 & 0,0211 & 0,034 \\
\hline 3 & 0,0284 & 0,0624 \\
\hline 4 & 0,0362 & 0,0986 \\
\hline 5 & 0,0459 & 0,1445 \\
\hline 6 & 0,0576 & 0,2021 \\
\hline 7 & 0,0733 & 0,2754 \\
\hline 8 & 0,0991 & 0,3745 \\
\hline 9 & 0,1554 & 0,5299 \\
\hline 10 & 0,4701 & 1 \\
\hline
\end{tabular}


Table 46: Inequality break-down by sub-groups

\begin{tabular}{|c|c|c|}
\hline Decomposition of inequality by sub-groups & & GE(1) \\
\hline Male & & 0,28 \\
\hline \multirow[t]{3}{*}{ Female } & & 0,39 \\
\hline & Intra group & 0,32 \\
\hline & Inter group & 0,00 \\
\hline By Educational Level & & $\mathrm{GE}(1)$ \\
\hline No schooling & & 0,17 \\
\hline Basic Education & & 0,22 \\
\hline Secondary & & 0,20 \\
\hline \multirow[t]{3}{*}{ Post secondary } & & 0,28 \\
\hline & Intra group & 0,22 \\
\hline & Inter group & 0,10 \\
\hline By place of Residence & & $\mathrm{GE}(1)$ \\
\hline Urban & & 0,31 \\
\hline \multirow[t]{3}{*}{ Rural } & & 0,19 \\
\hline & Intra group & 0,29 \\
\hline & Inter group & 0,04 \\
\hline By Island & & $\mathrm{GE}(1)$ \\
\hline Santo Antão & & 0,29 \\
\hline S. Vicente & & 0,41 \\
\hline S. Nicolau & & 0,18 \\
\hline Sal & & 0,27 \\
\hline Boavista & & 0,13 \\
\hline Maio & & 0,21 \\
\hline Santiago & & 0,30 \\
\hline Fogo & & 0,19 \\
\hline \multirow[t]{3}{*}{ Brava } & & 0,19 \\
\hline & Intra group & 0,31 \\
\hline & Inter group & 0,02 \\
\hline By Occupation & & $\mathrm{GE}(1)$ \\
\hline \multicolumn{2}{|c|}{ Management, Professional and Related Occupation } & 0,30 \\
\hline \multicolumn{2}{|c|}{ Army Forces, Administrative, Machine Operators } & 0,17 \\
\hline \multicolumn{2}{|c|}{$\begin{array}{c}\text { Non qualified Workers in Agriculture and Fishing, Non qualified Operators } \\
\text { and workers }\end{array}$} & 0,26 \\
\hline \multicolumn{2}{|c|}{ Non qualified Workers } & 0,21 \\
\hline & Intra group & 0,20 \\
\hline & Inter group & 0,12 \\
\hline By Sector of Activity & & $\mathrm{GE}(1)$ \\
\hline Primary Sector & & 0,22 \\
\hline Secondary Sector & & 0,33 \\
\hline Tertiary Sector excluding Public Administration & & 0,33 \\
\hline \multirow[t]{3}{*}{ Public Administration } & & 0,40 \\
\hline & Intra group & 0,20 \\
\hline & Inter group & 0,12 \\
\hline \multicolumn{3}{|l|}{ By Age Group } \\
\hline $15-24$ & & 0,20 \\
\hline $25-44$ & & 0,28 \\
\hline $44-64$ & & 0,47 \\
\hline \multirow[t]{3}{*}{65 or over } & & 0,18 \\
\hline & Intra group & 0,32 \\
\hline & Inter group & 0,00 \\
\hline \multicolumn{3}{|l|}{ By Family Size } \\
\hline 1 Person & & 0,34 \\
\hline 2 Persons & & 0,20 \\
\hline 3 Persons & & 0,18 \\
\hline 4 Persons & & 0,18 \\
\hline 5 Persons & & 0,16 \\
\hline \multirow[t]{3}{*}{6 and over } & & 0,13 \\
\hline & Intra group & 0,22 \\
\hline & Inter group & 0,10 \\
\hline
\end{tabular}

Source: IDRF 2000/2001, INE. 
Table 47: Logit Coefficients Model

\begin{tabular}{|c|c|c|}
\hline Estimated model & Coefficient & P- Value \\
\hline Constant & -1.40 & 0.0000 \\
\hline $\begin{array}{c}\text { Place of residence } \\
\text { Urban } \\
\text { Rural }\end{array}$ & $\begin{array}{l}-0.35 \\
0.41\end{array}$ & $\begin{array}{l}0.0000 \\
0.0000\end{array}$ \\
\hline $\begin{array}{c}\text { Household Size } \\
1 \\
2 \\
3-4 \\
5-6 \\
7-8 \\
9-10 \\
>10\end{array}$ & $\begin{array}{l}-2.00 \\
-1.14 \\
-0.33 \\
0.35 \\
0.90 \\
1.37 \\
1.68\end{array}$ & $\begin{array}{l}0.0000 \\
0.0000 \\
0.0000 \\
0.0000 \\
0.0000 \\
0.0000 \\
0.0000\end{array}$ \\
\hline $\begin{array}{c}\text { Gender of the Head of Household } \\
\text { Male } \\
\text { Female }\end{array}$ & $\begin{array}{l}-0.03 \\
0.04\end{array}$ & $\begin{array}{l}0.4223 \\
0.4223\end{array}$ \\
\hline $\begin{array}{c}\text { Years Migrated } \\
<12 \text { years } \\
>12 \\
\text { Never migrated } \\
\end{array}$ & $\begin{array}{l}-0.17 \\
-0.19 \\
0.13 \\
\end{array}$ & $\begin{array}{l}0.1240 \\
0.0044 \\
0.0003 \\
\end{array}$ \\
\hline $\begin{array}{l}\text { Educational Level } \\
\text { No schooling } \\
\text { Basic education } \\
\text { Secondary } \\
\text { Post Secondary }\end{array}$ & $\begin{array}{r}0.57 \\
0.09 \\
-0.65 \\
-2.91\end{array}$ & $\begin{array}{l}0.0000 \\
0.1577 \\
0.0007 \\
0.0030\end{array}$ \\
\hline $\begin{array}{c}\text { Weeks unemployed } \\
0-8 \\
9-24 \\
25-35 \\
36-52 \\
\end{array}$ & $\begin{array}{l}-0.09 \\
0.42 \\
0.30 \\
0.48\end{array}$ & $\begin{array}{l}0.0000 \\
0.0018 \\
0.0606 \\
0.0008\end{array}$ \\
\hline $\begin{array}{c}\text { Island } \\
\text { S. Antão } \\
\text { S. Vicente } \\
\text { S. Nicolau } \\
\text { Sal } \\
\text { Boavista } \\
\text { Maio } \\
\text { Santiago } \\
\text { Fogo } \\
\text { Brava }\end{array}$ & $\begin{array}{c}0.22 \\
0.12 \\
0.02 \\
-0.65 \\
-0.98 \\
-0.41 \\
0.02 \\
-0.04 \\
0.21\end{array}$ & $\begin{array}{l}0.0509 \\
0.2307 \\
0.9277 \\
0.0145 \\
0.0042 \\
0.1260 \\
0.5806 \\
0.7267 \\
0.3916\end{array}$ \\
\hline $\begin{array}{c}\text { Occupation } \\
\text { Management, Professional and Related Occupation, } \\
\text { Army Forces, Office Workers, Machine Operators } \\
\text { Non Qualified Workers in Agriculture and Fishing } \\
\text { Non Qualified Workers in Primary Sector } \\
\text { Non Qualified Workers in Secondary and Tertiary Sector } \\
\text { Non Qualified Workers in Public Administration } \\
\text { Actives and Inactive that never worked }\end{array}$ & $\begin{array}{l}-0.66 \\
-0.65 \\
-0.04 \\
0.33 \\
0.40 \\
0.57 \\
0.07\end{array}$ & $\begin{array}{l}0.0056 \\
0.0000 \\
0.7041 \\
0.0009 \\
0.0000 \\
0.0001 \\
0.3544\end{array}$ \\
\hline $\begin{array}{l}\text { Degrees of Freedom: } \\
\text { Maximum Likelihood test: } \\
\mathrm{P}-\text { Value } \\
\end{array}$ & 31 & $\begin{array}{c}0.0000 \\
1221.7031\end{array}$ \\
\hline
\end{tabular}




\section{Annex 2: Strategies and activities for Growth and Poverty Reduction}

\begin{tabular}{|c|c|c|c|c|c|c|c|c|c|c|c|c|c|}
\hline \multirow{2}{*}{$\begin{array}{l}\text { PILLARS, OBJECTIVES } \\
\text { AND ACTIVITIES } \\
\end{array}$} & \multirow[t]{2}{*}{ INDICATORS } & \multicolumn{3}{|l|}{ A CTIONS / GOALS } & \multirow{2}{*}{$\begin{array}{l}\text { DATA } \\
\text { SOURCE }\end{array}$} & \multicolumn{5}{|l|}{ BUDGET } & \multirow[b]{2}{*}{ COR } & \multicolumn{2}{|c|}{ TOTAL 2005-2007 } \\
\hline & & 2005 & 2006 & 2007 & & 2005 & COR & 2006 & COR & 2007 & & INV & COR \\
\hline \multicolumn{14}{|l|}{ Eixo 1} \\
\hline $\begin{array}{l}\text { Promoting good governance, } \\
\text { reinforcing effectiveness and } \\
\text { guaranteeing equity }\end{array}$ & $\begin{array}{l}\text { GDP per capita } \\
\text { Growth Rate; \% } \\
\text { Poor and Very Poor } \\
\text { Population }\end{array}$ & & & & & 149.590 & 475.360 & 144.915 & 337.977 & 82.947 & 345.795 & 377.452 & 1.159 .131 \\
\hline $\begin{array}{l}\text { Budget management system } \\
\text { efficient and transparent } \\
\text { (CFAA) }\end{array}$ & $\begin{array}{l}\text { Overall Budget } \\
\text { execution rate }\end{array}$ & & & & & 0 & 227.298 & 0 & 232.980 & 0 & 242.317 & 0 & 702.595 \\
\hline $\begin{array}{l}\text { 1.1.1Improvenent the } \\
\text { Budget Programming and } \\
\text { Preparation }\end{array}$ & $\begin{array}{l}\text { Appraisal Report on } \\
\text { GPRSP activities }\end{array}$ & $\begin{array}{l}\text { Indicative Budget } \\
\text { ceiling by Ministries }\end{array}$ & $\begin{array}{l}\text { Including macro } \\
\text { economic } \\
\text { projections }\end{array}$ & $\begin{array}{l}\text { Budget round } \\
\text { request } \\
\text { assessing } \\
\text { progress over } \\
\text { Government } \\
\text { program } \\
\end{array}$ & $\begin{array}{l}\text { MFP } \\
\text { Documents }\end{array}$ & & 69.508 & & 71.246 & & 74.101 & 0 & 214.855 \\
\hline $\begin{array}{l}1.1 .2 \text { Improvement the } \\
\text { Management and control of } \\
\text { Government Revenue }\end{array}$ & $\begin{array}{l}\text { Number of individual } \\
\text { and Business tax } \\
\text { contributors; } \\
\text { Number of appraisal } \\
\text { missions carried out; } \\
\text { efficient tax } \\
\text { collection }\end{array}$ & $\begin{array}{l}\text { Contributors } \\
\text { identified; Internal } \\
\text { audit created ; TI } \\
\text { system modernized } \\
\text {; Deal between } \\
\text { DGCl and BCA } \\
\text { audited ; }\end{array}$ & $\begin{array}{l}\text { Contributors not } \\
\text { included in NIF } \\
\text { identified; RF } \\
\text { information } \\
\text { system } \\
\text { harmonized; RF } \\
\text { inspection } \\
\text { program } \\
\text { elaborated }\end{array}$ & $\begin{array}{l}\text { Contributors } \\
\text { follow up } \\
\text { Program } \\
\text { implemented; }\end{array}$ & $\begin{array}{l}\text { MF } \\
\text { Documents }\end{array}$ & & 28.255 & & 28.962 & & 30.122 & 0 & 87.340 \\
\hline $\begin{array}{l}\text { 1.1.3 Improvement the } \\
\text { Management of Government } \\
\text { Treasury and public debt }\end{array}$ & $\begin{array}{l}\text { \% of Autonomous } \\
\text { Institutes managed } \\
\text { by } \\
\text { Treasurer Central } \\
\text { Account }\end{array}$ & $\begin{array}{l}\text { Quarterly payment } \\
\text { programming } \\
\text { adopted ; existing } \\
\text { protocols converted } \\
\text { into TB's and Bonds }\end{array}$ & $\begin{array}{l}75 \% \text { Autonomous } \\
\text { Institutes } \\
\text { managed by } \\
\text { Treasurer Central } \\
\text { Account; } \\
\text { Inventory of the } \\
\text { stock of internal } \\
\text { debt carried out } \\
\end{array}$ & $\begin{array}{l}\text { Management } \\
\text { of Public Debt } \\
\text { integrated with } \\
\text { Budget } \\
\text { management }\end{array}$ & Studies & & 16.953 & & 17.377 & & 18.073 & 0 & 52.404 \\
\hline $\begin{array}{l}\text { 1.1.4 Improvement the } \\
\text { Budget execution condition }\end{array}$ & $\begin{array}{l}\mathrm{N} .{ }^{\circ} \text { of. financial } \\
\text { controllers trained } \\
\text { and recruited }\end{array}$ & $\begin{array}{l}\text { Draft proposal of the } \\
\text { Decree Law creating } \\
\text { "financial } \\
\text { controllers" } \\
\text { prepared }\end{array}$ & $\begin{array}{l}\text { Draft Proposal of } \\
\text { decree Law } \\
\text { submitted to } \\
\text { Parliament }\end{array}$ & $\begin{array}{l}\text { Financial } \\
\text { Controllers } \\
\text { working in at } \\
\text { least two } \\
\text { ministries } \\
\end{array}$ & $\begin{array}{l}\text { MFP } \\
\text { documents }\end{array}$ & & 14.128 & & 14.481 & & 15.061 & 0 & 43.670 \\
\hline $\begin{array}{l}1.1 .5 \text { Improvement } n \text { the } \\
\text { Management of } \\
\text { Municipalities Finance }\end{array}$ & $\begin{array}{l}\text { Legal arrangement } \\
\text { transferring } \\
\text { jurisdiction to the } \\
\text { municipalities }\end{array}$ & $\begin{array}{l}\text { Basic Law on } \\
\text { decentralization and } \\
\text { municipalities } \\
\text { financial laws } \\
\text { submitted to the } \\
\text { parliament ; } 3 \\
\text { municipalities } \\
\text { working on NOSI's } \\
\text { procedure and } \\
\text { expenditure system }\end{array}$ & $\begin{array}{l}\text { Basic Law } \\
\text { implemented; } \\
\text { Municipalities } \\
\text { states revised ; } \\
\text { new financing } \\
\text { mechanisms; } \\
\text { Municipal records } \\
; 2 \text { municipalities } \\
\text { working with } \\
\text { procedure and } \\
\text { expenditure } \\
\text { system }\end{array}$ & $\begin{array}{l}\text { Deadline for } \\
\text { municipalities } \\
\text { Finance law } \\
\text { applied to } \\
\text { taxation } \\
\text { transfers. }\end{array}$ & $\begin{array}{l}\text { MFP } \\
\text { Documents }\end{array}$ & & 33.341 & & 34.175 & & 35.544 & 0 & 103.061 \\
\hline
\end{tabular}

CInternational Monetary Fund. Not for Redistribution 


\begin{tabular}{|c|c|c|c|c|c|c|c|c|c|c|c|c|c|}
\hline \multirow{2}{*}{$\begin{array}{l}\text { PILLARS, OBJECTIVES } \\
\text { AND ACTIVITIES }\end{array}$} & \multirow[t]{2}{*}{ INDICATORS } & \multicolumn{3}{|l|}{ A CTIONS / GOALS } & \multirow{2}{*}{\begin{tabular}{|l} 
DATA \\
SOURCE \\
\end{tabular}} & \multicolumn{5}{|l|}{\begin{tabular}{|l} 
BUDGET \\
\end{tabular}} & \multirow[b]{2}{*}{ COR } & \multicolumn{2}{|c|}{ TOTAL 2005-2007 } \\
\hline & & 2005 & 2006 & 2007 & & 2005 & COR & 2006 & COR & 2007 & & & COR \\
\hline $\begin{array}{l}\text { 1.1.6 Strengthen the capacity } \\
\text { of Finance General } \\
\text { Inspection }\end{array}$ & $\begin{array}{l}\text { Annual Reports } \\
\text { published }\end{array}$ & $\begin{array}{l}\text { Law on } \\
\text { reorganization and } \\
\text { competencies of } \\
\text { TDC and IGF } \\
\text { financial autonomy } \\
\text { submitted to } \\
\text { Parliament }\end{array}$ & - & $\begin{array}{l}\text { Review of the } \\
\text { account of } \\
\text { each of the } \\
\text { autonomous } \\
\text { institute; TC } \\
\text { computer } \\
\text { system } \\
\text { connected to } \\
\text { MF }\end{array}$ & $\begin{array}{l}\text { MFP } \\
\text { Documents }\end{array}$ & & 14.552 & & 14.915 & & 15.513 & 0 & 44.980 \\
\hline $\begin{array}{l}1.1 .7 \text { Improvement the } \\
\text { Management } \\
\text { of State Property }\end{array}$ & $\begin{array}{l}\text { Plan Action of } \\
\text { CPAR adopted }\end{array}$ & $\begin{array}{l}\text { Public bidding law } \\
\text { elaborated and } \\
\text { sent to parliament } \\
\text { for approval e }\end{array}$ & $\begin{array}{l}\text { Regulation } \\
\text { function } \\
\text { operational ; } \\
\text { public bidding } \\
\text { results available } \\
\text { on the web }\end{array}$ & - & $\begin{array}{l}\text { MFP } \\
\text { Documents }\end{array}$ & & 30.572 & & 31.337 & & 32.592 & 0 & 94.501 \\
\hline $\begin{array}{l}1.1 .8 \text { Improvement the } \\
\text { Management and follow up of } \\
\text { Food Aid Account }\end{array}$ & $\begin{array}{l}\text { Mechanism of the } \\
\text { Management Food } \\
\text { Aid reviewed ; } \\
\text { Base for } \\
\text { remuneration of } \\
\text { ANSA in the } \\
\text { context of market } \\
\text { liberalization no } \\
\text { defined } \\
\end{array}$ & - & 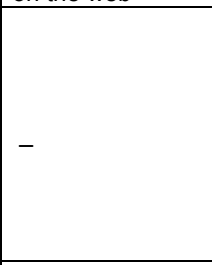 & - & $\begin{array}{l}\text { MFP } \\
\text { Documents }\end{array}$ & & 2.260 & & 2.317 & & 2.410 & 0 & 6.987 \\
\hline $\begin{array}{l}\text { 1.1.9 Technical Coordinating } \\
\text { Unit }\end{array}$ & Unit operational & Unit operational & - & - & $\begin{array}{l}\text { MFP } \\
\text { Documents }\end{array}$ & & 17.727 & & 18.171 & & 18.899 & 0 & 54.797 \\
\hline $\begin{array}{l}\text { Strength the Management } \\
\text { and the performance of the } \\
\text { economy }\end{array}$ & $\begin{array}{l}\text { QDMP elaborated e } \\
\text { implemented }\end{array}$ & - & - & - & - & 126.065 & 60.000 & 122.852 & 60.000 & 60.000 & 60.000 & 308.917 & 180.000 \\
\hline $\begin{array}{l}\text { 1.4.1 Strength statistical } \\
\text { devices to following up } \\
\text { poverty }\end{array}$ & $\begin{array}{l}\text { Social Board } \\
\text { created; Poverty } \\
\text { Chart elaborated ; } \\
\text { computers acquired } \\
\text {; statistical agenda } \\
\text { implemented } \\
\end{array}$ & $\begin{array}{l}\text { QBS finalized; } \\
\text { Poverty follow up } \\
\text { survey carried out;; } \\
\text { computers acquired ; } \\
\text { Statistical agenda } \\
\text { implemented }\end{array}$ & $\begin{array}{l}\text { Labor force } \\
\text { survey carried } \\
\text { out; computers } \\
\text { acquired; } \\
\text { Statistical agenda } \\
\text { implemented } \\
\end{array}$ & - & Survey & 55.945 & & 50.708 & & 0 & & 106.653 & 0 \\
\hline $\begin{array}{l}\text { 1.4.2 limprovement the } \\
\text { Data coverage quality }\end{array}$ & $\begin{array}{l}\mathrm{N} .{ }^{\circ} \text { of data base } \\
\text { improved }\end{array}$ & - & - & - & $\begin{array}{l}\text { Sectors } \\
\text { reports }\end{array}$ & 0 & & 0 & & 0 & & 0 & 0 \\
\hline $\begin{array}{l}\text { 1.4.3 Support to DECRP and } \\
\text { QDMP monitoring and } \\
\text { appraisal }\end{array}$ & Report published & $\begin{array}{l}\text { DGPRS and } \\
\text { QDMP reports } \\
\text { published }\end{array}$ & $\begin{array}{l}\text { GPRSP and } \\
\text { QDMP reports } \\
\text { published }\end{array}$ & - & $\begin{array}{l}\text { DECRP } \\
\text { follow up } \\
\text { report }\end{array}$ & 60000 & 60.000 & 60000 & 60.000 & 60.000 & 60.000 & 180.000 & 180.000 \\
\hline $\begin{array}{l}1.5 .1 \text { Improvement the } \\
\text { credibility and accessibility of } \\
\text { official statistics }\end{array}$ & $\begin{array}{l}\text { BDEO and } \\
\text { STATLINE } \\
\text { operational } \\
\end{array}$ & $\begin{array}{l}100 \% \text { half of data } \\
\text { base integrated }\end{array}$ & $100 \%$ STATLINE & - & $\begin{array}{l}\text { Sectors } \\
\text { reports }\end{array}$ & 10.120 & & 12.144 & & 0 & & 22.263 & 0 \\
\hline $\begin{array}{l}\text { Reforming and Modernizing } \\
\text { Public Administration }\end{array}$ & $\begin{array}{l}\text { Strategic Plan for } \\
\text { State Reforming } \\
\text { Public } \\
\text { Administration } \\
\text { elaborated and } \\
\text { implemented }\end{array}$ & - & - & - & - & 23.525 & 169.341 & 22.063 & 3.000 & 22.947 & 3.000 & 68.535 & 175.341 \\
\hline $\begin{array}{l}\text { 2.1.1 Implementing the } \\
\text { Citizen House }\end{array}$ & $\begin{array}{l}\text { Modern image of } \\
\text { Public } \\
\text { Administration }\end{array}$ & - & - & - & $\begin{array}{l}\text { MREAP } \\
\text { Reports }\end{array}$ & 2.000 & & 0 & & 0 & & 2.000 & 0 \\
\hline
\end{tabular}

CInternational Monetary Fund. Not for Redistribution 


\begin{tabular}{|c|c|c|c|c|c|c|c|c|c|c|c|c|c|}
\hline \multirow{2}{*}{$\begin{array}{l}\text { PILLARS, OBJECTIVES } \\
\text { AND ACTIVITIES } \\
\end{array}$} & \multirow[t]{2}{*}{ INDICATORS } & \multicolumn{3}{|l|}{ A CTIONS / GOALS } & \multirow{2}{*}{$\begin{array}{l}\text { DATA } \\
\text { SOURCE }\end{array}$} & \multicolumn{5}{|l|}{ BUDGET } & \multirow[b]{2}{*}{ COR } & \multicolumn{2}{|c|}{ TOTAL 2005-2007 } \\
\hline & & 2005 & 2006 & 2007 & & 2005 & COR & 2006 & COR & 2007 & & INV & COR \\
\hline $\begin{array}{l}\text { 2.1.2 Revision of the New } \\
\text { Technology Legislation }\end{array}$ & $\begin{array}{l}\text { Management } \\
\text { procedure of public } \\
\text { resources simplified }\end{array}$ & - & - & - & $\begin{array}{l}\text { MREAP } \\
\text { Reports }\end{array}$ & & 1.000 & & 0 & & 0 & 0 & 1.000 \\
\hline $\begin{array}{l}\text { 2.2.1 Creating an operational } \\
\text { mechanism to reform the } \\
\text { public Administration } \\
\text { including political decision } \\
\text { taking, coordination and } \\
\text { integration of activities }\end{array}$ & $\begin{array}{l}\text { Fundamental } \\
\text { Reforms validated } \\
\text { and implemented }\end{array}$ & $\begin{array}{l}\text { Mechanisms to } \\
\text { reform the public } \\
\text { administration } \\
\text { created }\end{array}$ & $\begin{array}{l}\text { Integrated } \\
\text { strategies to } \\
\text { reform the public } \\
\text { administration } \\
\text { validated and PA } \\
\text { finalized }\end{array}$ & $\begin{array}{l}\text { Annual reform } \\
\text { agenda } \\
\text { appraised }\end{array}$ & $\begin{array}{l}2.2 .1 \\
\text { Creating an } \\
\text { operational } \\
\text { mechanism } \\
\text { to reform } \\
\text { the public } \\
\text { Administrati } \\
\text { on } \\
\text { including } \\
\text { political } \\
\text { decision } \\
\text { taking, } \\
\text { coordinatio } \\
\text { n and } \\
\text { integration } \\
\text { of activities } \\
\end{array}$ & 0 & & 0 & & 0 & & 0 & 0 \\
\hline $\begin{array}{l}\text { 2.3.1 Producing a program to } \\
\text { assure decentralization of the } \\
\text { Public administration data } \\
\text { base }\end{array}$ & $\begin{array}{l}\text { Computerized } \\
\text { control of public } \\
\text { servants; } \\
\text { substitution of } \\
\text { individual files }\end{array}$ & $\begin{array}{l}\text { Data Base } \\
\text { operacional and } \\
\text { timely computerized }\end{array}$ & - & - & $\begin{array}{l}2.3 .1 \\
\text { Producing } \\
\text { a program } \\
\text { to assure } \\
\text { decentraliz } \\
\text { ation of the } \\
\text { Public } \\
\text { administrati } \\
\text { on data } \\
\text { base } \\
\end{array}$ & & 1.700 & 0 & & 0 & & 0 & 1.700 \\
\hline $\begin{array}{l}\text { 2.3.2 Producing a strategic } \\
\text { document for electronic } \\
\text { governance and } \\
\text { informational society }\end{array}$ & $\begin{array}{l}\mathrm{N} .{ }^{\circ} \text { computers per } \\
\text { public servants; } \\
\text { Government } \\
\text { network extended all } \\
\text { over the country }\end{array}$ & - & - & - & $\begin{array}{l}2.3 .2 \\
\text { Producing } \\
\text { a strategic } \\
\text { document } \\
\text { for } \\
\text { electronic } \\
\text { governance } \\
\text { and } \\
\text { information } \\
\text { al society }\end{array}$ & & 1.000 & & 0 & & 0 & 0 & 1.000 \\
\hline $\begin{array}{l}\text { 2.4.1 Analyses and revision } \\
\text { of PCCS }\end{array}$ & $\begin{array}{l}\text { Professional } \\
\text { Capacity / sector } \\
\text { and regional } \\
\text { mobilization of } \\
\text { qualification }\end{array}$ & $\begin{array}{l}\text { Human resources } \\
\text { Diagnostic carried } \\
\text { out }\end{array}$ & $\begin{array}{l}\text { Sustained } \\
\text { strategy for the } \\
\text { new PCCS } \\
\text { prepared in } \\
\text { collaboration } \\
\text { with responsible } \\
\text { Government } \\
\text { Office }\end{array}$ & $\begin{array}{l}\text { Strategy } \\
\text { implemented }\end{array}$ & $\begin{array}{l}2.4 .1 \\
\text { Analyses } \\
\text { and } \\
\text { revision of } \\
\text { PCCS }\end{array}$ & & 3.000 & & 3.000 & & 3.000 & 0 & 9.000 \\
\hline $\begin{array}{l}2.4 .2 \text { Implementation by } \\
\text { INAG of integrated plan for } \\
\text { all the areas of public } \\
\text { management }\end{array}$ & Plan implemented & - & - & - & $\begin{array}{l}2.4 .2 \\
\text { Implementa } \\
\text { tion by } \\
\text { INAG of } \\
\text { integrated } \\
\text { plan for all } \\
\text { the areas of }\end{array}$ & 21.525 & & 22.063 & & 22.947 & & 66.535 & 0 \\
\hline
\end{tabular}

CInternational Monetary Fund. Not for Redistribution 


\begin{tabular}{|c|c|c|c|c|c|c|c|c|c|c|c|c|c|}
\hline \multirow{2}{*}{$\begin{array}{l}\text { PILLARS, OBJECTIVES } \\
\text { AND ACTIVITIES }\end{array}$} & \multirow[t]{2}{*}{ INDICATORS } & \multicolumn{3}{|l|}{ A CTIONS / GOALS } & \multirow{2}{*}{\begin{tabular}{|l|} 
DATA \\
SOURCE \\
\end{tabular}} & \multicolumn{5}{|l|}{\begin{tabular}{|l} 
BUDGET \\
\end{tabular}} & \multirow[b]{2}{*}{ COR } & \multicolumn{2}{|c|}{ TOTAL 2005-2007 } \\
\hline & & 2005 & 2006 & 2007 & & \begin{tabular}{|l|}
2005 \\
\end{tabular} & COR & 2006 & COR & 2007 & & & COR \\
\hline & & & & & $\begin{array}{l}\text { public } \\
\text { manageme } \\
\text { nt }\end{array}$ & & & & & & & & \\
\hline $\begin{array}{l}\text { 2.4.3 Elaboration of a } \\
\text { Legislation for all Public } \\
\text { sector managers careers }\end{array}$ & $\begin{array}{l}\text { Integrated vision of } \\
\text { the public resources } \\
\text { for better usage and } \\
\text { linkage to the } \\
\text { objectives }\end{array}$ & \begin{tabular}{|l|} 
Public Managers \\
responsible at each \\
Government \\
departments, for the \\
management of the \\
investment and \\
operation \\
resources, for \\
human resources \\
and for \\
administrative reform \\
\end{tabular} & - & - & $\begin{array}{l}2.4 .3 \\
\text { Elaboration } \\
\text { of a } \\
\text { Legislation } \\
\text { for all } \\
\text { Public } \\
\text { sector } \\
\text { managers } \\
\text { careers }\end{array}$ & & 162.641 & & 0 & & 0 & 0 & 162.641 \\
\hline $\begin{array}{l}\text { Improve the operation of the } \\
\text { Justice system }\end{array}$ & $\begin{array}{l}\mathrm{N} .{ }^{\circ} \text { of poor assisted } \\
\text { by the judicial } \\
\text { assistance fund }\end{array}$ & 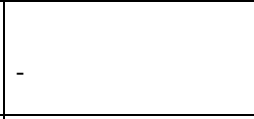 & - & - & $\begin{array}{l}\text { Improve the } \\
\text { operation of } \\
\text { the Justice } \\
\text { system }\end{array}$ & 0 & 18.721 & 0 & 41.996 & 0 & 40.478 & 0 & 101.196 \\
\hline $\begin{array}{l}\text { 3.1.1 Promoting informational } \\
\text { and communication } \\
\text { campaigns to further } \\
\text { knowledge and adequacy of } \\
\text { a democratic State }\end{array}$ & $\begin{array}{l}\mathrm{N} .{ }^{\circ} \text { of regional } \\
\text { communication } \\
\text { programs signed; \% } \\
\text { of people surveyed } \\
\text { with knowledge of } \\
\text { the existence of } \\
\text { regional } \\
\text { communication } \\
\text { program }\end{array}$ & $\begin{array}{l}17 \text { protocols signed } \\
\text { with municipalities } \\
\text { and other } \\
\text { stakeholders s }\end{array}$ & $\begin{array}{l}17 \\
\text { communication } \\
\text { programs } \\
\text { elaborated and } \\
\text { finalized }\end{array}$ & $\begin{array}{l}17 \text { Financial } \\
\text { mechanisms } \\
\text { created and } \\
\text { operational ; } \\
70 \% \text { of people } \\
\text { with } \\
\text { knowledge of } \\
\text { the existence } \\
\text { of regional } \\
\text { programs }\end{array}$ & \begin{tabular}{|l|}
3.1 .1 \\
Promoting \\
information \\
al and \\
communica \\
tion \\
campaigns \\
to further \\
knowledge \\
and \\
adequacy \\
of a \\
democratic \\
State \\
\end{tabular} & & 15.179 & & 20.239 & & 15.179 & 0 & 50.598 \\
\hline $\begin{array}{l}\text { 3.1.2 Assuring free and easy } \\
\text { access of poor to justice }\end{array}$ & $\begin{array}{l}\text { N. }{ }^{\circ} \text { of poor assisted } \\
\text { by judicial } \\
\text { assistance fund; } \\
\text { n. } \% \text { of people } \\
\text { surveyed with } \\
\text { knowledge of the } \\
\text { existence judicial } \\
\text { welfare fund }\end{array}$ & $\begin{array}{l}\text { Draft proposal of the } \\
\text { law on judicial } \\
\text { assistance } \\
\text { elaborated and } \\
\text { submitted to } \\
\text { approval by } \\
\text { National Assembly }\end{array}$ & $\begin{array}{l}\text { Law on judicial } \\
\text { assistance } \\
\text { approved and } \\
\text { published }\end{array}$ & $\begin{array}{l}\text { Judicial Fund } \\
\text { created and } \\
\text { operational }\end{array}$ & $\begin{array}{l}3.1 .2 \\
\text { Assuring } \\
\text { free and } \\
\text { easy } \\
\text { access of } \\
\text { poor to } \\
\text { justice } \\
\end{array}$ & & 2.530 & & 10.120 & & 17.709 & 0 & 30.359 \\
\hline $\begin{array}{l}\text { 3.1.3 Building and promoting } \\
\text { mechanism for Alternative } \\
\text { Quarrel Resolution of the } \\
\text { poor (ARD) }\end{array}$ & $\begin{array}{l}\mathrm{N} .{ }^{\circ} \text { of cases solved } \\
\text { through ARD }\end{array}$ & $\begin{array}{l}\text { Decree law on ADR } \\
\text { mechanism } \\
\text { presented to } \\
\text { National Assembly } \\
\text { for approval }\end{array}$ & $\begin{array}{l}\text { law on ADR } \\
\text { mechanism } \\
\text { approved and } \\
\text { published }\end{array}$ & $\begin{array}{l}\text { MJ Resolution } \\
\text { fixing rules and } \\
\text { norms for the } \\
\text { arbitration } \\
\text { centers and } \\
\text { training } \\
\text { programs for } \\
\text { mediators } \\
\text { executed }\end{array}$ & \begin{tabular}{|l|}
3.1 .3 \\
Building \\
and \\
promoting \\
mechanism \\
for \\
Alternative \\
Quarrel \\
Resolution \\
of the poor \\
(ARD) \\
\end{tabular} & & 1.012 & & 11.638 & & 7.590 & 0 & 20.239 \\
\hline Pillar 2 & & & & & & & & & & & & 0 & 0 \\
\hline $\begin{array}{l}\text { Promote competitiveness to } \\
\text { foster economic and } \\
\text { employment }\end{array}$ & $\begin{array}{l}\text { Foreign Direct } \\
\text { Investment (millions } \\
\text { of USD) }\end{array}$ & & & & & 1.535 .638 & 369.413 & 1.554 .404 & 339.828 & 1.585 .236 & 336.325 & 4.675 .278 & 1.045 .566 \\
\hline
\end{tabular}

CInternational Monetary Fund. Not for Redistribution 


\begin{tabular}{|c|c|c|c|c|c|c|c|c|c|c|c|c|c|}
\hline \multirow{2}{*}{$\begin{array}{l}\text { PILLARS, OBJECTIVES } \\
\text { AND ACTIVITIES }\end{array}$} & \multirow[t]{2}{*}{ INDICATORS } & \multicolumn{3}{|l|}{ A CTIONS / GOALS } & \multirow{2}{*}{$\begin{array}{l}\text { DATA } \\
\text { SOURCE }\end{array}$} & \multicolumn{5}{|l|}{ BUDGET } & \multirow[b]{2}{*}{ COR } & \multicolumn{2}{|c|}{ TOTAL 2005-2007 } \\
\hline & & 2005 & 2006 & 2007 & & 2005 & COR & 2006 & COR & 2007 & & INV & COR \\
\hline $\begin{array}{l}\text { Promoting/Developing } \\
\text { Tourism }\end{array}$ & $\begin{array}{l}\mathrm{N}^{\circ} \text { of } \\
\text { sleepover/tourists }\end{array}$ & & & & & 35.000 & 8.713 & 35.000 & 6.829 & 35.000 & 3.278 & 105.000 & 18.820 \\
\hline $\begin{array}{l}\text { 10.2.1 Preparation / training } \\
\text { of rural population in tourism } \\
\text { activities. Promoting } \\
\text { tourism decentralization }\end{array}$ & - & - & - & - & - & & 3.075 & & 3.152 & & 3.278 & 0 & 9.505 \\
\hline $\begin{array}{l}\text { 10.3.1 Training courses for } \\
\text { hotels and restaurants }\end{array}$ & - & - & - & - & - & & 3.588 & & 3.677 & & 0 & 0 & 7.265 \\
\hline $\begin{array}{l}\text { 10.4.1 Promoting the quality } \\
\text { of health and sanitation } \\
\text { conditions in the entire area } \\
\text { of tourism development } \\
\text { (ZDTI). Promoting the } \\
\text { accessibility to ZDTI }\end{array}$ & - & - & - & - & - & 35.000 & & 35.000 & & 35.000 & & 105.000 & 0 \\
\hline $\begin{array}{l}\text { 10.5.1 Elaboration of } \\
\text { Strategic Plan and } \\
\text { promotional activities } \\
\text { oriented towards } \\
\text { investments in the tourism } \\
\text { sector }\end{array}$ & - & - & - & - & - & & 2.050 & 0 & & 0 & & 0 & 2.050 \\
\hline $\begin{array}{l}\text { Consolidation and Promotion } \\
\text { of the private sector }\end{array}$ & $\begin{array}{l}\mathrm{N} .{ }^{\circ} \text { of industrial } \\
\text { Parks built }\end{array}$ & - & - & - & - & 205.000 & 51.250 & 210.125 & 24.164 & 218.545 & 21.855 & 633.670 & 97.269 \\
\hline $\begin{array}{l}\text { 11.3.1 Technical Study for } \\
\text { the creation of } 3 \text { new } \\
\text { industrial Parks to promote } \\
\text { the development of SME }\end{array}$ & - & - & - & - & - & 0 & & 0 & & 0 & & 0 & 0 \\
\hline $\begin{array}{l}\text { 11.3.2 Build the Industrial } \\
\text { Parks in Porto Novo }\end{array}$ & - & - & - & - & - & 0 & & 0 & & 218.545 & & 218.545 & 0 \\
\hline $\begin{array}{l}\text { 11.3.3 Build the Industrial } \\
\text { Park in Sal }\end{array}$ & - & - & - & - & - & 205.000 & & 0 & & 0 & & 205.000 & 0 \\
\hline $\begin{array}{l}\text { 11.3.4 Build the Industrial } \\
\text { Park in S. Catarina }\end{array}$ & - & - & - & - & - & 0 & & 210.125 & & 0 & & 210.125 & 0 \\
\hline $\begin{array}{l}\text { 11.4.1 Support the } \\
\text { development of the } \\
\text { entrepreneurship in Cape } \\
\text { Verde }\end{array}$ & - & - & - & - & - & & 51.250 & & 24.164 & & 21.855 & 0 & 97.269 \\
\hline $\begin{array}{l}\text { Promoting entrepreneurship } \\
\text { capacity, competitiveness, } \\
\text { growth and expansion of the } \\
\text { production base }\end{array}$ & & - & - & - & - & 0 & 2.050 & 0 & 0 & 0 & 0 & 0 & 2.050 \\
\hline $\begin{array}{l}\text { 12.3.1 Regulation of the } \\
\text { informal sector activities }\end{array}$ & - & - & - & - & - & & 2.050 & 0 & & 0 & & 0 & 2.050 \\
\hline $\begin{array}{l}\text { Reorganizing and } \\
\text { Developing the Fisheries } \\
\text { Sector }\end{array}$ & $\begin{array}{l}\text { Management Plan } \\
\text { executed }\end{array}$ & - & - & - & - & 250.000 & 250.000 & 250.000 & 250.000 & 250.000 & 250.000 & 750.000 & 750.000 \\
\hline $\begin{array}{l}\text { 13.2.1 Sustained } \\
\text { management of halieutic } \\
\text { resources * }\end{array}$ & $\begin{array}{l}\mathrm{N} .{ }^{\circ} \text { of campaign } \\
\text { carried over } ; n .{ }^{\circ} \text { of } \\
\text { control, follow up } \\
\text { and vigilante } \\
\text { missions } ; n .^{\circ} \\
\text { business interested }\end{array}$ & $\begin{array}{l}\text { Legislation revised } \\
\text {; Management Plan } \\
\text { approved; Inspection } \\
\text { Plan approved }\end{array}$ & $\begin{array}{l}\text { Legislation } \\
\text { applied ; } \\
\text { Management } \\
\text { Plan executed; } \\
\text { Inspection Plan } \\
\text { implemented } \\
\end{array}$ & 0 & $\begin{array}{l}\text { Official } \\
\text { Bulletin; } \\
\text { Sector } \\
\text { Reports }\end{array}$ & & 125.000 & & 125.000 & & 125.000 & 0 & 375.000 \\
\hline
\end{tabular}

CInternational Monetary Fund. Not for Redistribution 


\begin{tabular}{|c|c|c|c|c|c|c|c|c|c|c|c|c|c|}
\hline \multirow{2}{*}{$\begin{array}{l}\text { PILLARS, OBJECTIVES } \\
\text { AND ACTIVITIES }\end{array}$} & \multirow[t]{2}{*}{ INDICATORS } & \multicolumn{3}{|l|}{ A CTIONS / GOALS } & \multirow{2}{*}{\begin{tabular}{|l|} 
DATA \\
SOURCE
\end{tabular}} & \multicolumn{5}{|l|}{ BUDGET } & \multirow[b]{2}{*}{ COR } & \multicolumn{2}{|c|}{ TOTAL 2005-2007 } \\
\hline & & 2005 & 2006 & 2007 & & 2005 & COR & 2006 & COR & 2007 & & INV & COR \\
\hline & $\begin{array}{l}\text { in aquiculture } \\
\text { projects }\end{array}$ & & & & & & & & & & & & \\
\hline $\begin{array}{l}13.2 .2 \text { Valorization of } \\
\text { halieutic resources and their } \\
\text { quality }\end{array}$ & - & - & - & - & - & & 125.000 & & 125.000 & & 125.000 & 0 & 375.000 \\
\hline $\begin{array}{l}\text { 13.2.3 Fostering craftsman } \\
\text { fishing }\end{array}$ & $\begin{array}{l}\mathrm{N} .{ }^{\circ} \text { of fisherman } \\
\text { beneficiaries } \mathrm{n} .{ }^{\circ} \\
\text { crafts fisherman } \\
\text { changed to semi- } \\
\text { industrial; } \mathrm{n} .{ }^{\circ} \text { of } \\
\text { infra-structures } \\
\text { rehabilitated }\end{array}$ & - & - & - & - & 125.000 & & 125.000 & & 125.000 & & 375.000 & 0 \\
\hline $\begin{array}{l}\text { 13.2.4 Fostering Industrial } \\
\text { Fishing and industrials } \\
\text { manufacturing }\end{array}$ & $\begin{array}{l}\mathrm{N} .{ }^{\circ} \text { of joint-ventures } \\
\text { created }\end{array}$ & - & - & - & - & 125.000 & & 125.000 & & 125.000 & & 375.000 & 0 \\
\hline $\begin{array}{l}\text { Modernizing the agrarian } \\
\text { sector and Rural } \\
\text { Development }\end{array}$ & $\begin{array}{l}\% \text { of infrastructure } \\
\text { area with micro- } \\
\text { irrigation in relation } \\
\text { to total irrigated area }\end{array}$ & - & - & - & - & 1.045 .638 & 57.400 & 1.059 .279 & 58.835 & 1.081 .691 & 61.193 & 3.186 .608 & 177.428 \\
\hline $\begin{array}{l}\text { 14.1.1 Generalization of } \\
\text { localized watering system }\end{array}$ & $\%$ of area irrigated & $15 \%$ of the area & $20 \%$ of area & $\begin{array}{l}25 \% \text { of the } \\
\text { area }\end{array}$ & \begin{tabular}{|l|} 
Reports \\
and \\
inventories \\
\end{tabular} & 325.625 & & 326.266 & & 327.318 & & 979.209 & 0 \\
\hline $\begin{array}{l}\text { 14.1.2 Mobilization and } \\
\text { utilization of surface water * }\end{array}$ & $\begin{array}{l}\% \text { of surface water } \\
\text { used in relation to } \\
\text { availability }\end{array}$ & $5 \%$ of water used & $\begin{array}{l}10 \% \text { of water } \\
\text { used }\end{array}$ & $\begin{array}{l}15 \% \text { of water } \\
\text { used }\end{array}$ & $\begin{array}{l}\text { INMG, } \\
\text { INGRH } \\
\text { reports ; } \\
\text { INE } \\
\text { publication } \\
\end{array}$ & 286.057 & & 293.208 & & 304.958 & & 884.223 & 0 \\
\hline $\begin{array}{l}14.2 .1 \text { Increase the } \\
\text { production of horticulture, } \\
\text { tubercles and roots, in moist } \\
\text { and semi moist areas * }\end{array}$ & $\%$ of irrigated areas & $15 \%$ of the areas & $20 \%$ of the areas & $\begin{array}{l}25 \% \text { of the } \\
\text { areas }\end{array}$ & $\begin{array}{l}\text { Reports } \\
\text { and } \\
\text { inventories }\end{array}$ & 200.000 & & 200.000 & & 200.000 & & 600.000 & 0 \\
\hline $\begin{array}{l}\text { 14.2.2 Diversification and } \\
\text { increase in the production of } \\
\text { cattle raising }\end{array}$ & $\begin{array}{l}\text { Cattel raising } \\
\text { production volume }\end{array}$ & - & - & - & - & 13.581 & & 13.921 & & 14.479 & & 41.981 & 0 \\
\hline $\begin{array}{l}\text { 14.3.1 Creation of new wood } \\
\text { areas and valorization of } \\
\text { the existing ones }\end{array}$ & Wood areas & - & - & - & - & 25.625 & & 26.266 & & 27.318 & & 79.209 & 0 \\
\hline $\begin{array}{l}\text { 14.3.2 Management of } \\
\text { existing wood areas }\end{array}$ & $\begin{array}{l}N .{ }^{\circ} \text { of areas with } \\
\text { new management }\end{array}$ & - & - & - & - & & 41.000 & & 42.025 & & 43.709 & 0 & 126.734 \\
\hline $\begin{array}{l}\text { 14.3.3 Development of } \\
\text { arboriculture and shepherd } \\
\text { ship * }\end{array}$ & $\begin{array}{l}\text { Dry farming in semi } \\
\text { dry areas } \\
\text { reconverted in } \\
\text { shepherd ship * }\end{array}$ & $1 \%$ of the areas & $2 \%$ of the areas & $\begin{array}{l}3 \% \text { of the } \\
\text { areas }\end{array}$ & $\begin{array}{l}\text { Agriculture } \\
\text { Statistics ; } \\
\text { Annual } \\
\text { Reports } \\
\text { from } \\
\text { municipaliti } \\
\text { es ; annual } \\
\text { Reports } \\
\text { INIDA and } \\
\text { DGASP }\end{array}$ & 128.125 & & 131.328 & & 136.591 & & 396.044 & 0 \\
\hline
\end{tabular}

CInternational Monetary Fund. Not for Redistribution 


\begin{tabular}{|c|c|c|c|c|c|c|c|c|c|c|c|c|c|}
\hline \multirow{2}{*}{$\begin{array}{l}\text { PILLARS, OBJECTIVES } \\
\text { AND ACTIVITIES }\end{array}$} & \multirow[t]{2}{*}{ INDICATORS } & \multicolumn{3}{|l|}{ A CTIONS / GOALS } & \multirow{2}{*}{$\begin{array}{l}\text { DATA } \\
\text { SOURCE }\end{array}$} & \multicolumn{5}{|l|}{ BUDGET } & \multirow[b]{2}{*}{ COR } & \multicolumn{2}{|c|}{ TOTAL 2005-2007 } \\
\hline & & 2005 & 2006 & 2007 & & 2005 & COR & 2006 & COR & 2007 & & INV & COR \\
\hline $\begin{array}{l}\text { 14.4.1 Dissemination of } \\
\text { technology for creation and } \\
\text { utilization of forager } \\
\text { resources in accordance } \\
\text { with arable ecologic areas }\end{array}$ & Production Volume & - & - & - & - & & 10.250 & & 10.506 & & 10.927 & 0 & 31.684 \\
\hline $\begin{array}{l}14.5 .1 \text { Implementation of } \\
\text { quality control system for } \\
\text { concentrated food }\end{array}$ & $\begin{array}{l}\text { ARFA installed ; n. } \\
\text { of inspectors / } \\
\text { control carried out }\end{array}$ & - & - & - & - & 5.125 & & 5.253 & & 5.464 & & 15.842 & 0 \\
\hline $\begin{array}{l}\text { 14.5.2 Fostering the } \\
\text { provisioning of production } \\
\text { inputs for intense cattle } \\
\text { raising }\end{array}$ & $\begin{array}{l}\mathrm{N} .{ }^{\circ} \text { private business } \\
\text { in the sector } ; n .^{\circ} \text { of } \\
\text { existing and new } \\
\text { outlets }\end{array}$ & - & - & - & - & 51.250 & & 52.531 & & 54.636 & & 158.418 & 0 \\
\hline $\begin{array}{l}\text { 14.6.1 Training for all } \\
\text { operators engaged in all } \\
\text { phases of food chain } \\
\text { production in technology post } \\
\text { harvest, conservation and } \\
\text { transformation of livestock } \\
\text { products }\end{array}$ & $\begin{array}{l}\mathrm{N} .{ }^{\circ} \text { training carried } \\
\text { out }\end{array}$ & - & - & - & - & & 6.150 & & 6.304 & & 6.556 & 0 & 19.010 \\
\hline $\begin{array}{l}14.7 .1 \text { Increase in agricultural } \\
\text { production by creating and } \\
\text { utilizing technology better } \\
\text { suited to different arable } \\
\text { ecologic areas and } \\
\text { production type }\end{array}$ & $\begin{array}{l}\mathrm{N} .{ }^{\circ} \text { technological } \\
\text { package promoted } \\
\text { in the sector } \mathrm{S}\end{array}$ & - & - & - & - & 10.250 & & 10.506 & & 10.927 & & 31.684 & 0 \\
\hline PILLAR 3 & & & & & & & & & & & & 0 & 0 \\
\hline $\begin{array}{l}\text { Develop and upgrade human } \\
\text { capital }\end{array}$ & $\begin{array}{l}\text { Nr of training } \\
\text { courses } \\
\text { implemented }\end{array}$ & & & & & 1.996 .051 & 1.219 .482 & 1.418 .526 & 1.150 .213 & 680.903 & 1.115 .537 & 4.095 .480 & 3.485.232 \\
\hline $\begin{array}{l}\text { Modernizing, consolidated } \\
\text { and expand the Education } \\
\text { System }\end{array}$ & $\begin{array}{l}\text { Primary school } \\
\text { enrolment rate (net) } \\
\text {; Gross admission } \\
\text { rate in the } \\
\text { Secondary; adult; } \\
\text { illiteracy rate }\end{array}$ & - & - & - & - & 759.846 & 627.210 & 647.188 & 518.201 & 510.842 & 403.098 & 1.917 .876 & 1.548 .509 \\
\hline $\begin{array}{l}\text { 16.1.1 Continuous and on the } \\
\text { job training for staff in Pre- } \\
\text { Basic school }\end{array}$ & $\mathrm{N} .^{\circ}$ staff trained & $\begin{array}{l}140 \text { staff members in } \\
\text { Pre Basic trained }\end{array}$ & $\begin{array}{l}140 \text { staff } \\
\text { members in Pre } \\
\text { Basic trained }\end{array}$ & $\begin{array}{l}140 \text { staff } \\
\text { members in } \\
\text { Pre Basic } \\
\text { trained }\end{array}$ & $\begin{array}{l}\text { Reports of } \\
\text { MEVRH }\end{array}$ & & 16.400 & & 16.810 & & 17.484 & 0 & 50.694 \\
\hline $\begin{array}{l}\text { 16.1.2 Building Pre Basic } \\
\text { schools in conjunction with } \\
\text { Municipalities, NGO and } \\
\text { other Governmental } \\
\text { Institutions. }\end{array}$ & $\begin{array}{l}\mathrm{N} .{ }^{\circ} \text { of school rooms } \\
\text { built }\end{array}$ & $\begin{array}{l}50 \text { school rooms } \\
\text { built }\end{array}$ & $\begin{array}{l}50 \text { school rooms } \\
\text { built }\end{array}$ & $\begin{array}{l}50 \text { school } \\
\text { rooms built }\end{array}$ & $\begin{array}{l}\text { Reports of } \\
\text { MEVRH }\end{array}$ & 160.584 & & 164.598 & & 171.194 & & 496.376 & 0 \\
\hline $\begin{array}{l}\text { 16.1.3 Creating and } \\
\text { implementing an inter- } \\
\text { departmental and inter- } \\
\text { sector coordinating Institution }\end{array}$ & $\begin{array}{l}\text { Institution in } \\
\text { operation }\end{array}$ & - & - & - & $\begin{array}{l}\text { Reports of } \\
\text { MEVRH }\end{array}$ & 2.548 & & 2.612 & & 2.717 & & 7.877 & 0 \\
\hline $\begin{array}{l}\text { 16.1.4 Informational } \\
\text { campaigns to families } \\
\text { through the media }\end{array}$ & $\begin{array}{l}\mathrm{N} .{ }^{\circ} \text { of Information } \\
\text { campaign }\end{array}$ & $\begin{array}{l}15 \text { Informational } \\
\text { campaign carried } \\
\text { out }\end{array}$ & $\begin{array}{l}15 \text { Informational } \\
\text { campaign } \\
\text { carried out }\end{array}$ & $\begin{array}{l}20 \\
\text { Informational } \\
\text { campaign } \\
\text { carried out }\end{array}$ & $\begin{array}{l}\text { Reports of } \\
\text { MEVRH }\end{array}$ & & 3.844 & & 3.940 & & 4.098 & 0 & 11.881 \\
\hline $\begin{array}{l}\text { 16.2.1 Intensify the training } \\
\text { activities for teachers }\end{array}$ & $\begin{array}{l}\mathrm{N}^{\circ} \text { of teachers } \\
\text { trained }\end{array}$ & - & - & $\begin{array}{l}20 \% \text { of } \\
\text { training } \\
\text { accomplished }\end{array}$ & $\begin{array}{l}\text { Reports of } \\
\text { MEVRH }\end{array}$ & & 17.707 & & 18.150 & & 18.877 & 0 & 54.733 \\
\hline
\end{tabular}

CInternational Monetary Fund. Not for Redistribution 


\begin{tabular}{|c|c|c|c|c|c|c|c|c|c|c|c|c|c|}
\hline \multirow{2}{*}{$\begin{array}{l}\text { PILLARS, OBJECTIVES } \\
\text { AND ACTIVITIES } \\
\end{array}$} & \multirow[t]{2}{*}{ INDICATORS } & \multicolumn{3}{|l|}{ A CTIONS / GOALS } & \multirow{2}{*}{$\begin{array}{l}\text { DATA } \\
\text { SOURCE }\end{array}$} & \multicolumn{5}{|l|}{ BUDGET } & \multirow[b]{2}{*}{ COR } & \multicolumn{2}{|c|}{ TOTAL 2005-2007 } \\
\hline & & 2005 & 2006 & 2007 & & 2005 & COR & 2006 & COR & 2007 & & & COR \\
\hline $\begin{array}{l}\text { 16.2.2 Revision of programs } \\
\text { and school manuals for the } \\
\text { Basic Education * }\end{array}$ & $\begin{array}{l}\text { Programs and } \\
\text { school manuals } \\
\text { revised }\end{array}$ & - & - & $\begin{array}{l}100 \% \text { of } \\
\text { programs and } \\
\text { school } \\
\text { manuals } \\
\text { revised }\end{array}$ & $\begin{array}{l}\text { Reports of } \\
\text { MEVRH }\end{array}$ & & 100.614 & & 68.753 & & 0 & 0 & 169.367 \\
\hline $\begin{array}{l}16.2 .3 \text { Improvement in } \\
\text { internal efficiency of the } \\
\text { education system by } \\
\text { reducing drop out and } \\
\text { repetition }\end{array}$ & $\begin{array}{l}\text { Drop out and } \\
\text { repetition rate }\end{array}$ & - & - & $\begin{array}{l}\text { Repetition rate } \\
\text { below } 8 \% \\
\text { and drop out } \\
\text { below } 2 \%\end{array}$ & $\begin{array}{l}\text { Reports of } \\
\text { MEVRH }\end{array}$ & & 2.563 & & 2.627 & & 2.732 & 0 & 7.921 \\
\hline $\begin{array}{l}\text { 16.2.4 Strength the curricula } \\
\text { and pedagogical practices } \\
\text { of teachers in Basic } \\
\text { education in issues of values } \\
\text { related with citizenships, } \\
\text { Democracy, environment, } \\
\text { peace, social justice and } \\
\text { work }\end{array}$ & $\begin{array}{l}\text { Programs and } \\
\text { practice including } \\
\text { citizens values, } \\
\text { democracy, peace, } \\
\text { peace, social justice } \\
\text { and }\end{array}$ & - & - & $\begin{array}{l}100 \% \text { of } \\
\text { programs } \\
\text { including } \\
\text { values }\end{array}$ & $\begin{array}{l}\text { Reports of } \\
\text { MEVRH }\end{array}$ & & 4.305 & & 4.308 & & 4.480 & 0 & 13.093 \\
\hline $\begin{array}{l}\text { 16.2.5 Promotion and } \\
\text { dissemination of cape- } \\
\text { verdean culture in schools. }\end{array}$ & $\begin{array}{l}\mathrm{N} .{ }^{\circ} \text { of schools the } \\
\text { host artistic events }\end{array}$ & $\begin{array}{l}100 \% \text { schools the } \\
\text { hosting artistic } \\
\text { events }\end{array}$ & - & - & $\begin{array}{l}\text { Reports of } \\
\text { MEVRH }\end{array}$ & & 1.025 & & 1.051 & & 1.093 & 0 & 3.168 \\
\hline $\begin{array}{l}\text { 16.2.6 Implementation of a } \\
\text { plan for schools building, } \\
\text { expansion, maintenance, } \\
\text { specially those located in } \\
\text { peripheral areas }\end{array}$ & $\begin{array}{l}\mathrm{N} .{ }^{\circ} \text { of schools built, } \\
\text { repaired and } \\
\text { augmented }\end{array}$ & 10 augmented & $\begin{array}{l}5 \text { of schools } \\
\text { built and } \\
\text { augmented }\end{array}$ & $100 \%$ repaired & $\begin{array}{l}\text { Reports of } \\
\text { MEVRH }\end{array}$ & 205.000 & & 94.556 & & 49.173 & & 348.729 & 0 \\
\hline $\begin{array}{l}\text { 16.3.1 Strengthen the initial } \\
\text { and on the job training } \\
\text { qualification for teaching } \\
\text { staff for both general and } \\
\text { technical via. }\end{array}$ & $\begin{array}{l}\% \text { of teachers with } \\
\text { pedagogical training }\end{array}$ & - & - & $\begin{array}{l}80 \% \text { of } \\
\text { teachers with } \\
\text { pedagogical } \\
\text { training }\end{array}$ & $\begin{array}{l}\text { Reports of } \\
\text { MEVRH }\end{array}$ & & 87.638 & & 89.828 & & 93.428 & 0 & 270.894 \\
\hline $\begin{array}{l}\text { 16.3.2 Building and } \\
\text { equipment for schools in rural } \\
\text { areas }\end{array}$ & $N .^{\circ}$ of schools built & $50 \%$ of schools built & - & $\begin{array}{l}100 \% \text { of } \\
\text { schools built }\end{array}$ & $\begin{array}{l}\text { Reports of } \\
\text { MEVRH }\end{array}$ & 250.777 & & 346.023 & & 246.781 & & 843.581 & 0 \\
\hline $\begin{array}{l}\text { 16.3.3 Reformulation of } \\
\text { objectives, goals and } \\
\text { curricula structure for } \\
\text { secondary education }\end{array}$ & Curricula revised & - & - & $\begin{array}{l}\text { Programs for } \\
\text { the } 3 \text { cycles } \\
\text { revised }\end{array}$ & $\begin{array}{l}\text { Reports of } \\
\text { MEVRH }\end{array}$ & & 116.953 & & 51.376 & & 0 & 0 & 168.328 \\
\hline $\begin{array}{l}\text { 16.3.4 Reinforcing the library, } \\
\text { computer equipment, } \\
\text { laboratory and workshops, } \\
\text { for the existing schools }\end{array}$ & $\begin{array}{l}\mathrm{N} .{ }^{\circ} \text { library } \\
\text { furnished, } \\
\text { computer rooms, } \\
\text { laboratory and } \\
\text { workshops equipped } \\
\end{array}$ & - & - & $\begin{array}{l}100 \% \text { library } \\
\text { furnished } \\
\text { laboratory } \\
\text { and workshops } \\
\text { equipped } \\
\end{array}$ & $\begin{array}{l}\text { Reports of } \\
\text { MEVRH }\end{array}$ & 38.438 & & 39.398 & & 40.977 & & 118.813 & 0 \\
\hline $\begin{array}{l}16.3 .5 \text { Strength the program } \\
\text { and pedagogical practices } \\
\text { for the secondary education, } \\
\text { with values related with } \\
\text { citizenships, Democracy, } \\
\text { environment, peace, social } \\
\text { justice and work }\end{array}$ & $\begin{array}{l}\text { Programs and } \\
\text { practices including } \\
\text { values of } \\
\text { citizenships, } \\
\text { Democracy, } \\
\text { environment, peace, }\end{array}$ & - & - & $\begin{array}{l}100 \% \text { of } \\
\text { programs } \\
\text { including } \\
\text { values }\end{array}$ & $\begin{array}{l}\text { Reports of } \\
\text { MEVRH }\end{array}$ & & 5.125 & & 5.253 & & 5.464 & 0 & 15.842 \\
\hline $\begin{array}{l}\text { 16.3.6 Reinforcing technical } \\
\text { education and it's articulation } \\
\text { with professional training }\end{array}$ & $\begin{array}{l}\text { Curses operating in } \\
\text { all schools of the } \\
\text { country }\end{array}$ & $\begin{array}{l}100 \% \text { of technical } \\
\text { schools }\end{array}$ & - & - & $\begin{array}{l}\text { Reports of } \\
\text { MEVRH }\end{array}$ & & 1.538 & & 0 & & 0 & 0 & 1.538 \\
\hline
\end{tabular}

CInternational Monetary Fund. Not for Redistribution 


\begin{tabular}{|c|c|c|c|c|c|c|c|c|c|c|c|c|c|}
\hline \multirow{2}{*}{$\begin{array}{l}\text { PILLARS, OBJECTIVES } \\
\text { AND ACTIVITIES }\end{array}$} & \multirow[t]{2}{*}{ INDICATORS } & \multicolumn{3}{|l|}{ A CTIONS / GOALS } & \multirow{2}{*}{$\begin{array}{l}\text { DATA } \\
\text { SOURCE }\end{array}$} & \multicolumn{5}{|l|}{ BUDGET } & \multirow[b]{2}{*}{ COR } & \multicolumn{2}{|c|}{ TOTAL 2005-2007 } \\
\hline & & 2005 & 2006 & 2007 & & 2005 & COR & 2006 & COR & 2007 & & INV & COR \\
\hline $\begin{array}{l}\text { 16.3.7 Creating a system of } \\
\text { vocational guidance linked to } \\
\text { employment and training } \\
\text { centers and higher } \\
\text { education }\end{array}$ & $\begin{array}{l}\text { OEP created and } \\
\text { operational }\end{array}$ & - & - & - & $\begin{array}{l}\text { Reports of } \\
\text { MEVRH }\end{array}$ & 0 & & 0 & & 0 & & 0 & 0 \\
\hline $\begin{array}{l}\text { 16.3.8 Support to private } \\
\text { initiative in developing } \\
\text { secondary education by } \\
\text { mechanisms that facilitates } \\
\text { access to credit }\end{array}$ & $\begin{array}{l}\text { Mechanisms that } \\
\text { facilitates access to } \\
\text { credit created }\end{array}$ & - & - & - & $\begin{array}{l}\text { Reports of } \\
\text { MEVRH }\end{array}$ & 0 & & 0 & & 0 & & 0 & 0 \\
\hline $\begin{array}{l}\text { 16.3.9 Fostering the } \\
\text { democratization of secondary } \\
\text { schools by way of } \\
\text { autonomous management }\end{array}$ & $\begin{array}{l}\text { Schools managed } \\
\text { with parental } \\
\text { participation }\end{array}$ & $\begin{array}{l}100 \% \text { of schools } \\
\text { managed with } \\
\text { parental participation }\end{array}$ & - & - & $\begin{array}{l}\text { Reports of } \\
\text { MEVRH }\end{array}$ & & 1.599 & 0 & & 0 & & 0 & 1.599 \\
\hline $\begin{array}{l}\text { 16.4.1 Elaborating a law } \\
\text { package which includes: a) } \\
\text { higher education organization } \\
\text { and ordering b) statute of } \\
\text { private and cooperative } \\
\text { higher education ; c) } \\
\text { Revision of higher education } \\
\text { courses, it's authorization, } \\
\text { registration and operation }\end{array}$ & $\begin{array}{l}\text { Decrees laws } \\
\text { elaborated }\end{array}$ & - & - & - & $\begin{array}{l}\text { Reports of } \\
\text { MEVRH }\end{array}$ & 0 & & 0 & & 0 & & 0 & 0 \\
\hline $\begin{array}{l}\text { 16.4.2 Capacitate institutions } \\
\text { to take part of the Univ. of } \\
\mathrm{CV} \text {; a) Training for teaching } \\
\text { staff; b) training for non } \\
\text { teaching staff. }\end{array}$ & $\begin{array}{l}\text { On site and } \\
\text { distance training } \\
\text { courses }\end{array}$ & - & - & - & $\begin{array}{l}\text { Reports of } \\
\text { MEVRH }\end{array}$ & & 12.915 & 0 & & 0 & & 0 & 12.915 \\
\hline $\begin{array}{l}\text { 16.4.3 Expansion } \\
\text { /rehabilitation of physical } \\
\text { infrastructure }\end{array}$ & Faciliteis built & - & - & - & $\begin{array}{l}\text { Reports of } \\
\text { MEVRH }\end{array}$ & 102.500 & & 0 & & 0 & & 102.500 & 0 \\
\hline $\begin{array}{l}\text { 16.4.4 Add ional equipment, } \\
\text { libraries, laboratories and } \\
\text { computers }\end{array}$ & $\begin{array}{l}\text { Libraries furnished } \\
\text { computers rooms, } \\
\text { laboratories } \\
\text { equipped }\end{array}$ & - & - & - & $\begin{array}{l}\text { Reports of } \\
\text { MEVRH }\end{array}$ & 0 & & 0 & & 0 & & 0 & 0 \\
\hline $\begin{array}{l}16.5 .1 \text { Updating and } \\
\text { reformulation of curricula, } \\
\text { manuals, pedagogical } \\
\text { practices in the education of } \\
\text { youth and adult, strengthen } \\
\text { cultural values, citizenship, } \\
\text { democracy, environment and } \\
\text { social rules }\end{array}$ & $\begin{array}{l}\text { Programs and } \\
\text { supporting manuals } \\
\text { revised }\end{array}$ & $\begin{array}{l}100 \% \text { manuals } \\
\text { revised }\end{array}$ & - & - & $\begin{array}{l}\text { Reports of } \\
\text { MEVRH }\end{array}$ & & 10.250 & & 10.506 & 0 & & 0 & 20.756 \\
\hline $\begin{array}{l}\text { 16.5.2 Developing } \\
\text { Information, education and } \\
\text { communication activities } \\
\text { through mobile library to } \\
\text { disseminate issues related } \\
\text { with health education, } \\
\text { environment, family, } \\
\text { citizenship and gender }\end{array}$ & $\begin{array}{l}\text { Mobile library } \\
\text { furnished and fleet } \\
\text { renewed }\end{array}$ & $\begin{array}{l}\text { Mobile library } \\
\text { furnished in all } \\
\text { municipalities and } \\
50 \% \text { the fleet } \\
\text { renewed }\end{array}$ & - & - & $\begin{array}{l}\text { Reports of } \\
\text { MEVRH }\end{array}$ & & 15.734 & & 16.127 & & 16.773 & 0 & 48.634 \\
\hline
\end{tabular}




\begin{tabular}{|c|c|c|c|c|c|c|c|c|c|c|c|c|c|}
\hline \multirow{2}{*}{$\begin{array}{l}\text { PILLARS, OBJECTIVES } \\
\text { AND ACTIVITIES }\end{array}$} & \multirow[t]{2}{*}{ INDICATORS } & \multicolumn{3}{|l|}{ A CTIONS / GOALS } & \multirow{2}{*}{\begin{tabular}{|l} 
DATA \\
SOURCE
\end{tabular}} & \multicolumn{5}{|l|}{ BUDGET } & \multirow[b]{2}{*}{ COR } & \multicolumn{2}{|c|}{ TOTAL 2005-2007 } \\
\hline & & 2005 & 2006 & 2007 & & 2005 & COR & 2006 & COR & 2007 & & INV & COR \\
\hline $\begin{array}{l}16.5 .3 \text { Coordinate and follow } \\
\text { up the inclusion in the } \\
\text { curricula activities general } \\
\text { education issues related with } \\
\text { population and family life, } \\
\text { HIV/AIDS and environment } \\
\text { education. }\end{array}$ & $\begin{array}{l}\text { Follow up group } \\
\text { created in al } \\
\text { municipalities }\end{array}$ & - & - & $\begin{array}{l}100 \% \text { of } \\
\text { municipalities } \\
\text { covered }\end{array}$ & $\begin{array}{l}\text { Reports of } \\
\text { MEVRH }\end{array}$ & & 6.834 & & 7.003 & & 7.285 & 0 & 21.122 \\
\hline $\begin{array}{l}\text { 16.5.4 Developing } \\
\text { professional basic trainings } \\
\text { for adults, targeting post } \\
\text { alphabetization trainees by } \\
\text { promoting income generating } \\
\text { micro projects }\end{array}$ & $\begin{array}{l}\mathrm{N} .^{\circ} \text { of young people } \\
\text { trained in special } \\
\text { fields }\end{array}$ & $\begin{array}{l}1000 \text { of young } \\
\text { people trained }\end{array}$ & $\begin{array}{l}1000 \text { of young } \\
\text { people trained }\end{array}$ & $\begin{array}{l}1000 \text { of } \\
\text { young people } \\
\text { trained }\end{array}$ & $\begin{array}{l}\text { Reports of } \\
\text { MEVRH }\end{array}$ & & 25.625 & & 26.266 & & 27.318 & 0 & 79.209 \\
\hline $\begin{array}{l}\text { 16.6.1 Management } \\
\text { betterment and discipline for } \\
\text { social assistance }\end{array}$ & $\begin{array}{l}\text { Management team } \\
\text { created and } \\
\text { functioning }\end{array}$ & - & - & - & $\begin{array}{l}\text { Reports of } \\
\text { MEVRH }\end{array}$ & & 41.000 & & 42.025 & & 43.709 & 0 & 126.734 \\
\hline $\begin{array}{l}\text { 16.6.2 Consolidation of the } \\
\text { distribution of daily hot meals } \\
\text { for Basic Education students } \\
\text { and pre- School children } \\
\text { living in needed areas }\end{array}$ & $\begin{array}{l}\text { Hot meals served to } \\
\text { all children }\end{array}$ & $\begin{array}{l}100 \% \text { of children } \\
\text { with hot meals }\end{array}$ & $\begin{array}{l}100 \% \text { of young } \\
\text { people trained }\end{array}$ & $\begin{array}{l}100 \% \text { of } \\
\text { young people } \\
\text { trained }\end{array}$ & $\begin{array}{l}\text { Reports of } \\
\text { MEVRH }\end{array}$ & & 102.500 & & 105.063 & & 109.273 & 0 & 316.835 \\
\hline $\begin{array}{l}\text { 16.6.3 Expanding the } \\
\text { assistance to needed } \\
\text { families, by executing } \\
\text { transportation programs, } \\
\text { scholarships, financing } \\
\text { tuitions and supply of didactic } \\
\text { materials }\end{array}$ & $\begin{array}{l}\% \text { of needed } \\
\text { children with } \\
\text { transportation } \\
\text { scholarships, } \\
\text { financing tuitions } \\
\text { and supply of } \\
\text { didactic materials }\end{array}$ & $100 \%$ of children & $100 \%$ of children & $\begin{array}{l}100 \% \text { of } \\
\text { children }\end{array}$ & $\begin{array}{l}\text { Reports of } \\
\text { MEVRH }\end{array}$ & & 15.375 & & 15.759 & & 16.391 & 0 & 47.525 \\
\hline $\begin{array}{l}\text { 16.6.4 Strength basic } \\
\text { education school health }\end{array}$ & $\begin{array}{l}\% \text { managers, } \\
\text { coordinators } \\
\text { teachers trained in } \\
\text { school health; } \% \\
\text { of children that } \\
\text { develop basic } \\
\text { behavior in the } \\
\text { matters of nutrition } \\
\text { and health }\end{array}$ & $\begin{array}{l}100 \% \text { teachers and } \\
100 \% \text { children }\end{array}$ & $\begin{array}{l}100 \% \text { teachers } \\
\text { and } 100 \% \\
\text { children }\end{array}$ & $\begin{array}{l}100 \% \\
\text { teachers and } \\
100 \% \text { children }\end{array}$ & $\begin{array}{l}\text { Reports of } \\
\text { MEVRH }\end{array}$ & & 31.775 & & 32.569 & & 33.875 & 0 & 98.219 \\
\hline $\begin{array}{l}\text { 16.7. Reinforcing the } \\
\text { education information and } \\
\text { management system; central } \\
\text { and local training; staff } \\
\text { training to maintain the } \\
\text { system }\end{array}$ & $\begin{array}{l}\% \text { of the staff from } \\
\text { main services } \\
\text { trained and and able } \\
\text { to use ITC }\end{array}$ & $100 \%$ of staff & - & - & $\begin{array}{l}\text { Reports of } \\
\text { MEVRH }\end{array}$ & & 5.125 & & 0 & & 0 & 0 & 5.125 \\
\hline $\begin{array}{l}\text { 16.7.2 Publication of } \\
\text { statistics produced by GEP }\end{array}$ & $\begin{array}{l}\mathrm{N} .{ }^{\circ} \text { of annual } \\
\text { reports produced } \\
\text { containing official } \\
\text { data }\end{array}$ & 200 copies & 200 copies & 200 copies & $\begin{array}{l}\text { Reports of } \\
\text { MEVRH }\end{array}$ & & 769 & & 788 & & 820 & 0 & 2.376 \\
\hline $\begin{array}{l}\text { Capacity building and } \\
\text { creation of a system for } \\
\text { evaluating employment and } \\
\text { training }\end{array}$ & $\begin{array}{l}\% \text { of adults with } \\
\text { basic professional } \\
\text { training }\end{array}$ & . & - & - & - & 29.418 & 0 & 30.153 & 0 & 31.361 & 0 & 90.932 & 0 \\
\hline $\begin{array}{l}\text { 17.1.1 Expand to national } \\
\text { level training and } \\
\text { employment services } \\
\text { network }\end{array}$ & - & - & - & - & - & 26.317 & & 26.975 & & 28.056 & & 81.347 & 0 \\
\hline
\end{tabular}

CInternational Monetary Fund. Not for Redistribution 


\begin{tabular}{|c|c|c|c|c|c|c|c|c|c|c|c|c|c|}
\hline \multirow{2}{*}{$\begin{array}{l}\text { PILLARS, OBJECTIVES } \\
\text { AND ACTIVITIES }\end{array}$} & \multirow{2}{*}{ INDICATORS } & \multicolumn{3}{|l|}{ A CTIONS / GOALS } & \multirow{2}{*}{\begin{tabular}{|l|} 
DATA \\
SOURCE
\end{tabular}} & \multicolumn{5}{|l|}{ BUDGET } & \multirow[b]{2}{*}{ COR } & \multicolumn{2}{|c|}{ TOTAL 2005-2007 } \\
\hline & & 2005 & 2006 & 2007 & & \begin{tabular}{|l|}
2005 \\
\end{tabular} & COR & 2006 & COR & 2007 & & INV & COR \\
\hline 17.2.1 Executing Surveys & 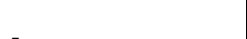 & 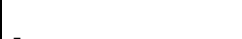 & 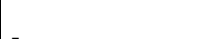 & 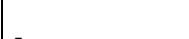 & _ & 3.101 & & 3.178 & & 3.305 & & 9.584 & 0 \\
\hline Population and development & $\begin{array}{l}\text { National Policy on } \\
\text { Population } \\
\text { published ; Action } \\
\text { Plan for equity } \\
\text { equality in gender } \\
\text { implemented }\end{array}$ & - & - & - & - & 6.571 & 18.375 & 6.571 & 17.465 & 6.571 & 16.143 & 19.713 & 51.982 \\
\hline $\begin{array}{l}\text { 20.1.1 Assistance for } \\
\text { National Policy on Population }\end{array}$ & $\begin{array}{l}\text { NPP revised and } \\
\text { published }\end{array}$ & PNP divulgada & $\begin{array}{l}\text { Political decision } \\
\text { takers and } \\
\text { citizens informed } \\
\text { over the content } \\
\text { of }\end{array}$ & - & $\begin{array}{l}\text { Reports of } \\
\text { DGP }\end{array}$ & & 2.232 & & 1.322 & & 0 & 0 & 3.554 \\
\hline $\begin{array}{l}\text { 20.2.1 Reinforcing the } \\
\text { capacity of Institute for } \\
\text { Women Condition } \\
\text { (ICF) }\end{array}$ & $\mathrm{N} .^{\circ}$ vacancy filled & $1 / 3$ of vacancy filled & $\begin{array}{l}\text { All of vacancy } \\
\text { filled }\end{array}$ & $\begin{array}{l}\text { ICF with ability } \\
\text { to assist } \\
\text { different } \\
\text { institutions in } \\
\text { the inclusion of } \\
\text { gender } \\
\text { perspective in } \\
\text { the process of } \\
\text { information }\end{array}$ & $\begin{array}{l}\text { Reports of } \\
\text { ICF }\end{array}$ & & 13.000 & & 13.000 & & 13.000 & 0 & 39.000 \\
\hline $\begin{array}{l}\text { 20.2.2 Multi-sector } \\
\text { Implementation of Plan of } \\
\text { Action for equity and equality } \\
\text { of gender }\end{array}$ & $\begin{array}{l}\text { Plan of Action } \\
\text { implemented }\end{array}$ & $\begin{array}{l}1 / 3 \text { of the scheduled } \\
\text { activities } \\
\text { implemented }\end{array}$ & $\begin{array}{l}\text { Half of } \\
\text { scheduled } \\
\text { activities } \\
\text { implemented }\end{array}$ & $\begin{array}{l}2 / 3 \text { of } \\
\text { scheduled } \\
\text { activities } \\
\text { implemented }\end{array}$ & $\begin{array}{l}\text { Reports of } \\
\text { ICF }\end{array}$ & & 3.143 & & 3.143 & & 3.143 & 0 & 9.428 \\
\hline $\begin{array}{l}\text { 20.2.3 Reinforce the activities } \\
\text { of NGO in collaboration with } \\
\text { ICF }\end{array}$ & \begin{tabular}{|l|}
$N .{ }^{\circ}$ offices that \\
offers psychic - legal \\
monotoring of \\
women victim of \\
violence; \% \\
women victim of \\
violence; \% of \\
women and man \\
with access to \\
training; $\mathrm{n}^{\circ}$ of NGO \\
capable of \\
developing \\
information \\
campaigns and \\
training activities; \\
N. of women with \\
access to the credit \\
system \\
\end{tabular} & $\begin{array}{l}\text { NGO's female law } \\
\text { department qualified }\end{array}$ & $\begin{array}{l}\text { Female NGO } \\
\text { reinforced; New } \\
\text { law firms created }\end{array}$ & $\begin{array}{l}\text { Activities of } \\
\text { NGO's that } \\
\text { promote } \\
\text { gender } \\
\text { equality with } \\
\text { national } \\
\text { coverage }\end{array}$ & $\begin{array}{l}\text { Reports of } \\
\text { ICF }\end{array}$ & 6.571 & & 6.571 & & 6.571 & & 19.713 & 0 \\
\hline $\begin{array}{l}\text { Promoting employment and } \\
\text { fostering qualification to } \\
\text { respond to social } \\
\text { development needs }\end{array}$ & Unemployment Rate & - & - & - & - & 18.860 & 52.846 & 19.332 & 54.168 & 20.106 & 56.338 & 58.298 & 163.352 \\
\hline $\begin{array}{l}22.1 .1 \text { Creating incentives to } \\
\text { promote the development of } \\
\text { micro enterprises }\end{array}$ & - & - & - & - & - & 18.860 & & 19.332 & & 20.106 & & 58.298 & 0 \\
\hline $\begin{array}{l}\text { 22.2.1 Re-initiation of the } \\
\text { apprenticeship program at } \\
\text { national level }\end{array}$ & - & - & - & - & - & & 22.038 & & 22.588 & & 23.494 & 0 & 68.120 \\
\hline
\end{tabular}

CInternational Monetary Fund. Not for Redistribution 


\begin{tabular}{|c|c|c|c|c|c|c|c|c|c|c|c|c|c|}
\hline \multirow{2}{*}{$\begin{array}{l}\text { PILLARS, OBJECTIVES } \\
\text { AND ACTIVITIES } \\
\end{array}$} & \multirow[t]{2}{*}{ INDICATORS } & \multicolumn{3}{|l|}{ A CTIONS / GOALS } & \multirow{2}{*}{$\begin{array}{l}\text { DATA } \\
\text { SOURCE }\end{array}$} & \multicolumn{5}{|l|}{ BUDGET } & \multirow[b]{2}{*}{ COR } & \multicolumn{2}{|c|}{ TOTAL 2005-2007 } \\
\hline & & 2005 & 2006 & 2007 & & \begin{tabular}{|l|}
2005 \\
\end{tabular} & COR & 2006 & COR & 2007 & & INV & COR \\
\hline $\begin{array}{l}\text { 22.2.2 Designe training } \\
\text { course for the targeted group }\end{array}$ & - & - & - & - & - & & 30.809 & & 31.579 & & 32.845 & 0 & 95.233 \\
\hline $\begin{array}{l}\text { Reforming the System to } \\
\text { foster health }\end{array}$ & \begin{tabular}{|l|} 
Infant-juvenile \\
mortality rate; \\
maternal mortality \\
rate; Rate assited \\
pregnant women \\
with HIV-
\end{tabular} & - & - & - & - & 1.181.357 & 521.051 & 715.282 & 560.380 & 112.022 & 639.958 & 2.008 .661 & 1.721 .389 \\
\hline $\begin{array}{l}23.1 .1 \text { Reinforcing the health } \\
\text { services in the Priority } \\
\text { Program } \\
\text { component(Attention: It } \\
\text { includes childhood disease, } \\
\text { expanded vaccination } \\
\text { program, health } \\
\text { reproduction, HIV, } \\
\text { Tuberculoses, Diseases } \\
\text { Vigilance) }\end{array}$ & $\begin{array}{l}{ }^{\circ} \text { of health } \\
\text { services that } \\
\text { implement the } \\
\text { strategy; \% of } \\
\text { children below } 1 \\
\text { year of age } \\
\text { completely } \\
\text { vaccinated; prenatal } \\
\text { mortality rate; } \\
\text { Detection rate and } \\
\text { cure of } \\
\text { Tuberculoses } \\
\text { prevalence }\end{array}$ & $\begin{array}{l}1 \text { Regional Hospital, } \\
1 \text { Central Hospital } \\
\text { and } 3 \text { Health } \\
\text { Centers; } 80 \% \text { of } \\
\text { children less than } 1 \\
\text { year completely } \\
\text { vaccinated; } \\
\text { decreasing by } 20 \% \\
\text { the prenatal mortality } \\
\text { rate }\end{array}$ & $\begin{array}{l}2 \text { Regional } \\
\text { Hospitals , } 1 \\
\text { Central Hospital } \\
\text { and } 5 \text { Health ; } \\
85 \% \text { of children } \\
\text { less than } 1 \text { year } \\
\text { completely } \\
\text { vaccinated; } \\
\text { Detection rate for } \\
\text { Tuberculoses: } \\
70 \% \text {; healing rate } \\
: 85 \%\end{array}$ & \begin{tabular}{|l}
3 Hospitais \\
Regionais, 2 \\
Hospitais \\
Centrais e 10 \\
Centros de \\
Saúde; 90 of \\
children less \\
than 1 year \\
completely \\
vaccinated
\end{tabular} & MS & & 66.465 & & 67.363 & & 76.581 & 0 & 210.409 \\
\hline $\begin{array}{l}\text { 23.1.2 Execution of National } \\
\text { Strategic Plan for HIV } \\
\text { Prevention }\end{array}$ & $\begin{array}{l}\text { \% of women and } \\
\text { man with knowledge } \\
\text { of how sexual } \\
\text { disease are } \\
\text { transmitted; \% of } \\
\text { women and man } \\
\text { (15 and 24years) } \\
\text { that knows that } \\
\text { condoms protects } \\
\text { against diseases ; } \\
\text { HIV rate among } \\
\text { pregnant women } \\
\text { detected during } \\
\text { prenatal visits }\end{array}$ & $\begin{array}{l}98 \% \text { Knows how } \\
\text { sexual disease are } \\
\text { transmitted; } 95 \% \\
\text { knows that condoms } \\
\text { protects against } \\
\text { disease ; Prevalence } \\
\text { rate }: 1 \%\end{array}$ & $\begin{array}{l}98 \% \text { Knows how } \\
\text { sexual disease } \\
\text { are transmitted; } \\
95 \% \text { knows that } \\
\text { condoms protects } \\
\text { against disease ; } \\
\text { Prevalence rate } \\
: 1 \%\end{array}$ & $\begin{array}{l}100 \text { Knows } \\
\text { how sexual } \\
\text { disease are } \\
\text { transmitted; } \\
99 \% 95 \% \\
\text { knows that } \\
\text { condoms } \\
\text { protects } \\
\text { against } \\
\text { disease } \\
\text { Prevalence } \\
\text { rate :1\% }\end{array}$ & $\begin{array}{l}\text { MS } \\
\text { Reports; } \\
\text { Survey }\end{array}$ & & 257.161 & & 298.857 & & 400.857 & 0 & 956.876 \\
\hline $\begin{array}{l}\text { 23.2.1 Reinforcing the } \\
\text { Sanitation Information } \\
\text { System }\end{array}$ & $\begin{array}{l}\text { Information to } \\
\text { improve the existing } \\
\text { management } \\
\text { system }\end{array}$ & $\begin{array}{l}\text { Information on } \\
\text { mortality, programs } \\
\text { morbidity resources } \\
\text { available }\end{array}$ & \begin{tabular}{|l|} 
Information on \\
mortality, \\
programs \\
morbidity \\
resources, \\
national account \\
available \\
\end{tabular} & \begin{tabular}{|l|} 
Information on \\
mortality, \\
programs \\
morbidity \\
resources \\
nosology \\
available \\
\end{tabular} & $\begin{array}{l}\text { MS; INE; } \\
\text { Reports } \\
\text { and study }\end{array}$ & 15.000 & & 5.000 & & 0 & & 20.000 & 0 \\
\hline $\begin{array}{l}23.2 .2 \text { Improving the Quality } \\
\text { of Health System net work } \\
\text { structure }\end{array}$ & \begin{tabular}{|l|}
$\%$ of the \\
municipalities \\
population \\
benefiting from \\
health services \\
\end{tabular} & $\begin{array}{l}47 \% \text { of the } \\
\text { municipalities } \\
\text { population benefiting } \\
\text { from health services }\end{array}$ & $\begin{array}{l}76 \% \text { of the } \\
\text { municipalities } \\
\text { population } \\
\text { benefiting from } \\
\text { health services } \\
\end{array}$ & \begin{tabular}{|l|}
$80 \%$ of the \\
municipalities \\
population \\
benefiting from \\
health services \\
\end{tabular} & $\begin{array}{l}\text { MS; MIT; } \\
\text { Municípios; } \\
\text { Reports }\end{array}$ & 1.155 .428 & & 698.260 & & 100.000 & & 1.953 .688 & 0 \\
\hline $\begin{array}{l}23.2 .3 \text { Improving the } \\
\text { accessibility of essential } \\
\text { drugs }\end{array}$ & $\begin{array}{l}\mathrm{N} .{ }^{\circ} \text { of drugs in the } \\
\text { list of the essential } \\
\text { drugs available at } \\
\text { peripheral health } \\
\text { outlets } \\
\end{array}$ & $\begin{array}{l}\text { Study published and } \\
\text { goals defined }\end{array}$ & - & - & Reports & & 10.221 & & 15.000 & & 15.000 & 0 & 40.221 \\
\hline
\end{tabular}

CInternational Monetary Fund. Not for Redistribution 


\begin{tabular}{|c|c|c|c|c|c|c|c|c|c|c|c|c|c|}
\hline \multirow{2}{*}{$\begin{array}{l}\text { PILLARS, OBJECTIVES } \\
\text { AND ACTIVITIES }\end{array}$} & \multirow[t]{2}{*}{ INDICATORS } & \multicolumn{3}{|l|}{ A CTIONS / GOALS } & \multirow{2}{*}{\begin{tabular}{|l|} 
DATA \\
SOURCE \\
\end{tabular}} & \multicolumn{5}{|l|}{ BUDGET } & \multirow[b]{2}{*}{ COR } & \multicolumn{2}{|c|}{ TOTAL 2005-2007 } \\
\hline & & 2005 & 2006 & 2007 & & \begin{tabular}{|l|}
2005 \\
\end{tabular} & COR & 2006 & COR & 2007 & & INV & COR \\
\hline $\begin{array}{l}23.3 .1 \text { Increasing the } \\
\text { capacity to train health staff } \\
\text { by organizing long and short } \\
\text { term training qualification in } \\
\text { the country }\end{array}$ & $\begin{array}{l}\text { Ratio nurses } \\
\text { linhabitants }\end{array}$ & $\begin{array}{l}\text { Ratio nurses } \\
\text { /ihhabitants : } 1 / 1967\end{array}$ & $\begin{array}{l}\text { Ratio nurses } \\
\text { linhabitants: } \\
1 / 1986\end{array}$ & $\begin{array}{l}\text { Ratio nurses } \\
\text { /inhabitants: } \\
\text { 1/1004 }\end{array}$ & $\begin{array}{l}\text { MS; } \\
\text { MEVRH; } \\
\text { Statistics }\end{array}$ & & 35.000 & & 25.000 & & 25.000 & 0 & 85.000 \\
\hline $\begin{array}{l}\text { 23.3.2 Building the conditions } \\
\text { for specialized training } \\
\text { abroad by offering } \\
\text { scholarship and study leave }\end{array}$ & $\begin{array}{l}\text { Ratio of Medical } \\
\text { Doctor/inhabitat }\end{array}$ & $\begin{array}{l}\text { Ratio Medical } \\
\text { Doctor/inhabitant: } \\
1 / 1920\end{array}$ & $\begin{array}{l}\text { Ratio Medical } \\
\text { Doctor/inhabitant } \\
: 1 / 1685\end{array}$ & $\begin{array}{l}\text { Ratio } \\
\text { médico/inhabit } \\
\text { ante: } 1 / 1555\end{array}$ & $\begin{array}{l}\text { MS; } \\
\text { MEVRH; } \\
\text { Statistics }\end{array}$ & & 48.000 & & 48.000 & & 48.000 & 0 & 144.000 \\
\hline $\begin{array}{l}\text { 23.4.1 Implementation of } \\
\text { integrated system of } \\
\text { diseases vigilance * }\end{array}$ & $\begin{array}{l}\text { \% of cases of } \\
\text { epidemic disease } \\
\text { whose declaration is } \\
\text { compulsory, timely } \\
\text { and completely } \\
\text { cited }\end{array}$ & $85 \%$ of cases cited & $\begin{array}{l}90 \% \% \text { of cases } \\
\text { cited }\end{array}$ & $\begin{array}{l}95 \% \% \text { of } \\
\text { cases cited }\end{array}$ & $\begin{array}{l}\text { Epidemiolo } \\
\text { gical } \\
\text { Vigilance } \\
\text { Bulletin ; } \\
\text { Reports }\end{array}$ & 10.929 & & 12.022 & & 12.022 & & 34.973 & 0 \\
\hline $\begin{array}{l}\text { 23.4.2 Execution and } \\
\text { monitoring of the } \\
\text { Tuberculoses Strategic Plan }\end{array}$ & Plan executed & . & _ & _- & - & & 27.864 & & 29.641 & & 0 & 0 & 57.505 \\
\hline $\begin{array}{l}23.4 .3 \text { Implementing } \\
\text { Blindness Prevention } \\
\text { Program }\end{array}$ & $\begin{array}{l}\% \text { o of people } \\
\text { treated with } \\
\text { ophthalmologic }\end{array}$ & Plan implemented & - & \begin{tabular}{|l|}
$20 \%$ of \\
diabetic \\
treated with \\
ophthalmologic \\
$; 50 \%$ of \\
people get \\
presbyopia \\
appointment at \\
45 year of age \\
and $50 \%$ \\
every 5 years \\
\end{tabular} & Reports & & 44.519 & & 44.519 & & 44.519 & 0 & 133.557 \\
\hline $\begin{array}{l}23.4 .4 \text { Improving the } \\
\text { knowledge of the situation, } \\
\text { elaboration and } \\
\text { implementation of an Action } \\
\text { Plan for the prevention of } \\
\text { nom transmissible diseases } \\
\text { in the country }\end{array}$ & $\begin{array}{l}\text { Studies carried out, } \\
\text { Action Plan } \\
\text { implemented }\end{array}$ & $\begin{array}{l}\text { Studies carried } \\
\text { out }\end{array}$ & $\begin{array}{l}\text { Results published } \\
\text { Action Plan } \\
\text { prepared }\end{array}$ & $\begin{array}{l}\text { Plano de } \\
\text { Acção } \\
\text { implementado }\end{array}$ & Reports & & 15.810 & & 15.000 & & 15.000 & 0 & 45.810 \\
\hline $\begin{array}{l}23.4 .5 \text { Implementing a } \\
\text { strategy to combat malaria }\end{array}$ & \begin{tabular}{|l|} 
Strategy \\
implemented
\end{tabular} & - & - & - & - & & 16.012 & & 17.000 & & 15.000 & 0 & 48.012 \\
\hline Pillar 4 & & & & & & & & & & & & 0 & 0 \\
\hline $\begin{array}{l}\text { Improve and develop basic } \\
\text { infrastructure, promote land } \\
\text { use planning, and protect the } \\
\text { environment }\end{array}$ & $\begin{array}{l}\text { Percentage of } \\
\text { families with access } \\
\text { to potable water } \\
\text { distribution network }\end{array}$ & & & & & 9.573 .406 & 248.399 & 8.742 .260 & 221.797 & 1.689 .003 & 103.600 & 20.004 .670 & 573.796 \\
\hline $\begin{array}{l}\text { Land Use Planning (LUP) } \\
\text { and urban planning }\end{array}$ & $\begin{array}{l}\text { \% rate of execution } \\
\text { of Santiago, Santo } \\
\text { Antão and Fogo's } \\
\text { LUP }\end{array}$ & - & - & - & - & 125.639 & 198.399 & 199.110 & 171.797 & 95.995 & 45.600 & 420.743 & 415.796 \\
\hline
\end{tabular}

CInternational Monetary Fund. Not for Redistribution 


\begin{tabular}{|c|c|c|c|c|c|c|c|c|c|c|c|c|c|}
\hline \multirow{2}{*}{$\begin{array}{l}\text { PILLARS, OBJECTIVES } \\
\text { AND ACTIVITIES } \\
\end{array}$} & \multirow[t]{2}{*}{ INDICATORS } & \multirow{2}{*}{\multicolumn{3}{|c|}{ A CTIONS / GOALS }} & \multirow{2}{*}{$\begin{array}{l}\text { DATA } \\
\text { SOURCE } \\
\end{array}$} & \multicolumn{5}{|l|}{ BUDGET } & \multirow[b]{2}{*}{ COR } & \multicolumn{2}{|c|}{ TOTAL 2005-2007 } \\
\hline & & & & 2007 & & 2005 & COR & 2006 & COR & 2007 & & INV & COR \\
\hline $\begin{array}{l}30.1 \text { Elaboration of legislative } \\
\text { package for LUP and urban } \\
\text { planning, rules and norms } \\
\text { for land uses, expropriation, } \\
\text { cadastre and cartography } \\
\text { production }\end{array}$ & $\begin{array}{l}\mathrm{N} .{ }^{\circ} \text { of decree laws } \\
\text { published }\end{array}$ & $\begin{array}{l}\text { Three decree laws } \\
\text { published: Basic } \\
\text { Law on LUP, } \\
\text { cadastre Law and } \\
\text { Law of cartography } \\
\text { production }\end{array}$ & Laws regulated & $\begin{array}{l}\text { Law } \\
\text { implemented } \\
\text { and applied }\end{array}$ & $\begin{array}{l}\text { Oficial } \\
\text { Bulletin; } \\
\text { Cabinet }\end{array}$ & & 3.000 & 0 & & 0 & & 0 & 3.000 \\
\hline $\begin{array}{l}30.2 \text { Implementing a program } \\
\text { for reconnaissance, } \\
\text { rehabilitation, densification, } \\
\text { and precision leveling of the } \\
\text { national geodesic network }\end{array}$ & $\begin{array}{l}\mathrm{N} .{ }^{\circ} \text { of islands } \\
\text { covered }\end{array}$ & $25 \%$ of the Islands & $\begin{array}{l}75 \% \text { of the } \\
\text { Islands }\end{array}$ & $\begin{array}{l}100 \% \text { of the } \\
\text { Islands }\end{array}$ & $\begin{array}{l}\text { DGOTH } \\
\text { Reports; list } \\
\text { of marks; } \\
\text { Maps }\end{array}$ & 14.812 & & 21.840 & & 0 & & 36.652 & 0 \\
\hline $\begin{array}{l}30.3 \text { Inventory of Arial - } \\
\text { photogrammetry of all } \\
\text { country for cartography } \\
\text { production }\end{array}$ & $\begin{array}{l}\text { Areas of } \\
\text { cartography } \\
\text { produced at } \\
1: 10000 \text { and } 1: 2000 \\
\text { for urban centers } \\
\end{array}$ & $\begin{array}{l}5 \% \text { of the country at } \\
1: 10000 ; 5000 \text { ha } \\
\text { from } 1: 2000 \text { of } \\
\text { urban centers }\end{array}$ & $\begin{array}{l}100 \% \text { country at } \\
1: 10000 ; 20000 \\
\text { ha from } 1: 2000 \\
\text { of urban centers }\end{array}$ & $\begin{array}{l}\text { Utilization of } \\
\text { cartography at } \\
1: 10000 ; \\
40000 \text { ha from } \\
1: 2000 \text { of } \\
\text { urban centers } \\
\end{array}$ & $\begin{array}{l}\text { DGOTH } \\
\text { and } \\
\text { municipaliti } \\
\text { es reports; } \\
\text { Maps }\end{array}$ & 35.110 & & 70.220 & & 70.220 & & 175.549 & 0 \\
\hline $\begin{array}{l}30.4 \text { Elaborating Land Use } \\
\text { Plans Plans }\end{array}$ & \begin{tabular}{|l} 
Execution \\
percentage \\
rate(phases) of 3 \\
LUPs (Santiago, $\mathrm{St}^{\circ}$ \\
Antão e Fogo \\
\end{tabular} & $\begin{array}{l}\text { Elaborating } 50 \% \text { of } \\
3 \text { EROT's }\end{array}$ & $\begin{array}{l}100 \% \text { of } 3 \\
\text { EROT's } \\
\text { executed }\end{array}$ & $\begin{array}{l}\text { Implementing } \\
\text { of } 3 \text { EROT's }\end{array}$ & $\begin{array}{l}\text { Preliminary } \\
\text { Reports; } \\
\text { Oficial } \\
\text { Bulletin; } \\
\text { Cabinet } \\
\end{array}$ & & 48.000 & & 8.000 & & 0 & 0 & 56.000 \\
\hline $\begin{array}{l}30.5 \text { Elaboration and } \\
\text { articulation with } \\
\text { municipalities for } \\
\text { implementation of municipal } \\
\text { LUPs and urban plans }\end{array}$ & $\begin{array}{l}\mathrm{N} .^{\circ} \text { of urban plans of } \\
\text { second generation } \\
\text { prepared }\end{array}$ & \begin{tabular}{|l|} 
Elaboration of plans \\
for St ${ }^{\mathrm{a}}$ Catarina, Sal, \\
$\mathrm{R} .{ }^{\mathrm{a}}$ Grande, \\
S.Miguel and \\
Tarrafal
\end{tabular} & $\begin{array}{l}\text { Elaboration of } \\
\text { plans for } \\
\text { S.Filipe, St }{ }^{a} \text { Cruz, } \\
\text { Boa Vista, Maio, } \\
\text { S.Nicolau and } \\
\text { Porto Novo } \\
\end{array}$ & $\begin{array}{l}\text { Elaboration of } \\
\text { plans for } \\
\text { S.Vicente, } \\
\text { S.Domingos, } \\
\text { paul, Mosteiros } \\
\text { and Brava }\end{array}$ & $\begin{array}{l}\text { DGOTH } \\
\text { and } \\
\text { Municipaliti } \\
\text { es reports; } \\
\text { Official } \\
\text { Bulletin } \\
\end{array}$ & & 108.799 & & 131.197 & & 32.000 & 0 & 271.996 \\
\hline $\begin{array}{l}30.6 \text { Organization of training } \\
\text { courses for topographers } \\
\text { and technicians for the } \\
\text { SIG/Territorial }\end{array}$ & $\begin{array}{l}\mathrm{N}^{\circ} \text { of technicians } \\
\text { trained and with } \\
\text { graduate degree }\end{array}$ & $\begin{array}{l}2 \text { technicians } \\
\text { attending graduate } \\
\text { degree; beginning } \\
\text { training of } 20 \text { SIT } \\
\text { technician }\end{array}$ & $\begin{array}{l}4 \text { technicians } \\
\text { attending } \\
\text { graduate degree; } \\
20 \text { technician } \\
\text { trained in SIT; } \\
\text { beginning course } \\
\text { of assistants } \\
\text { topographers } \\
\end{array}$ & $\begin{array}{l}2 \text { technicians } \\
\text { with graduate } \\
\text { degree and } \\
2 \text { attending }\end{array}$ & $\begin{array}{l}\text { Reports; } \\
\text { technicians } \\
\text { graduated }\end{array}$ & & 38.600 & & 32.600 & & 13.600 & 0 & 84.800 \\
\hline $\begin{array}{l}30.7 \text { Building a } \\
\text { geographic/territorial } \\
\text { information system }\end{array}$ & $\begin{array}{l}\text { Rate of progress of } \\
\text { the system }\end{array}$ & $\begin{array}{l}\text { The system building } \\
\text { block conceived }\end{array}$ & $\begin{array}{l}\text { Degree of } \\
\text { implementation } \\
\text { Satisfactory }\end{array}$ & $\begin{array}{l}\text { Degree of } \\
\text { implementation } \\
\text { Satisfactory }\end{array}$ & $\begin{array}{l}\text { Reports; } \\
\text { Data Base; } \\
\text { Results } \\
\text { achieved } \\
\end{array}$ & 16.117 & & 3.600 & & 3.600 & & 23.317 & 0 \\
\hline $\begin{array}{l}30.8 \text { Executing a pilot } \\
\text { cadastre and building a } \\
\text { National Cadastre System }\end{array}$ & $\begin{array}{l}\text { Rate of progress of } \\
\text { the system }\end{array}$ & $\begin{array}{l}\text { Methodology } \\
\text { conceived }\end{array}$ & $\begin{array}{l}\text { Methodology } \\
\text { published }\end{array}$ & $\begin{array}{l}\text { Degree of } \\
\text { implementation } \\
\text { Satisfactory }\end{array}$ & $\begin{array}{l}\text { Reports; } \\
\text { Methodolog } \\
\text { y; } \\
\text { information } \\
\text { Cadastre } \\
\end{array}$ & 59.600 & & 103.450 & & 22.175 & & 185.225 & 0 \\
\hline $\begin{array}{l}\text { Protection and Conservation } \\
\text { of the Environment }\end{array}$ & $\begin{array}{l}\% \text { of protected area } \\
\text { with adequate } \\
\text { management plan }\end{array}$ & - & - & - & & 643.188 & 50.000 & 659.267 & 50.000 & 685.686 & 58.000 & 1.988 .141 & 158.000 \\
\hline
\end{tabular}

CInternational Monetary Fund. Not for Redistribution 


\begin{tabular}{|c|c|c|c|c|c|c|c|c|c|c|c|c|c|}
\hline \multirow{2}{*}{$\begin{array}{l}\text { PILLARS, OBJECTIVES } \\
\text { AND ACTIVITIES }\end{array}$} & \multirow[t]{2}{*}{ INDICATORS } & \multicolumn{3}{|l|}{ A CTIONS / GOALS } & \multirow{2}{*}{$\begin{array}{l}\text { DATA } \\
\text { SOURCE }\end{array}$} & \multicolumn{5}{|l|}{ BUDGET } & \multirow[b]{2}{*}{ COR } & \multicolumn{2}{|c|}{ TOTAL 2005-2007 } \\
\hline & & 2005 & 2006 & 2007 & & 2005 & COR & 2006 & COR & 2007 & & INV & COR \\
\hline $\begin{array}{l}\text { 31.1.1 Consolidation of the } \\
\text { sector reform process } \\
\text { and involvement of the } \\
\text { benefiting population in } \\
\text { search of optimal solutions } \\
\text { for solving problems of } \\
\text { resources management in } \\
\text { the hydrographic valleys } \\
\text { level * }\end{array}$ & $\begin{array}{l}\mathrm{N} .{ }^{\circ} \text { hydrographic } \\
\text { valleys with } \\
\text { ordering plan }\end{array}$ & $\begin{array}{l}5 \% \text { hydrographic } \\
\text { valleys with ordering } \\
\text { plan }\end{array}$ & $\begin{array}{l}10 \% \\
\text { hydrographic } \\
\text { valleys with } \\
\text { ordering plan }\end{array}$ & $\begin{array}{l}15 \% \\
\text { hydrographic } \\
\text { valleys with } \\
\text { ordering plan }\end{array}$ & $\begin{array}{l}\text { Reports; } \\
\text { Ordering } \\
\text { plan } \\
\text { Documents }\end{array}$ & 615.000 & & 630.375 & & 655.636 & & 1.901 .011 & 0 \\
\hline $\begin{array}{l}\text { 31.1.2 Rural Access to } \\
\text { Improved Drinking Water } \\
\text { Source }\end{array}$ & $\begin{array}{l}\text { Coverage rate of } \\
\text { Drinking water in } \\
\text { rural areas }\end{array}$ & - & - & - & $\begin{array}{l}\text { Reports } \\
\text { from } \\
\text { municipaliti } \\
\text { es and } \\
\text { agencies } \\
\text { NGO's } \\
\text { Data Base; } \\
\text { INE } \\
\text { Publication } \\
\text { s }\end{array}$ & 15.375 & & 15.759 & & 16.391 & & 47.525 & 0 \\
\hline $\begin{array}{l}\text { 31.4.1 Training for } \\
\text { Environment Inspectors * }\end{array}$ & $\begin{array}{l}\text { No of Trained } \\
\text { Inspectors }\end{array}$ & $\begin{array}{l}\text { Facilities to initiate } \\
\text { training created }\end{array}$ & Training started & $\begin{array}{l}20 \text { Inspectors } \\
\text { trained }\end{array}$ & $\begin{array}{l}\text { DGA } \\
\text { Report }\end{array}$ & 0 & & 0 & & & 8.000 & 0 & 8.000 \\
\hline $\begin{array}{l}\text { 31.5.1 Functioning of } \\
\text { environment information } \\
\text { system * }\end{array}$ & $\begin{array}{l}\text { Environment } \\
\text { information system } \\
\text { created and } \\
\text { operational }\end{array}$ & $\begin{array}{l}\text { Implementation } \\
\text { started }\end{array}$ & $\begin{array}{l}\text { Operacional } \\
\text { System }\end{array}$ & - & $\begin{array}{l}\text { DGA } \\
\text { Report }\end{array}$ & 12.813 & & 13.133 & & 13.659 & & 39.604 & 0 \\
\hline $\begin{array}{l}31.6 .1 \text { Creating and } \\
\text { management of protected } \\
\text { areas * }\end{array}$ & $\begin{array}{l}\% \text { of protected } \\
\text { areas with } \\
\text { management plan } \\
\text { implemented }\end{array}$ & $\begin{array}{l}2 \% \text { of protected } \\
\text { areas }\end{array}$ & $\begin{array}{l}7 \% \text { of protected } \\
\text { areas }\end{array}$ & $\begin{array}{l}15 \% \text { of } \\
\text { protected } \\
\text { areas }\end{array}$ & $\begin{array}{l}\text { Reports s; } \\
\text { Manageme } \\
\text { nt plan } \\
\text { Documents }\end{array}$ & & 10.000 & & 10.000 & & 10.000 & 0 & 30.000 \\
\hline $\begin{array}{l}31.6 .2 \text { Conservation of } \\
\text { marine coastal areas * }\end{array}$ & $\begin{array}{l}\% \text { marine protected } \\
\text { areas circumscribed }\end{array}$ & $\begin{array}{l}10 \% \text { protected } \\
\text { areas }\end{array}$ & $\begin{array}{l}25 \% \text { protected } \\
\text { areas }\end{array}$ & $\begin{array}{l}50 \% \text { of } \\
\text { protected area }\end{array}$ & $\begin{array}{l}\text { DGA } \\
\text { Report }\end{array}$ & & 40.000 & & 40.000 & & 40.000 & 0 & 120.000 \\
\hline $\begin{array}{l}\text { Promoting and Reinforcing } \\
\text { Basic Sanitation }\end{array}$ & $\begin{array}{l}\text { Percentage of } \\
\text { families with access } \\
\text { to Drinking water } \\
\text { distribution network, } \\
\text { sewerage system } \\
\text { and covered by a } \\
\text { system of garbage } \\
\text { collection }\end{array}$ & 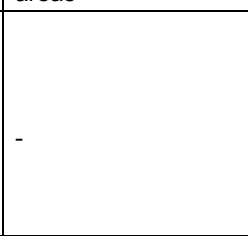 & son & 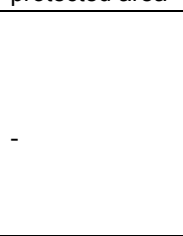 & - & 1.527 .045 & 0 & 2.169 .653 & 0 & 365.339 & 0 & 4.062 .037 & 0 \\
\hline $\begin{array}{l}\text { 32.1.1 Development of } \\
\text { infrastructure plan for water } \\
\text { supply and distribution * }\end{array}$ & $\begin{array}{l}\text { Coverage rate of } \\
\text { families with access } \\
\text { to Drinking water }\end{array}$ & $\begin{array}{l}50 \% \text { of household } \\
\text { with access to public } \\
\text { water system }\end{array}$ & $\begin{array}{l}65 \% \text { of } \\
\text { household with } \\
\text { access to public } \\
\text { water system }\end{array}$ & $\begin{array}{l}80 \% \text { of } \\
\text { household with } \\
\text { access to } \\
\text { public water } \\
\text { system }\end{array}$ & $\begin{array}{l}\text { Reports } \\
\text { from } \\
\text { municipaliti } \\
\text { es and } \\
\text { Agencies; } \\
\text { ONG Data } \\
\text { Base ; INE } \\
\text { publications }\end{array}$ & 577.075 & & 571.540 & & 105.339 & & 1.253 .954 & 0 \\
\hline $\begin{array}{l}\text { 32.2.1 Development of } \\
\text { infrastructure plan for } \\
\text { collection and treatment of } \\
\text { residual water * }\end{array}$ & $\begin{array}{l}\% \text { of residual water } \\
\text { treated and used }\end{array}$ & $\begin{array}{l}2 \% \text { of residual } \\
\text { water treated and } \\
\text { used }\end{array}$ & $\begin{array}{l}5 \% \text { of residual } \\
\text { water treated } \\
\text { and used }\end{array}$ & $\begin{array}{l}10 \% \text { of } \\
\text { residual water } \\
\text { treated and } \\
\text { used }\end{array}$ & $\begin{array}{l}\text { Reports } \\
\text { from } \\
\text { municipaliti } \\
\text { es and } \\
\text { Agencies; } \\
\text { ONG Data } \\
\text { Base ; INE } \\
\text { publications }\end{array}$ & 744.970 & & 1.098 .113 & & 0 & & 1.843 .083 & 0 \\
\hline
\end{tabular}

CInternational Monetary Fund. Not for Redistribution 


\begin{tabular}{|c|c|c|c|c|c|c|c|c|c|c|c|c|c|}
\hline \multirow{2}{*}{$\begin{array}{l}\text { PILLARS, OBJECTIVES } \\
\text { AND ACTIVITIES }\end{array}$} & \multirow{2}{*}{ INDICATORS } & \multicolumn{3}{|l|}{ A CTIONS / GOALS } & \multirow{2}{*}{$\begin{array}{l}\text { DATA } \\
\text { SOURCE }\end{array}$} & \multicolumn{5}{|l|}{ BUDGET } & \multirow[b]{2}{*}{ COR } & \multicolumn{2}{|c|}{ TOTAL 2005-2007 } \\
\hline & & 2005 & 2006 & 2007 & & 2005 & COR & 2006 & COR & 2007 & & & COR \\
\hline $\begin{array}{l}\text { 32.3.1 } 1 \text { Development of } \\
\text { infrastructure plans for } \\
\text { collection and treatment of } \\
\text { substantial waste * }\end{array}$ & $\begin{array}{l}\text { \% of the } \\
\text { population } \\
\text { covered by system } \\
\text { ware collection; } \\
\text { N. of sanitation } \\
\text { dumpster built ; } \\
\text { rate of waste } \\
\text { treatment }\end{array}$ & $\begin{array}{l}40 \% \text { of the } \\
\text { population covered } \\
\text { by system ware } \\
\text { collection; } \\
\text { Construction of } 3 \\
\text { sanitation dumpsters } \\
\text { started }\end{array}$ & $\begin{array}{l}50 \% \text { of the } \\
\text { population } \\
\text { covered by } \\
\text { system ware } \\
\text { collection; } \\
\text { Construction of } 3 \\
\text { sanitation } \\
\text { dumpsters }\end{array}$ & $\begin{array}{l}50 \% \text { of the } \\
\text { population } \\
\text { covered by } \\
\text { system ware } \\
\text { collection }\end{array}$ & $\begin{array}{l}\text { Reports } \\
\text { from } \\
\text { municipaliti } \\
\text { es and } \\
\text { Agencies; } \\
\text { ONG Data } \\
\text { Base ; INE } \\
\text { publications }\end{array}$ & 205.000 & & 500.000 & & 260.000 & & 965.000 & 0 \\
\hline Energy Sector Development & $\begin{array}{l}\text { Percentage of } \\
\text { household with } \\
\text { access to Electricity }\end{array}$ & - & r & - & 1 & 322.500 & 0 & 232.594 & 0 & 125.436 & 0 & 680.530 & 0 \\
\hline $\begin{array}{l}\text { 33.3.1 Decentralization of } \\
\text { Rural Electrification }\end{array}$ & $\begin{array}{l}\text { Electricity Coverage } \\
\text { Rate }\end{array}$ & $70 \%$ & $75 \%$ & $78 \%$ & $\begin{array}{l}\text { DGIE } \\
\text { Report }\end{array}$ & 50.000 & & 30.000 & & 20.800 & & 100.800 & 0 \\
\hline 33.3.2 Rural Electrification & $\begin{array}{l}\text { Electricity Coverage } \\
\text { Rate }\end{array}$ & $70 \%$ & $75 \%$ & $78 \%$ & $\begin{array}{l}\text { DGIE } \\
\text { Report } \\
\end{array}$ & 170.000 & & 45.000 & & 0 & & 215.000 & 0 \\
\hline $\begin{array}{l}\text { 33.4.1 Elaboration of } \\
\text { National Strategy for } \\
\text { Domestic Energy }\end{array}$ & $\begin{array}{l}\text { Index of LPG } \\
\text { utilization of } \\
\text { (national) }\end{array}$ & $\begin{array}{l}\text { Average Monthly } \\
\text { Consumption: } 2,2 \mathrm{Kg}\end{array}$ & $\begin{array}{l}\text { Average Monthly } \\
\text { Consumption } 2,3 \\
\text { Kg }\end{array}$ & $\begin{array}{l}\text { Average } \\
\text { Monthly } \\
\text { Consumption: } \\
2,5 \mathrm{Kg} \\
\end{array}$ & $\begin{array}{l}\text { Petroleum } \\
\text { company } \\
\text { sale data ; } \\
\text { INE } \\
\end{array}$ & 0 & & 0 & & 0 & & 0 & 0 \\
\hline $\begin{array}{l}33.4 .2 \text { Progressive } \\
\text { substitution of cooking woods } \\
\text { for LPG }\end{array}$ & $\begin{array}{l}\text { Index of LPG } \\
\text { utilization of } \\
\text { (national) }\end{array}$ & $\begin{array}{l}\text { Average Monthly } \\
\text { Consumption } 2,2 \mathrm{Kg}\end{array}$ & $\begin{array}{l}\text { Average Monthly } \\
\text { Consumption: } 2,3 \\
\text { Kg }\end{array}$ & $\begin{array}{l}\text { Average } \\
\text { Monthly } \\
\text { Consumption: } \\
2,5 \mathrm{Kg} \\
\end{array}$ & $\begin{array}{l}\text { Petroleum } \\
\text { company } \\
\text { sale data ; } \\
\text { INE } \\
\end{array}$ & 51.250 & & 105.063 & & 54.636 & & 210.949 & 0 \\
\hline $\begin{array}{l}\text { 33.6.1 Executing domiciliary } \\
\text { connection for social } \\
\text { purposes }\end{array}$ & $\begin{array}{l}\text { Electricity Coverage } \\
\text { Rate }\end{array}$ & $70 \%$ & $75 \%$ & $78 \%$ & $\begin{array}{l}\text { DGIE } \\
\text { Report }\end{array}$ & 51.250 & & 52.531 & & 50.000 & & 153.781 & 0 \\
\hline $\begin{array}{l}\text { Transport Infrastructure } \\
\text { Development }\end{array}$ & $\begin{array}{l}\text { Km of roads built, } \\
\text { rehabilitated or } \\
\text { improved }\end{array}$ & - & - & - & - & 6.955 .035 & 0 & 5.481 .636 & 0 & 416.548 & 0 & 12.853 .218 & 0 \\
\hline $\begin{array}{l}34.1 .1 \text { Gradual improvement } \\
\text { railways maintenance }\end{array}$ & 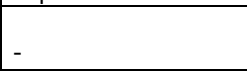 & - & - & - & - & 2.706 .000 & & 2.731 .625 & & 1.311 & & 5.438 .936 & 0 \\
\hline $\begin{array}{l}\text { 34.1.2: Building roads in } \\
\text { isolated localities }\end{array}$ & - & - & - & - & - & 4.068 .225 & & 2.750 .011 & & 415.236 & & 7.233 .472 & 0 \\
\hline $\begin{array}{l}34.2 .1 \text { Improvement of sea } \\
\text { ports in Sal, Boavista, Maio } \\
\text { and Brava islands }\end{array}$ & - & - & - & - & - & 180.810 & & 0 & & 0 & & 180.810 & 0 \\
\hline Pillar 5 & & & & & & & & & & & & 0 & 0 \\
\hline $\begin{array}{l}\text { Improve the effectiveness } \\
\text { and sustainability of the } \\
\text { social protection system }\end{array}$ & $\begin{array}{l}\% \text { of the population } \\
\text { covered by a system } \\
\text { of social protection }\end{array}$ & & & & & 943.624 & 865.311 & 962.733 & 864.919 & 855.074 & 829.526 & 2.761 .432 & 2.559 .756 \\
\hline $\begin{array}{l}\text { Protection, Integration and } \\
\text { Social Insertion }\end{array}$ & $\begin{array}{l}\mathrm{N} .{ }^{\circ} \text { of beneficiaries } \\
\text { of Minimum Social } \\
\text { Pension; N. } .^{\circ} \text { of } \\
\text { beneficiaries of } \\
\text { Social solidarity }\end{array}$ & - & - & - & - & 80.000 & 624.836 & 90.000 & 629.941 & 100.000 & 620.378 & 270.000 & 1.875 .155 \\
\hline $\begin{array}{l}\text { 25.1.1 Redefinition and } \\
\text { implementation of regulating } \\
\text { mechanism for the } \\
\text { decentralization process of } \\
\text { social protection services }\end{array}$ & $\begin{array}{l}\text { N. of protocols } \\
\text { approved and } \\
\text { sighed by } \\
\text { Government and } \\
\text { Municipalities }\end{array}$ & $\begin{array}{l}17 \text { protocols sighed } \\
\text { by Government and } \\
\text { Municipalities }\end{array}$ & $\begin{array}{l}\text { Mechanism of } \\
\text { articulation and } \\
\text { coordination } \\
\text { between Central } \\
\text { Local } \\
\text { Government and } \\
\text { in place and } \\
\text { functioning } \\
\end{array}$ & - & $\begin{array}{l}\text { Plan and } \\
\text { Annual } \\
\text { Reports of } \\
\text { DGSS }\end{array}$ & 0 & & 0 & & 0 & & 0 & 0 \\
\hline
\end{tabular}

CInternational Monetary Fund. Not for Redistribution 


\begin{tabular}{|c|c|c|c|c|c|c|c|c|c|c|c|c|c|}
\hline \multirow{2}{*}{$\begin{array}{l}\text { PILLARS, OBJECTIVES } \\
\text { AND ACTIVITIES } \\
\end{array}$} & \multirow[t]{2}{*}{ INDICATORS } & \multicolumn{3}{|l|}{ A CTIONS / GOALS } & \multirow{2}{*}{$\begin{array}{l}\text { DATA } \\
\text { SOURCE }\end{array}$} & \multicolumn{5}{|l|}{ BUDGET } & \multirow[b]{2}{*}{ COR } & \multicolumn{2}{|c|}{ TOTAL 2005-2007 } \\
\hline & & 2005 & 2006 & 2007 & & 2005 & COR & 2006 & COR & 2007 & & INV & COR \\
\hline $\begin{array}{l}25.1 .2 \text { Improving the } \\
\text { management and planning } \\
\text { instruments }\end{array}$ & $\begin{array}{l}\mathrm{N} .{ }^{\circ} \text { of beneficiaries } \\
\text { of social }\end{array}$ & $\begin{array}{l}\text { To be determined } \\
\text { from Social Map }\end{array}$ & $\begin{array}{l}\text { To be } \\
\text { determined from } \\
\text { Social Map }\end{array}$ & $\begin{array}{l}\text { To be } \\
\text { determined } \\
\text { from Social } \\
\text { Map } \\
\end{array}$ & $\begin{array}{l}\text { DGSS } \\
\text { Annual } \\
\text { Report }\end{array}$ & & 0 & & 0 & & 0 & 0 & 0 \\
\hline $\begin{array}{l}25.1 .3 \text { Creating a legal } \\
\text { framework of norms for } \\
\text { regulating the intervention in } \\
\text { social equipment sector }\end{array}$ & $\begin{array}{l}\text { Legal framework of } \\
\text { norms defined and } \\
\text { implemented }\end{array}$ & $\begin{array}{l}\text { Legal framework of } \\
\text { norms defined and } \\
\text { implemented }\end{array}$ & - & - & $\begin{array}{l}\text { DGSS } \\
\text { Annual } \\
\text { Report }\end{array}$ & & 0 & & 0 & & 0 & 0 & 0 \\
\hline $\begin{array}{l}\text { 25.1.4 Reinforce and train } \\
\text { human resource for } \\
\text { intervention in the sphere of } \\
\text { social protection }\end{array}$ & $\begin{array}{l}\mathrm{N}{ }^{\circ} \text { social } \\
\text { technician trained } \\
\text { and recruited }\end{array}$ & - & - & $\begin{array}{l}2 \text { technician } \\
\text { trained and } \\
\text { recruited for } \\
\text { each } \\
\text { municipalities } \\
\end{array}$ & $\begin{array}{l}\text { DGSS } \\
\text { Annual } \\
\text { Report }\end{array}$ & & 14.900 & & 14.900 & & & 0 & 29.800 \\
\hline $\begin{array}{l}25.1 .5 \text { Development of } \\
\text { institutional capacity to } \\
\text { conduct research and studies } \\
\text { in specific social subjects }\end{array}$ & $\begin{array}{l}\mathrm{N} .{ }^{\circ} \text { of research and } \\
\text { studies conducted }\end{array}$ & $\begin{array}{l}1 \text { research or study } \\
\text { conducted }\end{array}$ & $\begin{array}{l}1 \text { research or } \\
\text { study conducted }\end{array}$ & $\begin{array}{l}1 \text { research or } \\
\text { study } \\
\text { conducted }\end{array}$ & $\begin{array}{l}\text { DGSS } \\
\text { Annual } \\
\text { Report }\end{array}$ & & 0 & & 0 & & 0 & 0 & 0 \\
\hline $\begin{array}{l}25.2 .1 \text { Improving the } \\
\text { Management of the } \\
\text { Pension System (non } \\
\text { contributive regime ) }\end{array}$ & $\begin{array}{l}\text { \% of card holders } \\
\text { beneficiaries } \\
\text { identified; } N .^{\circ} \text { of } \\
\text { beneficiaries of } \\
\text { Minimum Social } \\
\text { Pension ; N. of } \\
\text { beneficiaries from } \\
\text { Social Solidarity } \\
\text { Pension }\end{array}$ & $\begin{array}{l}100 \% \text { card holders } \\
\text { beneficiaries } ; 7514 \\
\text { beneficiaries of } \\
\text { PSM; } 11427 \\
\text { beneficiaries of PSS }\end{array}$ & $\begin{array}{l}100 \% \text { card } \\
\text { holders } \\
\text { beneficiaries ; } \\
8014 \\
\text { beneficiaries of } \\
\text { PSM; } 12427 \\
\text { beneficiaries of } \\
\text { PSS }\end{array}$ & $\begin{array}{l}100 \% \text { card } \\
\text { holders } \\
\text { beneficiaries ; } \\
8614 \\
\text { beneficiaries of } \\
\text { PSM; } 13427 \\
\text { beneficiaries of } \\
\text { PSS }\end{array}$ & $\begin{array}{l}\text { DGSS } \\
\text { Annual } \\
\text { Report }\end{array}$ & & 0 & 0 & & 0 & & 0 & 0 \\
\hline $\begin{array}{l}25.2 .2 \text { Improving and expand } \\
\text { social assistance }\end{array}$ & $\begin{array}{l}\text { Amount of social } \\
\text { pension; \% of } \\
\text { population covered } \\
\text { by social assistance } \\
\text { system }\end{array}$ & $\begin{array}{l}\text { Increase from } 1300 \\
\text { to } 1500 \text { the amount } \\
\text { of present pension; } \\
10 \% \text { of population } \\
\text { covered by social } \\
\text { assistance system }\end{array}$ & $\begin{array}{l}20 \% \text { of } \\
\text { population } \\
\text { covered by } \\
\text { social assistance } \\
\text { system }\end{array}$ & $\begin{array}{l}30 \% \text { of } \\
\text { population } \\
\text { covered by } \\
\text { social } \\
\text { assistance } \\
\text { system }\end{array}$ & $\begin{array}{l}\text { DGSS } \\
\text { Annual } \\
\text { Report }\end{array}$ & & 566.636 & & 566.636 & & 566.636 & 0 & 1.699 .908 \\
\hline $\begin{array}{l}25.2 .3 \text { Promoting the access } \\
\text { of poor and the very needed } \\
\text { to education and } \\
\text { professional training services }\end{array}$ & $\begin{array}{l}\mathrm{N}^{\mathrm{a}} \text { of poor students } \\
\text { benefiting from free } \\
\text { tuitions }\end{array}$ & $\begin{array}{l}150 \text { student } \\
\text { benefiting free tuition }\end{array}$ & $\begin{array}{l}200 \text { students } \\
\text { benefiting from } \\
\text { free tuition }\end{array}$ & $\begin{array}{l}250 \text { student } \\
\text { benefiting free } \\
\text { tuition }\end{array}$ & $\begin{array}{l}\text { DGSS } \\
\text { Annual } \\
\text { Report }\end{array}$ & & 15.000 & & 20.000 & & 25.000 & 0 & 60.000 \\
\hline $\begin{array}{l}\text { 25.2.4 Promoting the acess } \\
\text { of poor and very poor to } \\
\text { health }\end{array}$ & $\begin{array}{l}\text { Beneficiaries rate ( } \\
\text { users of PSM, PSS } \\
\text { and social } \\
\text { equipment) with } \\
\text { access to medical } \\
\text { treatment and } \\
\text { medication }\end{array}$ & $\begin{array}{l}\text { Study to determine } \\
\text { the viability of } \\
\text { granting access to } \\
\text { Medicare and } \\
\text { medication } \\
\text { assistance }\end{array}$ & $\begin{array}{l}50 \% \text { of } \\
\text { beneficiaries with } \\
\text { access to } \\
\text { Medicare and } \\
\text { medication } \\
\text { assistance }\end{array}$ & - & $\begin{array}{l}\text { DGSS } \\
\text { Annual } \\
\text { Report }\end{array}$ & & 5.000 & & 5.000 & & 5.000 & 0 & 15.000 \\
\hline
\end{tabular}




\begin{tabular}{|c|c|c|c|c|c|c|c|c|c|c|c|c|c|}
\hline \multirow{2}{*}{$\begin{array}{l}\text { PILLARS, OBJECTIVES } \\
\text { AND ACTIVITIES }\end{array}$} & \multirow[t]{2}{*}{ INDICATORS } & \multicolumn{3}{|l|}{ A CTIONS / GOALS } & \multirow{2}{*}{$\begin{array}{l}\text { DATA } \\
\text { SOURCE }\end{array}$} & \multicolumn{5}{|l|}{ BUDGET } & \multirow[b]{2}{*}{ COR } & \multicolumn{2}{|c|}{ TOTAL 2005-2007 } \\
\hline & & 2005 & 2006 & 2007 & & 2005 & COR & 2006 & COR & 2007 & & INV & COR \\
\hline $\begin{array}{l}25.2 .5 \text { Promoting the access } \\
\text { of poor and very poor to } \\
\text { water, sanitation and } \\
\text { housing }\end{array}$ & $\begin{array}{l}\% \text { of needed } \\
\text { families with access } \\
\text { to water, sewerage } \\
\text { and social houses; } \\
N .{ }^{\circ} \text { poor } \\
\text { communities } \\
\text { covered by a } \\
\text { sanitation program }\end{array}$ & 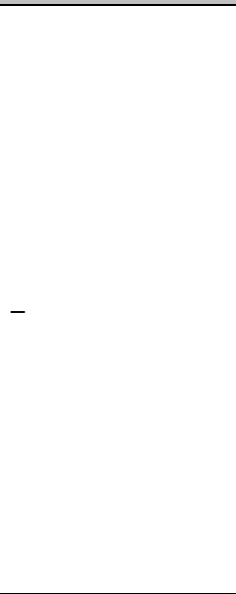 & - & $\begin{array}{l}100 \% \\
\text { degraded town } \\
\text { covered by the } \\
\text { program; } 700 \\
\text { houses built } \\
\text { substituting } \\
\text { tents; reducing } \\
\text { by } 50 \% \text { the } \\
\text { percentage of } \\
\text { families } \\
\text { without access } \\
\text { to sewerage or } \\
\text { ditch; } \\
\text { increasing by } \\
25 \% \text { those with } \\
\text { access to } \\
\text { water system; } \\
\text { increase by } \\
30 \% \text { those with } \\
\text { bathroom with } \\
\text { lavatory }\end{array}$ & Survey & 50.000 & & 50.000 & & 50.000 & & 150.000 & 0 \\
\hline 25.2.6 Feeding Access & $\begin{array}{l}\mathrm{N} .{ }^{\circ} \text { of elderly } \\
\text { covered; \% of } \\
\text { undernourished; } \\
\text { Incidence of food } \\
\text { lacking diseases; } \\
\% \text { of population } \\
\text { undernourished } \\
\text { school drop out rate }\end{array}$ & - & - & $\begin{array}{l}\text { All the elderly } \\
\text { users of social } \\
\text { equipment } \\
\text { covered (day } \\
\text { center and } \\
\text { Home) }\end{array}$ & $\begin{array}{l}\text { DGSS } \\
\text { Annual } \\
\text { Report }\end{array}$ & & 11.000 & & 15.000 & & 15.000 & 0 & 41.000 \\
\hline $\begin{array}{l}\text { 25.2.7 Reinforcing NGO's } \\
\text { and OSC's capacity to } \\
\text { intervene in social assistance } \\
\text { domain }\end{array}$ & $\begin{array}{l}\text { \% of NGO's and } \\
\text { OSC's with capacity } \\
\text { to intervene in social } \\
\text { assistance domain }\end{array}$ & $\begin{array}{l}50 \% \text { of ONG's and } \\
\text { OSC'S }\end{array}$ & $\begin{array}{l}50 \% \text { of ONG's } \\
\text { and OSC'S }\end{array}$ & $\begin{array}{l}50 \% \text { ONG's } \\
\text { and OSC'S }\end{array}$ & $\begin{array}{l}\text { DGSS } \\
\text { Annual } \\
\text { Report }\end{array}$ & 30.000 & & 40.000 & & 50.000 & & 120.000 & 0 \\
\hline $\begin{array}{l}25.3 .1 \text { Creating a network of } \\
\text { communities agents to } \\
\text { intervene in reducing poverty } \\
\text { and social depravation }\end{array}$ & $\begin{array}{l}\text { N. of local } \\
\text { communities } \\
\text { development } \\
\text { projects executed } \\
\text { (protocols signed); } \\
\text { Reference basis ; } \\
\mathrm{N} .{ }^{\circ} \text { of communities } \\
\text { agents identified ; } \\
\mathrm{N}{ }^{\circ} \text { of program } \\
\text { beneficiaries } \\
\text { implemented }\end{array}$ & $\begin{array}{l}\text { To be determined } \\
\text { through Social Map }\end{array}$ & $\begin{array}{l}\text { To be } \\
\text { determined } \\
\text { through Social } \\
\text { Map }\end{array}$ & $\begin{array}{l}\text { To be } \\
\text { determined } \\
\text { through Social } \\
\text { Map }\end{array}$ & $\begin{array}{l}\text { DGSS } \\
\text { Annual } \\
\text { Report }\end{array}$ & & 5.125 & & 5.253 & & 5.464 & 0 & 15.842 \\
\hline $\begin{array}{l}\text { 25.3.2 Reinforce the AGR, } \\
\text { employment, professional } \\
\text { training for targeted groups } \\
\text { in social depravation situation }\end{array}$ & $\begin{array}{l}\mathrm{N} .^{\circ} \text { of poor working } \\
\text { in income } \\
\text { generating activities }\end{array}$ & $\begin{array}{l}100 \text { persons by } \\
\text { municipalities }\end{array}$ & $\begin{array}{l}200 \text { persons by } \\
\text { municipalities }\end{array}$ & $\begin{array}{l}300 \text { persons } \\
\text { by } \\
\text { municipalities }\end{array}$ & $\begin{array}{l}\text { DGSS } \\
\text { Annual } \\
\text { Report }\end{array}$ & 0 & & 0 & & 0 & & 0 & 0 \\
\hline $\begin{array}{l}\text { 25.3.3 Reinforce the } \\
\text { information /training } \\
\text { campaign of the community } \\
\text { for poverty related issues }\end{array}$ & $\begin{array}{l}\mathrm{N} .{ }^{\circ} \text { of information } \\
\text { campaign carried } \\
\text { out }\end{array}$ & - & - & $\begin{array}{l}\text { All } \\
\text { communities } \\
\text { /municipalities } \\
\text { with higher } \\
\text { poverty } \\
\text { incidence } \\
\text { informed }\end{array}$ & $\begin{array}{l}\text { DGSS } \\
\text { Annual } \\
\text { Report }\end{array}$ & & 0 & & 0 & & 0 & 0 & 0 \\
\hline
\end{tabular}

CInternational Monetary Fund. Not for Redistribution 


\begin{tabular}{|c|c|c|c|c|c|c|c|c|c|c|c|c|c|}
\hline \multirow{2}{*}{$\begin{array}{l}\text { PILLARS, OBJECTIVES } \\
\text { AND ACTIVITIES } \\
\end{array}$} & \multirow[t]{2}{*}{ INDICATORS } & \multicolumn{3}{|l|}{ A CTIONS / GOALS } & \multirow{2}{*}{$\begin{array}{l}\text { DATA } \\
\text { SOURCE } \\
\end{array}$} & \multicolumn{5}{|l|}{ BUDGET } & \multirow[b]{2}{*}{ COR } & \multicolumn{2}{|c|}{ TOTAL 2005-2007 } \\
\hline & & 2005 & 2006 & 2007 & & 2005 & COR & 2006 & COR & 2007 & & INV & COR \\
\hline $\begin{array}{l}25.3 .4 \text { Implementing } \\
\text { instruments to monitor social } \\
\text { conditions in the } \\
\text { municipalities }\end{array}$ & $\begin{array}{l}\text { Instruments } \\
\text { implemented }\end{array}$ & $\begin{array}{l}\text { Instruments } \\
\text { implemented }\end{array}$ & - & - & $\begin{array}{l}\text { DGSS } \\
\text { Annual } \\
\text { Report }\end{array}$ & & 7.175 & & 3.152 & & 3.278 & 0 & 13.605 \\
\hline Protection Child Rights & $\begin{array}{l}\text { N. of children and } \\
\text { adults socially } \\
\text { intergraded }\end{array}$ & - & - & - & - & 53.300 & 115.528 & 54.633 & 91.147 & 56.822 & 76.491 & 164.754 & 283.166 \\
\hline $\begin{array}{l}\text { 26.1.1 Definition and } \\
\text { implementation of } \\
\text { institutional mechanisms and } \\
\text { technical assistance to } \\
\text { organizations that works in } \\
\text { minority }\end{array}$ & Diagnostic available & $\begin{array}{l}1 \text { Diagnostic } \\
\text { available }\end{array}$ & - & - & $\begin{array}{l}\text { ICM } \\
\text { Reports }\end{array}$ & & 5.125 & 0 & & 0 & & 0 & 5.125 \\
\hline $\begin{array}{l}26.1 .2 \text { Reinforcing } \\
\text { intervention in minority } \\
\text { domain in all municipalities of } \\
\text { the country }\end{array}$ & $\begin{array}{l}\mathrm{N}^{\circ} \text { of children } \\
\text { benefited and } \mathrm{n}^{\circ} \text { of } \\
\text { social equipment } \\
\text { expanded }\end{array}$ & $\begin{array}{l}\text { To be determined } \\
\text { through Social Map }\end{array}$ & $\begin{array}{l}\text { To be } \\
\text { determined } \\
\text { through Social } \\
\text { Map }\end{array}$ & $\begin{array}{l}\text { To be } \\
\text { determined } \\
\text { through Social } \\
\text { Map }\end{array}$ & $\begin{array}{l}\text { ICM } \\
\text { Reports }\end{array}$ & & 19.475 & & 19.962 & & 20.762 & 0 & 60.199 \\
\hline $\begin{array}{l}26.2 .1 \text { Implementation } \\
\text { program to assit and to } \\
\text { qualify families }\end{array}$ & $\begin{array}{l}\text { Programs } \\
\text { implemented }\end{array}$ & $\begin{array}{l}\text { Programs } \\
\text { implemented }\end{array}$ & का & 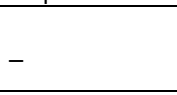 & $\begin{array}{l}\text { ICM } \\
\text { Reports }\end{array}$ & & 49.200 & & 50.430 & & 52.451 & 0 & 152.081 \\
\hline $\begin{array}{l}\text { 26.2.2 Reinforce and } \\
\text { expanding the network of } \\
\text { social equipment }\end{array}$ & $\begin{array}{l}N^{0} \text { of childhood } \\
\text { social equipment }\end{array}$ & $\begin{array}{l}\text { To be determined } \\
\text { through Social Map }\end{array}$ & $\begin{array}{l}\text { To be } \\
\text { determined } \\
\text { through Social } \\
\text { Map } \\
\end{array}$ & $\begin{array}{l}\text { To be } \\
\text { determined } \\
\text { through Social } \\
\text { Map }\end{array}$ & $\begin{array}{l}\text { ICM } \\
\text { Reports }\end{array}$ & 53.300 & & 54.633 & & 56.822 & & 164.754 & 0 \\
\hline $\begin{array}{l}\text { 26.3.1 Reinforce human } \\
\text { resource and development of } \\
\text { specialized training } \\
\text { programs in minority areas }\end{array}$ & $\begin{array}{l}\mathrm{N} .{ }^{\circ} \text { of persons } \\
\text { trained and recruited }\end{array}$ & - & $x_{1}$ & r & $\begin{array}{l}\text { ICM } \\
\text { Reports }\end{array}$ & & 38.653 & & 17.603 & & 0 & 0 & 56.256 \\
\hline $\begin{array}{l}\text { 26.3.2 Diversification of } \\
\text { programs in the domain of } \\
\text { minority intervention }\end{array}$ & $\begin{array}{l}\mathrm{N} .{ }^{\circ} \text { of children and } \\
\text { adults socially } \\
\text { intergraded }\end{array}$ & - & - & - & $\begin{array}{l}\text { ICM } \\
\text { Reports }\end{array}$ & & 3.075 & & 3.152 & & 3.278 & 0 & 9.505 \\
\hline Assuring Food security & Undernourished rate & - & - & - & - & 330.624 & 124.948 & 326.408 & 143.831 & 320.169 & 132.657 & 977.201 & 401.435 \\
\hline $\begin{array}{l}28.1 .1 \text { Improving the } \\
\text { bargaining capacity and } \\
\text { management of Food Aid }\end{array}$ & $\begin{array}{l}\text { National food } \\
\text { production volume }\end{array}$ & - & - & $\begin{array}{l}\text { Improving the } \\
\text { contribution of } \\
\text { nationals in } \\
\text { food } \\
\text { production } \\
\text { supply }\end{array}$ & $\begin{array}{l}\text { DSSA } \\
\text { Reports }\end{array}$ & & 513 & & 525 & 0 & & 0 & 1.038 \\
\hline $\begin{array}{l}\text { 28.1.2 Promoting a greater } \\
\text { participation of private } \\
\text { businesses in the } \\
\text { provisioning of basic foods } \\
\text { in particular cereals }\end{array}$ & $\begin{array}{l}\text { National food } \\
\text { production volume }\end{array}$ & - & - & $\begin{array}{l}\text { Improving the } \\
\text { contribution of } \\
\text { nationals in } \\
\text { food } \\
\text { production } \\
\text { supply }\end{array}$ & $\begin{array}{l}\text { DSSA } \\
\text { Reports }\end{array}$ & 227.550 & & 233.239 & & 242.585 & & 703.374 & 0 \\
\hline $\begin{array}{l}28.1 .3 \text { Improving the } \\
\text { commercial and distribution } \\
\text { network and storage of food } \\
\text { products }\end{array}$ & $\begin{array}{l}\text { Volume of Food Aid } \\
\text { biannual convention } \\
\text { signed ; reports } \\
\text { allocating FCP } \\
\text { timely submitted to } \\
\text { donors and foreign } \\
\text { currencies reserve } \\
\text { for imports of basic } \\
\text { food }\end{array}$ & - & - & $\begin{array}{l}1 \text { Improving } \\
\text { bargaining } \\
\text { capacity and } \\
\text { management } \\
\text { of Food Aid }\end{array}$ & $\begin{array}{l}\text { DSSA } \\
\text { Reports }\end{array}$ & 80.319 & & 82.138 & & 66.656 & & 229.113 & 0 \\
\hline
\end{tabular}

CInternational Monetary Fund. Not for Redistribution 


\begin{tabular}{|c|c|c|c|c|c|c|c|c|c|c|c|c|c|}
\hline \multirow{2}{*}{$\begin{array}{l}\text { PILLARS, OBJECTIVES } \\
\text { AND ACTIVITIES } \\
\end{array}$} & \multirow[t]{2}{*}{ INDICATORS } & \multicolumn{3}{|l|}{ A CTIONS / GOALS } & \multirow{2}{*}{$\begin{array}{l}\text { DATA } \\
\text { SOURCE } \\
\end{array}$} & \multicolumn{5}{|l|}{ BUDGET } & \multirow[b]{2}{*}{ COR } & \multicolumn{2}{|c|}{ TOTAL 2005-2007 } \\
\hline & & 2005 & 2006 & 2007 & & 2005 & COR & 2006 & COR & 2007 & & INV & COR \\
\hline $\begin{array}{l}\text { 28.1.4 Regulation, } \\
\text { regulamentation and } \\
\text { inspection of market of } \\
\text { essential food }\end{array}$ & $\begin{array}{l}\text { N. of private } \\
\text { operators in market } \\
\text { of essential food }\end{array}$ & - & - & $\begin{array}{l}\text { Greater } \\
\text { participation of } \\
\text { private } \\
\text { operators in } \\
\text { provisioning } \\
\text { essential food } \\
\text { in particular } \\
\text { cereals }\end{array}$ & $\begin{array}{l}\text { DSSA } \\
\text { Reports }\end{array}$ & & 52.173 & & 63.983 & & 55.620 & 0 & 171.775 \\
\hline $\begin{array}{l}\text { 28.3.1 Reinforcing and } \\
\text { decentralization of the Food } \\
\text { Security Information System } \\
\text { (SISA), and in particular the } \\
\text { consolidation of warning } \\
\text { devices for food crises } \\
\text { prevention }\end{array}$ & $\begin{array}{l}\mathrm{N} .{ }^{\circ} \text { of regular } \\
\text { publications; Food } \\
\text { crises situation } \\
\text { quickly assessed } \\
\text { and managed }\end{array}$ & $\begin{array}{l}6 \text { regulars } \\
\text { publications; } 1 \\
\text { month between } \\
\text { colleting and } \\
\text { publication of food } \\
\text { crises situation }\end{array}$ & $\begin{array}{l}12 \text { regulars } \\
\text { publications; } 1 \\
\text { month between } \\
\text { colleting and } \\
\text { publication of } \\
\text { food crises } \\
\text { situation }\end{array}$ & $\begin{array}{l}10 \text { regulars } \\
\text { publications; } 1 \\
\text { month } \\
\text { between } \\
\text { colleting and } \\
\text { publication of } \\
\text { food crises } \\
\text { situation }\end{array}$ & $\begin{array}{l}\text { Official } \\
\text { Bulletin }\end{array}$ & 22.755 & & 11.032 & & 10.927 & & 44.714 & 0 \\
\hline $\begin{array}{l}28.3 .2 \text { Regulamentation and } \\
\text { operation of National } \\
\text { Commission For Food } \\
\text { Security (CNASA), conceived } \\
\text { as multi- sectors forum for } \\
\text { coordination and articulation } \\
\text { of foods security programs } \\
\text { and policies }\end{array}$ & $\begin{array}{l}\mathrm{N}^{\mathrm{a}} \text { meetings carried } \\
\text { out }\end{array}$ & $\begin{array}{l}1 \text { National and } 2 \\
\text { local meetings }\end{array}$ & $\begin{array}{l}1 \text { National and } 2 \\
\text { local meetings }\end{array}$ & $\begin{array}{l}1 \text { National and } \\
2 \text { local } \\
\text { meetings }\end{array}$ & $\begin{array}{l}\text { To be } \\
\text { defined }\end{array}$ & & 5.125 & & 5.253 & & 5.464 & 0 & 15.842 \\
\hline $\begin{array}{l}28.3 .3 \text { Consolidating the } \\
\text { institutional framework of } \\
\text { food security and reinforce } \\
\text { the concerned actors on this } \\
\text { matters }\end{array}$ & $\begin{array}{l}\text { N. of regular } \\
\text { publications; Food } \\
\text { crises situation } \\
\text { quickly assessed } \\
\text { and managed }\end{array}$ & $\begin{array}{l}6 \text { regulars } \\
\text { publications; } 1 \\
\text { month between } \\
\text { colleting and } \\
\text { publication of food } \\
\text { crises situation }\end{array}$ & $\begin{array}{l}12 \text { regulars } \\
\text { publications; } 1 \\
\text { month between } \\
\text { colleting and } \\
\text { publication of } \\
\text { food crises } \\
\text { situation }\end{array}$ & $\begin{array}{l}10 \text { regulars } \\
\text { publications; } 1 \\
\text { month } \\
\text { between } \\
\text { colleting and } \\
\text { publication of } \\
\text { food crises } \\
\text { situation }\end{array}$ & $\begin{array}{l}\text { Official } \\
\text { Bulletin }\end{array}$ & & 15.375 & & 15.759 & & 10.927 & 0 & 42.062 \\
\hline $\begin{array}{l}\text { 28.3.4 Harmonization of food } \\
\text { security policies, strategies } \\
\text { and projects at local, } \\
\text { regional and international } \\
\text { levels }\end{array}$ & OB Publication & - & - & - & $\begin{array}{l}\text { Official } \\
\text { Bulletin }\end{array}$ & & 513 & & 525 & & 546 & 0 & 1.584 \\
\hline $\begin{array}{l}28.4 .1 \text { Fitting and reinforce } \\
\text { the legal and institutional } \\
\text { framework and the } \\
\text { supervision to assure the } \\
\text { quality and innocuity of food } \\
\text { and water }\end{array}$ & $\begin{array}{l}\text { N. }{ }^{\circ} \text { firms using the } \\
\text { HACCP control } \\
\text { system }\end{array}$ & - & - & $\begin{array}{l}\text { Integrated } \\
\text { system of food } \\
\text { quality control } \\
\text { implemented, } \\
\text { efficient and } \\
\text { operating }\end{array}$ & $\begin{array}{l}\text { Official } \\
\text { Bulletin }\end{array}$ & & 5.125 & & 5.253 & & 5.464 & 0 & 15.842 \\
\hline $\begin{array}{l}\text { 28.4.2 Lodging and operation } \\
\text { of ARFA, institution } \\
\text { responsible for food quality } \\
\text { control }\end{array}$ & $\begin{array}{l}\text { Institutional and } \\
\text { legal framework of } \\
\text { food security control } \\
\text { in place; ARFA } \\
\text { functioning }\end{array}$ & - & - & $\begin{array}{l}\text { Integrated } \\
\text { system of food } \\
\text { quality control } \\
\text { implemented, } \\
\text { efficient and } \\
\text { operating } \\
\end{array}$ & $\begin{array}{l}\text { Official } \\
\text { Bulletin }\end{array}$ & 0 & & 0 & & 0 & & 0 & 0 \\
\hline $\begin{array}{l}\text { 28.4.3 Reinforce technical } \\
\text { capacity of the institution } \\
\text { responsible food quality }\end{array}$ & $\begin{array}{l}\text { Institutional and } \\
\text { legal framework of } \\
\text { food security control } \\
\text { in place; ARFA } \\
\text { functioning }\end{array}$ & - & - & $\begin{array}{l}\text { Integrated } \\
\text { system of food } \\
\text { quality control } \\
\text { implemented, } \\
\text { efficient and } \\
\text { operating }\end{array}$ & $\begin{array}{l}\text { Official } \\
\text { Bulletin }\end{array}$ & & 20.500 & & 26.266 & & 27.318 & 0 & 74.084 \\
\hline
\end{tabular}

CInternational Monetary Fund. Not for Redistribution 


\begin{tabular}{|c|c|c|c|c|c|c|c|c|c|c|c|c|c|}
\hline \multirow{2}{*}{$\begin{array}{l}\text { PILLARS, OBJECTIVES } \\
\text { AND ACTIVITIES }\end{array}$} & \multirow{2}{*}{ INDICATORS } & \multicolumn{3}{|l|}{ A CTIONS / GOALS } & \multirow{2}{*}{$\begin{array}{l}\text { DATA } \\
\text { SOURCE }\end{array}$} & \multicolumn{5}{|l|}{ BUDGET } & \multirow[b]{2}{*}{ COR } & \multicolumn{2}{|c|}{ TOTAL 2005-2007 } \\
\hline & & 2005 & 2006 & 2007 & & 2005 & COR & 2006 & COR & 2007 & & INV & COR \\
\hline $\begin{array}{l}\text { 28.4.4 Incentives to the } \\
\text { development of Consumers } \\
\text { Protection Association }\end{array}$ & $\begin{array}{l}\text { N. }{ }^{\circ} \text { Consumers } \\
\text { Protection } \\
\text { Association }\end{array}$ & - & - & $\begin{array}{l}\text { Consumers } \\
\text { Protection } \\
\text { Association } \\
\text { operating }\end{array}$ & $\begin{array}{l}\text { Official } \\
\text { Bulletin }\end{array}$ & & 5.125 & & 5.253 & & 5.464 & 0 & 15.842 \\
\hline $\begin{array}{l}28.4 .5 \text { Implementation of } \\
\text { system to disseminate } \\
\text { information and to inform } \\
\text { the population in order } \\
\text { improve the food diet of the } \\
\text { population }\end{array}$ & $\begin{array}{l}\text { Undernourished rate } \\
\text { and presence of } \\
\text { other food related } \\
\text { disease }\end{array}$ & - & - & $\begin{array}{l}\text { Food Diet of } \\
\text { the population } \\
\text { improved in } \\
\text { term of } \\
\text { quantity and } \\
\text { quality }\end{array}$ & Survey & & 10.250 & & 10.506 & & 10.927 & 0 & 31.684 \\
\hline $\begin{array}{l}\text { 28.4.6 Developing permanent } \\
\text { and efficient monitoring of } \\
\text { undernourishment situation } \\
\text { at national levels }\end{array}$ & $\begin{array}{l}\text { Undernourished } \\
\text { rate and presence } \\
\text { of other food related } \\
\text { disease }\end{array}$ & - & - & $\begin{array}{l}\text { Food Diet of } \\
\text { the population } \\
\text { improved in } \\
\text { term of } \\
\text { quantity and } \\
\text { quality }\end{array}$ & Survey & & 10.250 & & 10.506 & & 10.927 & 0 & 31.684 \\
\hline $\begin{array}{l}\text { Adjustment and re-evaluation } \\
\text { the housing promotion }\end{array}$ & $\begin{array}{l}\mathrm{N} .^{\circ} \text { of families } \\
\text { benefiting from } \\
\text { social housing } \\
\text { programs }\end{array}$ & - & - & 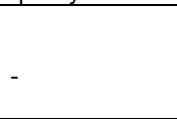 & - & 479.700 & 0 & 491.693 & 0 & 378.084 & 0 & 1.349 .476 & 0 \\
\hline $\begin{array}{l}29.1 \text { Promoting programs of } \\
\text { social housing and } \\
\text { assistances to needing family } \\
\text { in building and rehabilitating } \\
\text { houses }\end{array}$ & 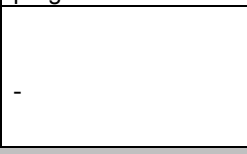 & - & - & - & - & 479.700 & & 491.693 & & 378.084 & & 1.349 .476 & 0 \\
\hline TOTAL & & & & & & 14.198.310 & 3.177.965 & 12.822 .838 & 2.914.734 & 4.893.164 & 2.730 .783 & 31.914.311 & 8.823 .481 \\
\hline
\end{tabular}




\section{Annex 3: Summary table of the MDG in national programming}

\begin{tabular}{|c|c|c|c|}
\hline $\begin{array}{l}\text { Area/Millennium Goals } \\
\text { (2015 time horizon ) }\end{array}$ & National Indicators & ECRP Objectives & $\begin{array}{l}\text { Execution Perspective in } \\
2015 \text { horizon }\end{array}$ \\
\hline $\begin{array}{l}\text { Goal } 1 \text {. Eradicate extreme } \\
\text { poverty and famine } \\
\text { Objective } 1 \text {. Decrease by half } \\
\text { the percentage of population } \\
\text { living with a less of a one dollar } \\
\text { a day } \\
\text { Objective } 2 \text {. Decrease by half } \\
\text { the percentage of population } \\
\text { that suffers from famine }\end{array}$ & $\begin{array}{l}\text { The indicators are the } \\
\text { same as the world } \\
\text { indicators ; } \\
\text { The food security } \\
\text { indicators were given } \\
\text { preference over } \\
\text { famine ones }\end{array}$ & $\begin{array}{l}\text { Global objectives aiming at } \\
\text { economic growth and } \\
\text { poverty reduction }\end{array}$ & $\begin{array}{l}\text { Policies directed to poor are } \\
\text { needed for economic } \\
\text { growth to bring about } \\
\text { poverty reduction and } \\
\text { inequality in Cape Verde }\end{array}$ \\
\hline $\begin{array}{l}\text { Goal 2. Achieve universal } \\
\text { primary education } \\
\text { Objective } 3 \text {. Ensure all children } \\
\text { the means to accomplish a full } \\
\text { cycle of study }\end{array}$ & $\begin{array}{l}\text { The indicators are the } \\
\text { same as the world } \\
\text { indicators }\end{array}$ & $\begin{array}{l}\text { Accomplishing the indicators } \\
\text { defined by Education, } \\
\text { namely: } \\
\text { - consolidate the results } \\
\text { already achieved in the } \\
\text { realization of the objective } \\
\text { of ensuring education for all } \\
\text { - improve education quality } \\
\text { - reduce drop outs and } \\
\text { repetitions. }\end{array}$ & $\begin{array}{l}\text { Basic Education for all is has } \\
\text { been accomplished. The } \\
\text { priority now is on ensuring } \\
\text { quality of the basic } \\
\text { education, } \\
\text { Secondary and higher } \\
\text { education will be developed } \\
\text { to create a favorable } \\
\text { situation to consolidate the } \\
\text { good results already } \\
\text { obtained in primary } \\
\text { education }\end{array}$ \\
\hline $\begin{array}{l}\text { Goal 3. Promote gender } \\
\text { equality and empower women } \\
\text { Objective } 4 \text {. Eliminate gender } \\
\text { disparities in primary and } \\
\text { secondary by } 2005\end{array}$ & $\begin{array}{l}\text { To the word indicators } \\
\text { were added those of } \\
\text { violence against } \\
\text { women }\end{array}$ & $\begin{array}{l}\text { Eliminate gender disparities } \\
\text {, namely in education and } \\
\text { increasing women } \\
\text { employment. }\end{array}$ & $\begin{array}{l}\text { The perspectives to execute } \\
\text { this objective are good. }\end{array}$ \\
\hline $\begin{array}{l}\text { Goal 4. Reduce child mortality } \\
\text { Objective } 5 \text {. Reduzir by two } \\
\text { third the mortality rate for } \\
\text { childrn under five years of age }\end{array}$ & $\begin{array}{l}\text { The indicators are the } \\
\text { same as the world } \\
\text { indicators }\end{array}$ & $\begin{array}{l}\text { Accomplishing the indicators } \\
\text { defined by health sector } \\
\text { namely, reducing childhood } \\
\text { mortality rate and improve } \\
\text { the access and quality of } \\
\text { health service. } \\
\text { Improve the monitoring of } \\
\text { the execution of this } \\
\text { objective }\end{array}$ & $\begin{array}{l}\text { The perspectives to } \\
\text { execute this objective are } \\
\text { encouraging, execution } \\
\text { needed to be monitored, } \\
\text { however }\end{array}$ \\
\hline $\begin{array}{l}\text { Goal 5.Improve Maternal } \\
\text { Health } \\
\text { Objective 6. Reduce by two } \\
\text { third the maternal mortality rate }\end{array}$ & $\begin{array}{l}\text { The indicators are the } \\
\text { same as the world } \\
\text { indicators }\end{array}$ & $\begin{array}{l}\text { indicators defined by health } \\
\text { sector, namely and in } \\
\text { particular, reducing } \\
\text { maternal mortality rate. } \\
\text { Improve the monitoring of } \\
\text { the execution of this } \\
\text { objective }\end{array}$ & $\begin{array}{l}\text { The perspectives to } \\
\text { execute this objective are } \\
\text { encouraging, execution } \\
\text { needed to be monitored, } \\
\text { however }\end{array}$ \\
\hline $\begin{array}{l}\text { Goal 6. Combat HIV-AIDS, } \\
\text { malaria and and other diseases } \\
\text { Objective } 7 . \text { Stop the } \\
\text { proliferation of HIV/AIDS and } \\
\text { start to revert the actual trend }\end{array}$ & $\begin{array}{l}\text { The perspective to } \\
\text { execute this objective } \\
\text { are encouraging, } \\
\text { execution needed to } \\
\text { be monitored, } \\
\text { however }\end{array}$ & $\begin{array}{l}\text { Decrease the HIV/ AIDS } \\
\text { occurrence rate, in particular } \\
\text { in pregnant. Increase the } \\
\text { control of paludism and } \\
\text { tuberculoses }\end{array}$ & $\begin{array}{l}\text { A tight vigilance is needed } \\
\text { in order to stop the } \\
\text { proliferation of HIV/AIDS } \\
\text { given it's low occurrence } \\
\text { now. Change in behavior } \\
\text { will be determinant. }\end{array}$ \\
\hline
\end{tabular}




\begin{tabular}{|l|l|l|l|}
\hline $\begin{array}{l}\text { Objective 8. Control paludism } \\
\text { and other diseases and start } \\
\text { to revert the actual trend }\end{array}$ & & $\begin{array}{l}\text { The control of paludism and } \\
\text { tuberculoses should be a } \\
\text { concern in order to stop and } \\
\text { revert the trend }\end{array}$ \\
\hline $\begin{array}{l}\text { Goal 7. Ensure environmental } \\
\text { sustainability }\end{array}$ & $\begin{array}{l}\text { The indicators are the } \\
\text { same as the world } \\
\text { indicators }\end{array}$ & $\begin{array}{l}\text { Operation of environment } \\
\text { quality monitoring system; } \\
\text { Developing and participative } \\
\text { management of protected } \\
\text { areas; } \\
\text { Objective 9. Integrate the } \\
\text { principals of durable } \\
\text { development in national policies } \\
\text { and revert the actual trend of } \\
\text { wasting environmental } \\
\text { resources }\end{array}$ & $\begin{array}{l}\text { The Access to Drinking } \\
\text { water. Improved rapidly. } \\
\text { However regional inequality } \\
\text { needed to be corrected. The } \\
\text { same in relation to } \\
\text { sanitation }\end{array}$ \\
$\begin{array}{l}\text { Objective } 10 . \text { Decrease by half } \\
\text { the percentage of population } \\
\text { percentage of families with } \\
\text { access to potable water. } \\
\text { supply access to lasting }\end{array}$ & $\begin{array}{l}\text { Increase by } 65 \% \text { the } \\
\text { percentage of families with } \\
\text { Access to sewerage system }\end{array}$ & \\
$\begin{array}{l}\text { Objective } 11 . \text { Improve } \\
\text { considerably the living condition } \\
\text { of people living in tents } \\
\text { neighborhoods }\end{array}$ & & & \\
\hline
\end{tabular}


Annex 4: Development partners, by area of assistance

\begin{tabular}{|c|c|c|c|}
\hline Partner & Aid instrument & Area of preference & Context \\
\hline Germany & $\begin{array}{l}\text { Investment projects, AT, food aid, concessionals } \\
\text { loans, KFW, NGO's } \\
\text { With the announcement of retreat only the project } \\
\text { Natural Resources Protection will go on till } 2007 .\end{array}$ & $\begin{array}{l}\text { Arial and maritime } \\
\text { transportation infrastructure, } \\
\text { supply of water, energy, } \\
\text { primary education, } \\
\text { professional training, health } \\
\text { reproduction, forestry, } \\
\text { fishing, environment, } \\
\text { decentralization, }\end{array}$ & $\begin{array}{l}\text { Municipalities of Fogo ande Brava } \\
\text { islands, }\end{array}$ \\
\hline Austria & $\begin{array}{c}\text { Institutional assistance, projects, scholarship, food } \\
\text { aid, NGO's }\end{array}$ & $\begin{array}{c}\text { SME Promotion, primary } \\
\text { education , professional } \\
\text { training, water, } \\
\text { decentralization, internal } \\
\text { debt (Trust-Fund), cultural } \\
\text { cooperation } \\
\end{array}$ & Municipalities of Santiago island \\
\hline $\begin{array}{l}\text { African Development Bank } \\
\text { /ADF }\end{array}$ & $\begin{array}{c}\text { Investment projects, Institutional assistance , } \\
\text { triangular cooperation }\end{array}$ & $\begin{array}{c}\text { Arial transportation, } \\
\text { infrastructure, professional } \\
\text { training, industrial fishing, } \\
\text { soil, education, }\end{array}$ & $\begin{array}{l}\text { Praia/Santiago } \\
\text { National }\end{array}$ \\
\hline BADEA & Investment projects & $\begin{array}{c}\text { Arial and terrestrial } \\
\text { transportation infrastructure, } \\
\text {, industrial fishing }\end{array}$ & Praia/Santiago, National \\
\hline World Bank / IDA & $\begin{array}{l}\text { According to July portfolio revision, the amount of } \\
\text { projects in the portfolio ascend US } \$ 90,6 \text { million, with } \\
\text { US } \$ 33,7 \text { million to be disbursed . } \\
\text { Grants has been directed to investment projects } \\
\text { and structural adjustment assistance but in progress } \\
\text { the first operation of Poverty Reduction Support } \\
\text { Credit. }\end{array}$ & $\begin{array}{c}\text { Arial and terrestrial } \\
\text { transportation infrastructure } \\
\text {, supply of water, energy, } \\
\text { primary education, social } \\
\text { protection, privatization, } \\
\text { public administration and } \\
\text { financial management of the } \\
\text { State } \\
\end{array}$ & National \\
\hline Belgium & Food Aid (Others), projects NGO's & Reforestation, enviroment & National \\
\hline Brasil & $\begin{array}{l}\text { TA, institucional assistance, higher education, short } \\
\text { term scholarship, triangular cooperation triangular }\end{array}$ & $\begin{array}{c}\text { Public Administration, } \\
\text { Agricultura, Health, } \\
\text { Education }\end{array}$ & National \\
\hline CEDEAO & Projects & Health Facilities & Sal, Maio, Boa Vista, Fogo \\
\hline China & $\begin{array}{c}\text { Infrastructures projets, TA, Training } \\
\text { Concessional loans, economic and commercial } \\
\text { cooperation , grants }\end{array}$ & $\begin{array}{l}\text { Public Administration, } \\
\text { Agriculture, Health, } \\
\text { Education , industry, } \\
\text { Fishing, Culture, PMI/PME }\end{array}$ & National (namely Santiago) \\
\hline
\end{tabular}

CInternational Monetary Fund. Not for Redistribution 


\begin{tabular}{|c|c|c|c|}
\hline Cuba & $\begin{array}{c}\text { TA, institucional assistance, Higher education, } \\
\text { scolatship, triangular cooperation }\end{array}$ & $\begin{array}{c}\text { Education, Health, Food } \\
\text { Security }\end{array}$ & National \\
\hline Denmark & $\begin{array}{l}\text { Investment Projects, multilateral and decentralized } \\
\text { cooperation ( i.g. NGO BORNEfonden). }\end{array}$ & $\begin{array}{l}\text { Education, Health, Aeolic } \\
\text { energy }\end{array}$ & National \\
\hline Spain & $\begin{array}{c}\text { Projects, TT, Scholarships, Food Aid, Loans, } \\
\text { institutional assistance, decentralized cooperation, } \\
\text { NGO }\end{array}$ & $\begin{array}{c}\text { Culture, urban } \\
\text { management/environment, } \\
\text { education ,profissional } \\
\text { training, policy }\end{array}$ & National \\
\hline United States of America & Food aid, institutional assistance , projects, TA/NGO & $\begin{array}{l}\text { Reforestation, environment, } \\
\text { micro credit, civil } \\
\text { proteccional, areal } \\
\text { transportation } \\
\end{array}$ & Nacional \\
\hline WFP & $\begin{array}{l}\text { Institucional assistance , } \mathrm{TA} \text {, multilateral } \\
\text { cooperation, triangular coopertion }\end{array}$ & $\begin{array}{l}\text { Agriculture, Reforestation, } \\
\text { environment food security } \\
\text { multilateral cooperation }\end{array}$ & National \\
\hline FIDA & Projects, Institucional assistance , TA & & National \\
\hline France & $\begin{array}{c}\text { Investment projects, TA, food aid, concessional } \\
\text { loans ,AFD, NGO's, small grants, multilateral } \\
\text { cooperation }\end{array}$ & $\begin{array}{l}\text { Education, health, custom, } \\
\text { statistics, finance } \\
\text { water/environment, } \\
\text { decentralization, culture } \\
\end{array}$ & National \\
\hline UNFPA & $\begin{array}{c}\text { Projects, Institucional assistance } \\
\text { cooperation }\end{array}$ & $\begin{array}{l}\text { Health, demography, } \\
\text { Population, women and } \\
\text { development }\end{array}$ & National \\
\hline Holland & $\begin{array}{c}\text { Investment projects, TA, institutional assistance, } \\
\text { food aid (foreign exchange), budgetary aid, Trust- } \\
\text { Fund, multilateral cooperation and economic and } \\
\text { enterprises cooperation }\end{array}$ & $\begin{array}{l}\text { Environment ,Education, } \\
\text { health, sanitation, PMI/PME }\end{array}$ & National \\
\hline Italy & $\begin{array}{c}\text { Investment projects, TA, food aid, NGO's, } \\
\text { multilateral cooperation }\end{array}$ & $\begin{array}{l}\text { Agriculture, environment, } \\
\text { Social housing, Health }\end{array}$ & National \\
\hline Japan & $\begin{array}{l}\text { Investment projects TA, food aid, small grants, } \\
\text { multilateral cooperation }\end{array}$ & $\begin{array}{l}\text { Transportation infrastructure, } \\
\text { fishing, telecommunication, } \\
\text { industry, culture, health }\end{array}$ & National \\
\hline Kuwait & Investment projects & $\begin{array}{l}\text { Water and sanitation } \\
\text { infrastructure }\end{array}$ & Sal, Boa Vista \\
\hline Luxemburgo & Investment projects, TA, Food Aid, Training & $\begin{array}{c}\text { Basic Sanitation, health, } \\
\text { education, road } \\
\text { infrastructure, electrification, } \\
\text { tourism } \\
\end{array}$ & $\begin{array}{c}\text { Santo Antão, S. Nicolau, Santiago and } \\
\text { national (food aid) }\end{array}$ \\
\hline ILO & $\begin{array}{c}\text { Investment projects, multilateral cooperation } \\
\text { triangular cooperation }\end{array}$ & Protecção social, sindicalismo & National \\
\hline WHO & TA & External trade & National \\
\hline WHO & $\begin{array}{c}\text { Multilateral cooperation, } \begin{array}{c}\text { triangular cooperation } \\
\text { institutional assistance, }\end{array} \\
\end{array}$ & Health & National \\
\hline OPEC & Investment projects, institutional assistance & $\begin{array}{l}\text { Electric energy/Aeolic, water, } \\
\text { sanitation }\end{array}$ & Santiago, S. Vicente, Sal \\
\hline
\end{tabular}

CInternational Monetary Fund. Not for Redistribution 


\begin{tabular}{|c|c|c|c|}
\hline WFP & Food aid, projects & $\begin{array}{l}\text { Pre-basic and basic } \\
\text { education, school lunch }\end{array}$ & National \\
\hline Portugal & $\begin{array}{c}\text { Financial assistance (balance of payment } \\
\text { assistance), investment projects, TA, institutional } \\
\text { assistance, concessional loans, small grants, multi- } \\
\text { lateral and decentralized cooperation, Trust-Fund, } \\
\text { youth, professional training }\end{array}$ & $\begin{array}{l}\text { Infrastructure, education, } \\
\text { higher education, } \\
\text { Transportation, health, } \\
\text { sanitation, environment, } \\
\text { culture, industry, PMI/PME, } \\
\text { justice } \\
\end{array}$ & National \\
\hline UNDP & institutionnel assistance, TA & $\begin{array}{l}\text { Good governance } \\
\text { (decentralization, human } \\
\text { rights) Poverty fight, } \\
\text { environment, external aid } \\
\text { coordination }\end{array}$ & National \\
\hline Russia & Scholarship & Higher education & National \\
\hline Sweden & Training, TA, NGO's, Trust-Fund, & $\begin{array}{l}\text { Environment, transportation, } \\
\text { poverty fight, public } \\
\text { administration, agriculture, } \\
\text { industry, port security }\end{array}$ & National \\
\hline Switzerland & $\begin{array}{l}\text { Investment Project, TA, institutional assistance, food } \\
\text { aid (others), Trust-Fund }\end{array}$ & $\begin{array}{c}\text { Higher education, } \\
\text { water/sanitation, PMI/PME, } \\
\text { environment, culture, health } \\
\text { infrastructure and education }\end{array}$ & $\begin{array}{c}\text { National (namely Boa Vista and } \\
\text { Santiago) }\end{array}$ \\
\hline European Union & $\begin{array}{c}\text { In April, } 2002 \text { a indicative Program was signed } \\
\text { based on } 9^{\circ} \text { FED resources, where the strategy for } \\
\text { cooperation and intervention of European Union was } \\
\text { established for the first five years of the execution of } \\
\text { the first financial protocol of Cotonou Accord (total: } \\
\qquad 32 \text { milhões) } \\
\text { Aid Modality: Investment Projects, TA, food aid, } \\
\text { food aid (foreign exchange), budgetary, micro- } \\
\text { realizations, Trust-Fund }\end{array}$ & $\begin{array}{l}\text { From PIN 9a FED total of } \\
€ 32 \text { million , } 25 \text { million euro } \\
\text { was directed to water } \\
\text { concentration and sanitation } \\
\text { Others areas : reinforce } \\
\text { administration capacity, } \\
\text { partnerships with civil society } \\
\text { and private sector, justice, } \\
\text { environment and food } \\
\text { security }\end{array}$ & National \\
\hline UNICEF & Investment assistance, $\mathrm{TA}$, food aid & $\begin{array}{l}\text { water/sanitation, health, } \\
\text { child protection }\end{array}$ & National \\
\hline
\end{tabular}




\section{Bibliography}

Bourdet, Y. (2002), Analysis of Political Business cycle in Cape Verde

Carling, J. (2001), Aspiration and Ability in International Migration: Cape Verdean, Experiences of Mobility and Immobility, Dissertations \& Theses No 5/2001, Centre for Development and Environment (SUM), University of Oslo

Cornia, G. Andea, e Kiiskii, S. (2001), Trends in Income Distribution in the Post- World War II Period, Discussion Paper No 2003/28, United Nations University, Wider.

Direcção Geral do Ambiente (2002), Plan of Action for the Environment II

Cape Verde Government (2002), Government Head Office . Great Options of the Plan: A Strategic Agenda

Cape Verde Government (2003), Documents for Consultation Meeting with Development Partners, 29-30 of Aprill, 2003

Cape Verde Government (2003), National Plan of Action for Human Rights and Citizenship in Cape Verde

INE (2004), Poverty Profile for Cape Verde

Instituto do Emprego e Formação Profissional, Employment survey, 1996

Langworhy, M., e Finan, T. J. (1997) Waiting for Rain- Agriculture and Ecological Imbalance in Cape Verde, Lynne Rienner Publishers, Boulder and London

Ministry of Finance, Planning and Regional Development (2003), Évaluation de la Gestion des Finances Publiques et des Pratiques de la Comptabilité du Secteur Privé.

MFP (2004),Fiscal Incidence in Cape Verde - Analysis based on the IRDF, 2001-2002

MFP (2004 b), Systematization of Information on measures to fight poverty.

MFP (2004 a), Croissance, Emploi et Politique de Réduction de la Pauvreté

MFP (2004 c), Crescimento, Emprego, Rendimento e Pobreza em Cabo Verde, Elementos de Análise.

MFP (2004 d) Actividades Ecconómicas das Populações Rurais e seu Acesso a Terra

Word Bank (2004), Public Expenditure Review - Cape Verde 